\title{
Fostering Student-Faculty Relationships in \\ 3. Higher Education
}

How Relationship Quality Affects Student Involvement
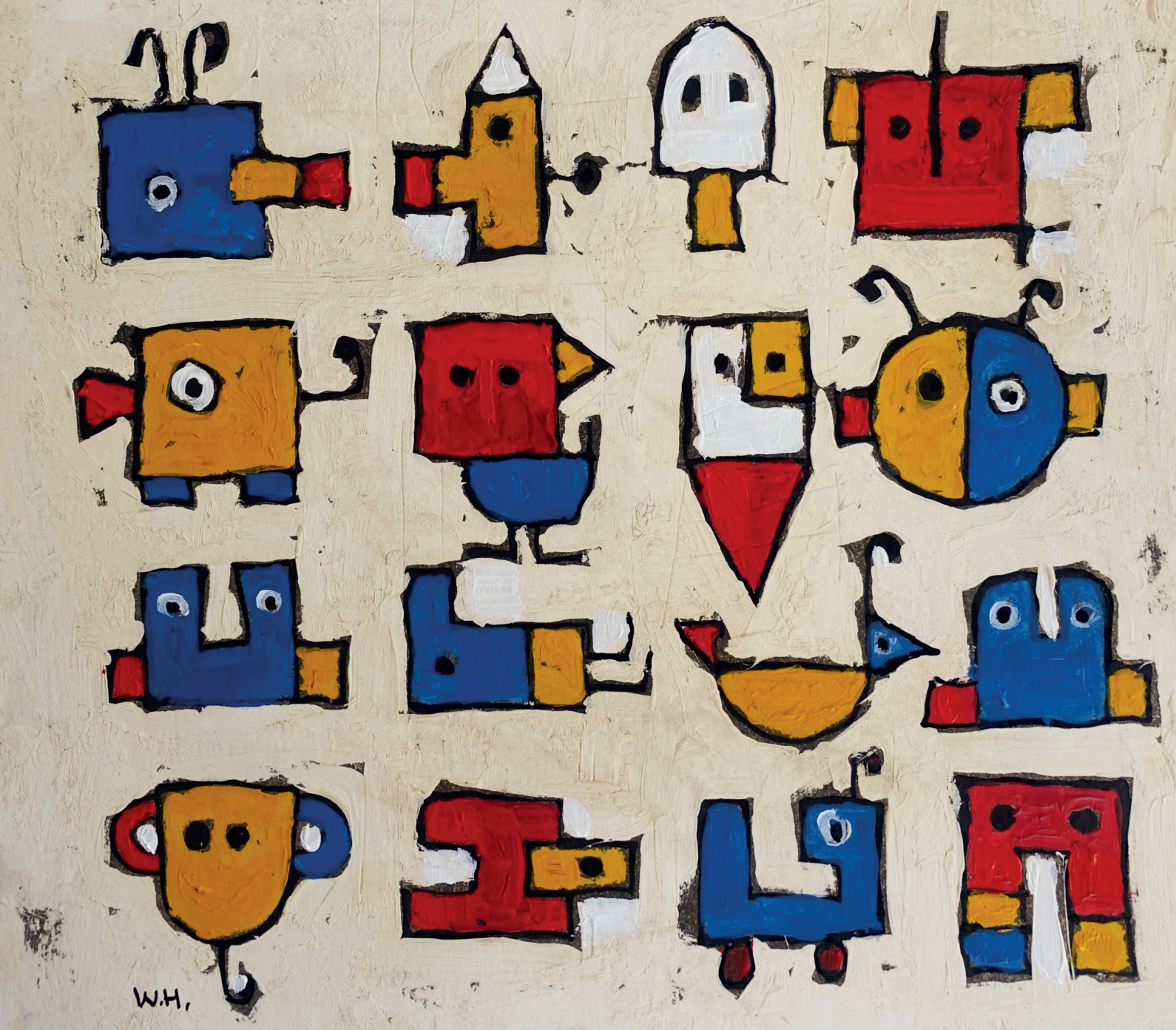

Ingrid Snijders 


\section{Fostering Student-Faculty Relationships in Higher Education}

How Relationship Quality Affects Student Involvement 
(c) Ingrid Snijders, 2021

ISBN: 978-94-93184-80-0

DOI: https://doi.org/10.33540/460

Cover art: Wim Hofman

Layout and print: Guus Gijben | Proefschrift-aio.nl 


\section{Fostering Student-Faculty Relationships in Higher Education How Relationship Quality Affects Student Involvement}

Het Bevorderen van de Relaties tussen Studenten en hun Opleiding

De Invloed van Relatiekwaliteit op Studentbetrokkenheid

in het Hoger Onderwijs

Proefschrift

ter verkrijging van de graad van doctor aan de

Universiteit Utrecht

op gezag van de

rector magnificus, prof.dr. H.R.B.M. Kummeling, ingevolge het besluit van het college voor promoties

in het openbaar te verdedigen op

woensdag 10 maart 2021 des middags te 12.45 uur

door

Ingrid Snijders

geboren op 19 juni 1976

te Middelburg 


\section{Promotoren:}

Prof. dr. S.M.M. Loyens

Prof. dr. R.M.J.P. Rikers

\section{Copromotor:}

Dr. L. Wijnia

This research was supported by the Netherlands Organisation for Scientific Research (NWO) under project number: 023.006.035 


\section{Contents}

Chapter 1 Student-faculty relationships in higher education: An introduction

Chapter 2 Relationship quality time: The validation of a relationship quality scale in higher education

Chapter 3 What's in a student-faculty relationship? A template analysis of students' positive and negative critical incidents with their educational faculty and staff

Chapter 4 Building bridges in higher education: Student-faculty relationship quality, student engagement, and student loyalty

Chapter 5 Alumni loyalty drivers in higher education

Chapter 6 Relationship quality and the interplay with student engagement, 109 and loyalty

Chapter 7 Summary and discussion

Chapter 8 Samenvatting en discussie (Summary and discussion in Dutch)

About the author 
75

\section{i. तो}

$+\infty$

$\lambda$
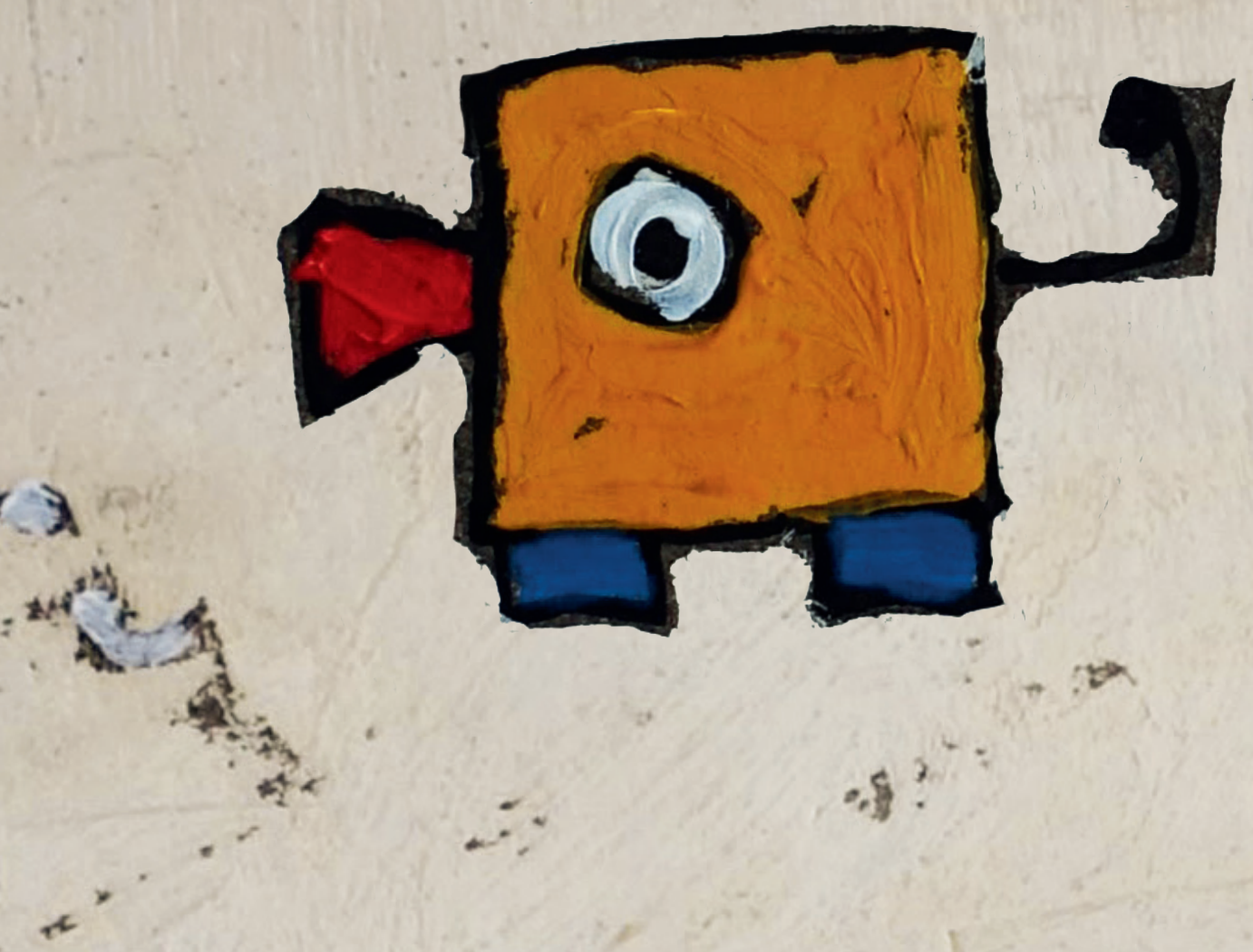


\section{Student-Faculty Relationships in Higher Education: An Introduction}

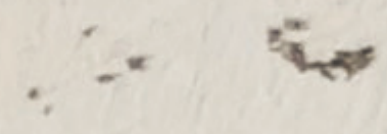


Chapter 1 - Student-faculty relationships in higher education: An introduction

\section{Introduction}

Placing students at the heart of education is a phrase often used by many higher education institutions and universities around the world today. To put this into practice, some educational institutions welcome potential students by stressing that, for example, "teachers and staff put great emphasis on individual coaching" (HZ University of Applied Sciences, 2020, "Where students matter" section). Previous and recent studies have emphasized the importance of student relationships with their academic institution (e.g., Bowden, 2011; Cotten \& Wilson, 2006; Dollinger \& Lodge, 2020; Hagenauer \& Volet, 2014; Hagenauer et al., 2015; Helgesen, 2008). However, how to establish and maintain prolonged positive relationships with students during their study and after graduation remains largely unclear. The explanations for this might be the changes that have taken place in the landscape of higher education, and the worldwide marketization of higher education (see Hemsley-Brown \& Oplatka, 2010; Molesworth et al., 2011). In particular, the funding of many public European higher education institutions became performance based (Estermann \& Claeys-Kulik, 2016), where government financial support is determined by for instance drop-out and graduation rates. Increased global competition among higher education institutions by their relative ratings influence how they communicate to new and enrolled students. In response, higher education students increasingly act and behave more like customers (Bunce et al., 2017; Woodall et al., 2014). As a result, students respond to their higher education institution such as to their university (Bunce et al., 2017), either positively in the form of a compliment or positive rating, or negatively in the form of a complaint (Guilbault, 2016; Robinson \& Celuch, 2016). Indirectly, positive student satisfaction ratings will presumably attract potential students which, in turn, may lead to a growing number of enrolled students (Estermann \& ClaeysKulik, 2016; Jones, 2016).

How students perceive their educational experience is influenced by the approaches and responses of their higher education institution (Chirikov, 2016; Elken et al., 2016). Hence, the changes and developments just described imply that higher education institutions should focus on forming bonds with their students. Therefore, a closer look at how students perceive interpersonal relationships with their higher education institution (educational faculty and staff) is necessary.

Interpersonal relationships in education within the school context are mostly formed between students and teachers (Roorda et al., 2011). However, the child-adult relationship in primary and secondary education develops into an adult-adult relationship in higher education (Hagenauer \& Volet, 2014). Multiple frameworks exist that are relevant for teacher-student relationships, such as self-determination theory from Deci and Ryan (2008), which focuses on human motivation. However, in higher education, a student also builds a relationship 
with other people within their higher education institution/university. Besides their teachers, students have multiple and sequential interactions with other representatives of the higher education institution, such as librarians, student psychologists, study counselors, or other staff members. The interpersonal relationships resulting from those interactions form a focal point in the educational process. How students perceive these relational ties will affect their future interactions with, and attitudes, intentions, and behaviors or actions towards their higher education institution (T. Gibbs \& Kharouf, 2020; Palmatier, 2008).

Another distinction of relationship-building in higher education is the place where these interactions occur. Whereas in primary and secondary education, most interactions happen in class, an essential part of the educational process in higher education also takes place in outof-class environments. For instance, students can receive personal attention for example by their mentor frequently asking about a student's situation (Meeuwisse et al., 2010). Both kinds of interactions can have either a formal (e.g., classroom assignment or evaluation of study progress) or informal (e.g., personal issues unrelated to academics; Komarraju et al., 2010; Meeuwisse et al., 2010) character.

The educational psychology literature implies that high-quality relationships with students result in positive academic outcomes (Engels et al., 2016; Farr-Warton et al., 2018; GarcíaMoya et al., 2019; Gehlbach et al., 2012; Košir \& Tement, 2014; Roorda et al., 2011). Positive student-faculty interactions contribute to pedagogical objectives in terms of intellectual and personal student development, such as increased student motivation, engagement, social integration, and academic performance (Y. K. Kim \& Lundberg, 2016; Klem \& Connell, 2004; Pascarella \& Terenzini, 2005), and may subsequently promote student retention and perseverance to achieve a degree (O'Keeffe, 2013; Vander Schee, 2008a, 2008b). Furthermore, when interpersonal relationships between students and their institution are perceived positively by students, students may develop a sense of belonging or (growing) connection to their institution (García-Moya et al., 2020; Y. K. Kim \& Lundberg, 2015).

In summary, positive student-faculty relationships are vital because they can positively influence student outcomes, such as students' their engagement to study (Pascarella \& Terenzini, 2005; Pianta et al., 2012) or a willingness to continue to interact and engage in the relationship within the educational service process (Bowden, 2011; Zeithaml et al., 2009). Furthermore, research has indicated that students' engagement with their studies can affect student and alumni loyalty (Bowden, 2011). Student loyalty attitude and loyalty behaviors can be expressed by positive word-of-mouth, recommendations to other potential students, a positive rating of the institution, or alumni offerings of student traineeships and re-investment in further education after graduation (Bowden, 2011; Brodie et al., 2011; Macintosh, 2007). Both outcomes "engagement and loyalty" are essential for the growth of 
higher education institutions (Schlesinger et al., 2017) and their continuity (Hatch \& Garcia, 2017). Recent studies in the field of educational psychology have highlighted the need for further research about the importance of student-faculty relationships in higher education (García-Moya et al., 2018), and the present thesis tries to fill this gap.

The purpose of this thesis is to explore how to strengthen the bonds between students and their higher education institution so that that students become (more) involved (i.e., their engagement with their studies and becoming loyal). The aim is to provide better insight into how to apply a relational approach that may improve and enrich higher education policy and practice. To help understand how the relationships between students and their higher education institutions may be prolonged, we use social exchange theory (SET) as the overarching framework for the underlying studies (Cropanzano et al., 2017). SET is a broad conceptual paradigm applied in various contexts where in general, two parties are involved wherein the interaction between an actor with a recipient occurs either positively or negatively.

The next section describes the relevance of SET, introducing a model of how bonds are formed as the foundation for the empirical studies.

\section{Social Exchange Theory and Higher Education}

SET posits that human relationships are formed by the use of subjective cost-benefit analysis and the comparison of alternatives (e.g., Blau, 1964; Emerson, 1976; Homans, 1961). In economic terms, worth expresses relationship value, based on rewards minus costs. Positive evaluations of a relationship can be considered to be based upon its rewards (i.e., sources of positive reinforcement such as social acceptance or approval, respect, or prestige). Negative evaluations can be considered to be based upon its costs (i.e., punishments or lost rewards). One of the premises of SET is that people will respond to one another in similar ways; they respond to kindness with similar levels of benevolence and to harm with indifference or forms of retaliation (Murdvee, 2009). Whenever the rewards are greater than the relationship's costs, the result will be that the actor stays in the relationship (i.e., the continuation of the relationship). In turn, when the costs are higher than the rewards in any kind of relationship (e.g., romantic, friendly, professional, or economic), the actor discontinues the relationship. More specifically, concerning interpersonal relationships, Blau (1964) defined social exchanges as "voluntary actions of individuals that are motivated by the returns they are expected to bring and typically do in fact bring from others" (p. 91). At least one of the parties is dependent on the other, which is what prompts the social exchange. That is, a person's personal goal can only be met through interaction with another person (Blau, 1964). In the case of higher education, this means that a student who wants to learn and earn a degree desires an educational 
service in terms of guidance from a teacher, professor, or mentor. However, this is not a oneway interaction: a reciprocal exchange exists in which the two are co-dependent in order to co-create the educational service experience. Foa and Foa (1980) investigated interpersonal behaviors and development in social encounters. They illustrated that when it comes to services specifically, it is the personal relatedness that matters in the exchange. Relatedness refers to having a close and affectionate relationship with others, and is considered to be a universal basic psychological need (Deci \& Ryan, 2008).

Parallel to SET, other perspectives/theories place social relations at the heart of services exchanges as well, such as the service-dominant (S-D) logic perspective, the services management literature, and the relationship management literature. S-D logic is a framework that considers the understanding of human exchange (Lusch \& Vargo, 2014). Within S-D logic, all economies are recognized as service economies. Therefore, this perspective applies to all kinds of actors (parties) in relationships, such as in business organizations, government organizations, and nonprofit organizations. S-D logic focuses on the nature of the actors doing the exchanging and what is being exchanged. Actors are entities who have agency and the ability to act purposefully; in the (service) exchange, they are both service providers and service beneficiaries. Service is the basis of exchange, that is, the application of resources to benefit another actor or oneself (Lusch \& Vargo, 2014). When applied to education and within this thesis, the educational service is central (i.e., the service provided by faculty and staff of higher education institutions to their students).

The services management literature (e.g., Grönroos, 2016; Lovelock \& Wirtz, 2016; Zeithaml et al., 2009) puts the role and unique characteristics of services to the fore and specifically implies a customer-focused approach in connection with service exchanges. Within services management research, the customer is the foundation for all actions undertaken by any kind of organization (Zeithaml et al., 2009). Lovelock and Wirtz (2016) highlighted that when it comes to interactive consumption, human involvement is essential in the service delivery process (i.e., the process between the service provider and consumer/buyer/recipient). As such, high-quality service delivery can only be formed through good relationships (De Vries et al., 2012). These relationships are defined as "a series of interactions that take place over a long period between two or more parties (e.g., between a service provider and beneficiary) where commitment or loyalty arises" (De Vries et al., 2012, p. 156). In education, the service provided mostly consists of interactions (Grönroos, 2016), making it important to focus on how students (i.e., the recipient of the service) perceive the quality of their relationships and interactions with staff and faculty. Therefore, this thesis focuses on relationship quality.

The services and relationship management literature explicitly focuses on the exchange as a matter of building relationships with key stakeholders in the service delivery process 
(e.g., Berry, 2002; Crosby et al., 1990; Dagger et al., 2009; Dick \& Basu, 1994; Grönroos, 2016; Lovelock \& Wirtz, 2016). Relationship management's cornerstone is to develop, retain, and strengthen (customer) relationships in the long run. In general, strong ties are characterized by a high level of closeness, reciprocity, and trust. However, to understand the "structural features and the dynamics of a relationship, the environment in which it takes place has to be considered" (Castaldo, 2007, p. 20). Recent studies in education (e.g., Cropanzano et al., 2017; García-Moya et al., 2020; T. Gibbs \& Kharouf, 2020; Yousaf et al., 2020) have acknowledged the application of ideas from SET and the services and relationship management literature, and have called for further research on building lasting relationships between service providers and recipients; this thesis examines student and alumni loyalty as a potential outcome of relationship quality.

Within the underlying studies in this thesis, we build on the premises of SET and related literature in the context of higher education. To explain, we will introduce a model of relationship formation in higher education (see Figure 1.1). We focus on the relationships between the institution and students as key stakeholders within the higher education context. Therefore, other stakeholders, are not included in the model. Below, the link between the S-D logic, services management, and relationship management literature and this thesis will be discussed in more detail.

Figure 1.1

Proposed Model of Relationship Formation in Higher Education

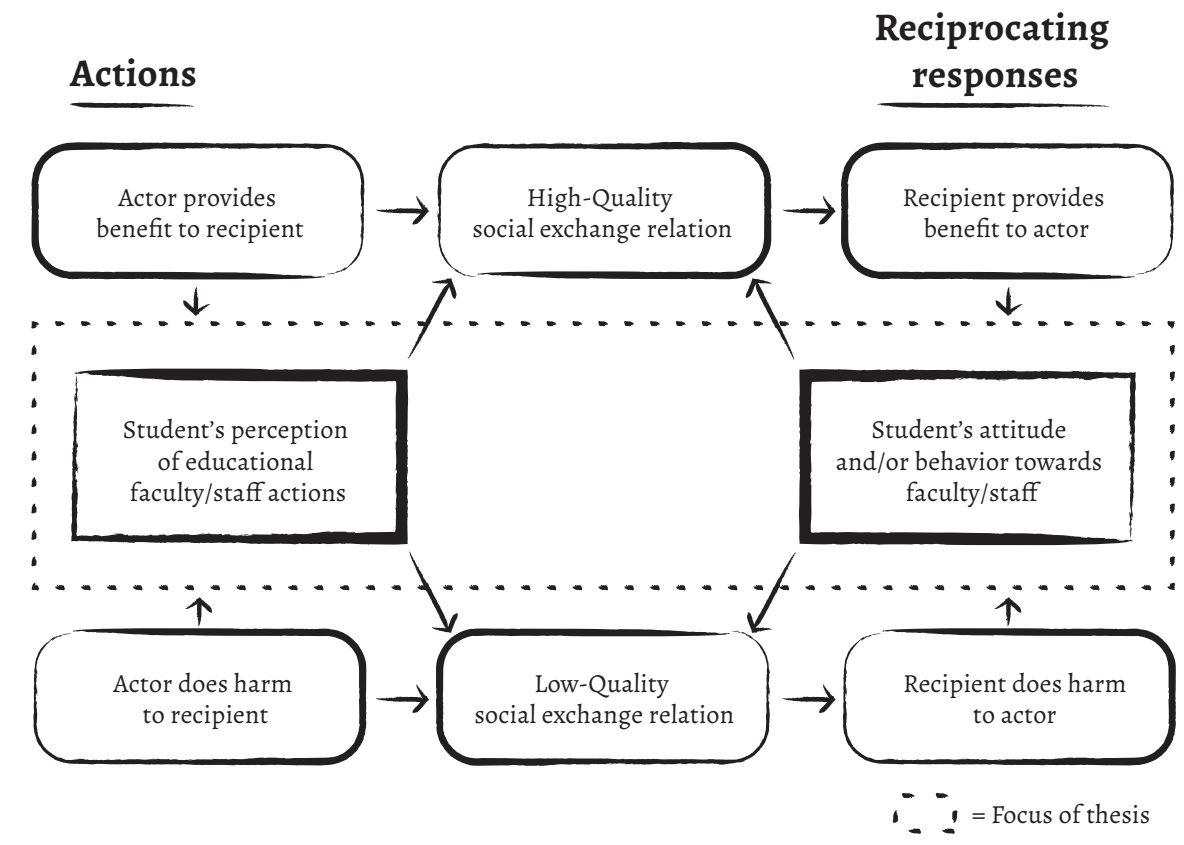

Note. The model is based on SET and the research by Cropanzano et al. (2017). 
In Figure 1.1, we emphasize the relevance of the social exchange relationships between students and their faculty and staff. In line with the services management literature, we place the student's perceptions and attitudes at the center of the educational experience. Based on students' perceptions of the positive and negative interactions that students experience they may think better or worse of the interpersonal relationships they have with faculty and staff.

One way to examine relationships in relationship quality research is a dyadic approach in which the relationship's characteristics are investigated (Jiang et al., 2016). This approach was used for the empirical studies presented in this thesis. The focus was on measuring relationship quality in higher education, that is, students' perceptions of the quality of the relationships they have with their faculty and staff. Studies in primary and secondary education have focused mainly on student-teacher relationships (e.g., Mason et al., 2017). However, as already mentioned, in higher education, students may also have contact with mentors, deans, student psychologists, and other staff members (e.g., librarians, receptionists, and janitors). Therefore, this thesis focuses on the student experience of the overall quality of their past or present relationships with educational faculty and staff from their institution. Specifically, we examined students' perceptions of all social interactions they have, within and outside the classroom (face-to-face and online). Therefore, we believe we have used a comprehensive approach to measure relationship quality in higher education in all its richness. Furthermore, we adopted both quantitative and qualitative approaches. To that end, we included positive and negative relational aspects. Our goal was to capture all aspects of the relationship quality concept.

In services management research, a customer focus is essential, especially in high-quality service delivery processes such as those in higher education. Within higher education, the services consist of frequent human interactions between students and their educational faculty and staff. The gap model by Parasuraman and colleagues (1991) is still commonly used to improve the quality of services and applies explicitly to high service encounters (interactions; Zeithaml et al., 2009). The gap model is based on the analysis of the expectations and perceptions of users of services. By examining the difference between what is expected by the user (actor or party) and the service offered, one can gain insight into possible gaps. The first step in the model is to understand customers' expectations and perceptions. Students can be seen as consumers of the educational service (Bowden, 2011; Bunce et al., 2017; Molesworth et al., 2011). Therefore, we specifically focused on measuring relationship quality in higher education from the student's point of view. In prior services management research, service quality instruments often focused on clients' or recipients' expectations (before the service) and their experience (after the service; see Zeithaml et al., 2009). However, recipients found it difficult to reflect on the expectations 
they had beforehand. A performance-only adaptation (i.e., measuring only services perceptions instead of expectations) was found to be more suitable (e.g., Nadiri et al., 2009; Oldfield \& Baron, 2000). Therefore, in line with the services management literature, we also measured our study variables by asking students only for their relationship quality perceptions. We included both positive and negative relational aspects in measuring students' perceptions of the quality of their relationships with faculty and staff, that is, relationship quality. The value of investing in positive bonds between faculty/staff and their students may seem evident because these relationships can contribute in a positive way to students' involvement during and after their time in higher education. Positive relationships between students and their higher education institution can be fruitful in terms of engagement and loyalty intentions and behaviors. For instance, students' and alumni's positive recommendations and financial support can help to sustain a college or university's continuity and growth.

In the present thesis, student engagement and student/alumni loyalty were investigated as possible relationship quality outcomes. In the next section, the meanings and operational definitions of relationship quality, student engagement, and student/alumni loyalty as part of the empirical studies are discussed.

\section{Relationship Quality in Higher Education}

Relationship quality is the starting point of the empirical studies in this thesis. The focus is on students' perceptions of the quality of their relationships with their faculty and staff. In relationship quality research, there are many different conceptualizations of relationship quality (Athanasopoulou, 2009), due to the context-specific descriptions of actors that are used in definitions of relationship quality. For instance, in businessto-business management, Woo and Ennew (2004) referred to relationship quality as the "overall evaluation of the relationship between a buyer and seller" (p. 1256). In marketing, Hennig-Thurau and Klee (1997) defined relationship quality as "the degree of appropriateness of the relationship to fulfill the needs of a customer" (p. 751). The specific definitions of the terms "buyer," "seller," and "customer" may not make sense in the context of research outside the field of marketing and management. However, relationship quality is a universal construct. It applies to every kind of interpersonal relationship between two parties, whoever they may be, such as a patient-doctor relationship, or, more generally speaking, a consumer-provider or actor-actor (parties) relationship. Therefore, a general approach seems more appropriate when "researchers want to capture the overall caliber of relationship ties and their overall impact on outcomes" (Palmatier, 2008, p. 85). 
The measurement of the relationship quality construct that we used was based on relationship quality research by Roberts and colleagues (2003). Measuring the quality of the relationships between students and their educational faculty and staff considers the relational bonds such as social, knowledge-based, and psychological relationships, where the voluntary aspect of an actor within the relationship is assured. Within this thesis, the relationship quality measurement instrument used parallels the original scale; however, the wording of some items was modified to make them appropriate within the higher education context (e.g., educational faculty/staff replaced service provider).

Relationship quality was treated as a multidimensional construct. The dimensions include students' trust in educational faculty/staff's honesty, and trust in educational faculty/ staff's benevolence, affective conflict (as a negative indicator of relationship quality), affective commitment, and overall satisfaction related to their educational faculty/staff's performance. Each dimension is described below.

\section{Relationship Quality Dimensions and Conceptual Model}

\section{Trust}

Trust is essential within any kind of relationship between humans, and can be considered a vital construct of relationship quality (Jiang et al., 2016). Trust refers to the reliability and integrity one perceives (see commitment-trust theory; R. M. Morgan \& Hunt, 1994). The amount of trust a recipient perceives is based on previous interactions, and will, as a result, induce expectations of future behaviors (Murdvee, 2009). Trust (trustworthiness) was studied earlier in higher education by Ghosh et al. (2001). They defined trust as "the degree to which a student is willing to rely on the institute to take appropriate steps that benefit and help [the student] to achieve learning and career objectives" (Ghosh et al., 2001, p. 325). In the context of higher education, students have multiple and sequential encounters with their educational faculty and staff. When relationships between two parties are prolonged, the trust or distrust may change over time (Lewicki et al., 2006). In relationship quality research, trust is often divided into two essential elements: trust in honesty and trust in benevolence (Kumar et al., 1995; Roberts et al., 2003).

Trust in Honesty. Trust in honesty represents the trust students have in a university's integrity as represented by the faculty and staff, such as the sincerity of educational faculty and staff and the belief that they will perform their role effectively and reliably. For instance, it is reflected in the trust students have in a university's credibility (sincerity or reliability; e.g., "My university is trustworthy").

Trust in Benevolence. Trust in benevolence is the extent to which students believe faculty and staff are concerned about their welfare (e.g., "When I confide my problems to my 
educational faculty and staff, I know they will respond with understanding"). Trust in benevolence reflects the belief that faculty and staff have intentions and motives beneficial to students, as well as the belief that faculty and staff will avoid acting in a way that will result in negative outcomes for students.

\section{Affect \\ One of the positive consequences of trust that has been given attention in relationship management research is the reduction of conflict. In turn, less conflict positively influences one's commitment to and the satisfaction with the quality of the relationship (Castaldo, 2007).}

Affective Conflict. Affective conflict is a negative indicator of relationship quality in connection with lack of trust, such as the tension that arises from an imbalance in expected and desired service performance (Roberts et al., 2003). In higher education, it may show in feelings of hostility, frustration, or anger (e.g., "I am angry with my university"). Although insights into how students perceive affective conflict are essential, only a few studies have examined affective conflict reduction in higher education (e.g., Meyers, 2003; Meyers et al., 2006). Meyers (2003) indicated that how students perceived interpersonal conflicts with faculty in class could have an important impact on how students evaluated their course. Eventually, conflict might result in complaint behavior or in discontinuing the relationship. Affective conflict was investigated in this thesis in order to provide a broader understanding of how students perceive this counterpart of relationship quality. Another affective component of relationship quality is the feeling of being committed to the relationship.

Affective Commitment. One of the main reasons to continue a relationship is based on commitment. In general, commitment is the enduring desire to maintain a valued relationship. Relationship commitment represents the confidence one has in service providers' reliability and integrity (see commitment-trust theory; R. M. Morgan \& Hunt, 1994). A distinction can be made between two types of commitment: affective and calculative commitment (De Vries et al., 2012). In contrast to calculative commitment, which is cost based (i.e., transaction, learning, or artificial costs), affective commitment is the desire to continue a relationship because one person likes the other person, and the relationship gives that person pleasure. In the present thesis, we focused on affective commitment, in line with the work by Roberts et al. (2003). Affective commitment within this thesis refers to students' willingness to belong or be connected to their university (i.e., their faculty and staff). It develops over time as students become accustomed to positive responses from universities' faculty and staff (e.g., "I continue to deal with my university because I like being associated with them"). 
Satisfaction. Satisfaction is a service-related quality perception (Hennig-Thurau \& Klee, 1997). It is mainly built on previous experiences and eventually leads to an emotional state, resulting in an overall quality evaluation (Hennig-Thurau \& Klee, 1997). In the studies in this thesis, satisfaction was included as part of the relationship quality construct (Crosby et al., 1990; Roberts et al., 2003). In this thesis, satisfaction refers to cumulative student satisfaction with the overall quality of the student-faculty relationship. Students' cognitive and affective evaluations based on their personal experiences across all educational service encounters were considered, that is, every time they interacted with someone from their university (e.g., "I am delighted with the performance of my university").

It is essential to consider all relationship quality dimensions in order to build good quality relationships between students and their educational faculty and staff. The conceptual model for the empirical studies was based on the work by Zeithaml et al. (1996); see Figure 1.2. An adapted version of the relationship quality instrument developed by Roberts et al. (2003) was used to measure relationship quality. We assumed that relationship quality would be positively associated with students' intentions and behavior (see Figure 1.2).

Figure 1.2

Conceptual Model

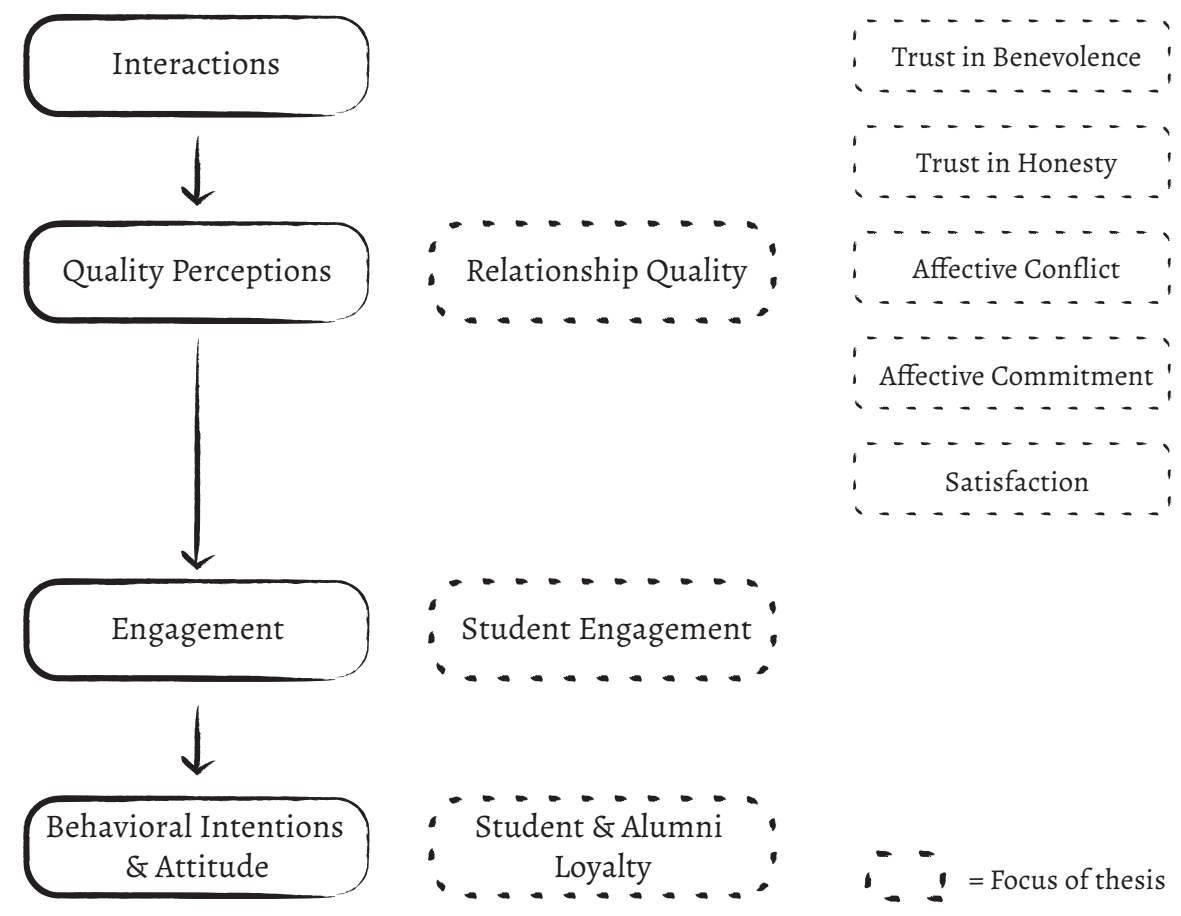


T. Gibbs and Kharouf (2020) indicated that perceptions of relationship quality may affect service users' attitudes, behaviors, and actions and can result in positive relational exchange outcomes. We built on those ideas and assumed that when students perceive these relationships positively, the relationships are expected to have positive associations with students' engagement during their education (Zepke et al., 2014). Within this thesis, we therefore hypothesized that the stronger (i.e., the more positive) the relationship quality is, the higher students' involvement will be, such as their engagement in their studies (Bowden, 2011).

\section{Student Engagement}

Previous studies have shown the importance of students being engaged in their program of studies, course, or task. The educational literature suggests engagement is a metaconstruct that consists of different dimensions, such as behavioral, emotional/affective, and cognitive engagement (Fredricks et al., 2016), or other subtypes such as academic and psychological engagement (Appleton et al., 2006). In her work, Bowden (2009) expanded on the definition of engagement by McEwen (2004, as cited in Bowden, 2009) as "relating to a combination of rational and emotional bonds" (Bowden, 2009, p. 65). Drawing upon these ideas, Bowden et al. (2019) investigated student engagement in the context of higher education. They redefined it as "a multidimensional construct considering a student's social, cognitive, emotional, and behavior investments made when interacting with their tertiary institution and its focal agents (such as peers, employees, and the institution itself)" (p. 4).

Building on the ideas of services and relationship management, positive perceptions of the quality of services will lead to (customer) engagement (Zeithaml et al., 1996); that is, the extent to which one is engaged with the process of service delivery. To delineate the meaning of student engagement in higher education within this thesis, we drew upon the work of Schaufeli and Bakker (2003). They interpreted and defined student engagement similarly to work engagement (see Schaufeli \& Bakker, 2003). Explicitly, they defined student engagement as "a positive, fulfilling work-related state of mind that is characterized by vigor, dedication, and absorption" (Schaufeli \& Bakker, 2003, p. 4). Vigor refers to "high levels of energy and resilience while working" (Schaufeli \& Bakker, 2003, p. 4/5), e.g., "When I get up in the morning, I feel like going to class". Dedication is characterized by "being strongly involved in one's work and experiencing a sense of significance, enthusiasm, inspiration, pride, and challenge" (Schaufeli \& Bakker, 2003, p. 5) e.g., "I am proud of my studies". Absorption is "the state of being fully concentrated and happily engrossed in one's work, whereby time passes quickly and one has difficulties with detaching oneself from work (Schaufeli \& Bakker, 2003, p. 5), e.g., "When I am studying, I forget everything else around me". 
To foster student engagement and students' supportive behavior (i.e., showing commitment or loyalty), higher education institutions need to cultivate good relationships with their students (Sung \& Yang, 2009). One response to that relationship could be that students enjoy their studies. Our assumptions are based on the literature on relationship building. We expect that, in higher education, the better experience students have of their education through the relationships they have with faculty and staff, the more engaged they are in their studies (Taylor \& Parsons, 2011; Xerri et al., 2018). When students are more engaged and experience more positive relationship quality, the more loyalty intentions and behavior they will show (Bowden, 2009; Brodie et al., 2011). We hypothesized that relationship quality positively affects student loyalty, either directly or indirectly, through student engagement.

\section{Student and Alumni Loyalty}

In the international literature on student behavior, student loyalty is considered to be a critical measure of higher education institutions' success (Rojas-Méndez et al., 2009). The focus in prior research mainly included the drivers of student loyalty, such as trust (Carvalho \& de Oliveira Mota, 2010), service quality (Ali et al., 2016; Thomas, 2011; Usman $\&$ Mokhtar, 2016) or a combination of factors such as satisfaction, institutional image, and shared values (e.g., R. M. Brown \& Mazzarol, 2009; Nesset \& Helgesen, 2009; Schlesinger et al., 2017).

Building on services management research in the context of higher education, student loyalty in the present thesis refers to the extent to which a student feels connected to the higher education institution and how attitude and behavioral intentions express this connection (e.g., "I am very interested in keeping in touch with my faculty"). As pointed out by Helgesen and Nesset (2009), loyalty can be related both to the period when a student is formally enrolled as well as the period after the student has completed their formal education at the institution (i.e., as alumni). Alumni form an important group that can support their former higher education institution in various ways (Doña Toledo \& Martínez, 2020; Hennig-Thurau et al., 2001). Because of their time and financial means, alumni are a valuable resource for higher education institutions (Ebert et al., 2015; Weerts \& Ronca, 2008), for instance, by reflecting on current curricula, providing job opportunities or offering internships, guest lectures, and donations. As pointed out by Yousaf et al. (2020), "developing student loyalty requires building a strong foundation and solid long-term relationship with students not only for the time they are studying but also beyond it" (p. 883).

In the next section, the studies conducted are briefly discussed, including the research questions and designs, followed by a general overview. 


\section{Overview of the Studies}

The studies in this thesis examined students' perceptions of the quality of their relationships with faculty and staff, that is, overall relationship quality. We examined the associations between relationship quality and students' involvement in terms of their engagement in their studies and their loyalty towards their faculty/staff. We hypothesized that if students perceive their educational experiences more positively, this will positively enhance their involvement, expressed by student engagement and loyalty. To investigate this main hypothesis, we conducted five empirical studies where we drew upon SET as the overarching framework (Blau, 1964; Emerson, 1976; Homans, 1961). Related ideas from services and relationship management were applied, in combination with those from the educational literature.

Altogether, these studies try to find an answer to the central research question of this thesis: What are students' perceptions of relationship quality in higher education, and how is relationship quality associated with students' involvement? An overview of this thesis is presented in Figure 1.3, including the research designs of the studies that were conducted. In sum, the measurement and construct of relationship quality in higher education were investigated in Studies 1 and 2. The association of relationship quality with student engagement was examined in Study 3, followed by an investigation of alumni loyalty in Study 4. Finally, the sequential interplay between the dimensions of relationship quality and cause-and-effect relations between relationship quality, student engagement, and student loyalty were examined in Study 5.

The first research question was: What is relationship quality in higher education, and how can we measure it? To answer our first research question, we collected both quantitative and qualitative data. In Study 1, described in Chapter 2, we investigated the development of a relationship quality scale that we applied in the higher education context. We asked students to complete the relationship quality survey. A confirmatory factor analysis was used to analyze the quantitative data. Next, we collected additional qualitative data from a focus group discussion with students from different years of study and programs of study. The focus group discussion aimed to corroborate and explore in greater depth the ideas higher education students have about relationship quality dimensions, based on the quantitative survey findings. 


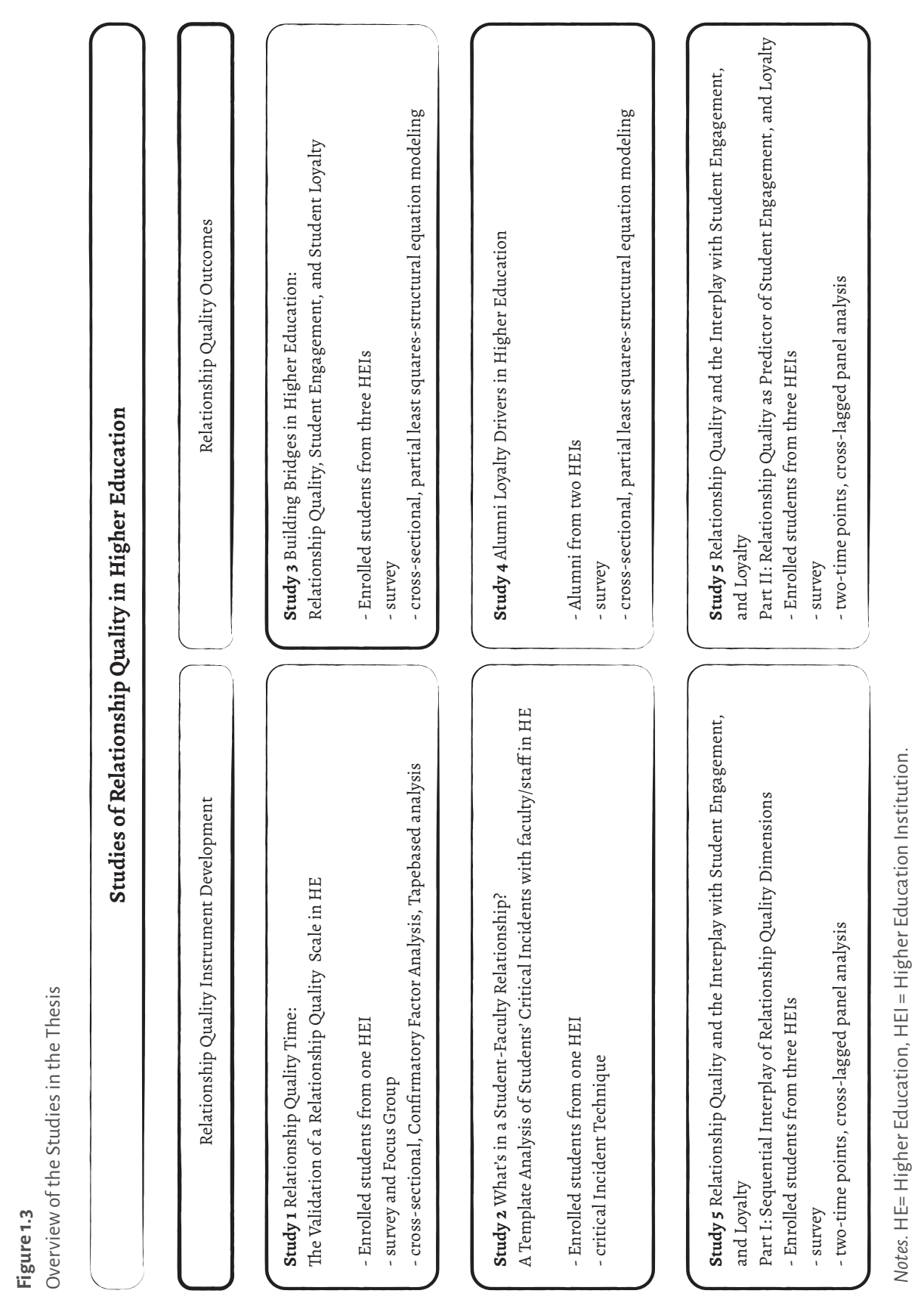


Chapter 1 - Student-faculty relationships in higher education: An introduction

To learn more about what students think about relationship quality aspects, we wanted to know what kinds of relational elements they refer to when asked about the quality of relationships with their educational faculty and staff. Therefore, in Study 2 (Chapter 3) we used a qualitative approach to explore students' positive and negative relationship quality experiences, applying a critical incident technique. To analyze the data, we used the five a priori relationship quality dimensions as a template. The research findings were exploratory and complementary to the overarching research question. The study's findings provide a more comprehensive understanding of real-life examples of students' positive and negative perceptions regarding relationship quality.

In Chapter 4, we describe Study 3, which focused on the second research question: What associations does relationship quality have with student engagement, and (in turn) with student loyalty? We developed and empirically tested a conceptual framework with relationship quality as an independent variable and student engagement and student loyalty as dependent variables to examine this question. Starting with a pilot study, we conducted an online survey among enrolled students from two different higher education institutions; after that, we examined direct and indirect effects of the independent variables on the dependent variables. In the main study, we repeated the same survey among a larger sample of enrolled higher education students from three higher education institutions. To analyze the data, we used partial least squares-structural equation modeling (PLS-SEM). The study's findings indicated relationship quality dimensions as predictors of student engagement and student loyalty.

In Study 4 (Chapter 5), we tested a replication of the conceptual model with alumni. The research question that guided this study was: What associations do alumni's perceptions of their relationship quality have with their previous engagement and (in turn) with their current loyalty? Within this study, the sample consisted of former students (alumni) from two different higher education institutions. We again examined the hypothesized model exploring relationship quality dimensions as predictors for former student engagement dimensions and student loyalty using PLS-SEM. We also surveyed alumni for their loyalty intentions and behavior (e.g., for their willingness to recommend the institution, to select it again for future study, and to maintain contact). Our assumption partially confirmed that alumni's positive perceptions of former relationship quality and former engagement lead to more current loyalty intentions towards their faculty and staff/university (after graduation).

In Study 5 (Chapter 6), we extended our investigation of the model using data from two time points gathered over two academic years. The study involved two parts. Our first research question was: How do relationship quality dimensions develop over time? First, 
the temporal stability of the relationship quality construct was examined. We further focused on the strength of relations among the dimensions within the relationship quality construct. Based on the existing literature in relationship quality research (e.g., Castaldo, 2007; Hennig-Thurau et al., 2001), we investigated trust at Time 1 as a predictor of the affective relationship quality dimensions of commitment, conflict, and satisfaction at Time 2. Our second research question in Study 5 was: Does relationship quality at Time 1 predict student engagement and loyalty at Time 2 ? Students' responses to a survey were collected in two consecutive years.

Finally, in Chapter 7, we summarize this thesis, followed by a general discussion of the findings and their theoretical and practical implications. 


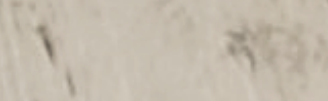

4

$t$

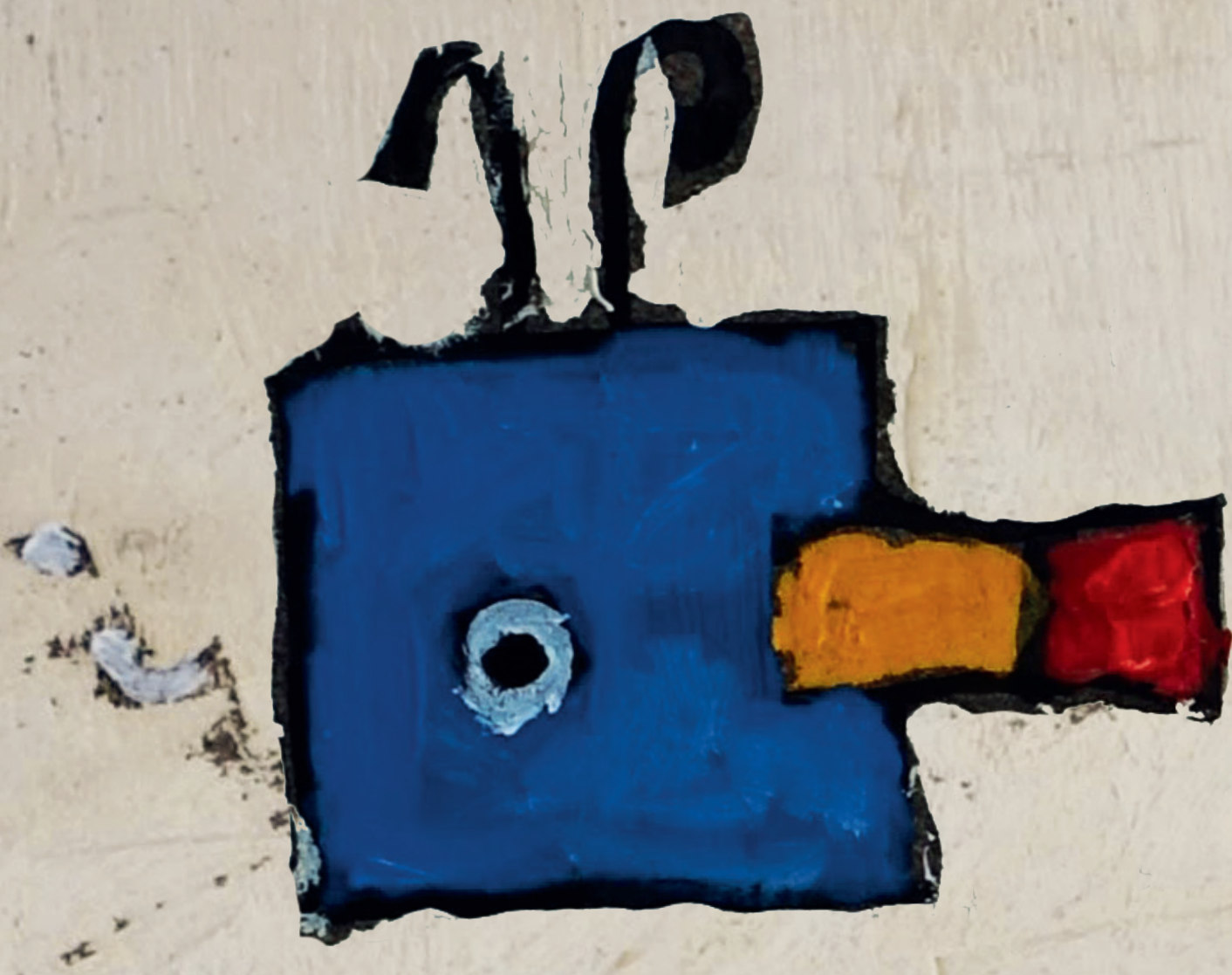

$-1$ 


\section{Relationship Quality Time: The Validation of \\ a Relationship Quality Scale in Higher Education}
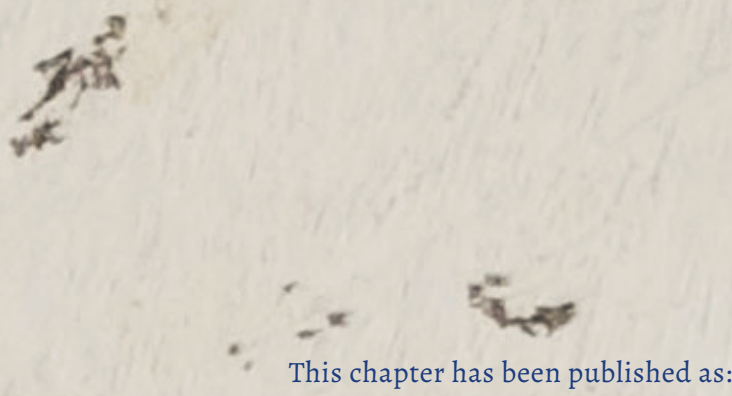

Snijders, I., Rikers, R. M. J. P., Wijnia, L., \& Loyens, S. M. M. (2018). Relationship quality time: The validation of a relationship quality scale in higher education. Higher Education Research $\&$ Development, 37(2), 404-417. https://doi.org/10.1080/07294360.2017.1355892

The data were presented at the inaugural Biennial International Seminar on the Teaching of Psychological Science (BISTOPS), Paris, France, 9-13 July 2018

Acknowledgement of author contributions: IS, LW, RR, and SL designed the study, IS recruited participants and collected the data, IS and LW analyzed the data, IS drafted the manuscript, all authors contributed to critical revisions of the paper, LW, RR and SL supervised the study. 


\section{Abstract}

This study investigated the overall quality of the interpersonal relationship students have with faculty and staff, that is, relationship quality. In relationship management research, relationship quality is paramount for the creation of bonds with customers, which in turn is necessary for the sustainability of organizations, that is, continuity and growth. In higher education, it is not only recent changes in the funding of education that urge us to further investigate relationship quality, as students having relational bonds with their teachers and faculty/staff is important as well. We expect that these relationships are expected to influence students' college experiences positively. Although educational literature addresses the importance of student-faculty relationships, little is known about students' perceptions of the quality of their relationship with their program. The aim of this study was, therefore, to get a more in-depth understanding of the concept and measurement of relationship quality within a higher education context. To that end, an existing relationship quality scale was used measuring five dimensions: trust in honesty, trust in benevolence, satisfaction, affective commitment, and affective conflict. A confirmatory factor analysis (CFA) was conducted on survey responses of 551 students from a Dutch university of applied sciences. Next to the CFA, a small-scale focus group discussion was held to validate the quantitative findings of students' perceptions of relationship quality. The findings confirm that the relationship quality instrument is an adequate instrument to investigate relationship quality in a higher education context. Additional qualitative results also suggest that students acknowledge the relevance of relationship quality and the need for having a good relationship with their faculty and staff. 


\section{Introduction}

Time to degree completion is of growing concern to the funding of public higher education institutions (Suhre et al., 2013). As a result, the importance of student-faculty relationships becomes of interest, because these relationships are expected to positively influence students' college experiences (Fuentes et al., 2014; Y. K. Kim \& Sax, 2009), and can, therefore, contribute to timely degree completion. Tinto (1997) already asserted that student-faculty interactions are indicative of the student's level of academic integration in the college environment and that students who engage in academic and social integration experiences are less likely to leave their institution. For instance, students who develop positive interactions with their peers, teachers, and faculty/staff are more likely to persist and complete a degree, and in the future, will be better able to build rapport. Positive student-faculty interactions also contribute to students' intellectual and personal development such as increased motivation, study success, engagement (Y. K. Kim \& Sax, 2009; Klem \& Connell, 2004; Pascarella \& Terenzini, 1991), and retention (O'Keeffe, 2013; Vander Schee, 2008b; 2010). Also, to improve students' overall evaluation of and satisfaction with their university, the relationships between students and their faculty/staff appear most crucial (Arena et al., 2010).

Research in the field of services and relationship management in higher education indicates that positive interactions and relationships are associated with student loyalty (Bowden, 2011; Helgesen, 2008; Hennig-Thurau et al., 2001; Macintosh, 2007). In turn, student loyalty is crucial for the continuity and growth of higher education institutions (e.g., word-of-mouth, recommendations to other potential students, the ranking of higher education institutions, alumni offerings of student traineeships, and enrollment in post-graduate education). General ideas from the services and relationship management literature suggest that for any kind of service organization (profit or non-profit), it is essential to retain customers. To establish long-term benefits for organizations such as customer retention and loyalty, service organizations should attract, maintain, and enhance client relationships (Berry, 2002; Gummesson \& Grönroos, 2012; Zeithaml, 1981). Previous studies indicated that having a focus on establishing a good relationship with students is of interest to higher education institutions (Cook-Sather \& Luz, 2015; Cotten \& Wilson, 2006; Zepke et al., 2014), for instance, to reduce dropout rates (Helgesen, 2008; Schertzer \& Schertzer, 2004) and improve student loyalty (Hennig-Thurau et al., 2001). However, little is known about the overall quality of the interpersonal relationships students have with university faculty and staff from a student's perspective, that is, relationship quality. Relationship quality is especially important when the offered services are complex, delivered over time, and customized because interpersonal relationships are expected to be more vital in these contexts (Crosby et al., 1990). Higher education settings 
meet these criteria because the educational service consists of a high degree of interaction between students and faculty/staff (i.e., complex), expressed in multiple educational services encounters with different people, and continuing over time. Moreover, through the students' choice of courses, internships, and research projects, students customize their educational programs. The aim of this paper was, therefore, to get a more in-depth understanding of the concept and measurement of relationship quality within a higher education context.

\section{Relationship Quality}

Relationship quality can be defined as the overall assessment of the strength of a relationship between two parties (Bowden, 2011; Dagger et al., 2009). Previous educational literature mainly focused on one or a few aspects of the student-faculty relationship, such as frequency or quality of interaction between students and teachers. However, relationship quality in relationship management research is often conceptualized as a multidimensional construct capturing different but related facets of a relationship (Lages et al., 2005; Palmatier et al., 2006) such as trust, commitment, and satisfaction (Hennig-Thurau et al., 2001). Building on the work of Roberts, Varki, and Brodie (2003), relationship quality adjusted to a higher education setting consists of five dimensions: trust in honesty, trust in benevolence, satisfaction, affective commitment, and affective conflict.

\section{Trust in Honesty}

Trust in honesty of faculty and staff means trust in a university's credibility. This is based on the extent to which students believe university faculty and staff's word can be relied on, that they are sincere, and that they will perform their role effectively and reliably.

\section{Trust in Benevolence}

Trust in benevolence of faculty and staff means the extent to which students believe staff and faculty are concerned about students' welfare. This includes having intentions and motives beneficial to students and avoiding acting in a way that will result in negative outcomes for students.

\section{Satisfaction}

Satisfaction refers to cumulative student satisfaction with the overall quality of the relationship a student has with faculty and staff. It is the students' cognitive and affective evaluation based on their personal experience across all educational service encounters (i.e., every time a student interacts with someone from their university). 


\section{Affective Commitment}

Affective commitment refers to students' commitment to the university. Furthermore, affective commitment develops over time as individuals (service users/students) become accustomed to positive responses, leading them to become more and more secure in the relationship (with the university).

\section{Affective Conflict}

Affective conflict is a negative indicator of relationship quality, that is, resulting in lower levels of relationship quality. In line with Roberts et al. (2003), affective conflict is used as a measure of the retained level of conflict felt by students concerning their relationship with faculty and staff.

\section{Present Study}

In this study, we aim to get a more in-depth understanding of the concept of relationship quality in higher education. Drawing upon recent research in the field of services and relationship management in higher education (Arnett et al., 2003; Bowden, 2011; Helgesen, 2008; Woodall et al., 2014), we assume that relationship quality in higher education can be applied similarly as in a for-profit context. This study addresses this issue by incorporating the concept of relationship quality as described in services and relationship management literature and investigated it in the context of higher education. First, we administered a questionnaire to measure relationship quality and examined whether this instrument and its five dimensions applied to a higher education context. A confirmatory factor analysis (CFA) was conducted to analyze the survey data.

To grasp students' perceptions of relationship quality from the students' point of view, we held an additional small-scale focus group discussion to validate the quantitative findings. The focus group discussion aimed to verify students' ideas of relationship quality dimensions. Focus groups can be used either as a method in their own right or to complement other methods such as quantitative research (D. L. Morgan, 1997; D. L. Morgan \& Krueger, 1993; Wolff et al., 1993), for example, checking validity (A. Gibbs, 1997). A combination described by D. L. Morgan (1997) is one where a survey is used as a primary method, and a focus group acts as a follow-up research method that assists in interpreting the survey results. Drawing upon these ideas, in the present study, we conducted a focus group discussion after the survey. 


\section{Relationship Quality Questionnaire}

\section{Method}

\section{Participants}

Participants were students enrolled in an educational program at a Dutch university of applied sciences $(N=551)$. Most participants were female $(59 \%)$, which is a slight overrepresentation when compared to the average percentage of female students enrolled at the institution under study (49.5\%). All respondents were distributed across all study years, although students in their first year were highly represented $(57.7 \%$; $12.2 \%$ second year; $12 \%$ third year; $18.1 \%$ fourth year). The average age of participants was 20.97 years old $(S D=4.54)$.

\section{Materials and Procedure}

A questionnaire consisting of 15 items, distributed over five subscales (i.e., trust in honesty, trust in benevolence, satisfaction, affective commitment, and affective conflict) was used to measure relataionship quality. Each dimension was measured by three items (Roberts et al., 2003). All items were structured on a 7-point Likert-type scale ranging from 1 (strongly disagree) to 7 (strongly agree).

The survey was administered in Dutch. To ensure that the original items were correctly translated, a forward-back translation process was employed (Epstein et al., 2015). At the end of the 2014-2015 academic year, a questionnaire containing a short description of the purpose of the study was sent by campus email to all 4600 students from the university under study. Filling out the questionnaire took approximately 10-15 minutes. First-year students who were not familiar with the questionnaire tool were asked to fill out the questionnaire in a classroom setting. When needed, they were assisted by their tutor, but only for practical purposes and not related to answering the questions (e.g., assistance in logging into the questionnaire tool). Participation was voluntary. Students were given 27 days to respond (one month before their exams started). Students who did not complete the survey received another email reminding them of the first email, and after a fortnight, they were asked again to fill out the questionnaire. A book voucher was rewarded to 15 randomly selected respondents.

\section{Analyses}

To investigate the applicability of the existing relationship quality scale in the context of higher education, we conducted a CFA on the survey consisting of 15 items. Based on the services and relationship management literature and empirical research on relationship quality, we postulated a model and tested it for its validity, given the sample data. In this way, we determined the extent to which the items measured the relationship quality 
dimensions. All items comprising an relationship quality dimension (i.e., its subscale) were therefore expected to load onto their related factors. An alternative model of relationship quality with a one-factor structure was constructed to test whether this could lead to a better fit with the data. Thus, the second model contained all 15 items loading on one latent factor, relationship quality (RQ). A schematic representation of these models is shown in Figure 2.1.

\section{Figure 2.1}

Measurement models
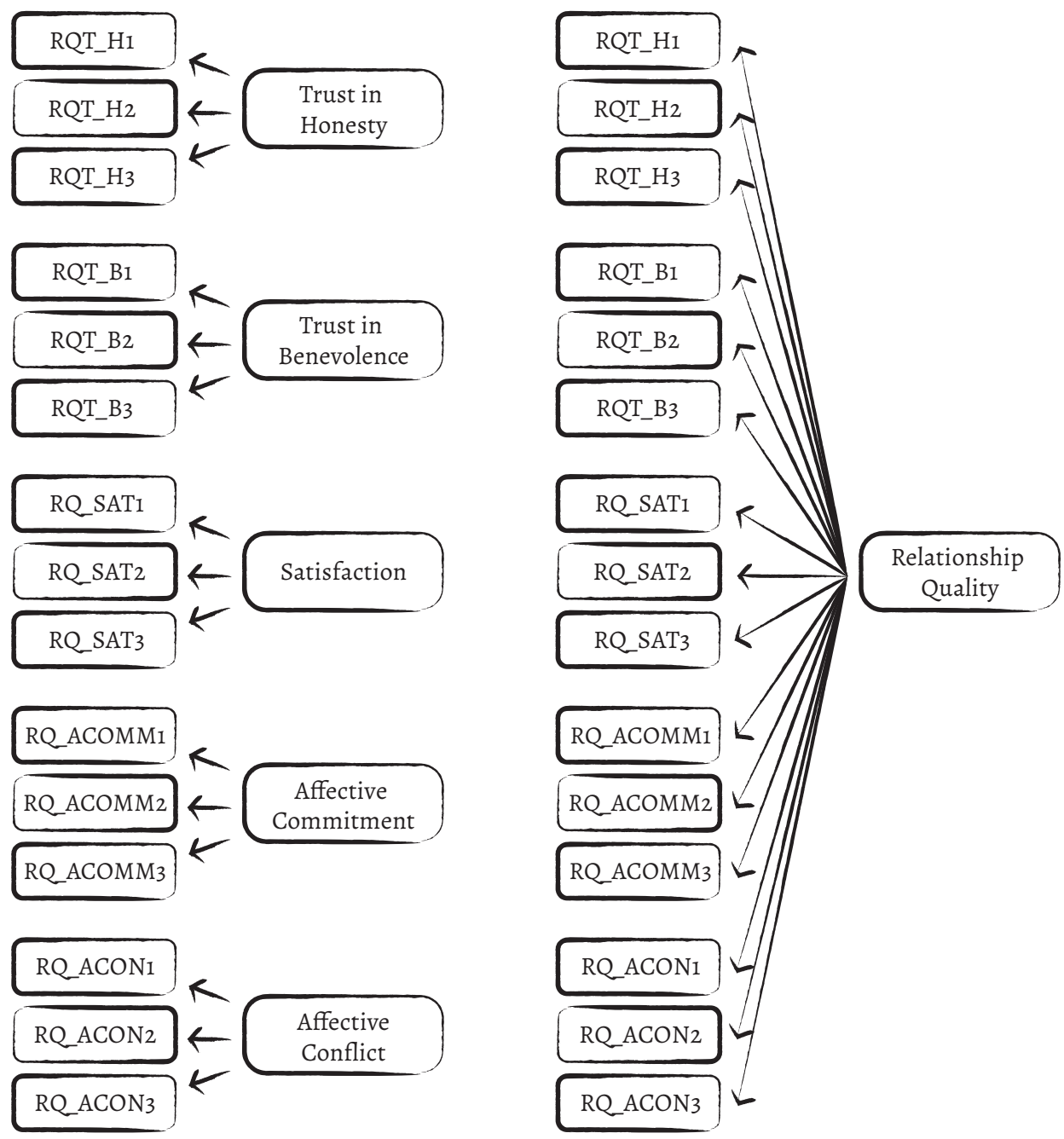
Model I (see Figure 2.1) postulates a priori that relationship quality is a five-factor structure composed of trust in honesty, trust in benevolence, satisfaction, affective commitment, and affective conflict. There are five-factors (dimensions), as indicated by the five ellipses labeled Trust in Honesty (RQT_H), Trust in Benevolence (RQT_B), Satisfaction (RQSAT), Affective Commitment (RQ_ACOMM), and Affective Conflict (RQ_ACON). These five-factors are determined by 15 observed variables, as indicated by the 15 rectangles. Likewise, Model 2 (see Figure 2.1) is an relationship quality model with one latent factor, as indicated by the ellipse labeled relationship quality. In this model, all 15 variables, as indicated by the rectangles, are expected to load on one latent variable, relationship quality. Responses to negatively stated items, that is, for affective conflict, were reversed so that for all items, the highest response was indicative of a favorable rating of each of the five latent constructs.

Data were analyzed using a structural equation modeling approach (Byrne, 2013) to test whether the underlying dimensional structure of relationship quality had a good fit to the data, and hence whether this five-factor structure could be applied to a higher education context. A CFA was conducted on the models presented in Figure 1 using Amos 22 (Arbuckle, 2013). For the estimation of the model's parameters, maximum likelihood estimations were used. Two groups of fit indices were selected: absolute and incremental.

In the present study, we used $\chi^{2}$, accompanied by degrees of freedom, sample size, and p-value, as well as the root mean square error of approximation (RMSEA; Steiger, 1990) and standardized root mean square residual (SRMR) as absolute fit indices. $\chi^{2}$ was used to test the closeness of fit between an observed and predicted covariance matrix. For RMSEA, the lower the value, the better the fit, with a cut-off value close to .06. RMSEA appears to be sensitive to model specification, minimally influenced by sample size, and not overly influenced by the estimation method. SRMR values of .08 or lower are generally considered to show a good fit (L. Hu \& Bentler, 1999). The Tucker-Lewis index (TLI) and the comparative fit index (CFI) were included as incremental fit indices. Both indices range from 0 to 1 , with higher values indicating a better fit. Values close to .95 or .96 are suggested by Byrne (2013) to be associated with well-fitting models.

Results of the Questionnaire. Table 2.1 reports the questionnaire items with their factor loadings and the hypothesized dimensions of relationship quality together with Cronbach's alpha $(\alpha)$, means, and standard deviations (SD). Cronbach's $\alpha$ values for the five dimensions ranged from 0.84 to 0.96 , all exceeding the 0.70 cut-off value (Nunnally, 1967).

The results confirm the five-factor structure. Analysis of the hypothesized model resulted in a $\chi^{2}(80, N=551)=202.43, p<.001$, CFI of .98, a TLI of .98, an RMSEA of .05, and an SRMR of .03. $\chi^{2}$ statistics were statistically significant, which suggests that the hypothesized 
model does not fit the data very well. Nevertheless, the other indices of fit indicated a fairly good fit of the specified model with the data and are to be preferred when evaluating a particular model (Marsh et al., 1993). A $\chi^{2}$-difference test showed that the five-factor structure model had a significantly better fit than the one-factor structure model, $\Delta \chi^{2}(10)=1705.55$, $p<.001$ (Table 2.2).

\section{Table 2.1}

Relationship Quality (RQ) Dimensions and Items

\begin{tabular}{|c|c|c|c|c|}
\hline Relationship quality dimensions and items & Mean & SDs & $\begin{array}{l}\text { Cronbach's } \\
\text { a }\end{array}$ & $\begin{array}{l}\text { Factor } \\
\text { loadings }\end{array}$ \\
\hline \multicolumn{5}{|l|}{ Trust in honesty (RQT_H) } \\
\hline My service provider is honest about my problems & 4.83 & 1.47 & .865 & .88 \\
\hline My service provider has high integrity & 4.96 & 1.49 & & .84 \\
\hline My service provider is trustworthy & 5.00 & 1.65 & & .77 \\
\hline \multicolumn{5}{|l|}{ Trust in benevolence (RQT_B) } \\
\hline My service provider is concerned about my welfare & 4.57 & 1.65 & .840 & .88 \\
\hline $\begin{array}{l}\text { I can count on my service provider considering how their actions } \\
\text { affect me }\end{array}$ & 4.90 & 1.57 & & .73 \\
\hline $\begin{array}{l}\text { When I confide my problems to my service provider, I know they will } \\
\text { respond with understanding }\end{array}$ & 5.32 & 1.44 & & .79 \\
\hline Satisfaction (RQ_SAT) & & & . & \\
\hline I am delighted with the performance of my service provider & 4.80 & 1.50 & 961 & .94 \\
\hline I am happy with my service provider's performance & 4.67 & 1.52 & & .96 \\
\hline I am content with my service provider's performance & 4.78 & 1.55 & & .94 \\
\hline \multicolumn{5}{|l|}{ Affective commitment (RQACOMM) } \\
\hline I feel emotionally attached to my service provider & 4.57 & 1.63 & .873 & .87 \\
\hline $\begin{array}{l}\text { I continue to deal with my service provider because I like being } \\
\text { associated with them }\end{array}$ & 4.79 & 1.74 & & .83 \\
\hline $\begin{array}{l}\text { I continue to deal with my service provider because I genuinely enjoy } \\
\text { my relationship with them }\end{array}$ & 4.75 & 1.57 & & .80 \\
\hline \multicolumn{5}{|l|}{ Affective conflict (RQACON) } \\
\hline I am angry with my service provider & 2.60 & 1.64 & .903 & .88 \\
\hline I am frustrated with my service provider & 3.23 & 1.78 & & .90 \\
\hline I am annoyed with my service provider & 3.21 & 1.75 & & .84 \\
\hline
\end{tabular}

Table 2.2

Fit indices for the hypothesized and alternative one-factor model

\begin{tabular}{|c|c|c|c|c|c|}
\hline Model & $\chi^{2}$ & df & RMSEA & CFI & TLI \\
\hline \multicolumn{6}{|l|}{ Model 1} \\
\hline Hypothesized 15-item model, five-factor & $202.43^{*}$ & 80 & .05 & .98 & .98 \\
\hline \multicolumn{6}{|l|}{ Model 2} \\
\hline 15-item model, one-factor & $1907.98^{*}$ & 90 & .19 & .74 & .69 \\
\hline
\end{tabular}

Note. ${ }^{*} p<.01 . \Delta \chi^{2}=$ difference of $\chi^{2}$ values, $\chi^{2}=$ chi-square, $d f=$ degrees of freedom, $\mathrm{CFI}=$ comparative fit index, $\mathrm{TLI}=$ Tucker-Lewis index, and RMSEA = root mean square error of approximation 


\section{Focus Group Discussion}

\section{Method}

\section{Participants}

Participants in the focus group discussion were students from the same university at which the survey study was conducted $(N=9)$. The average age of participants was 24.89 years old $(S D=8.70)$. Participants were selected following convenience and purposive sampling techniques (C. Brown et al., 2009) to have a group consisting of an equal mix of male and female students from all study years and different educational programs. As suggested by Krueger and Casey (2000), a group consisting of five to 10 respondents is appropriate. In the present study, the group consisted of five female and four male students. They participated in the survey conducted earlier. Participants were distributed over all study years and enrolled in different educational programs (first year: 2; second year: 3 ; third year: 1 ; and, fourth year and longer: 3 ), and enrolled in different educational programs (i.e., pedagogics, aquatic eco technology, communication, ICT, logistics engineering, maritime officer, social work, and commercial economics).

\section{Materials and Procedure}

To get a more in-depth understanding of the concept under study, that is, relationship quality (Wolff et al., 1993), we organized a focus group discussion shortly after the survey was administered (i.e., October 2015, a few months after the survey was completed). We aimed to clarify and elaborate on students' perceptions of relationship quality. Therefore, with the focus group questions, we sought to gain a better understanding and interpretation of relationship quality, such as practical examples of a priori defined relationship quality dimensions.

Focus group performance was based on the main steps suggested by Krueger and Casey (2000). Ground rules for the discussion (e.g., there are no good or wrong answers to the questions, it is your opinion that counts and every participant's opinion is equally important) and general information about the topics to be discussed were given in advance to prepare participants to properly react to the questions and the discussion that followed. The focus group discussion was to be held in a surrounding that was not related to the students' university setting. After participants were given a brief explanation of the research objectives and were assured that all information provided would remain confidential, they were asked to sign a consent form. The session was guided by an independent moderator/facilitator, who was not familiar to the participants. 
Before the start of the focus group discussion, each participant was asked to write down an example of a situation related to the relationship quality dimension (five in total). Then the actual focus group discussion started. For the exact formulation of the focus group questions, see Appendix A.

First, we questioned, "Please give an example of your experience regarding the quality of the relationship between you as a student and university faculty and staff." Next, we questioned students about each relationship quality dimension. Finally, we asked whether students thought that relationship quality is important concerning their study achievements, their relationship with the university in general, or even in life itself. After each question, the moderator summarized the discussion findings for that specific topic. Students' written examples were collected at the end of the focus group discussion (specific examples are listed in Table 2.3).

To increase our understanding of the relationship quality dimensions, we asked participants for consensus on the discussion findings (Onwuegbuzie et al., 2009). The session lasted for 1 hour and 15 minutes.

Table 2.3

Illustrative Responses to Relationship Quality (RQ) Dimensions

\begin{tabular}{ll}
\hline RQ dimensions & Illustrative example from focus group discussion \\
\hline $\begin{array}{l}\text { Trust in university's } \\
\text { honesty }\end{array}$ & $\begin{array}{l}\text { "During the first conversation with my study counselor, it was stated clearly that at all } \\
\text { times, we have to be honest with each other, in order for teachers to get a clear picture of } \\
\text { me as a student." (SD, male, first year) }\end{array}$ \\
$\begin{array}{l}\text { Trust in university's } \\
\text { benevolence }\end{array}$ & $\begin{array}{l}\text { "I consider my teachers as being helpful and understanding, in reaction to what I pointed } \\
\text { out my study problems are, and when and where I think I need support...." (MvD, female, } \\
\text { long-term student) }\end{array}$ \\
$\begin{array}{l}\text { Satisfaction } \\
\text { "I am satisfied about the quality of the relationship I have with my university. Good! A lot } \\
\text { of understanding, although, sometimes it takes a long time before you get a reaction." } \\
\text { (Anonymous) } \\
\text { Affective }\end{array}$ & $\begin{array}{l}\text { "I think I am very strongly committed to my educational program. Part of this is because } \\
\text { of my own assertiveness. This is rewarded by people from my educational program. I } \\
\text { believe I enjoy special treatment by teachers, and everyone takes me seriously when I } \\
\text { have something to say...Currently, I am chairman of one of the students' associations. For } \\
\text { both ways, this stimulates commitment." (L., male, second year) }\end{array}$ \\
$\begin{array}{l}\text { Affective conflict } \\
\text { program. He does not want to compromise [frustration]." (RA, male, fourth year) }\end{array}$
\end{tabular}




\begin{abstract}
Analyses
To reflect on and further analyze the focus group findings, the discussion was videotaped. Focus group quotes were combined with the tape-based analysis. Although this mode of analyzing data is less rigorous than a transcript-based analysis, this type of analysis is helpful for the researcher to focus on the research questions (Onwuegbuzie et al., 2009), which suits the primary goal of this focus group to follow up on the questionnaire data.
\end{abstract}

Results of Focus Group. First, all participants could provide examples of relationship quality based on their experience. This validated our idea that students are aware of relationship quality aspects within the relationship with their university. Moreover, all participants reacted to the examples that were introduced by their fellow students, resulting in a vivid and fruitful discussion.

Students referred to different situations during service encounters with faculty and staff when they were asked to provide examples of the relationship quality dimensions in their educational service experience. At first, the examples only related to teacher-student interactions, which constituted the main part of students' encounters. However, other examples of their evaluations of relationship quality followed, such as encounters with the international office or study counselors. Interactions with staff from additional services such as the library, audiovisual services, and catering, which are also part of the total university offering, were not mentioned.

Furthermore, we wanted to know how these examples were related to their educational service experience. Therefore, participants were asked to elaborate upon and discuss examples of the five relationship quality dimensions. The discussion led to a better idea of how students perceive relationship quality aspects. This was established by the positive and negative examples of relationship quality and the naming of distinct situations based on the quality of student-faculty relationships.

Next, we wanted to know how these examples were related to their educational service experience. In general, focus group participants reacted positively to the question to what degree they are satisfied with the quality of the relationship between them and university faculty and staff. However, some participants made critical remarks, for example, regarding teachers' willingness to (quickly) respond to students' questions by email. Among participants, different interpretations of affective commitment and affective conflict were derived. For instance, students' commitment to their education and the interpersonal relationships between students and faculty/staff seemed to be based on reciprocity. In other words, the more a student is committed, from the student's point of view, the more willing a teacher is to help and advise. 
Regarding affective conflict, frustrating or irritating situations can occur during one's program, for instance, when receiving critical remarks about one's work. Nevertheless, in retrospect, students understand and value these occasions.

To conclude, we covered all aspects of relationship quality, we discussed the proposed dimensions (i.e., five-factor structure) and sought to find additional ones. Based on this focus group discussion, we were not able to find other relationship quality aspects, directly or indirectly pointed out by students.

Finally, we questioned whether students believe that relationship quality is important in relation to their academic achievements, in their relationship with the university in general, or even in life itself. Participants claimed that the importance of relationship quality was paramount, not only during courses to achieve better study results, but also in students' preparation to become a successful young professional who can connect to others and build fruitful professional relationships. In conclusion, the focus group findings support the quantitative results of the survey.

\section{Discussion}

This study aimed to contribute to an improved understanding of the concept of relationship quality in higher education. To that end, five relationship quality dimensions were examined from a student's perspective: trust in honesty, trust in benevolence, satisfaction, affective commitment, and degree of affective conflict. Furthermore, we explored the concept and dimensions of relationship quality employing a small-scale focus group discussion to investigate whether students acknowledge the concept of relationship quality and whether they can relate to practical examples based on their experience.

Based on our qualitative and quantitative findings, we found a good fit of the fivedimensional model of relationship quality and the assumed importance of relationship quality from a student's point of view. Our findings thus confirm prior assumptions that a relationship management approach (e.g., Bowden, 2011; Helgesen, 2008; Hennig-Thurau et al., 2001), or more specifically, relationship quality in higher education, is appropriate and seems to be an important issue for both higher education institutions and students.

Recent studies on interpersonal relationships still mainly focus on the relationship between teachers and students (see Hagenauer \& Volet, 2014; Pianta et al., 2012). The current study adds to that research by taking a broader interpretation of the educational environment. Instead of only focusing on teachers, in our study, we consider all personnel students 
have contacts within the context of their educational program, such as employees of the educational administrative office, library, or exam committee. Furthermore, in contrast to prior studies that have investigated one or a few aspects of student-faculty relationships, such as frequency of interaction (e.g., Cotten \& Wilson, 2006; Kuh \& $\mathrm{Hu}$, 2001), our study emphasizes the overall measure of relationship quality. We used a fivedimensional structure for relationship quality in higher education, which enriches the conceptualization of relationship quality and strengthens its measurement in higher education contexts. By applying a more comprehensive and relational approach to investigate students' perceptions of the quality of student-faculty relationships, we believe that our findings contribute to a better understanding of how relationship quality can positively influence educational performance outcomes for students and higher education institutions.

A recent study by Jones (2016) indicated that a consumer's attitude towards relationship management has an impact on their willingness to engage in relationships with service organizations. In other words, if organizations apply relationship marketing tactics, consumers are more likely to (voluntarily) proceed in the relationship with their service provider. By adopting a relationship philosophy focused on understanding the customer, and in this case, the student, organizations are better able to meet students' changing needs and expectations (Zeithaml et al., 2009).

\section{Implications}

For policy-makers of higher education institutions, the relationship quality dimensions provide guidelines that are applicable in educational services. For example, trust in honesty of faculty and staff is reflected in the advice given to students. Besides institutional and educational program restrictions, staff members should be informed of students' skills as well. They then can provide reliable advice when, for example, students ask for information about their study career choices and chances to go abroad or start an internship in a specific field.

The degree of responsiveness by teachers, for instance, by grading an exam or responding to email, reflects trust in benevolence. Active students are more likely to receive help and guidance from teachers compared with non-active students, who are expected to be left to their own devices. Transparency in when to respond seems to be important to communicate adequately to students.

Students' satisfaction with the quality of the relationship is part of the overall satisfaction students have about their educational services. It is, therefore, an important indicator of the students' willingness to participate and to engage in the educational experience. Unsatisfied students are not expected to be involved in educational activities. Moreover, 
they can have a bad influence on other students. Evaluations during courses could be informative regarding the degree of student satisfaction and ways to improve when necessary.

To be able to build good relationships with students, commitment is required. This commitment is not only stimulated by the course offering itself, but also by other educational activities (e.g., being a student member of a student association).

Finally, both quantitative and qualitative findings indicate that the degree of affective conflict, such as irritation and frustrations, experienced by students is also part of the quality of the relationship perceived by students and can influence the relationship positively. Although sometimes the initial conflict is seen as negative, students indicate that during their personal development throughout their educational program, their view on their relationship with people from the educational program might change. Nevertheless, higher education institutions should provide customer services and the possibility to respond to complaint behavior adequately or even foresee service recovery strategies.

\section{Limitations and Suggestions for Further Research}

Although this study provides new insights into the concept of relationship quality in higher education, it also has limitations. In particular, the study was conducted in only one university of applied sciences. Future research should test if our findings hold in other samples. Also, one could examine differences among students by study year. As relationships grow over time, the evaluation of relationship quality could be influenced.

The qualitative findings were meant as a complementary study to the quantitative findings; however, multiple focus groups would provide a full qualitative methodology to study relationship quality among students. Because of the cross-sectional nature of the data, we were not able to demonstrate causality. Longitudinal approaches with relationship quality as an antecedent could be of interest.

\section{Conclusion}

The overall quality of the interpersonal relationship between students and faculty and staff is based on multiple interactions and sequential service encounters between students and different people from their university. Therefore, it is not simple to interpret and describe relationship quality in higher education. Nevertheless, our measurement of relationship quality does indicate the students' perceptions of the quality of the relationship they 
have with their university. Our results suggest that in the context of higher education, relationship quality has a place in an overall model of educational quality/academic success. The findings confirm that the five-dimensional relationship quality instrument is an adequate instrument to investigate relationship quality in a higher education context.

If higher education institutions acknowledge the importance of relationship quality, also seen from a services and relationship management point of view, they can positively influence their relationship with students (e.g., prompt reaction to students' questions and providing honest feedback). In line with the existing services and relationship marketing literature (Bowden, 2011; Helgesen, 2008; Hennig-Thurau et al., 2001; Macintosh, 2007), this could be beneficial for both higher education institutions and students. A good relationship between students and teachers and other faculty and staff is expected to have positive influence on the engagement of students during their education (Zepke et al., 2014), such as in classroom meetings or other extracurricular activities. Their engagement can increase their loyalty to the university (Bowden, 2011). Also, chances for achieving better study results might increase (Klem \& Connell, 2004), which is a positive outcome not only for students but in terms of efficiency and performance outcomes for higher education institutions as well. 


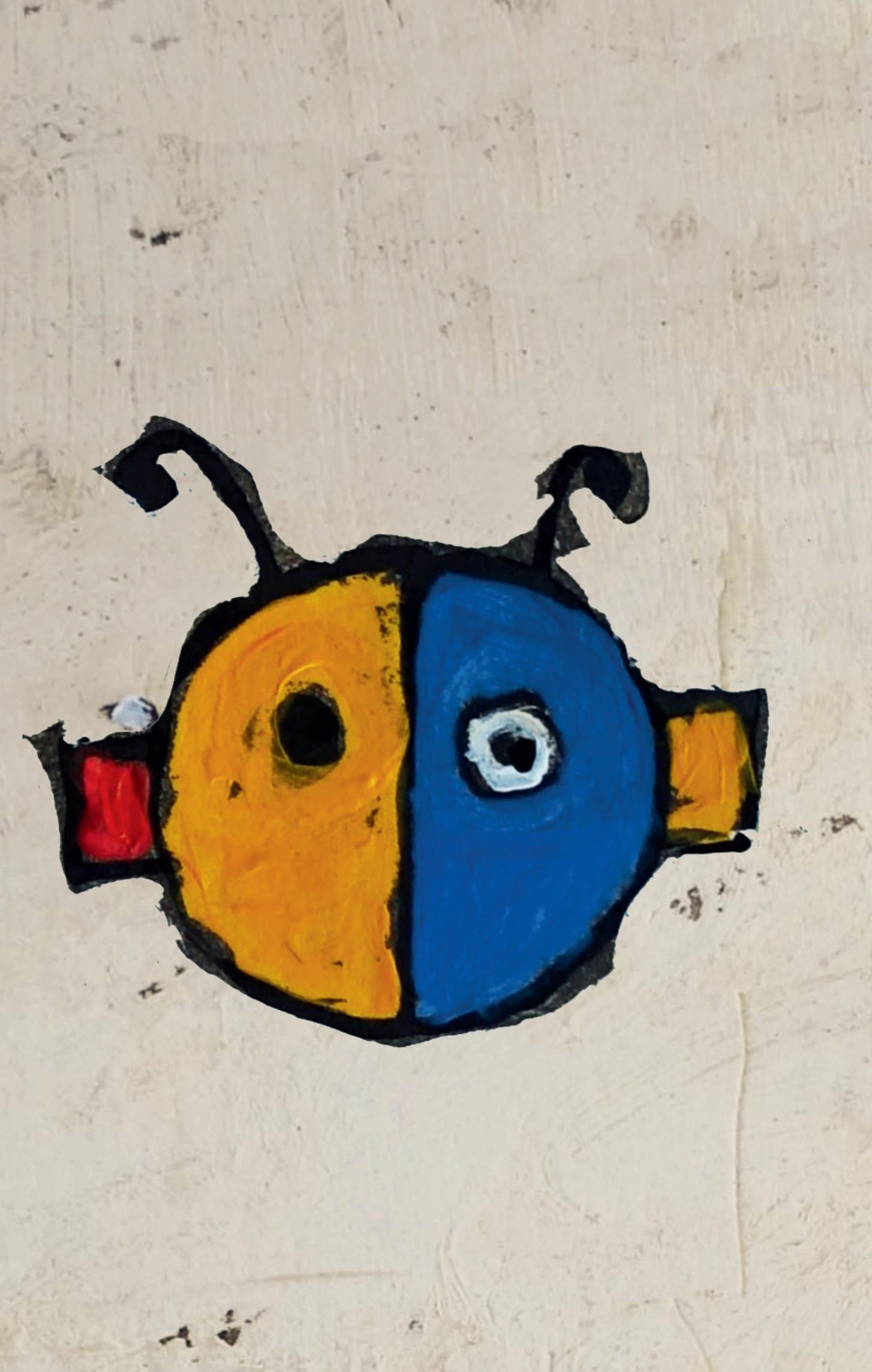




\section{Chapter 3}

\section{What's in a Student-Faculty Relationship?}

\section{A Template Analysis of Students' Positive and Negative Critical Incidents With Their Educational Faculty and Staff}
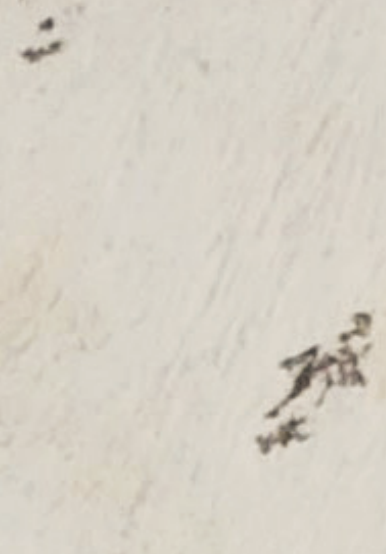

This chapter has been submitted for publication as:

Snijders, I., Wijnia, L., Dekker, J. J., Rikers, R. M. J. P., \& Loyens, S. M. M. (2020). What's in a student-faculty relationship? A template analysis of students' positive and negative critical incidents with their educational faculty and staff [Manuscript submitted for publication]. University College Roosevelt, Utrecht University

The research reported in this chapter was also accepted for presentation at the American Educational Research Association (AERA), San Francisco, CA, United States April 17-212020 (conference canceled due to eOVID-19). http://tinyurl.com/ugrnn6p

Acknowledgement of author contributions: IS, LW, RR, and SL designed the study, IS recruited participants and collected the data, IS, HD, and LW analyzed the data, IS drafted the manuscript, all authors contributed to critical revisions of the paper, LW, RR and SL supervised the study. 


\section{Abstract}

Supportive relationships between students and their educational faculty and staff foster positive outcomes such as students' involvement and development. However, research investigating how students perceive the quality of their relationships with educational faculty/staff (i.e., relationship quality) so far remains scarce. This study aimed to gain more insight into the construct of relationship quality in higher education using a qualitative approach. Based on social exchange theories, students' descriptions of their positive and negative relationship experiences were investigated using a critical incident technique (final sample $N=513$ critical incidents) followed by a template analysis with a priori themes (i.e., relationship quality dimensions: trust in honesty, trust in benevolence, satisfaction, affective commitment, affective conflict). Results indicated that students, rather than affective commitment, most often mentioned trust in honesty and trust in benevolence. Affective conflict was not always explicitly mentioned in negative experiences, nor satisfaction in positive experiences. The study's findings provide a new view of how students might positively and negatively perceive the quality of their relationship with educational faculty and staff. This study adds to the theoretical and practical implications of relationship quality research in higher education and how relational aspects are important for students. 


\section{Introduction}

Interactions and relationships between students and their educational faculty and staff are pivotal for educational learning processes (Cotten \& Wilson, 2006; García-Moya et al., 2020; Hagenauer \& Volet, 2014; Hagenauer et al., 2015). Positive outcomes include students' development and involvement in several ways, such as (higher levels of) student motivation (Komarraju et al., 2010; Pascarella et al., 1978; Trolian et al., 2016), well-being (Roffey, 2012), school or student engagement (Bonet \& Walters, 2016; Maulana et al., 2013, Roorda et al., 2011, Umbach \& Wawrzynski, 2005), institutional commitment (Tinto, 1975), and student and alumni loyalty (Helgesen \& Nesset, 2007; Hennig-Thurau et al., 2001; Snijders et al., 2019, Snijders, Wijnia, Rikers, \& Loyens, 2020). Despite the importance of positive student-faculty relationships, so far only a few studies have shed light on the quality of those relationships in higher education (i.e., relationship quality; see Cho \& Auger, 2013, Hennig-Thurau et al., 2001; Snijders et al., 2018, 2019; Snijders, Wijnia, Rikers, \& Loyens, 2020).

A relationship quality approach was applied by Hennig-Thurau et al. (2001). Their study included the measurement of students' trust in educational staff, students' perceptions of the quality of teaching services, and students' emotional (affective), cognitive, and goal commitment. Their findings indicated that students' emotional commitment to their educational institution is essential in building long-term relationships with the institution. Similarly, the study by Cho and Auger (2013) measured the relationship quality dimensions of trust, satisfaction, commitment, and control mutuality (i.e., lack of power imbalances between parties). Their results were inconclusive, yet pointed out that students who had good-quality interactions with their faculty were more satisfied. Recent studies by Snijders et al. (2018, 2019; Snijders, Wijnia, Rikers, \& Loyens, 2020) applied a five-dimensional relationship quality scale and indicated that the relationship quality instrument was applicable in higher education and relevant for positive outcomes.

To conclude, these quantitative studies imply that relationship quality might be necessary for students' educational experience. In turn, for higher education institutions and educational practitioners, relationship quality is essential in terms of relationship quality's educational/academic outcomes such as student engagement and student loyalty (Hennig-Thurau et al., 2001; Snijders et al., 2019, Snijders, Wijnia, Rikers, \& Loyens, 2020). Despite the importance of building strong, high-quality relationships with students through relationship quality in higher education, the topic is still underresearched. 
Recent studies in the field of educational psychology called for qualitative research (e.g., Clem et al., 2020; García-Moya et al., 2020). These studies suggested examining the development of (positive) interactions between students and their higher education institutions (i.e., teachers, professors, mentors, and other faculty and staff). The current study addresses this gap.

To understand the interactions that form student-faculty relationship quality, within the present study, we used social exchange theory (SET: e.g., Blau, 1964; Cook \& Rice, 2003; Emerson, 1976; Thibaut \& Kelley, 1959) as the overarching framework. According to SET, human relationships are formed by using a subjective cost-benefit analysis expressed by the value (or worth) of a relationship (i.e., rewards/benefits minus costs). Qualitative data based on students' descriptions of their positive (benefits) and negative (costs) experiences were examined by a template analysis of five a priori relationship quality dimensions: students' trust in faculty/staff's honesty, students' trust in faculty/staff's benevolence; students' overall satisfaction with faculty/staff's performance; students' affective commitment; and students' affective conflict (Snijders et al., 2018, 2019; Snijders, Wijnia, Rikers, \& Loyens, 2020).

\section{Relationship Quality in Higher Education}

\section{Trust}

Trust is a "psychological state comprising the intention to accept vulnerability based upon positive expectations of the intentions or behavior of another" (Rousseau et al., 1998, p. 395). To build and establish long-term (enduring/lasting) relationships such as in the higher education context, students' trust in their interpersonal relationship with their educational faculty and staff is paramount (Tett et al., 2017). Two types of trust can be distinguished; trust in an entity's credibility (or honesty) and trust in an entity's benevolence (Roberts et al., 2003).

\section{Trust in Honesty}

Trust in honesty reflects students' perceptions of the educational faculty/staff or university's credibility and integrity. Previous research indicated the importance of an instructor's credibility, as perceived by students, and its positive effect on the effectiveness of their learning (Myers, 2004) and higher motivation to learn (Martin et al., 1997). In other words, trust in honesty resembles the extent to which students believe educational faculty/staff's word can be relied upon, considering their sincerity and their effective and reliable performance. 


\section{Trust in Benevolence}

Trust in benevolence refers to whether students feel that their faculty/staff or university understands and cares about their welfare (Roberts et al., 2003; Snijders et al., 2018). If students experience trust in benevolence, they believe that faculty/staff have intentions and motives that are beneficial and that staff/faculty avoid acting in a way that will result in negative outcomes for them (Roberts et al., 2003; Snijders et al., 2018). Students derive these beliefs, for instance, from how educational faculty/staff or the university respond(s) to students when they confide their problems.

\section{Satisfaction}

Satisfaction with a relationship can be considered a 'summary measure that provides an evaluation of the quality of all past interactions with the service provider' (Roberts et al., 2003, p. 178). As a relationship quality dimension in higher education, satisfaction refers to the level of cumulative satisfaction that students experience (Schlesinger et al., 2017), that is, the evaluation of all past interactions shapes future interaction expectations. Douglas, McClelland, and Davies (2008) found that the most important source of satisfaction for students was the university's communication and responsiveness. Recent studies (e.g., Tompkins et al., 2016) indicated that university faculty/staff's support was found to predict the satisfaction of the educational program best.

\section{Affective Commitment}

The consensus among researchers is that commitment is an essential indicator of relationship quality. When there is no commitment, this will automatically lead to no relationship. A crucial indicator of a relationship's health is a (customer's) commitment to a service organization, such as an institutions in higher education. Commitment should thus be included as a dimension of relationship quality (Roberts et al., 2003). As the process of commitment develops over time, one might become accustomed to positive emotional responses, and, as a result, one becomes more secure in the relationship (Roberts et al., 2003). Affective commitment refers to the way someone feels attached. Within this study, affective commitment reflects students' commitment to their educational faculty/staff (or university in general). Previous research indicated that when students perceived the interactions with their educational faculty/staff as satisfying, students showed a more significant commitment to the university (Strauss \& Volkwein, 2004).

\section{Affective Conflict}

The level of affective conflict represents a negative indicator of relationship quality. Conflict generally negatively affects the relationship between students and their educational faculty/staff or university, for instance, in weak interpersonal relationships, high stress, decreased student success, and increased absenteeism (Zhu \& Anagondahalli, 
2017). Roberts et al. (2003) described affective conflict in terms of feelings of hostility, frustration, and anger towards a partner that might lead to conflict manifestation as an outcome behavior (e.g., complaint behavior or disagreement). A recent study by Clem et al. (2020) that investigated achievement emotions among young adolescent learners confirmed that teacher-student conflict harms their learning and might result, for instance, in anxiety.

\section{Relationships and Interactions in Higher Education}

From a social psychological perspective, an interpersonal relationship can be considered a strong, deep, or close association or acquaintance between people. More generally, a relationship can be defined as the formation of bonds (Roberts et al., 2003). It is the nature of the interactions that affect and shape the quality of a relationship -for instance, in education between students and their teachers/staff (Roffey, 2012).

Student-faculty interactions form the basis for (the quality of) the relationships between students and their educational faculty and staff (Cotten \& Wilson, 2006; Hagenauer et al., 2015; Y. K. Kim \& Sax, 2017). Contact between students and educational faculty/staff can be either formal or informal and in class or out of class (Meeuwisse et al., 2010). Formal contact between students and the educational faculty/staff often happens in class, where students and faculty stay in their roles as 'student' or 'teacher/lecturer' (Dobransky \& Frymier, 2004). Informal contact happens between both parties when they communicate as individuals, which often occurs outside the classroom. Based on the abovementioned literature on student-faculty interactions, both types of contact seem to be relevant to students.

Pascarella and Terenzini (1977) found that interactions focused on course-related content were a more important predictor of retention than other, informal matters. However, later on, informal contact that extends beyond academic content appeared the most influential (Pascarella, 1980). Pascarella (1980) further stated that the relationship quality derived from these informal interactions is the main predictor of the chance that a student will reach out to faculty in an informal manner. Another study by Cotten and Wilson (2006) found that context seems to be highly crucial for whether formal or informal interactions have an impact. They stated that when students have interactions with faculty members who do not lecture in any of their courses, formal interaction related to academics was found to be more important. 
In contrast, when students interact with their instructors, informal interaction with a social nature was found to be important. When students were engaged in out-ofclass contact with faculty, they reported higher levels of intimacy and shared control than students who did not participate in this type of interaction. However, the level of trust students experienced was not affected by out-of-class communication. While some studies (Cotten \& Wilson, 2006) emphasized the relevance of formal contact (e.g., academic advising as effective out-of-class interaction; Allen \& Smith, 2008), other research indicated informal (out-of-class) interactions between students and their faculty and staff to be essential for students' success (e.g., Alderman, 2008; Komarraju et al., 2010).

In sum, these studies indicated that both formal and informal interactions between students and their educational faculty/staff and how they take place, when, with whom, and where seem to be important for positive (academic) outcomes. However, the importance of these interactions as part of the quality of the relationships between students and their educational faculty and staff in higher education (i.e., relationship quality) is yet unclear. Insight into students' perceptions of relationship quality is needed to know how to build positive relationships between students and their educational faculty and/or staff.

\section{Present Study}

The present study aims to gain insight into students' perceptions of their relationship with their educational faculty and staff. In that way, this study seeks to add to the theoretical and practical underpinnings of the relationship quality construct in higher education. Within this study, through the lens of SET, aspects of relationship quality are addressed based on the analyses of qualitative data (i.e., real-life experiences presented in students' examples).

The goal is to examine possible patterns of themes across the dataset as a whole so that we can further conceptualize relationship quality in the higher education context. To this end, we applied the critical incident technique (CIT) to collect the data concerning students' reflections on positive and negative relationship encounters (i.e., critical incidents). We used template analysis as described by King and Brooks (2016) to analyze the data. The a priori themes, that is, relationship quality dimensions, were based on previous studies of relationship quality in higher education (Snijders et al., 2018; 2019; Snijders, Wijnia, Rikers, \& Loyens, 2020). 
The following research questions guided this study:

1. How do students perceive the quality of their relationships with educational faculty and staff (i.e., relationship quality dimensions)?

2. What positive and/or negative experiences do students describe?

3. How do students refer to the time (when), place (where) and/or form (how), and actors (who), regarding the quality of relationships with educational faculty and staff?

\section{Materials and Method}

\section{Context and Participants}

This study was conducted at a Dutch university of applied sciences. Within the Dutch higher education system, two types of institutions can be distinguished: research universities and universities of applied sciences. Both systems have a bachelor's-master's degree structure. However, a difference is that it generally takes three years to complete a bachelor's degree at a university and four years at a university of applied sciences. There are different kinds of roles for faculty/teachers and staff members at the institution under study. First of all, teachers are mainly the ones students have contact with regarding their learning process and other (personal) matters. However, study career coaches, student psychologists, mentors, or other contact personnel from institutional services, such as receptionists, janitors, and other staff members, can interact with students.

The students in this study were enrolled in different educational programs in the fields of economics, technology, and social work. The response rate of the online survey used was $15.26 \%$, resulting in a total of 656 participants $\left(71.1 \%\right.$ female students; $M_{\text {age }}=21.25$ years, $S D=4.50$ ). The vast majority of the participants were Caucasian, which is representative of all students at the university under study.

Although all students were invited to participate, mainly first-year students $(n=237 ; 165$ females) took the survey. In addition, more descriptions of critical incidents from female students ( $n=364$ ) than from male students ( $n=148$; 1 missing) were included in the final sample of students' responses. Overall, female students described slightly more positive experiences $(218 ; 59 \%)$, than male students $(85 ; 57 \%)$. Students from all educational programs were represented in the final sample of described experience $(n=492,23$ missing; economics $n=128$, technology $n=114$, and social work $n=250$ ). 


\section{Data Collection and Procedure}

This study was part of a larger project on relationship quality within higher education (Snijders et al., 2018). The aim was to examine the measurement of the relationship quality construct. For this particular study, we focused on qualitative online written feedback by students. Using the critical incident technique (CIT; see Butterfield et al., 2005; Douglas, Davies, et al., 2008; Douglas et al., 2009), we asked participants to describe concrete examples of at least one positive and one negative experience regarding relationship quality. Enrolled students at the university under study were invited to take an online survey sent out by campus email to all potential participants (approximately 4500) during the second semester. In that way, first-year students were also sufficiently able to provide answers reflective of their first-year experiences. As part of the survey, students were asked to describe a positive and/or negative occurrence that influenced their perception of the quality of their relationships with the university and their educational faculty/staff. To do so, we asked them to answer four open-ended questions concerning each occurrence they described: 1) Briefly describe the situation/incident in your own words; 2) When and where did the situation/incident happen?; 3) What was done or said during the interaction?; 4) What made you feel very positive and/or very negative about the relationship with contact persons from your university in that particular situation?

As part of the complete survey, participants were asked for details about their age, gender, and educational program or major. We indicated that their participation was voluntary and that there were no right or wrong answers. At the end of the questionnaire, participants were asked for their permission to use their responses for research (i.e., informed consent) and that their responses would be treated anonymously (i.e., no one from their university could trace their remarks back to them individually). Ethical approval for the research undertaken was obtained following the policy of the institution under study. The Netherlands Code of Conduct for Research Integrity covered the research project. It was previously reviewed and approved by a committee from the Dutch Organization of Scientific Research.

\section{Analyses}

To analyze the data, we took the template analysis proposed by King (2012), using a priori themes (i.e., the five relationship quality dimensions). Template analysis is a stepwise type of thematic analysis (Frambach et al., 2014). In line with Kidd (2008), three researchers were involved in the data analyses, 'making sure they discussed their own possible biases throughout, and continuously looking for evidence that contradicted the themes as well as confirmed them' (Kidd, 2008, p. 172). The coding process was iterative, included a search for disconfirming evidence (see Frambach et al., 2014), and was conducted with the three coders, thereby contributing to the trustworthiness of the data analysis process (Kidd, 2008). 
Relationship quality can be conceptualized on two levels: relationship quality between students and their educational faculty/staff (i.e., interpersonal level) and relationship quality between students and their higher education institution (organizational level; Rauyruen \& Miller, 2007). However, in practice, these levels are sometimes intertwined. In the present study, we, therefore, interpreted students' descriptions including both levels. To analyze the students' quality perceptions, Grönroos's total perceived quality model (1990) helped to organize the relationship quality construct in higher education. In general, quality perceptions concerning services are based on three levels; 1) evaluation of the functional quality (i.e., process quality, such as how the service is delivered), 2) evaluation of the technical quality (i.e., outcome quality, such as what was offered, either tangible or intangible), 3) evaluation of the interpersonal quality (i.e., relationship quality, such as the quality of the relationship with whoever delivered the service). The first two levels form the perceived service quality (tangible and intangible service quality aspects). The third level can be considered the perceived relationship quality. However, where services consist of multiple and ongoing interactions such as in higher education, the perceived quality of relationships (i.e., with "whom"), that is, relationship quality, is also influenced by "how" contact personnel act and "what" is delivered (service quality). Hence, although there is a theoretical difference between relationship quality and service quality, both constructs have similarities.

Figure 3.1 shows the template analysis process. The initial coding started with 50 cases that all three coders analyzed, keeping in mind the five a priori relationship quality dimensions (i.e., trust in honesty, trust in benevolence, satisfaction, affective commitment, and affective conflict). The first calibration discussed procedural steps and conceptual ideas on relationship quality. The aim was to become further familiarized with the data and determine that all three coders had the same conceptualization of the constructs when allocating a relationship quality dimension to a particular critical incident. Further, all three coders analyzed another five cases and applied an initial template regarding relationship quality dimensions. During the second calibration, the three coders discussed the results from the subsample of five cases and refined the template. Procedural steps were added to the template, such as completeness and interpretability of descriptions and actors who were mentioned; for example, if the actors referred to educational faculty/staff, then the description could be related to relationship quality. If not, then the description was left outside the analysis, that is, the incident does not refer to the relationship between students and their educational faculty/staff and should be deleted from the final analysis. 


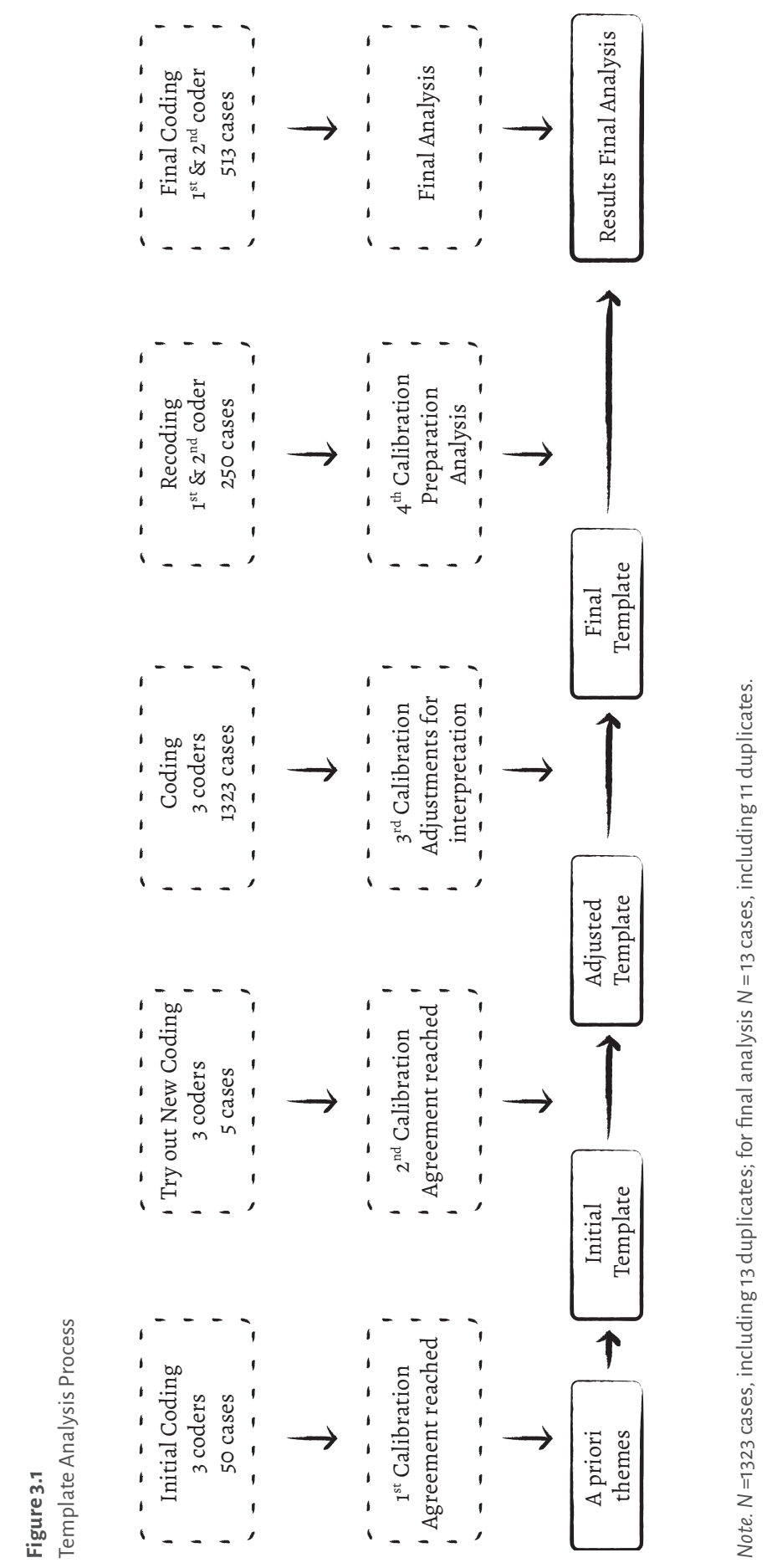


Furthermore, some clarification of the conceptual ideas concerning the relationship quality dimensions was needed. All three coders were aware that theoretically, relationship quality (who) and service and functional quality (what and how) differ. However, based on the critical incidents within the present study, it was sometimes hard to pinpoint what quality aspect the student was referring to; was it the relationship with educational faculty/staff, or the way educational faculty/staff (should) perform(s) professionally? All three coders analyzed the sample of 1323 cases applying the adjusted template. In the third calibration, we discussed the findings, which resulted in a few minor adjustments to the final template. Then two coders independently analyzed a sample of 250 cases (i.e., cases on which coders did not have initial agreement) using the final template and discussed interpretations of differences during the fourth calibration. Finally, the first and second coders addressed the preparation of the final analysis. They analyzed 513 cases that were interpretable, complete, and considered to be related to students' perceptions of the quality of their relationship with educational faculty/staff.

Additionally, all coders kept track of a codebook where they noted their remarks, similarities, or curious examples that were useful for calibration sessions and communication among coders. SPSS version 24 was used for the coding of transcripts and to determine inter-rater agreement. See Appendix B for the coding applied in the final template.

First, descriptions that were incomplete or ambiguous, and therefore unable to be interpreted, were left outside the analysis. Some of the described incidents were not always related to the relationship with the educational faculty/staff. For example, one of the students described a positive incident regarding good teamwork with fellow international students. Therefore, the descriptions that did not refer to a relationship with educational faculty/staff were discussed for calibration, and these cases were not included in further analysis (see Figure 3.1). As a result, in the total sample of 1323 cases (including duplicates), 544 descriptions were rated as 'not interpretable' by all three coders, 107 by two coders; 67 cases were coded differently by all three coders (e.g., a combination of coding by coder 1 who indicated'yes'; coder 2 'ambiguous/unclear'; and coder 3 'no'). Intercoder agreement percentages among all three coders based on the sample of 1323 cases were: trust in honesty, $69.5 \%$; trust in benevolence, $66.1 \%$; satisfaction $81.6 \%$; affective commitment, $92.7 \%$; and affective conflict, $94.6 \%$ agreement. 


\section{Results}

The results will be discussed by the three research questions that guided this study.

\section{Students' Perceptions of Relationship Quality With Educational Faculty and Staff}

All of the included incidents described a negative, positive, or mixed positive/negative experience of the relationship between students with their educational faculty/staff. Within one description, multiple relationship quality dimensions were sometimes identified and categorized. More negative $(n=395)$ than positive $(n=294)$ incidents were described by students. Based on the template analysis, we found that overall, trust in benevolence was most frequently coded, followed by trust in honesty. Incidents describing trust in benevolence $(n=355)$ were equally distributed over positive and negative incidents. However, trust in honesty was more often referred to in negative $(n=145)$ than in positive incidents $(n=51)$. In 97 cases, satisfaction was coded, nearly equally divided between positive and negative descriptions. Only a small number of critical incidents indicated affective commitment $(n=22)$ or affective conflict $(n=19)$, the latter only found in negative experiences.

\section{What Positive and/or Negative Experiences do Students Describe?}

Students described both positive and negative examples of the quality of their relationship with their educational faculty and staff. Based on the template analysis using a priori relationship quality dimensions, we present the results of the analysis of students' perceptions for their relationship experiences by category, indicating frequency, relationship quality indicators, and a student example (see Appendix C).

Besides the a priori dimensions of relationship quality, within the analysis, we also noted other relational aspects. While it is hard to cluster these aspects under one umbrella, the descriptions of positive and negative incidents by students indicated that students value a personal interest in them shown by faculty/staff, for example, displaying educational faculty and staff's affection, such as in praise and attention. For instance, one of the students mentioned:

During one of the exam inspections, I entered the room, and one teacher said to another teacher: 'Look; there we have [student name]. She has scored an 88 and still comes in to see her exam. Now that's what I consider a motivated student.' I really felt appreciated. First of all, because the teacher mentioned my name and mark. Second, for the teacher complimenting me on my effort. [F, 20, 1st year] 
Students also value how they are treated as equals, for example, as responsible adults. For instance, one of the students mentioned:

A positive event is the fact that I had scored the highest grade in class.... Teachers also appreciated the fact that I had scored a good grade and were regarding me differently. $[\mathrm{M}, 19,1$ st year]

\section{When, Where, How, and Who is Involved?}

Within the analysis, we also coded the situational factors related to the critical incident that took place by study year, the form of contact (classroom related or not or via email), and institutional actors, namely, which member of the educational faculty and staff students interacting with (e.g., teachers/lecturers, head of the department, someone from institutional services). Overall, the results indicated that students considered teachers/ lecturers as their primary contact person with whom they build a relationship. However, within their descriptions, students also mentioned, for instance, their mentors or study career coaches (who are sometimes not one of their teachers/lecturers) or the head of the department. For example, one of the respondents indicated appreciation for her study career coach for listening to her and fellow students who had worries about their study group. Although the described incidents mainly concerned teachers/lecturers, other educational contact personnel were also mentioned to be necessary. Furthermore, both in-class and out-of-class situations were described, and discussed in person or via email. In Table 3.1, the results are presented by category, indicating frequency and situational factors for each relationship quality dimension.

\section{Discussion}

The primary purpose of this study was to get a deeper understanding of relationship quality in higher education. Drawing upon SET, we investigated students' positive and negative relational experiences with educational faculty and staff. We initially used five a priori relationship quality dimensions that were used in previous research examining relationship quality in higher education (Snijders et al., 2018; 2019; Snijders, Wijnia, Rikers, \& Loyens, 2020): students' trust in honesty, students' trust in benevolence, students' overall satisfaction, students' affective commitment, and students' affective conflict (as a negative indicator of relationship quality).

The survey's open-ended questions prompted students to describe their recent positive and/or negative experiences related to relationship quality. However, within our study, while coding the critical incidents with a priori themes, we also noticed an overlap between the relationship quality dimensions (see Table 3.1). For instance, a case could describe trust in benevolence and 
also refer to satisfaction or another relationship quality dimension. For example, we coded a female [19, first-year] student's description “... I felt comforted by the way things were dealt with. The way of responding and the understanding that was showed felt really good.... it resulted in me being satisfied with the coach" for trust in honesty, but also satisfaction because the words 'felt really good' and, 'satisfied' also indicated this relationship quality dimension. These findings are in accordance with the theoretical concept of relationship quality, which is formed by distinct but related dimensions (Grönroos, 1990; Roberts et al., 2003).

Table 3.1

Time, Place, Form, and Actors Regarding Relationship Quality-Related Experience $(N=513)$

\begin{tabular}{|c|c|c|c|c|c|}
\hline Category & $\begin{array}{c}\text { Trust in } \\
\text { honesty } \\
(196 / \%)\end{array}$ & $\begin{array}{c}\text { Trust in } \\
\text { benevolence } \\
(355 / \%)\end{array}$ & $\begin{array}{c}\text { Satisfaction } \\
(97 / \%)\end{array}$ & $\begin{array}{c}\text { Affective } \\
\text { commitment } \\
(22 / \%)\end{array}$ & $\begin{array}{c}\text { Affective } \\
\text { Conflict } \\
(19 / \%)\end{array}$ \\
\hline \multicolumn{6}{|l|}{ When } \\
\hline \multicolumn{6}{|l|}{ Students' contact during their ${ }^{a}$ : } \\
\hline First year & $74(38)$ & $145(41)$ & $48(49)$ & $10(45)$ & $6(32)$ \\
\hline Second year & $29(15)$ & $44(12)$ & $14(14)$ & $1(5)$ & $3(16)$ \\
\hline Third year & $38(19)$ & $60(17)$ & $12(12)$ & $3(17)$ & $4(21)$ \\
\hline Fourth year & $29(15)$ & $66(19)$ & $16(16)$ & $7(32)$ & $5(26)$ \\
\hline Fifth year or later & $15(8)$ & $22(6)$ & $4(4)$ & - & $1(5)$ \\
\hline Internship & $35(18)$ & $61(17)$ & $14(14)$ & $2(9)$ & $2(10)$ \\
\hline \multicolumn{6}{|l|}{ Where/how } \\
\hline \multicolumn{6}{|l|}{ Students' contact that was: } \\
\hline Classroom-related & $26(13)$ & $25(7)$ & $16(16)$ & $3(14)$ & $1(5)$ \\
\hline Not classroom-related & $104(53)$ & $221(62)$ & 48( 49) & $13(59)$ & $8(42)$ \\
\hline Via email & $23(12)$ & 49 (14) & 11(11) & $2(9)$ & $7(37)$ \\
\hline Unclear/different coding & $33(17)$ & $60(17)$ & $22(22)$ & $4(18)$ & $3(16)$ \\
\hline \multicolumn{6}{|l|}{ With whom } \\
\hline \multicolumn{6}{|l|}{ Students' contact with: } \\
\hline Teachers/lecturers/mentors & $151(77)$ & $287(81)$ & $80(82)$ & $19(86)$ & $15(79)$ \\
\hline Head of the department & $1(1)$ & $2(1)$ & $1(1)$ & - & - \\
\hline $\begin{array}{l}\text { Teaching team/the educational } \\
\text { department }\end{array}$ & $13(7)$ & $15(4)$ & $4(4)$ & $1(5)$ & $1(5)$ \\
\hline Institutional services & $1(1)$ & $2(1)$ & - & - & - \\
\hline Educational institution & $1(1)$ & $3(1)$ & $1(1)$ & $1(5)$ & - \\
\hline Examination board & $4(2)$ & $4(1)$ & $2(2)$ & $1(5)$ & $1(5)$ \\
\hline Internship mentor & $1(1)$ & $2(1)$ & $1(1)$ & - & - \\
\hline Unclear/different coding & $24(12)$ & 40 (11) & $8(8)$ & - & $2(11)$ \\
\hline
\end{tabular}

Note. ${ }^{a} N=490 ; 23$ students did not indicate their study year. 
Interestingly, the study's findings also revealed that more negative $(n=395)$ than positive ( $n=294$ ) incidents were described by students, which supports research by Clem et al. (2020). They indicated that students' negative emotions, such as their perceived conflict, are more influential factors in the teacher-student relationship than closeness. Most negative experiences in our study pointed at students' perceptions of lack inof responsiveness by faculty/staff, for instance, email response time, returning a grade, or the time it takes to provide feedback on an assignment. Our results are in line with the study by Tantleff-Dunn, Dunn, and Gokee (2002), who also found that students' perceptions regarding grades were the most often reported items by students concerning their perceived conflict.

The present study's findings also revealed that for students, it is essential to be able to rely on honest and benevolent (re)actions from faculty and staff. Lack of trust in honesty and benevolence was described in many negative incidents. Attribution theory (Weiner, 1972) might provide an explanation; students' attributions for success are mostly internally based, and attributions for failure are mostly externally based. Internal attribution refers to the process of assigning the cause of behavior to internal characteristics, such as motivation to learn in education-for example, a student who enjoys studying because he or she receives a high grade. External attribution refers to interpreting someone's behavior that may be caused by external forces on the individual within a specific situation. When students experience their relationship quality negatively, within this study, it might be due to their lack of trust in their educational faculty and staff's honesty as an external force, not because of their internal characteristics.

Positive experiences were often described in which students referred to how they were treated by their educational faculty/staff positively, for instance, by saying hello, asking how a student was doing, sometimes regarding personal matters (informal interaction), or otherwise asking questions about their progress (formal interaction). Students mostly referred to out-of-class interaction in their positive examples of relationship quality with teachers/lecturers. Our findings support previous research (Alderman, 2008; Dobransky \& Frymier, 2004; Meeuwisse et al., 2010) that indicated out-of-class interactions are important in the relationship between students and their educational faculty and staff.

In light of how Roberts et al. (2003) considered the development of affective commitment (i.e., one gets accustomed to positive emotional responses, and therefore it makes one more secure in the relationship), interestingly, within this study, we did not find convincing proof or indications of a growing feeling of trust. For instance, students in their last year before graduation did not explicitly express a more profound or higher commitment. In a similar vein, Sklar and McMahon (2019) referred to the stages of entrustment between teachers and learners, indicating that there must first be a 
presumptive trust to undergo deeper stages of trust based on experiences. Tett and colleagues (2017) also underlined that a trusting relationship must also develop for students to feel some sort of connection towards their teachers, faculty, and/or staff. More generally, Bowden (2011) indicated that a positive relationship must contain a special status or a sense of closeness or attachment. Based on the number of descriptions of trust in the present study, we presume that students' trust in honesty and benevolence form the basis for relationship quality in higher education, and the affective components such as commitment, conflict, and satisfaction (Schlesinger et al., 2017) are results of the trust students experience. However, further research is needed to examine the sequential interplay of the relationship quality dimensions (Hennig-Thurau et al., 2001; Roberts et al., 2003). To our knowledge, no longitudinal study on relationship quality in higher education has been conducted before.

Last, students' descriptions in the present study also pointed at students' feelings of wanting 'to be treated as equals,' which we did not assign to one of the five a priori relationship quality dimensions. An explanation may be found in research on inequality or fairness in SET (e.g., Molm et al., 2006). When fairness or equality is lacking, in students' perceptions, a relational (affective) feeling of conflict might arise (e.g., "I was not treated fairly, and, therefore, I felt angry"). However, within the present study's coding process, we did not find explicit reasoning for this in the students' descriptions.

Students also indicated 'receiving attention and compliments' as positive, which we labeled as praise and attention. However, we found it difficult to assign these examples to one of the five a priori relationship quality dimensions. In their study based on positive psychology, Stevic and Ward (2008) pointed out that "receiving recognition and praise represent a type of positive interaction between two or more individuals... [which] could play a vital role in creating positive emotions in a student's life" (p. 524). In other words, what students might tell us is that receiving attention, for instance, from a teacher, will make them feel good about the quality of the relationship. In that way, praise and attention might lead to students' overall satisfaction.

Nevertheless, based on the descriptions in this study, further research is needed to know whether this assumption holds. Moreover, it is most likely that how the receiver perceives the compliment, praise or attention, depends on the type of compliment (praise or attention) and the one who is giving it (i.e., the kind of relationship one has with the receiver). If the receiver looks up to that person, then the praise or attention is positively received and may presumably affect the relationship positively. On the other hand, if the receiver has no connection with the one giving attention or praise, it is unlikely this will have an effect on that relationship. 


\section{Practical Implications}

To put these findings into practice, educational faculty and staff should consider how students perceive relational aspects. To date, most European higher education institutions use surveys to evaluate students' opinions. Although these surveys, such as the National Student Survey (NSE), shed light on students' general satisfaction level, which is important to know, they lack a deep understanding of how students perceive the quality of their relationship with their institution. Therefore, we recommend that for universities, it is necessary to regularly evaluate students' perceptions of their positive and negative relationship-quality-related experiences in an alternative way. This examination is much better to conduct qualitatively, for instance, using a CIT through focus group discussions instead of more general ideas taken from student satisfaction surveys, such as the NSE might indicate. To collect useful student feedback, a CIT enables gathering meaningful data on students' satisfiers and dissatisfiers and/or student loyalty intentions (Douglas et al., 2009).

Furthermore, based on the students' descriptions in this study, it seems that interactions and communication via email might be a powerful tool. Students in their last years before graduation described how it is essential to receive prompt feedback, especially within this phase. Previous research already indicated that for students, the most dissatisfying reaction is when teachers/professors do not react to a student's problem (Tantleff-Dunn et al., 2002). For educational practitioners who want to interact and communicate either formally or informally with students, the use of email in reaction to students' questions might help to respond in a timely way, and subsequently initiate students' trust in educational faculty and staff's benevolence. As a result, students might, in turn, perceive less affective conflict.

\section{Limitations and Directions for Further Research}

Although this study's findings shed light on students' perceptions of relationship quality, this study has a few limitations. First, reliance on retrospective reports of experiences (Kidd, 2008) is ambiguous (i.e., memory and attribution biases). Next, students' willingness to respond to the questionnaire might be a possible issue. Students' descriptions of their experiences influenced the number of cases that were eventually analyzed with the template we used. CIT has been demonstrated to be a valid method to use (Hughes, 2008). However, when collecting data from a student's perspective (see Douglas, Davies, et al., 2008; Douglas et al., 2009), we saw that not every respondent followed the instructions carefully to answer all questions or did not take the time to describe a critical experience adequately. As a result, parts of the descriptions were not always related to the quality of the relationship with educational faculty/staff (e.g., "I was very frustrated because I could not find a parking place nearby campus"). Because we 
asked students to respond online, correction of misinterpretations was not possible. In this study, as a result, a large portion of the responses were not included in the analyses because they fell outside the scope of this study's purpose or were not sufficiently interpretable.

Furthermore, we only considered one side of the relationship (i.e., students' perceptions). In line with interpersonal relationship research, it is crucial to collect information from both parties within the relationship to assess the stability of that relationship (Duck, 1990). Interactions between students and their educational faculty and staff are interrelated and may affect each other. Therefore, we recommend that future studies examine teachers' (and other staff members') evaluations of the interpersonal relationship they have with students. Last, to gain more insight into the relationship quality construct in higher education, Roorda et al. (2011) implied that the affective quality of relationships is important for students' engagement and achievement, especially among adolescent learners. Therefore, further research should focus on longitudinal data to determine cause-and-effect relations within the relationship quality construct and its outcomes such as student involvement (e.g., student engagement and student loyalty). Cross-cultural research on relationship quality would also be useful to conduct to examine cultural differences in the way relationship quality in higher education is perceived (García-Moya et al., 2020).

\section{Conclusion}

In conclusion, this study was based on 513 real-life descriptions of students' perceptions, examining relationship quality in higher education. For educational policy-makers and practitioners who want to build and sustain positive relationships with students, it is of interest to know how their interactions affect students' relationship quality. Furthermore, it is necessary to understand what relational aspects are essential for students from their perspective (e.g., how students perceive their educational service either positively and negatively by way of (in)formal, in, or out-of-class interactions, orally or by email).

With our study's findings, this research adds value to the growing literature on relationship quality in higher education. The results indicate that a relational approach in higher education seems to be essential to build and maintain positive relationships with students. Furthermore, this study calls for follow-up research on relationship quality. In the context of higher education, further research is needed to better understand the relationship quality dimensions and their outcomes for students and higher education institutions in which students and educational faculty and staff socially interact. 


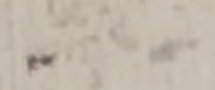

wer
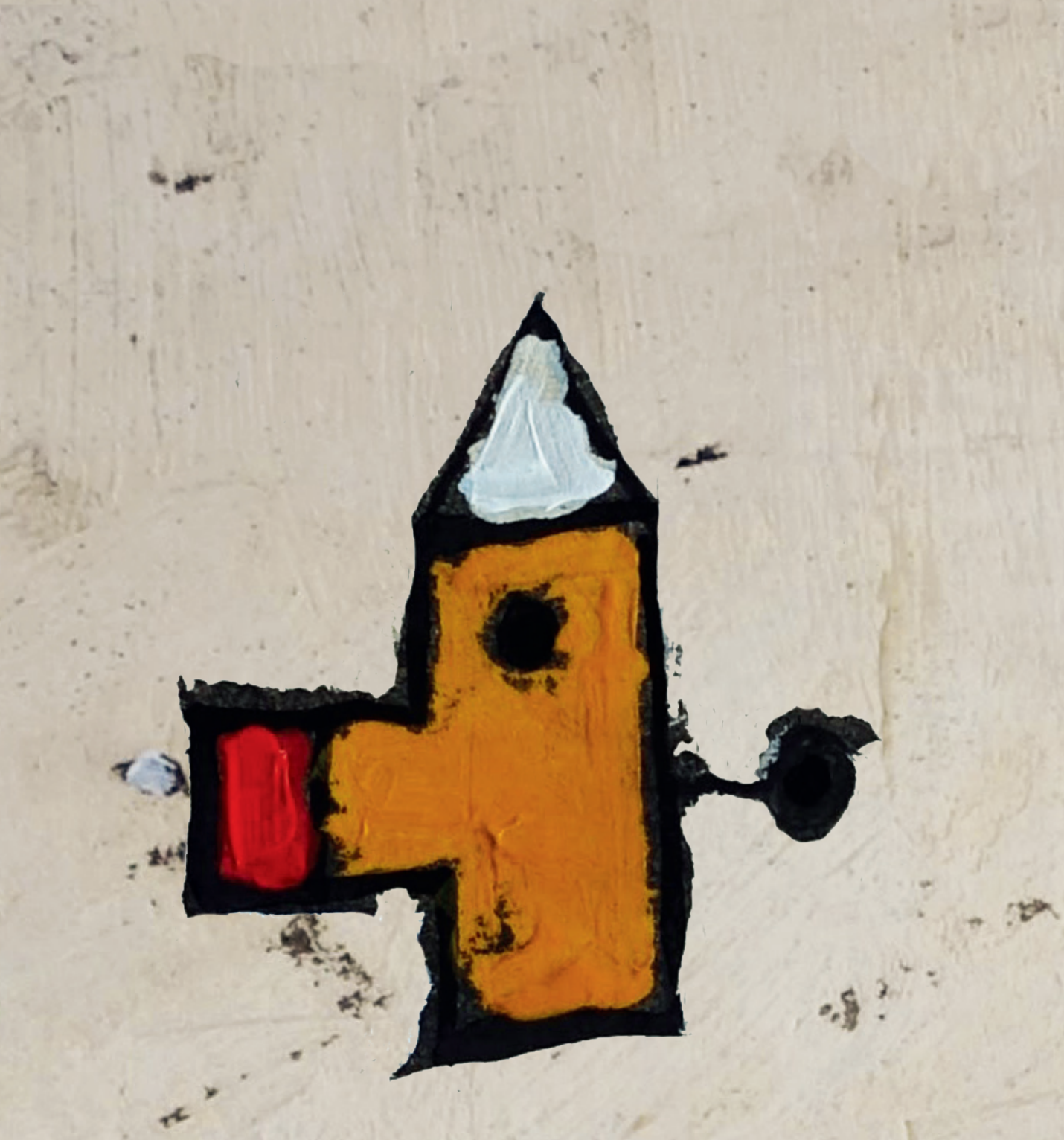

$-4 \div$ 


\section{Building Bridges in Higher Education: Student-Faculty Relationship Quality, Student Engagement, $\therefore$ and Student Loyalty}

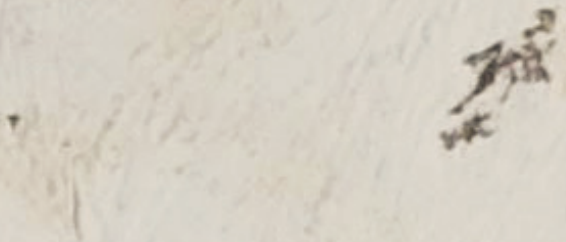

This chapter has been accepted for publication ases

Snijders, I., Wijnia, L., Rikers, R. M. J. P., \& Loyens, S. M. M. (2020). Building bridges in higher education: Student-faculty relationship quality, student engagement, and student loyalty. International Journal of Educational Research, 100, Article 101538. https://doi.org/10.1016/j.ijer.2020.101538

The research reported in this chapter was also presented at the conference of the American Educational Research Association (AERA), San Antonio, Texas, April 2016; and at the meeting of the European Association for Research on Learning and Instruction (EARLI), Tampere, Finland, August 2017

Acknowledgement of author contributions: IS, LW, RR, and SL designed the study, IS recruited participants and collected the data, IS and LW analyzed the data, IS drafted the manuscript, all authors contributed to critical revisions of the paper, LW, RR and SL supervised the study. 
Chapter 4 - Building bridges in higher education

\section{Abstract}

This study aimed to investigate a hypothesized model examining the associations between students' perceptions of the quality of their relationship with their educational faculty and staff (i.e., relationship quality) and students' involvement. The relationship quality measurement included students' experiences with all educational faculty and staff to predict student engagement and student loyalty. Based on data from 454 higher education students, findings indicate that affective commitment and affective conflict are important relationship quality dimensions that influence the student engagement dimensions of absorption, dedication, and vigor. The main conclusion is that a relationship management approach in higher education is fruitful to achieve positive academic outcomes such as student engagement and student loyalty. 


\section{Introduction}

Research on relationships between students and their educational faculty and staff has become increasingly important due to recent developments in higher education. The use of degree completion rates to evaluate universities (Estermann \& Claeys-Kulik, 2016; Jones, 2016) or other forms of performance-based funding (Hagedorn, 2015), as well as global competition among institutions and about their rankings (Chirikov, 2016; Elken et al., 2016), and increasingly customer-like behavior by students (Woodall et al., 2014), all bring a focus on developing positive relationships with higher educational stakeholders to the fore. Positive student-faculty relationships in higher education can contribute to students' involvement and achievement (Umbach \& Wawrzynski, 2005); they are related to higher student retention rates (O'Keeffe, 2013), better academic performance (Klem \& Connell, 2004), sense of school belonging (Wong et al., 2019), and decreased student dropout rates (Klem \& Connell, 2004). Because positive student-faculty relationships can lead to engaged students who enjoy studying and, therefore, might be connected to their educational faculty and staff during and after graduation, they deserve the attention of higher education institutions (Atnip, 2015).

Prior educational research on student-faculty or teacher-student relationships has demonstrated that these relationships, when perceived positively, can lead to positive outcomes (e.g., M. Kim \& Schallert, 2011; Y. K. Kim \& Sax, 2009; Veldman et al., 2013). For instance, a recent qualitative study in a primary school setting by Lee (2012) showed that encouragement and support from teachers as well as respect are important to foster students' participation in education. In an earlier study conducted in secondary education, Wubbels and Brekelmans (2005) focused on teacher behavior. They indicated that investigating teacher interaction with students might be useful for evaluating students' perceptions of the teacher-student relationship.

In higher education, Y. K. Kim and Lundberg (2016) used a structural equation modeling approach to examine associations between student-faculty interactions, classroom engagement, and cognitive skills development. Their research indicated, among other things, that "student-faculty interaction is related to greater levels of classroom engagement" (Y. K. Kim \& Lundberg, 2016, p. 288). Some other studies have focused on one or a few aspects of student-faculty relationships, such as the frequency of interactions (Cotten \& Wilson, 2006) or on formal/ informal interactions (Meeuwisse et al., 2010). Nevertheless, the need to further investigate the consequences of the quality of relationships between students and their educational faculty/staff remains (Bowden, 2011; Hagenauer \& Volet, 2014; Hennig-Thurau et al., 2001). This study addresses this knowledge gap. The goal is to examine how higher education institutions can build and 
sustain relationships by emphasizing aspects of the quality of relationships between students and their educational faculty/staff. Higher education institutions may be better able to influence positive academic involvement if they understand the mechanisms through which student-faculty relationship quality affects student engagement and, in turn, student loyalty (Taylor \& Parsons, 2011).

Gaining such valuable insight for higher education institutions into the attitudinal and behavioral processes determining student involvement, such as student loyalty (Buttle \& Maklan, 2015), is essential in the current context. Loyal behavior could be expressed by students' intentions to continue with their studies, but also by their positive recommendations to potential future students. This kind of student behavior is essential for the continuity and growth of higher education institutions. Therefore, possible predictors of students' supportive behaviors should be further considered. Further research is needed to help higher education institutions and educational practitioners gain better insight into what the relationship between student and faculty holds and how relationship quality aspects might contribute to students' engagement in learning and student loyalty intentions. To our knowledge, few studies exist on this topic.

The present study addresses this issue by using a consumer-focused approach. The concept of 'consumer' is context-related. For example, in business-to-business relations, consumers or customers are called buyers. In contrast, in commercial services such as life insurance, customers are called clients, and in health care, they are called patients. While rarely applied to institutions of higher education ( $\mathrm{Ng}$ \& Forbes, 2009), measurement of relationship quality as defined in consumer services is also applicable to the higher education-context (Bowden, 2011; Hennig-Thurau et al., 2001; Snijders et al., 2018, 2019) Although the 'student as consumer' approach is still debated in the literature (see Bunce et al., 2017; Tomlinson, 2017), students can be regarded as the primary recipients of educational services (Braun \& Zolfagharian, 2016).

Using the lens of social exchange theory, we developed our hypothesized model based on Crosby et al.'s (1990) theoretical framework linking service relationships to organizational outcomes. The services and relationship management literature explicitly focus on building and maintaining relationships with customers (Bowden, 2009; Grönroos, 1994; Gummesson, 1994). Relationships between provider and consumer are essential in the service delivery process to establish engagement and loyalty (Zeithaml et al., 2009). The customer's evaluation of the interpersonal relationship with the contact person has a significant influence on the continuation of the existing service relationship (i.e., customer retention; Macintosh, 2007), and thus, the organization's continuity and/or growth. In other words, positioning students as key participants in the educational service experience (Braun \& 
Zolfagharian, 2016) implies that higher education institutions should attend to nurturing students and the institution's relationships with them. Just like customers' evaluations, students' perceptions of the quality of the relationship they have with their educational faculty/staff should also be considered. In higher education, positive interactions between students and their faculty and staff could have a positive influence on student development and involvement (Y. L. Hu et al., 2015; Y. K. Kim \& Sax, 2009; Kuh \& Hu, 2001). In turn, students' perceptions of the quality of their relationships with educational faculty and staff (i.e., relationship quality), which is based on these interactions, might result in student engagement (Bowden, 2009) and student loyalty (Hennig-Thurau et al., 2001).

\section{Relationship Quality}

The definition of relationship quality varies according to the research context (Osobajo \& Moore, 2017). However, the existing relationship quality literature "suggests that relationship quality is widely used to describe how healthy a relationship is based on the evaluation or assessment of the parties within that relationship" (p. 4). Thus, relationship quality considers a party's overall perception or judgment of the quality of the relationship he or she has. In the context of services, the emphasis is on the intangible aspects of ongoing (relational) interactions (Roberts et al., 2003). Hence, in such a context, the concept of relationship quality is focused on enduring relationships, which is similar to studentfaculty relationships in higher education. The relationship quality construct includes five relationship quality dimensions (Roberts et al., 2003). Based on the relationship quality research by Roberts et al. (2003), Snijders et al. (2018, 2019) applied these dimensions in the context of higher education where they represent: students' trust in educational faculty/staff's honesty, students' trust in educational faculty/staff's benevolence, students' affective conflict, students' affective commitment, and students' overall satisfaction related to their educational faculty/staff's performance (Snijders et al., 2018; 2019).

\section{Trust}

Trust is directed toward two essential elements: honesty and benevolence (Kumar et al., 1995).

\section{Trust in Honesty}

Trust in honesty refers to the trust students have in a university's credibility. It concerns students' perceptions of the staff and faculty's sincerity and whether they will perform their role effectively and reliably. Furthermore, students' trust in the honesty of educational staff is based on the extent to which they believe educational faculty and staff's word can be relied on. 


\section{Trust in Benevolence}

Benevolence represents the willingness to help; trust in benevolence refers to the extent to which students believe staff and faculty are concerned about students' welfare, including having intentions and motives beneficial to students and avoiding acting in a way that will result in negative outcomes for students.

\section{Affective Conflict}

Affective conflict is a negative indicator of relationship quality (i.e., lack of trust). Students can also evaluate their relationships with faculty and staff based on the conflicts they perceive, which will lower levels of perceived relationship quality. It is used as an indicator of the retained level of conflict felt by students concerning their relationship with university faculty and staff (e.g., irritation, frustration, and anger).

\section{Affective Commitment}

Affective commitment refers to students' feelings of wanting to belong or be connected to their educational faculty and staff. In the relationship management literature, relationship commitment represents the confidence one has in a service provider's reliability and integrity (see, e.g., commitment-trust theory; R. M. Morgan \& Hunt, 1994), and serves as a precursor to a loyal attitude (see, e.g., Dick \& Basu, 1994). Students' affective commitment develops over time as they become accustomed to positive responses from faculty and staff, leading them to become more and more secure in the relationship they have with their educational faculty and staff.

\section{Satisfaction}

Satisfaction reflects the cumulative student satisfaction with the overall quality of the student-faculty relationship, such as students' cognitive and affective evaluation based on their personal experience across all educational service encounters (i.e., every time a student interacts with someone from their university).

Educational research indicates that students' perceptions of relationship quality might positively influence student development and outcomes (Astin, 1999; Kuh \& Hu, 2001), such as academic performance (Pascarella et al., 1978). A key contribution by HennigThurau et al. (2001) took a relationship management approach. Their research implied that higher quality of student-faculty relationships (i.e., relationship quality) led to higher levels of student loyalty, for example, students' positive recommendations. Furthermore, recent studies (see Xerri et al., 2018) have supported the suggestion that these relationships play "a pivotal role in the very process of engagement" (Pianta et al., 2012, p. 366). 


\section{Student Engagement}

Previous studies have examined the concept and importance of engagement extensively in educational settings (e.g., Bakker et al., 2015; Betts et al., 2010; Fredricks \& McColskey, 2012; Jang et al., 2010) and management settings (e.g., Bowden, 2009; Jarvis et al., 2014; Van Doorn et al., 2010; Verhoef et al., 2010). Yet, the theoretical understanding and conceptualizations of engagement remain fragmented and untested (Kahu, 2013). According to the perspective adopted in this study, student engagement in the context of higher education can best be defined as "a positive, fulfilling, work-related state of mind that is characterized by vigor, dedication, and absorption" (Schaufeli \& Bakker, 2003, p. 4). The student engagement scale developed by Schaufeli et al. (2002) was previously investigated by them in a higher education context, examining the student engagement dimensions of vigor, dedication, and absorption. These student engagement dimensions can be described as follows (Schaufeli \& Bakker, 2003): "vigor is characterized by high levels of energy and mental resilience while working, the willingness to invest effort in one's work, and persistence even in the face of difficulties" (Schaufeli \& Bakker, 2003, p. 4). Dedication refers to "being strongly involved in one's work and experiencing a sense of significance, enthusiasm, inspiration, pride, and challenge" (Schaufeli \& Bakker, 2003, p. 4/5). Finally, absorption is "characterized by being fully concentrated and happily engrossed in one's work, whereby time passes quickly, and one has difficulties detaching oneself from work" (Schaufeli \& Bakker, 2003, p. 5). With these three dimensions, all aspects of engagement are captured: behavioral, emotional/affective, and cognitive engagement (Fredricks et al., 2016).

The assumption is that the better the educational experience students have through higher relationship quality, the more they will be engaged with their studies. Engagement, in turn, can positively influence students' involvement in academic, social, or extracurricular activities. Therefore, engagement is considered crucial for achieving positive academic outcomes such as degree completion and for showing the outcome of positive relationships between students and their educational faculty/staff (Connell \& Wellborn, 1991), namely, student involvement and supportive behavior outside the classroom. The latter can also be captured under the concept of 'student loyalty' (Bowden, 2009).

\section{Student Loyalty}

In the international literature on student behavior, student loyalty is increasingly considered to be a critical measure of the success of higher education institutions (RojasMéndez et al., 2009). Student loyalty refers to the extent to which students feel connected 
to the institution and how their attitudes and/or behaviors express this connection (Nesset \& Helgesen, 2009). Loyalty has two aspects: attitude and behavior (Hallowell, 1996). In higher education, a loyal attitude may refer to the (positive) feelings students have related to their faculty/staff and/or university. Student loyalty is expressed in loyalty intentions and behavior during and/or after their enrollment period, for example, (positive) recommendations from students about their educational faculty/staff and/ or university, or active participation in extracurricular activities. Higher education institutions benefit from loyal and successful students in terms of their involvement. Prior research has shed some light on student loyalty by investigating its relationship with positive word-of-mouth about the institution (Alves \& Raposo, 2007) and commitment towards the institution (Perin et al., 2012).

Other studies have examined possible student loyalty drivers such as trust, commitment, quality of facilities, perceived value/quality, service quality, and image (e.g., R. M. Brown \& Mazzarol, 2009; Carvalho \& de Oliveira Mota, 2010; Nesset \& Helgesen, 2009). Thus, universities need to cultivate good relationships with their students to foster students' supportive behavior, such as positive recommendations or donations by students and/or alumni (Sung \& Yang, 2009).

\section{Present Study}

This study aims to provide new insight into relationship quality (as expressed in the identified dimensions) as a predictor of student engagement (as expressed in the identified dimensions) and student loyalty. The assumption is that high-quality relationships between students and faculty/staff positively influence students' involvement in terms of their engagement and loyalty. To investigate this assumption, we used a relationship quality instrument used in consumer services research, which we adapted and validated in previous studies and found to be applicable in higher education (Snijders et al., 2018, 2019). Other studies have taken a qualitative approach, such as focus group studies, where the emphasis is on interactions within or outside the classroom (e.g., Cotten \& Wilson, 2006; Kuh \& Hu, 2001), or considered only the teacher-student relationship (e.g., Fraser $\&$ Walberg, 2005). However, this study has a quantitative design for testing a model of the relations between relationship quality, student engagement, and student loyalty. We used an instrument evaluating relationship quality in higher education that included students' experiences with all educational faculty and staff. This study contributes in several ways to the existing literature on student-faculty relationships. 
First, within this study, the approach was to investigate relationship quality by applying five distinct but related dimensions, thereby covering the relationship quality construct as a whole. We believe we therefore provide a more specific view of relationship quality in higher education. Our study differs from previous relationship quality studies (e.g., Hennig-Thurau et al., 2001), where the examination of relationship quality among alumni included trust, commitment, and perceived quality of teaching services, leaving out other important relationship quality dimensions. Moreover, although we value the relationship quality research among alumni, in line with Snijders and colleagues (2019), to overcome the limitations of retrospective research, the present sample consisted of enrolled students.

Second, instead of solely focusing on part of the student-faculty relationship, such as student-faculty interactions (see Y. K. Kim \& Lundberg, 2016), the present study investigated the quality of the relationship between students and their educational faculty/staff, which is different from other studies. We believe that when asking students about their relationship quality, all persons related to their education should be included. In other words, perhaps the teacher is not always the most important contact person. Therefore, relationship quality perceptions regarding all educational faculty and staff should be considered.

Third, we hypothesized that when students perceive themselves to have relationships with their educational faculty and staff, relationship quality aspects act as predictors of their engagement in their studies, and (in)directly of their loyalty intentions. This study is one of the first attempts to capture a broader idea of how relationship quality contributes to building relationships with enrolled students that can lead to positive educational consequences. More engaged students might be happier at school, enjoying their studies. One can imagine that, overall, engaged students are less likely to drop out of school, which is good for students, parents, and higher education institutions. According to relationship management theory, loyal students, like any other type of customer, are necessary for the continuity and growth of the higher education institution or university.

The research question that guided this study was: To what extent do relationship quality dimensions (in)directly and positively relate to student engagement and student loyalty? We hypothesized that having high-quality relationships with educational faculty/ staff will positively influence students' student engagement and, in turn, their attitudinal and/ or behavioral loyalty. Therefore, possible drivers of student loyalty were examined (see Figure 4.1). Employing partial least squares structural equation modeling (PLS-SEM), we tested the following hypotheses: 
H1: Relationship quality dimensions (a-e) will each be positively related to student engagement (e.g., Taylor \& Parsons, 2011; Xerri et al., 2018);

$\mathrm{H} 2$ : Student engagement dimensions (a-c) will each be positively related to student loyalty (e.g., Bowden, 2009);

H3: Relationship quality dimensions (a-e) will each be positively related to student loyalty (for reasons of clarity, these relations were not depicted in Figure. 4.1);

$\mathrm{H} 4$ : Student engagement dimensions (a-c) will each mediate the relation between each of the relationship quality dimensions (a-e) and student loyalty (for reasons of clarity, these relations were not depicted in Figure. 4.1).

\section{Figure 4.1}

Hypothesized Model

\section{Relationship Quality \\ Student Engagement}

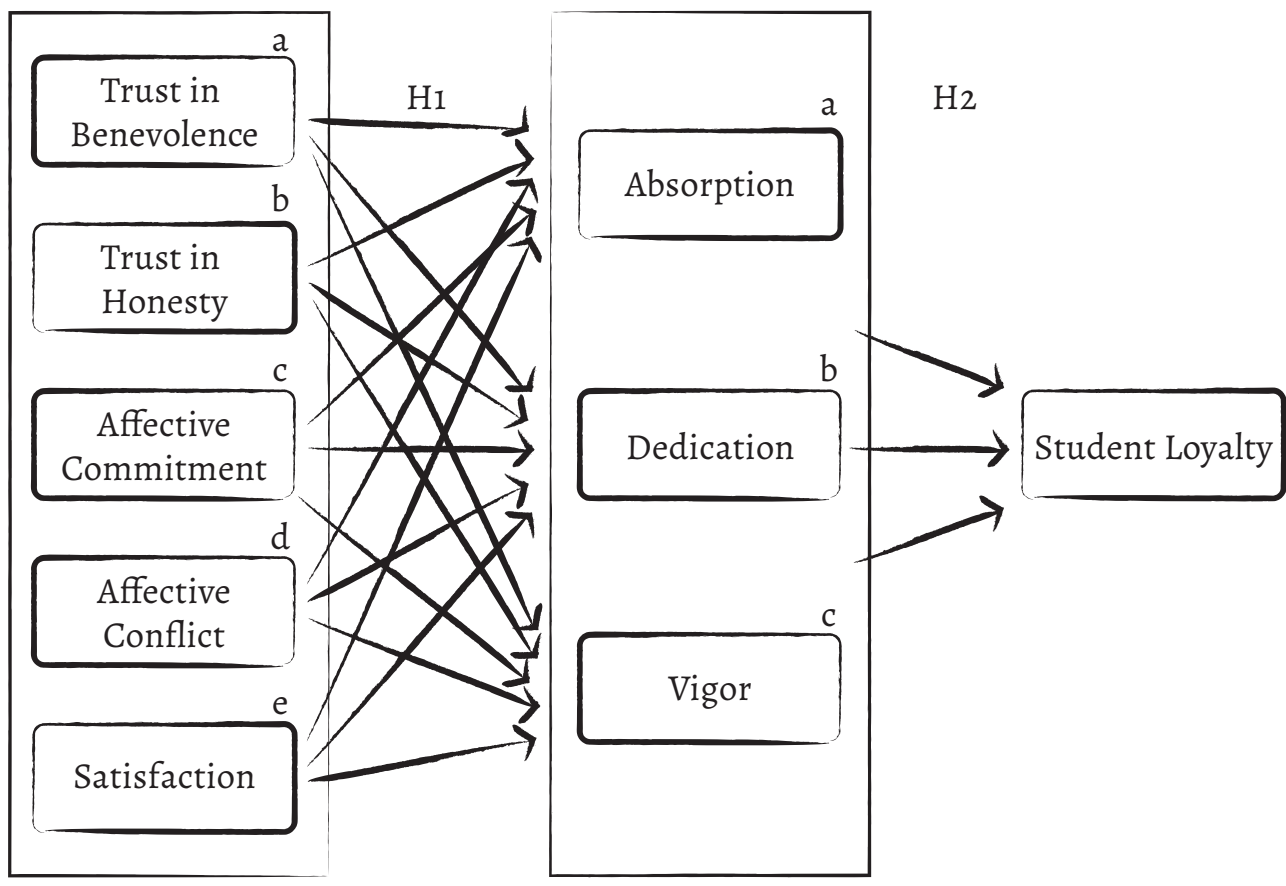

Note. For reasons of clarity, $\mathrm{H}_{3}$ and $\mathrm{H}_{4}$ are not depicted in the model. 


\section{Method}

\section{Pilot Study}

The hypothesized model was pretested in a pilot study. Participants were 271 students in higher education $\left(M_{\text {age }}=23.19, S D_{\text {age }}=6.87,91.5 \%\right.$ female $)$ attending a four-year pedagogy program $(n=106)$ or a social work program $(n=165)$. The main results suggested that the relationship quality dimensions of affective commitment and affective conflict had a statistically significant association with the student engagement dimension of dedication. In turn, dedication had a statistically significant association with student loyalty. The pilot study was followed up by further examining and validating these findings using a more diverse sample, namely, higher education students from a broader range of academic departments.

\section{Participants}

Participants were 454 higher education students $\left(M_{\text {age }}=21.81, S D_{\text {age }}=5.27,64.8 \%\right.$ female $)$ from a Dutch university of applied sciences located in the southwest of the Netherlands, having an enrollment of approximately 4500 students. Participants responded to a solicitation to complete an online survey. Respondents were distributed across all years of study (19.8\% first year; $19.6 \%$ second year; $24.7 \%$ third year; $25.1 \%$ fourth year) and three fields of study (31.28\% technical department; $27.31 \%$ economics department; $41.41 \%$ social department).

\section{Procedure}

A link to an online survey was distributed through campus email. The survey could be completed at home or on campus. To help boost the response rate, we encouraged students to complete the survey during one of their classes (i.e., the instructor brought the survey to students' attention; instructions were given in the email and survey introduction). Students were instructed that participation was voluntary. They were told that there were no right or wrong answers to the items, as long as their answers reflected their personal opinions. Completing the survey took approximately fifteen minutes. Students were given two months to respond. Students who did not complete the online survey were reminded by email.

The survey was made up of several parts (different questionnaires). The questionnaire items for relationship quality and student loyalty were tested using a forward-backward translation procedure (from English to Dutch to English). The set of items asking about student engagement were taken from a student engagement questionnaire that was already available in Dutch and had been tested in a higher education context by Schaufeli and Bakker (2003). In case students wanted to comment on the survey in general, or on specific parts of the survey, students could respond to an open-ended question for that purpose. 
Ethical approval was obtained following the policy of the institution under study. The research project was covered by the Netherlands Code of Conduct for Research Integrity and was previously reviewed and approved by a committee from the Dutch Organization for Scientific Research. All participants were asked for informed consent via a question in the online survey. Their responses were voluntary. Only participants who gave their permission to use their answers for research were included within this study's analyses. Students' responses were treated anonymously and were not traceable by their institution to individual students.

\section{Materials}

A combination of existing scales was used to measure the constructs under study (see Table 4.1 for items associated with each construct and scale reliabilities).

Relationship Quality. Relationship quality was measured by a 15-item questionnaire adapted from an existing relationship quality scale with a five-factor structure: trust in honesty, trust in benevolence, affective conflict, affective commitment, and satisfaction (Roberts et al., 2003). The measurement instrument was tested in a previous study and found to be applicable in a higher education context (Snijders et al., 2018). Students were asked to indicate on a 7-point Likert scale how much they agreed with various statements, ranging from 1 (strongly disagree) to 7 (strongly agree).

Student Engagement. Student engagement was measured by 9 items from the Utrecht Work Engagement Scale-Student shortened version (UWES-S-9; Schaufeli \& Bakker, 2003) with a three-factor structure: vigor, dedication, and absorption. Students were asked to indicate how they experienced their education in terms of their vigor, dedication, and absorption on a 7-point Likert scale, ranging from 1 (almost never/a few times a year or less) to 7 (always/every day).

Table 4.1

Construct Items Measurement Model

\section{Scale constructs}

Outer loadings

Relationship quality dimensions ${ }^{a}$

Trust in faculty/staff's benevolence $(C R=.94, C A=.91, A V E=.85)$

My faculty/staff is concerned about my welfare (RQT_BOI)

When I confide my problems to my faculty/staff, I know they will respond with understanding 92 (RQT_BO2)

I can count on my faculty/staff considering how their actions affect me (RQT_BO3) 
Trust in faculty/staff's honesty $(C R=.93, C A=.89, A V E=.82)$

My faculty/staff is honest about my problems (RQT_HoI)

My faculty/staff has high integrity (RQT_Ho2) $\quad .90$

My faculty/staff is trustworthy (RQT_Ho3) 9.90

Affective commitment $(C R=.94, C A=.90, A V E=.83)$

I feel emotionally attached to my faculty/staff (RQ_ACOMMOI)

I continue to interact with my faculty/staff because I like being associated with them .91

(RQACOMMO2)

I continue to interact with my faculty/staff because I genuinely enjoy my relationship with

them (RQACOMMO3)

Affective conflict $(C R=.95, C A=.91, A V E=.85)$

I am angry with my faculty/staff (RQ_ACONoI)

I am frustrated with my faculty/staff (RQ_ACONO2)

I am annoyed with my faculty/staff (RQACONo3)

Satisfaction $(C R=.96, C A=.94, A V E=.90)$

I am delighted with the performance of my faculty/staff (RQ_SATO1) .95

I am happy with my faculty/staff's performance (RQ_SATO2) .95

I am content with my faculty/staff's performance (RQ_SATO3)

Student engagement dimensions ${ }^{b}$

Absorption $(C R=.83, C A=.72, A V E=.62)$

Times flies when I am studying ( $S E \_A B O 1$ )

When I am studying, I forget everything else around me (SE_ABO2)

I am immersed when I'm studying (ABO3)

Dedication $(C R=.91, C A=.85, A V E=.76)$

I find the studying that I do full of meaning and purpose (SE_DEOI)

My studying inspires me (SE_DE2)

I am proud of the studying that I do (SE_DEO3)

Vigor $(C R=.89, C A=.81, A V E=.72)$

At the university, I feel bursting with energy (SE_VIOI)

At the university, I feel strong and vigorous (SE_VIO2) $\quad .85$

When I get up in the morning, I feel like going to school (SE_VIO3) $\quad .85$

Student loyalty ${ }^{c}(C R=.89, C A=.89, A V E=.69)$

$\begin{array}{ll}\text { I'd recommend my course of studies to someone else (SLOI) } & .87\end{array}$

I'd recommend my university to someone else (SLO2) $\quad .84$

I'm very interested in keeping in touch with "my faculty" (SLO3) $\quad .78$

If I were faced with the same choice again, I'd still choose the same course of studies (SLO4) $\quad .81$

If I were faced with the same choice again, I'd still choose the same university (SLO5) $\quad .83$

Note. $\mathrm{CR}=$ composite reliability, $\mathrm{CA}=$ Cronbach's alpha, $\mathrm{AVE}=$ Average Variance Extracted. $N=454$.

a. Adapted from Roberts et al. (2003). b. Adopted from Schaufeli and Bakker (2003). c. Adopted from Hennig-Thurau et al. (2001). 


\section{Analyses}

Partial least squares structural equation modeling (PLS-SEM) using SMART-PLS (Ringle et al., 2015) was conducted to analyze the data based on the hypothesized model. PLS-SEM is used to develop theories in exploratory research (Hair et al., 2017) as a prediction-oriented variance-based approach that focuses on endogenous constructs/dependent variables (i.e., student engagement and student loyalty). The goal is predicting target constructs or identifying key 'driver' constructs (Hair et al., 2017), as with relationship quality in the current study. Our primary objective in applying structural modeling is the prediction and explanation of the constructs under study. Therefore, we preferred to use PLS-SEM because this study's research objective is theory development and interpretation of variance (i.e., prediction of the constructs). The PLS method aims at maximizing the variance explained by exogenous constructs (i.e., relationship quality dimensions).

A two-stage approach was followed in the analysis. First, the testing of the measurement model was conducted. Next, analysis of the structural model followed, using a bootstrapping procedure with relationship quality as an exogenous latent variable, student engagement as an endogenous latent, mediating variable, and student loyalty modeled as an endogenous latent variable (as depicted in Figure 4.1).

\section{Measurement Model}

Assessment of the measurement model was based on internal consistency reliability, convergent and discriminant validity, and is reported for every construct within the PLS model. To assess convergent validity, we tested the significance and analyzed the magnitude of each indicator's loading on its intended latent variable (Anderson \& Gerbing, 1988).

\section{Structural Model}

Evaluation of the structural model was assessed by $R^{2}$, the significance of estimated values for path relationships, and effect sizes for each effect (Cohen, 1998). Assessment of the structural model was done by applying a bootstrapping procedure (Hair et al., 2017) to assess the significance of path coefficients, using 5000 bootstrap samples, no sign change included. $R^{2}$ values were assessed, with $R^{2}$ values of $0.25, .50$, or 0.75 considered to be weak, moderate, and substantial, respectively (Hair et al., 2017). Effect sizes ( $\left.f^{2}\right)$ were examined to indicate the exogenous construct's contribution to the endogenous latent variable's $R^{2}$ value.

\section{Mediator Analysis}

To verify whether student engagement mediates the relation between relationship quality dimensions and student loyalty, we used a mediator analysis procedure following Hair et al. 
(2017). First, we determined whether the direct effects of relationship quality dimensions on student loyalty were significant. Second, after including the mediating variables (vigor, dedication, and absorption), we examined the significance of the indirect effects.

\section{Results}

\section{Measurement Model}

Assessment of the measurement model showed that all items corresponding with each relationship quality dimension and each student engagement dimension loaded on the intended constructs. Outer loadings (i.e., the estimated relationships in reflective measurement models represented by the arrows from the latent variable to its indicators that determine an item's contribution to its assigned construct) for relationship quality ranged from 0.78 to 0.95 .

Construct reliability was acceptable for all latent variables (i.e., relationship quality, student engagement, and student loyalty), as indicated by composite reliability and Cronbach's alpha values exceeding .70. Convergent validity was verified with AVE values for all constructs that were greater than the threshold value of .50 (Fornell \& Larcker, 1981). AVE values, outer loadings of the construct items from the measurement model, and composite reliability for each scale are included in Table 4.1.

Finally, discriminant validity was tested by comparing the square root of the AVE of each construct to its correlations with the other latent constructs (i.e., Fornell-Larcker criterion). For every pair of latent variables, the square root of the AVE was higher than the correlation between the variables, thus indicating acceptable discriminant validity (Fornell \& Larcker, 1981; see Table 4.2).

\section{Structural Model}

Assessment of the structural model showed $R^{2}$ values that are reasonable for an exploratory study: the structural model explained $55 \%$ of the variance in student loyalty; for student engagement, the explained variance was $31 \%$ for absorption, $45 \%$ for dedication, and $37 \%$ for vigor. Trust in benevolence and satisfaction did not have a statistically significant association with any dimension of student engagement (Hia \& e). Trust in benevolence had a statistically significant association with dedication $(\mathrm{Hib})$, but not with absorption and vigor. Affective conflict had a (negative) association with absorption and vigor (Hic), but not with dedication. Affective commitment had a statistically significant association with all student engagement sub-dimensions, that is, vigor, dedication, and absorption (Hid). Satisfaction did not have a statistically significant association with dedication, absorption and vigor (Hie). 
The student engagement dimension of absorption did not have a statistically significant association with student loyalty (H2a). Dedication, as well as vigor, had a statistically significant association with student loyalty ( $\mathrm{H} 2 \mathrm{~b} \& \mathrm{c})$. Figure 4.2 shows the diagram of the path model, including statistically significant path loadings and significance levels.

\section{Figure 4.2}

Path model and PLS-SEM estimates

Relationship Quality Student Engagement

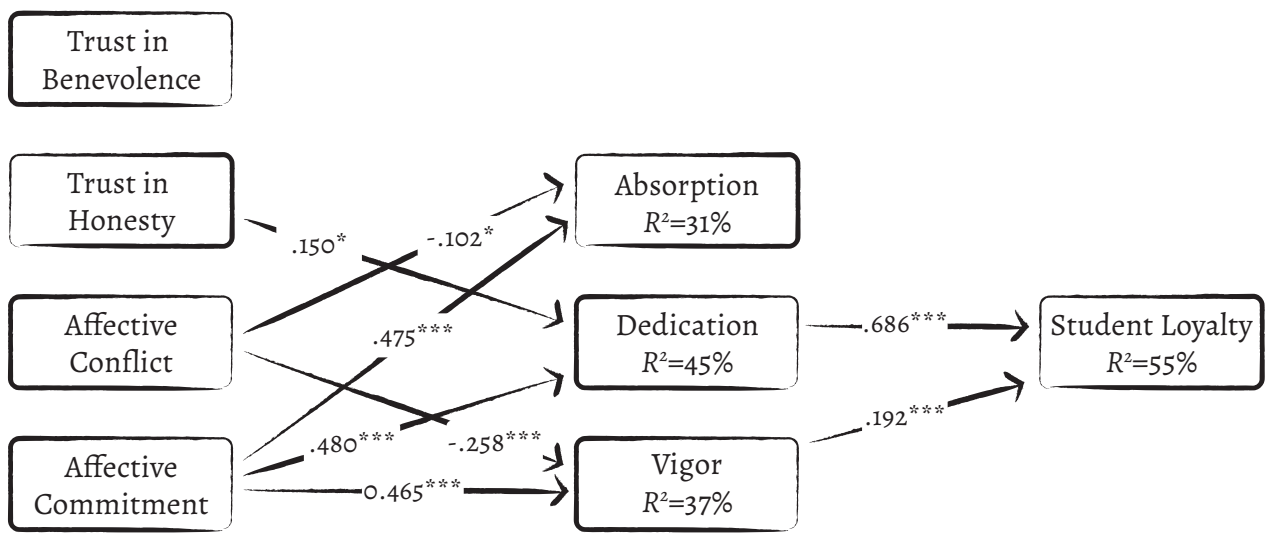

Satisfaction

Note. $N=454$ samples: ${ }^{* * * *} p<.001,{ }^{* *} p<.01,{ }^{*} p<.05, \rightarrow=$ significant path.

Effect sizes $f^{2}$ range from weak $(<.02)$ to small (> .02) to medium (.15) to large (.35; Cohen, 1988). In this study, large effect sizes were found for the effect of affective commitment on absorption, dedication, and vigor, and the effect of dedication on student loyalty. Affective conflict had a medium (negative) effect on vigor, and vigor had a medium effect on student loyalty.

\section{Mediator Analysis}

Direct effects of relationship quality dimensions on student loyalty (H3a-e) were found for affective commitment $(.382, p<.001)$, affective conflict $(-.130, p<.001)$, satisfaction $(.221, p<.001)$, and trust in honesty $(.224, p<.001)$. No direct effect was found for trust in benevolence (see Appendix D). Hence, we continued the mediator analysis by further examining the indirect effects and direct effects following the procedure by Hair et al. (2017). 


\begin{tabular}{|c|c|c|c|c|c|c|c|c|c|c|}
\hline & & 1 & 2 & 3 & 4 & 5 & 6 & 7 & 8 & 9 \\
\hline 1. & RQT_B & .92 & & & & & & & & \\
\hline 2. & RQT_H & .76 & .90 & & & & & & & \\
\hline 3. & RQ ACOMM & .64 & .58 & .91 & & & & & & \\
\hline 4. & RQ_ACON & -.49 & -.45 & -.37 & .92 & & & & & \\
\hline 5. & RQ_SAT & .73 & .71 & .60 & -.53 & .95 & & & & \\
\hline 6. & SE_AB & .42 & .35 & .55 & -.30 & .37 & .83 & & & \\
\hline 7. & SE_DE & .51 & .52 & .64 & -.37 & .52 & .76 & .87 & & \\
\hline 8. & SE_VI & .41 & .37 & .46 & -.43 & .43 & .77 & .69 & .85 & \\
\hline 9. & SL & .66 & .67 & .70 & -.50 & .69 & .56 & .73 & .58 & .83 \\
\hline & Mean & 5.32 & 5.37 & 5.01 & 4.78 & 4.99 & 4.32 & 5.32 & 4.30 & 5.28 \\
\hline & SD & 1.33 & 1.17 & 1.44 & 1.52 & 1.34 & 1.26 & 1.23 & 1.23 & 1.36 \\
\hline
\end{tabular}

Note. The numbers on the diagonal represent the square root of the AVE for each construct. $N=454$. All correlations are significant $(p<.05)$. RQ = Relationship quality, $T_{-} B=$ Trust in benevolence, $T_{-} H=$ Trust in honesty, $A C O M M=$ Affective commitment, $A C O N=$ Affective conflict, $S A T=$ Satisfaction; $S E=$ Student engagement, $A B=A b s o r p t i o n$, $\mathrm{DE}=$ Dedication, $\mathrm{VI}=$ Vigor; $\mathrm{SL}=$ Student loyalty. Response scales ranged from 1 to 7 , with a higher score indicating a greater level of the construct.

When including the mediating variables of dedication, vigor, and absorption, the analysis showed that affective commitment had positive indirect effects on student loyalty. In addition, affective conflict (i.e., a negative sample mean value for an inverse relation according to the hypothesized model, see Figure 4.2) also had positive indirect effects on student loyalty. In the association between affective commitment on the one hand, and student loyalty on the other, both indirect and direct effects (after including the mediating variables) were found to be significant through student engagement's dedication. Furthermore, in the association between affective conflict and student loyalty, also, both indirect and direct effects (after including the mediating variables) were found to be significant through student engagement's dedication. The direct effect of satisfaction on student loyalty disappears when including the mediating variables. However, none of the indirect effects of satisfaction on student loyalty through student engagement's dimensions are statistically significant. For the relation between trust in honesty and student loyalty, the direct effect disappears when including the mediating variables. However, the indirect effect through dedication is significant (see Appendix D). 


\section{Discussion}

Relationship quality deserves attention in higher education because students can be seen as one of the main stakeholders of higher education institutions (Bowden, 2011; Temmerman, 2018; Woodall et al., 2014). Students' perspectives should be considered when investigating what relational quality aspects are essential for building positive relationships with them. Establishing positive relationships might lead to positively engaged and loyal students. The hypotheses based on the study's design were partly confirmed: the hypothesized model with relational quality as an exogenous latent variable explained $31 \%$ of the variance in the student engagement dimension of absorption, $45 \%$ in the student engagement dimension of dedication, $37 \%$ in the student engagement dimension of vigor, and, $55 \%$ in student loyalty.

\section{Relationship Quality}

The relationship quality construct was measured with five different but related dimensions. Therefore, care should be taken when interpreting the results for each relationship quality dimension apart from the other relationship quality dimensions. However, we tried to explain the findings for each relationship quality dimension separately, because this might give a more detailed view of the configuration of a relational approach that educational practitioners could apply.

\section{Trust in Benevolence}

Trust in benevolence did not have a statistically significant association with student engagement (Hia). One explanation might be that the degree of educational faculty/staff's willingness to help students (e.g., show concern and respond with understanding) does not always positively influence students' experience as far as their studying. Students might evaluate the expression of educational faculty/staff's benevolence more specifically. In other words, students' ideas about willingness and helpfulness are perhaps different from 'benevolent' actions by educational faculty/staff. Our findings are in line with Tschannen-Moran and Gareis (2015), who pointed out with regard to the principal-teacher relationship that "the perception of benevolence (also) involves cognitive judgment of the behaviors of others and one's experiences with them" (p. 260) and these might not be in sync with each other. However, this view is not always supported. For instance, Wentzel (2018), indicated that with young adolescents, "if a student feels that a teacher cares about them [students] and is going to be supportive of them as an individual [student], they [students] are more likely to listen to the teacher and to engage in what the teacher wants them to do." Further research is needed to support this idea. 


\section{Trust in Honesty}

Trust in honesty had a statistically significant association with dedication (Hib). The more positively students perceive their educational faculty/staff's honesty, the more positively they engage in their studies. Similarly, recent organizational research highlighted the importance of building trust to enhance work engagement (see McManus \& Mosca, 2015). Furthermore, a recent study within a healthcare environment indicated trust to be essential to develop and maintain reciprocal relationships (Wilkins, 2018). We believe that is similar to higher education, where there is also an 'imbalance of power' within the relationship; for a student to become engaged, development of trust is essential, especially by showing honesty. It could be that students who appreciate faculty/staffs' honesty might also feel loyal to their educational faculty and staff. However, the causal part is still unclear and needs to be further investigated in longitudinal studies.

\section{Affective Conflict}

Affective conflict had a statistically significant association with student engagement's dimensions of absorption and vigor (Hic). Affective conflict addresses negative affective/emotional aspects of relationship quality. The more conflict (e.g., irritations or frustrations students feel during their studies), the less positive students might feel. Contrary to the findings in the pilot study, which had a narrower sample as far as gender, year of study, and educational program, in this study, the degree of conflict during students' studies did not affect students' dedication to their studies. These findings are in line with a similar study among alumni (Snijders et al., 2019). A statistically significant association was also found for the relation between affective conflict and student loyalty (direct effect).

\section{Affective Commitment}

Affective commitment had a statistically significant association with all dimensions of student engagement ( $\mathrm{H} 1 \mathrm{~d}$ ), and with student loyalty (direct effect). Affective commitment also addresses affective/emotional aspects of relationship quality. Within this study's sample, perhaps for students to be "dedicated" to something or someone, there must be some sort of relatedness or feelings of belonging and/or affection as a middle ground to establish loyalty eventually. In other words, affective commitment (as part of relationship quality) might precede dedication (as part of student engagement), which in turn precedes student loyalty (towards students' faculty/staff and the course of studies). These ideas are in line with R. M. Morgan and Hunt's (1994) commitment-trust theory, where they posited that commitment is central for the existence of a relationship and forming bonds (i.e., mutual respect and understanding). A study by Bowden and Wood (2011) also confirmed the idea that students' affective and emotional bonds with their university predict student loyalty (behavior). 


\section{Satisfaction}

In line with research on perceived quality by Zeithaml et al. (2009), our assumption was that satisfaction with the overall quality of the performance of faculty/staff would be necessary for student engagement (Hie). Kuh (2009), for instance, stated that student engagement is "the time and effort students devote to activities that are empirically linked to desired outcomes of college and what institutions do to induce students to participate in these activities" (Kuh, 2009, p. 683). However, no statistically significant association was found with student engagement. Based on feedback received via the open-ended question in the survey, no valid explanation could be found for the lack of relation between satisfaction and the dimensions of student engagement. Further research is needed to investigate the sequence of relationship quality dimensions and their (educational) consequences.

\section{Student Engagement}

The idea was that students' evaluation of their engagement in studying would be related to their loyalty (in terms of attitude and/or behavior) towards their institution and/or educational faculty/staff. This study's findings confirm that the student engagement dimensions of dedication and vigor have a statistically significant association with student loyalty. Furthermore, affective commitment had an indirect effect on student loyalty through dedication and vigor.

\section{Absorption}

The positive relation between absorption and student loyalty was not statistically significant (H2a). However, although it failed to reach statistical significance, there was a positive trend between absorption and loyalty. Apparently, in this study's sample, even if students are more absorbed in their studies, this does not have a statistically significantly effect on students' loyal attitude and/or behavior. In other words, students might be very enthusiastic about what they are studying. However, this does not necessarily lead to another positive state of mind in terms of loyal affections or (intentions for) behavior towards their educational faculty/staff or university. Perhaps absorption is an over-stated variable to use in students' evaluations of engagement and stretches too far.

\section{Dedication}

Dedication was positively related to student loyalty $(\mathrm{H} 2 \mathrm{~b})$ and trust in honesty and affective commitment had an indirect effect on loyalty through dedication ( $\mathrm{H} 3 \mathrm{~b} \& \mathrm{c}$ ). There seems to be a strong connection between students' dedication to their studies and their affective commitment to their educational faculty/staff, their trust in the honesty of their educational faculty/staff, and their experienced lack of affective conflict. Perhaps the idea that commitment-through its influence on dedication-might act as a precursor for loyalty also holds in a higher education context (see commitment-trust theory; R. M. Morgan \& Hunt, 
1994). Student engagement in the form of dedication has a positive, statistically significant direct influence on student loyalty. It also partially mediates the relations of affective commitment and affective conflict with loyalty.

Furthermore, elaborating on relationship research (e.g., Tschannen-Moran \& Gareis, 2015), due to the presence of a student's dedication to their studies, trust in honesty may positively influence student loyalty ( $\mathrm{Hib}$ ). This is an interesting finding for faculty/staff who want to incorporate these ideas within the guidance they give to students (e.g., via communication/ feedback to students). Honest reactions to students seem to evoke positive and loyal intentions and behavior.

\section{Vigor}

Vigor was positively related to student loyalty and affective commitment, and affective conflict had an indirect effect on student loyalty through vigor. Induced by affective commitment and affective conflict, it seems that the more students feel vigorous at their studies (H2c), the more they will develop a loyal attitude towards their institution and/ or faculty/staff (e.g., intentions or willingness to be present at institutional open house days). In turn, they might show loyal behavior (e.g., giving positive recommendations) due to the interpersonal relations students build and establish at school, such as with their educational faculty and staff. However, they also might feel positive about being at school in general because they like being there to work on their studies, for instance, with their peers and fellow students.

\section{Implications, Limitations, and Future Research}

This study's findings have implications for educational practitioners and policymakers. By focusing on students' expectations and monitoring factors that influence the educational experience, for instance, by showing positive responses to students in terms of helpfulness behavior (i.e., being willing to be of assistance and giving feedback), institutions of higher education may positively influence the quality of the relationship with their students. In other words, ensuring educational faculty/staffs' sincerity in their guidance to students and reducing students' feelings of affective conflict could help establish positive, fruitful relationships between educational faculty/staff and students. In turn, this could be beneficial for higher education institutions and their educational faculty/staff (e.g., student retention, O'Keeffe, 2013; completion rates, Estermann \& Claeys-Kulik, 2016; Jones, 2016; positive reflection on job satisfaction, M. Kim \& Schallert, 2011; Veldman et al., 2013; and sense of belonging, Y. K. Kim \& Lundberg, 2016). By building relationships with students in such a way, higher education institutions could be rewarded with student loyalty. 
Although this study contributes to the body of knowledge of student-faculty relationship quality and the importance of building relationships with students, it has its limitations. First, this study was an initial attempt to identify key drivers of student engagement and, in turn, student loyalty. Although we used validated scales to test our hypothesized model and thereby increased its validity, the relations are only correlational; causal relations cannot be indicated. Parallel to this quantitative research, a qualitative approach could be useful to provide a broader view of relational bonds between students and their educational faculty and staff and to gain further insight into relationship quality in higher education. Future research may focus on examination of how students and educational faculty and staff perceive their relationship quality. For example, data collected among enrolled students might be interesting, asking students to describe positive and negative experiences related to the quality of their relationships with educational faculty and staff or their university in general. Second, this study's sample consisted of students from one university of applied sciences. One could replicate the study by including students from other universities in other courses of study or also examine differences between male and female students.

Furthermore, the research design did not rule out the possibility that the directionality of the relation between relationship quality and student engagement may go the other way or be bi-directional. In this study, the educational faculty/staff's perceptions of the relationship quality were also not included.

In this study, the focus was on student-faculty relationship quality dimensions as key drivers for the dimensions of student engagement, and, in turn, for student loyalty. The contribution of this study lies in the fact that it provides new insights into possible influences on students' educational experiences related to their bonds with educational faculty/staff. The assumptions were that having high-quality relationships with students will positively influence their academic involvement in terms of student engagement and, in turn, their student loyalty. Although the model explained $55 \%$ of the variance in student loyalty, $45 \%$ of the variance in student loyalty was still unexplained. Dimensions of relationship quality and student engagement explained part of the variance in student loyalty and are, therefore, to be considered important drivers of student loyalty. To further examine other drivers of student loyalty, future research should include possible alternative predictors such as the institutional image (R. M. Brown \& Mazzarol, 2009) or perceived value of education (Ledden et al., 2007; Woodall et al., 2014). Recent studies have investigated academic performance or a derivative thereof (e.g., academic achievement, academic success, student success, success in studies, or school success) in relation to student engagement (Bakker et al., 2015). In this study, academic performance was not included in the model because of the cross-sectional design. However, academic performance could be of interest; for example, the association between student engagement and academic performance (Bakker et al., 2015). Prior research 
has indicated that the grades students earn are expected to be the most important indicator of success in future studies (Pascarella \& Terenzini, 2005).

Another possibility for future longitudinal research would be to gain insight into the extent to which relationship quality and students' intentions and behavior develop over time. In line with this, alumni also form an interesting group to investigate (e.g., McAlexander et al., 2006; Snijders et al., 2019). Alumni can offer valuable insights regarding their current professional requirements and how well their former program prepared them for those requirements. Alumni loyalty could be expressed by (satisfied) alumni, who are likely to give financial donations to their university or provide positive word-of-mouth communication. In addition, using other kinds of indicators (e.g., behavioral indicators) instead of relying only on self-report could be of interest for examining student engagement and student loyalty.

\section{Conclusion}

Through the lens of social exchange theory applied in a higher education context, this study investigated students' perceptions of the quality of the relationship with their educational faculty and staff and its associations with student engagement, and student loyalty. Based on these findings, this study suggests that a relationship management approach is fruitful for higher education policymakers. They should focus on building and nurturing student/ institutional relationships due to the positive effect on student engagement and student loyalty. Educational faculty and staff should be aware of relationship quality aspects. Moreover, they need to consider and elaborate on students' evaluations of the quality of their relationships with educational faculty and staff. They should discuss students' perceptions within the educational faculty and staff's team. A one-size-fits-all approach will not work, so they need to learn what individual students' relational needs are. Therefore, it is essential to evaluate students' needs regularly and consider relationship quality dimensions, as suggested in this study. Including these dimensions in educational and faculty/staff's way of providing guidance, such as by providing honest feedback towards students, showing care and concern, and willingness to help when needed, are good starting points in this respect. 


\section{$75=21$}

1

सैद्र

$+$

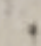

12

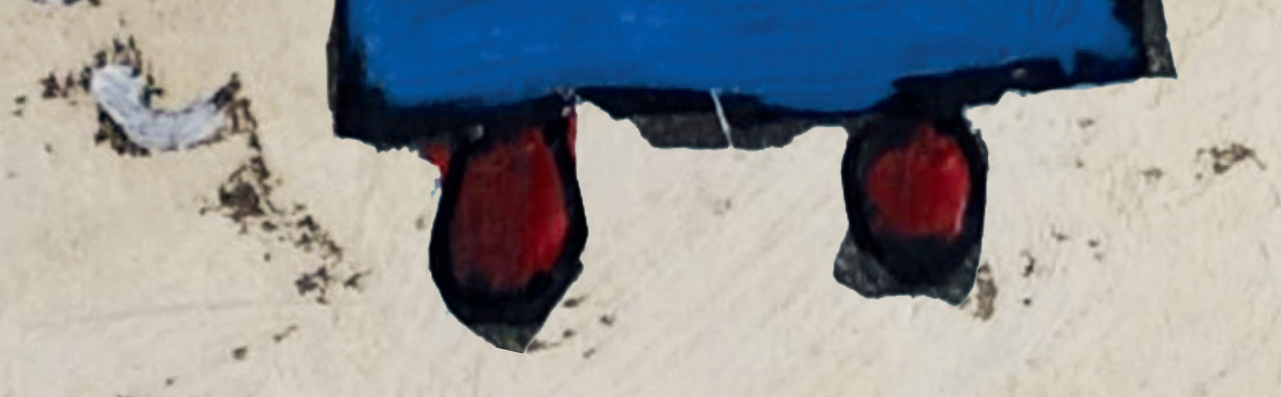

$a^{\prime}$ 


\section{Abstract}

Alumni can be of enormous value for higher education institutions because of the time and money they can spend on their former institution. Going beyond prior research that has as yet mostly considered alumni giving, this study focuses on exploring drivers for non-monetary alumni behavior (i.e., alumni loyalty). Modeling analysis was conducted on 152 alumni responses from two Dutch universities of applied sciences. Based on social exchange theory, a structural equation model was tested in which relationship quality dimensions were associated with student engagement, which in turn were related to alumni loyalty. Findings showed that the relationship quality dimensions of trust in benevolence and affective commitment had a statistically significant positive association with the student engagement dimensions of absorption, dedication, and vigor, and with alumni loyalty. The findings of this study support the importance of relationship quality dimensions in higher education for initiating long-lasting relationships with students even after their graduation and for establishing non-monetary contributions in terms of alumni loyalty. 


\section{Introduction}

Strong alumni relations can be of enormous value to a university. Alumni may assist the university from which they have graduated, resulting in non-monetary or monetary support. Therefore, they form an interesting and relevant group (Iskhakova et al., 2017). Their involvement can contribute to current students' higher education experience, such as by their reflection on current curricula and future job opportunities (Ebert et al., 2015; Moore \& Kuol, 2007). In addition, "engaging with higher education institutions in designing and delivering curriculum not only allows businesses to influence the education of the future workforce but to engage with prospective future employees throughout their educational experience" (Plewa et al. 2015, p. 36). Other examples of alumni support are, for instance, financial sponsorship, offering internships, giving guest lectures, and participation in advisory boards (Ebert et al., 2015; Moore \& Kuol, 2007). Due to their more prominent role, alumni could be regarded as among the primary stakeholders of higher education institutions (Barnard \& Rensleigh, 2008). As a result, alumni loyalty has become an increasingly important strategic theme for (European) universities (Iskhakova et al., 2017). Alumni loyalty can even be called a key factor for higher education institutions' survival and success (Schlesinger et al., 2017) because of alumni nonmonetary and monetary support, such as alumni giving.

In some countries such as the United States (US), alumni giving is considered to be essential to the funding of public higher education institutions as a result of decreasing governmental financial support (Lambert \& Miller, 2014; Newman \& Petrosko, 2011). Therefore, the importance of alumni has long been recognized (Newman \& Petrosko, 2011). Previous literature on alumni loyalty has been mainly based on studies from the US, with a focus on monetary contributions (Guzman, 2015; Koenig-Lewis et al., 2016) such as donations and buying the universities' merchandise. While US-based alumni often automatically become alumni association members, in European countries such as the Netherlands, Belgium, and Germany, this practice is not common. Following the American example, most Dutch universities nowadays have started to invest in building relationships with former students and regional businesses. Nevertheless, compared to the US, the majority of higher education institutions in the Netherlands still do not have a structured and sustainable alumni policy (Jadnanansing, 2015).

In Europe, and more specifically in Dutch higher education, alumni involvement occurs more often in the form of non-monetary 'membership,' that is, voluntary contributions such as serving on advisory boards (Weerts et al., 2010). 
Further research is needed to contribute to the limited knowledge of alumni loyalty drivers (Weerts \& Ronca, 2008), including non-monetary alumni involvement. This study begins to address this knowledge gap (Iskhakova et al., 2017) by exploring new possible factors that could predict whether students remain loyal after graduation, that is, drivers of non-monetary alumni loyalty. We assume that alumni will report higher (retrospective) engagement when they perceive their past educational experiences positively in terms of the relationship they had with their former educational faculty and staff. Consequently, after their graduation, such former students might become (more) loyal in terms of positive intentions (e.g., positive word of mouth) and behavior after their graduation (e.g., becoming part of an educational advisory board). Using the lens of social exchange theory (Blau, 1964; Emerson, 1976), we based this assumption on several ideas from the services and relationship management field, in combination with educational research literature. In services and relationship management, the philosophy is on keeping and improving relationships with key stakeholders (Zeithaml et al., 2009). In higher education, former students are among the key stakeholders.

The educational literature also stresses the importance of building positive student-faculty relationships (e.g., Bowden, 2009; Kahu, 2013; Taylor \& Parsons, 2011). Higher education institutions may benefit from positive student-faculty relationships, as such relationships might result in (higher) student involvement during their studies, for example, positive recommendations by students and students being engaged in studying within and outside the classroom. Benefits could also include former students' involvement after graduation, such as giving guest lectures and being part of an educational advisory committee. How former students perceive the quality of the relationship they had with their educational faculty/staff might be an essential predictor of how former students perceived their studies, and consequently, of how they were engaged in studying and how they now (still) feel connected to their previous university and show their loyalty. This study aims to add to the theoretical and practical understandings of alumni loyalty in higher education. The following research question guided this research: What are the associations between alumni perceptions of the quality of the relationship they had with their former educational faculty/staff (i.e., relationship quality), their perceptions of their student engagement, and alumni loyalty?

Building on previous work on the dynamics of students' relationships with their university (e.g., Kahu, 2013, Zeithaml et al., 1996), we developed and tested a hypothesized model (see Figure 5.1, Hypothesized model). Hence, we propose the following hypotheses: 
H1: Relationship quality dimensions a-e, are each positively associated with each student engagement dimension.

H2: Student engagement dimensions a-c are each positively associated with alumni loyalty.

Mediation of the relation between relationship quality dimensions and student loyalty by student engagement dimensions is also tested. Drawing upon the ideas of Farrow and Yuan (2011), who implied that the strength of ties between faculty/staff and former students may influence alumni loyalty in terms of attitude and behavior, this study also tests direct effects of relationship quality dimensions on alumni loyalty, with the following hypothesis:

H3: Relationship quality dimensions a-e are each positively associated with alumni loyalty.

For reasons of clarity, direct relations between relationship quality dimensions and alumni loyalty are not depicted in Figure 5.1.

\section{Aim of the Present Study}

This study aims to explore possible drivers of alumni loyalty, including nonmonetary alumni involvement. With this study, we intend to assist higher education practitioners and institutions in their pursuit of maintaining student-faculty relationships after graduation. By examining the effect of different dimensions of relationship quality on engagement and alumni loyalty, insights from this study can provide a broader view of how to build and sustain positive student-faculty relationships. These relationships can be fruitful in the short, as well as the long run for higher education institutions. 
Figure 5.1

Hypothesized Model

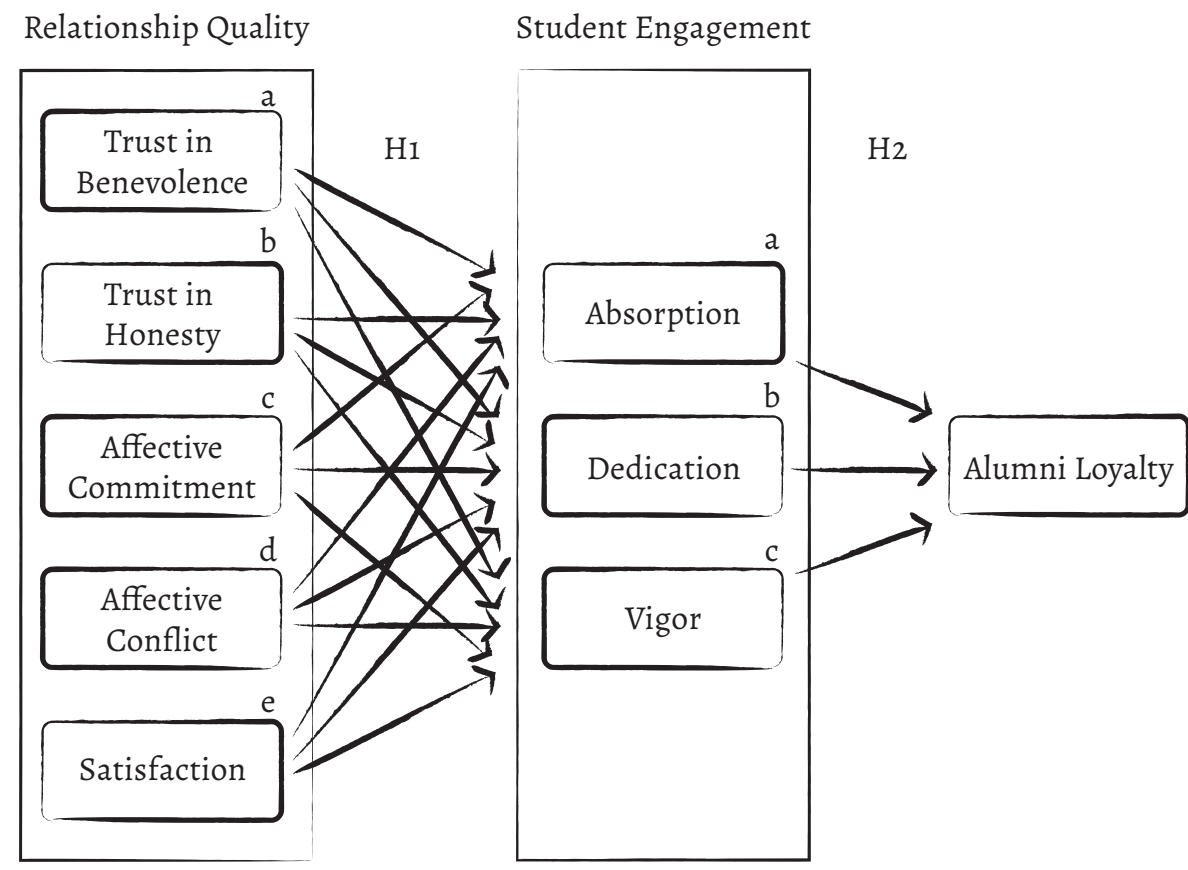

\section{Theoretical Background}

\section{Alumni Loyalty}

Student loyalty, in general, refers to the extent to which students feel connected to the educational institution in which they are enrolled, expressed by their attitudinal and/or behavioral actions (Hennig-Thurau et al., 2001). Loyalty can refer to the time a student was formally enrolled as well as the time after the student has completed his/her formal education at the institution (Nesset \& Helgesen, 2009). In other words, it can be considered "a multiple concept that stretches from enrolment to graduation and beyond" (Koenig-Lewis et al., 2016, p. 59), resulting in alumni loyalty. Alumni loyalty is also referred to as the faithfulness or devotion of alumni (Iskhakova et al., 2017). Two interrelated components form the basis for that loyalty: attitudinal and behavioral aspects (Hennig-Thurau et al., 2001). Attitudinal alumni loyalty intentions can be defined as "a desire to implement financial support, a desire to keep in touch with the university, interest in obtaining university news, and a willingness to be a member of the alumni association" (Iskhakova et al., 2016, p. 302). Behavioral alumni loyalty is often expressed in monetary (i.e., financial) support. Newman and Petrosko (2011) 
also mentioned other forms of alumni contributions. Expressions of non-monetary alumni behavior could be wearing universities' merchandise (Fogg, 2008), and offering their expertise and skills, such as in the form of serving on advisory boards (Weerts et al., 2010). Although its importance has been acknowledged (Schlesinger et al., 2017), little research has been conducted on possible drivers of alumni loyalty (R. M. Brown \& Mazzarol, 2009). Based on the relationship and service management literature, to achieve positive academic outcomes such as alumni loyalty through students' bonds with their university (Bowden, 2009; Sung \& Yang, 2009), student engagement might be crucial.

\section{Student Engagement}

Student engagement is a broad concept (Di Battista et al., 2014; Farr-Wharton et al., 2018). Promoting engagement is a global issue and of educational importance for developed countries (Coates, 2010; Zepke, 2015). The concept is widely theorized and researched (Kahu, 2013). Multiple definitions have been used in student engagement research in the past years. However, student engagement can be considered to be a variety of constructs that measure both the time and energy students devote to educationally purposeful activities and how students perceive different facets of the institutional environment that facilitate and support their learning (Kuh, 2001). Therefore, student engagement can be seen as a meta-construct (Fredricks et al., 2004).

In line with recent studies (e.g., Farr-Wharton et al., 2018), in this study, the definition by Schaufeli and Bakker (2003) that focuses on students' studying experience is adopted. In these terms, student engagement is "a positive, fulfilling, work-related state of mind that is characterized by vigor, dedication, and absorption" (p. 4). Schaufeli et al. (2006) defined the student engagement sub-dimensions as follows: "Vigor is characterized by high levels of energy and mental resilience while studying, the willingness to invest effort in one's studies, and persistence even in the face of difficulties". "Dedication refers to being strongly involved in one's studies and experiencing a sense of significance, enthusiasm, inspiration, pride, and challenge". Finally, absorption is characterized by "being fully concentrated and happily engrossed in one's studies, whereby time passes quickly, and one has difficulties with detaching oneself from studying". Schaufeli et al. (2002) conducted research within a higher education context, examining the student engagement dimensions of vigor, dedication, and absorption. In line with previous research (Bakker et al., 2014), within the present study, we expect that the more students are engaged, the more positively they experience their education. A recent study by Xerri et al. (2018) indicated that the stronger the teacher-student relationships were, the higher student engagement was in academic activities. Therefore, it is essential to examine the associations between student engagement and loyalty and the role of relationship quality (Bowden, 2011). 


\section{Relationship Quality}

Relationship quality, in general, can be defined as the overall strength of a relationship between two parties, such as the relationship between students and faculty/staff (Bowden, 2011). Previous studies (e.g., Pascarella, 1980) have already indicated that student-faculty relationships are important in higher education. Social relations during one's time at university may even lead to improved school attachment (Li \& Frieze, 2016). Recent research has suggested that the conceptualization and measurement of relationship quality, as defined in consumer services, are also applicable to a higher education context (Hennig-Thurau et al., 2001; Snijders et al., 2018; Snijders, Wijnia, Rikers, \& Loyens, 2020). Previous research (Snijders et al., 2018) based on the relationship quality study by Roberts et al. (2003) indicated that relationship quality in higher education could be considered a five-dimensional construct. The five dimensions are trust in honesty, trust in benevolence, affective commitment, affective conflict, and satisfaction.

Trust in honesty means the trust students have in the educational faculty/staffs' credibility, that they are sincere, and that they will perform their role effectively and reliably. Trust in benevolence refers to the extent to which students believe faculty and staff are concerned about students' welfare, including having intentions and motives beneficial to students, and avoiding acting in a way that will result in negative outcomes for students. Students' feelings of wanting to belong or be connected to their educational faculty/staff represent affective commitment. Affective conflict is a negative indicator of relationship quality, that is, lack of trust. Last, satisfaction is the cumulative student satisfaction with the overall quality of the student-faculty/staff relationship.

Qualitative research by Cotten and Wilson (2006) suggested that the frequency and quality of interactions between students and their faculty/staff could stimulate positive relationships between all parties. Recent research (e.g., Pianta et al., 2012; Xerri et al., 2018) have pointed out that students' perceptions of the relations between students and their faculty/staff can positively influence students' engagement, and in turn, students' current loyalty (Snijders, Wijnia, Rikers, \& Loyens, 2020; Sung \& Yang, 2009). For instance, in an earlier study (Snijders, Wijnia, Rikers, \& Loyens, 2020), findings indicated that affective commitment and affective conflict are important relationship quality dimensions that positively link with the student engagement of enrolled students. Furthermore, Farrow and Yuan (2011) suggested that the strength of ties between faculty/ staff and former students may positively relate to loyalty in terms of attitude and behavior.

In sum, as a result of the interactions between students and educational faculty and staff, the quality of their relationship might improve, which in turn could positively influence student/alumni (intentional and behavioral) involvement. However, so far, little is known 
about how student loyalty after graduation can be established, for instance, in terms of non-monetary alumni loyalty (Iskhakova et al., 2017).

\section{Method}

\section{Participants and Procedure}

Participants were based on a convenience sample consisting of 152 alumni from two Dutch universities of applied sciences located in the south of the Netherlands. Alumni to whom a questionnaire was administered $\left(M_{\text {age }}=32.58, S D_{\text {age }}=9.69 ; 82.2 \%\right.$ female $)$ all hold a degree from a social work study program (see Appendix E for sample characteristics). Alumni from the two Dutch universities of applied sciences were approached by email. Email addresses were obtained from the educational administration office. Approximately 1000 former students were sent an email invitation with a link to a questionnaire for participating in the research; however, the majority of emails sent were undeliverable. Respondents were told that there were no right or wrong answers to the items, as long as the answers reflected their personal opinions. Completing the online survey took approximately 15 minutes. Students were given a two-month period to respond. A reminder was sent after a 2 - to 4 -week period to the alumni who did not respond.

Ethical approval for this study was obtained in accordance with the policy of the institutions under study. Furthermore, the research project was covered by the Netherlands Code of Conduct for Research Integrity and reviewed by a committee from the Dutch Organization for Scientific Research that funded the research project. Participants were asked for informed consent via a question at the end of the online survey. Only participants who gave their permission to use their answers for research were included in this study. The responses from alumni were treated anonymously, and their responses were not traceable by their former institution to individual former students.

\section{Materials}

To measure relationship quality, student engagement, and alumni loyalty, a survey instrument using existing scales (that were adapted to fit our context as necessary) had been validated in previous research (Snijders et al., 2018; Snijders, Wijnia, Rikers, \& Loyens, 2020; see Table 5.1). All items regarding relationship quality and student engagement were formulated in the past tense, as respondents were to recall their past educational experiences; those for their current loyalty were in the present tense. The questionnaire also included an open-ended question to allow alumni to give their opinion about the questionnaire, either about specific parts of the questionnaire or the questionnaire in general. Alumni were also asked some general questions related to their 
age, gender, ethnicity, graduation year, and current job status to get a broader picture of alumni who responded.

\section{Relationship Quality}

Questionnaire items for relationship quality were based on previous research by Roberts et al. (2003), using a forward-backward translation procedure to put them into Dutch. The items had been found suitable for a higher education context in earlier studies (Snijders et al., 2018; Snijders, Wijnia, Rikers, \& Loyens, 2020). Relationship quality (RQ) was measured by a 15 -item questionnaire, based on an existing relationship quality scale with a five-factor structure: trust in honesty, trust in benevolence, affective conflict, affective commitment, and satisfaction. Students had to indicate on a 7-point Likert scale how much they agreed with the provided statements, ranging from 1 (strongly disagree) to 7 (strongly agree).

\section{Student Engagement}

Student engagement was measured by 9 items from the Utrecht Work Engagement ScaleStudent version (Shortened version UWES-S; Schaufeli \& Bakker, 2003; Schaufeli et al., 2006). A Dutch version of the UWES-S had already been tested in a previous study (Schaufeli \& Bakker, 2003). Students had to indicate how they experienced their education in terms of vigor, dedication, and absorption on a 7-point Likert scale, ranging from 1 (almost never/a few times a year or less) to 7 (always/every day).

Table 5.1

Scales and Items for Constructs Included in the Measurement Model

\section{Scale constructs}

Outer loadings

Relationship quality dimensions ${ }^{a}$

Trust in faculty/staff's benevolence ( $C R=.91, C A=.85, A V E=.76$ )

My university ${ }^{d}$ was concerned about my welfare (RQT_BOI)

When I confided my problems to my university, I knew they would respond with understanding $\quad .94$ (RQT_BO2)

I could count on my university considering how their actions affected me (RQT_BO3)

Trust in faculty/staff's honesty $(C R=.93, C A=.87, A V E=.81)$

My university was honest about my problems (RQT_Ho1) $\quad .85$

My university had high integrity (RQT_Ho2) $\quad .95$

My university was trustworthy (RQT_Ho3) $\quad .90$

Affective commitment $(C R=.91, C A=.85, A V E=.77)$

I felt emotionally attached to my university (RQ_ACOMMo1) $\quad .82$

I continued to interact with my university, because I liked being associated with them .91 (RQ_ACOMMO2)

I continued to interact with my university, because I genuinely enjoyed my relationship $\quad .90$ with them (RQACOMMO3) 
Affective conflict $(C R=.93, C A=.91, A V E=.82)$

I was (sometimes) angry with my university (RQ ACONOI)

I was (sometimes) frustrated with my university (RQ_ACONO2)

I was (sometimes) annoyed with my university (RQ_ACONo3)

Satisfaction $(C R=.97, C A=.95, A V E=.90)$

I was delighted with the performance of my university (RQ_SATOI)

I was happy with my university's performance (RQ_SATO2)

I was content with my university's performance (RQ_SATO3)

Student engagement dimensions ${ }^{b}$

Absorption ( $C R=.90, C A=.83, A V E=.74)$

Times flew when I was studying (SE_ABOI)

When I was studying I forgot everything else around me SE_(ABO2)

I was immersed when I was studying ( $S E \_A B O 3$ )

Dedication (CR $=.91, C A=.85, A V E=.76)$

I found the studying that I did full of meaning and purpose (SE_DEOI)

My studies inspired me (SE_DE2)

I was proud of the studying that I did (SE_DEO3)

Vigor $(C R=.90, C A=.84, A V E=.75)$

At university, I felt bursting with energy (SE_VIOI)

At university, I felt strong and vigorous (SE_VIO2)

When I got up in the morning, I felt like going to school (SE_VIo3)

Alumni loyalty ${ }^{c}(C R=.93, C A=.91, A V E=.57)$

I would recommend my course of studies to someone else (SLOI)

I would recommend my university to someone else (SLO2)

I am very interested in keeping in touch with "my faculty" (SLO3)

If I were faced with the same choice again, I would still choose the same course of studies (SL04) $\quad .76$

If I were faced with the same choice again, I would still choose the same university (SLO5) $\quad .72$

I found value in my education from [institution] ALO1) $\quad .85$

I am proud to be an alumnus/a of [institution] (ALO2) $\quad .83$

I have positive feelings about [institution] (ALO3) $\quad .90$

I want others to know I am a alumn of [institution] (ALO4) $\quad .48$

My education at [institution] has improved my life (ALO5) $\quad .74$

Note. $\mathrm{CR}=$ composite reliability, $\mathrm{CA}=$ Cronbach's alpha, $\mathrm{AVE}=$ Average variance extracted.

a Adapted from Roberts et al. (2003). b Adopted from Schaufeli and Bakker (2003). c Adopted from Hennig-Thurau et al. (2001) and partially from the survey based on the study by Newman and Petrosko (2011); positive alumni feelings, i.e., last five items. d 'My university' is short for "students' educational faculty/staff". 


\section{Alumni Loyalty}

To measure loyalty, we used an existing five-item scale by Hennig-Thurau et al. (2001) that measured attitudinal and behavioral loyalty aspects, along with five items from Newman and Petrosko (2011) that measured alumni positive feelings. Items were to be rated on a 7-point Likert scale ranging from 1 (do not agree) to 7 (do agree; see Table 5.1). Within the questionnaire, students were asked about intentions related to financial support as well as behavioral loyalty aspects (e.g., alumni's willingness to recommend, maintain contact, and select the institution again for future study or join an alumni organization; R. M. Brown \& Mazzarol, 2009). Hence, both loyalty intentions and behavioral loyalty aspects were considered within the current study.

\section{Analyses}

Partial least squares structural equation modeling (PLS-SEM) using SmartPLS (Ringle et al., 2015) was used to analyze the data based on the hypothesized model (see Figure 5.1). The primary objective of the current study was to predict alumni loyalty and student engagement and help to further develop a theory on relationship quality in higher education. Therefore, the PLS-SEM method was found to be appropriate (Hair et al., 2017).

A structural equation model with nine latent constructs was composed. The model consisted of two components: first, the structural (inner) model showed the relationships (paths) between the latent constructs. Second, the measurement (outer) model included the unidirectional predictive relationships between each latent construct and its associated observed indicators (Hair et al., 2014). Within the measurement models used for this study, all indicators were reflective and were well represented by its outer loadings. A two-stage approach was followed in examining the structural equation model. First, the latent construct scores of relationship quality dimensions, student engagement dimensions, and alumni loyalty were estimated via a four-step process, as suggested by Hair et al. (2014). Second, the structural equation model's path coefficients were estimated. In addition, a mediator analysis was conducted to investigate whether student engagement dimensions mediated the relation between relationship quality dimensions and alumni loyalty.

\section{Measurement Model}

Assessment of the reflective measurement model was based on construct reliability and validity and discriminant validity (Hair et al., 2017). All indicator outer loadings were above the recommended 0.70 , except for two alumni loyalty items: ALo4 ("I want others to know I am an alum") and SLO3 ("I am very interested in keeping in touch with my faculty". However, these items were not deleted because their composite reliability as well discriminant validity were above threshold values (Hair et al., 2017). Cronbach alpha 
values and composite reliability values all exceeded the threshold value of 0.70 . AVE values were 0.5 or higher, therefore establishing convergent validity. The Fornell-Larcker criterion was assessed for evaluating discriminant validity of the measurement model; the square root of AVE values should be higher than the maximum value of each construct's correlations with any other construct involved in the hypothesized model (Hair et al., 2017).

\section{Structural Model}

The procedure suggested by Hair et al. (2017) was followed for the assessment of the structural model. First, a bootstrapping procedure was applied to assess the significance of path coefficients using 5000 bootstrap samples. Evaluation of the structural model was assessed by $R^{2}$, the significance of estimated values for path relationships, and effect sizes for each effect (Cohen, 1988; see Figure 5.1 and Table 5.2). Following Hair et al. (2017), $R^{2}$ values were assessed, considering $R^{2}$ values of .25, .50, or .75 as weak, moderate, and substantial, respectively. To indicate the exogenous constructs' contribution to the endogenous latent variables' $R^{2}$ value, effect sizes $\left(f^{2}\right)$ were examined.

\section{Results}

\section{Measurement Model}

Assessment of the measurement model indicated outer loadings for relationship quality that ranged from .79 to .97. Thus, all items corresponding to each relationship quality sub-dimension loaded on the intended constructs.

In line with recent studies (e.g., Hodge et al., 2018), the UWES-S-9 shortened version suggested by Schaufeli and Bakker (2003) was used to collect data for the analysis of the measurement model for student engagement. Each of the nine items loaded on its intended construct, with outer loadings ranging from .84 to 89. Alumni loyalty was conceptualized as a one-dimensional construct. Outer loadings ranged from .48 to .90.

Construct reliability was acceptable for all latent variables (i.e., relationship quality, student engagement, and alumni loyalty), as indicated by composite reliability and Cronbach's alpha values exceeding .70. Convergent validity was verified with AVE values for all constructs that were greater than the threshold value of .50 (Fornell \& Larcker, 1981). Therefore, no indicators with outer loadings $<.70$ (ALO4 $=.48$ and SLO3 $=.59$ ) were deleted. AVE values, outer loadings of construct items in the measurement model, and composite reliabilities for each scale are included in Table 5.1. 
By comparing the square root of the AVE of each construct to its correlations with the other latent constructs (i.e., the Fornell-Larcker criterion), discriminant validity was tested. For an exploratory study, acceptable discriminant validity for every pair of latent variables was indicated by the square root of the AVE being higher than the correlation between the variables (Fornell \& Larcker, 1981; see Table 5.2).

\section{Structural Equation Model}

Considering the exploratory nature of this study, assessment of the structural equation model showed $R^{2}$ values that are reasonable. The structural equation model explained $53 \%$ of the variance in student loyalty, $23 \%$ of the variance in absorption, $30 \%$ of the variance in dedication, and $20 \%$ of the variance in vigor.

\section{Table 5.2}

Construct Correlations

\begin{tabular}{|c|c|c|c|c|c|c|c|c|c|}
\hline & 1. & 2. & 3. & 4. & 5. & 6. & 7. & 8. & 9. \\
\hline 1. AL & 0.76 & & & & & & & & \\
\hline 2. RQT_B & 0.54 & 0.87 & & & & & & & \\
\hline 3. RQT_H & 0.53 & 0.80 & 0.9 & & & & & & \\
\hline 4. RQ_ACOMM & 0.55 & 0.47 & 0.46 & 0.88 & & & & & \\
\hline 5. RQ_ACON & -0.19 & -0.18 & -0.18 & -0.16 & 0.9 & & & & \\
\hline 6. RQ SAT & 0.52 & 0.56 & 0.59 & 0.45 & -0.33 & 0.95 & & & \\
\hline 7. SE_AB & 0.50 & 0.39 & 0.25 & 0.43 & -0.14 & 0.26 & 0.86 & & \\
\hline 8.SE_DE & 0.74 & 0.46 & 0.39 & 0.52 & -0.09 & 0.37 & 0.72 & 0.87 & \\
\hline 9. SE_VI & 0.46 & 0.33 & 0.22 & 0.36 & -0.13 & 0.33 & 0.72 & 0.66 & 0.87 \\
\hline Mean & 5.07 & 5.30 & 5.31 & 5.00 & 5.18 & 4.97 & 4.11 & 5.00 & 4.38 \\
\hline SD & 1.06 & 1.04 & 1.06 & 1.25 & 1.21 & 1.16 & 1.29 & 1.13 & 1.13 \\
\hline
\end{tabular}

Note. The italicized numbers on the diagonal represent the square root of the AVE for each construct. All correlations are statistically significant $(p<.05)$.

$A L=$ Alumni Loyalty, $R Q=$ Relationship quality, $T_{-} B=$ Trust in Benevolence, $T_{-} H=$ Trust in Honesty, $A C O M M=A f f e c t i v e$ Commitment, $\mathrm{ACON}=$ Affective Conflict, $\mathrm{SAT}=$ Satisfaction, and $\mathrm{SE}=$ Student engagement, $\mathrm{AB}=\mathrm{Absorption}$, $\mathrm{DE}=$ Dedication, $\mathrm{VI}=$ Vigor

$N=152$, responses range from 1 to 7 , with a higher score indicating a greater level of the construct.

Within the sample, trust in benevolence had a statistically significant positive association with all student engagement sub-dimensions, that is, vigor, dedication, and absorption (Hia). Trust in honesty had a statistically significant negative association with student engagement's absorption and vigor ( $\mathrm{Hib}$ ), but no statistically significant association with dedication. Affective commitment had a statistically significant positive effect on all student engagement dimensions (Hic). Affective conflict did not have a statistically 
significant association with any student engagement dimensions (Hid). Last, satisfaction had a statistically significant positive association with student engagement's dimension of vigor (Hie). However, no statistically significant association was found with student engagement's dimensions of absorption and dedication.

Further examination of the structural model indicated that absorption ( $\mathrm{H} 2 \mathrm{a})$ and vigor (H2c) did not have a statistically significant association with alumni loyalty, in contrast to dedication, which did have a statistically significant association with alumni loyalty (H2b). Figure 5.2 shows the path model diagram, including statistically significant path loadings and significance levels.

Figure $\mathbf{5 . 2}$

Path model and PLS-SEM estimates $(N=152)$.

Relationship Quality Student Engagement

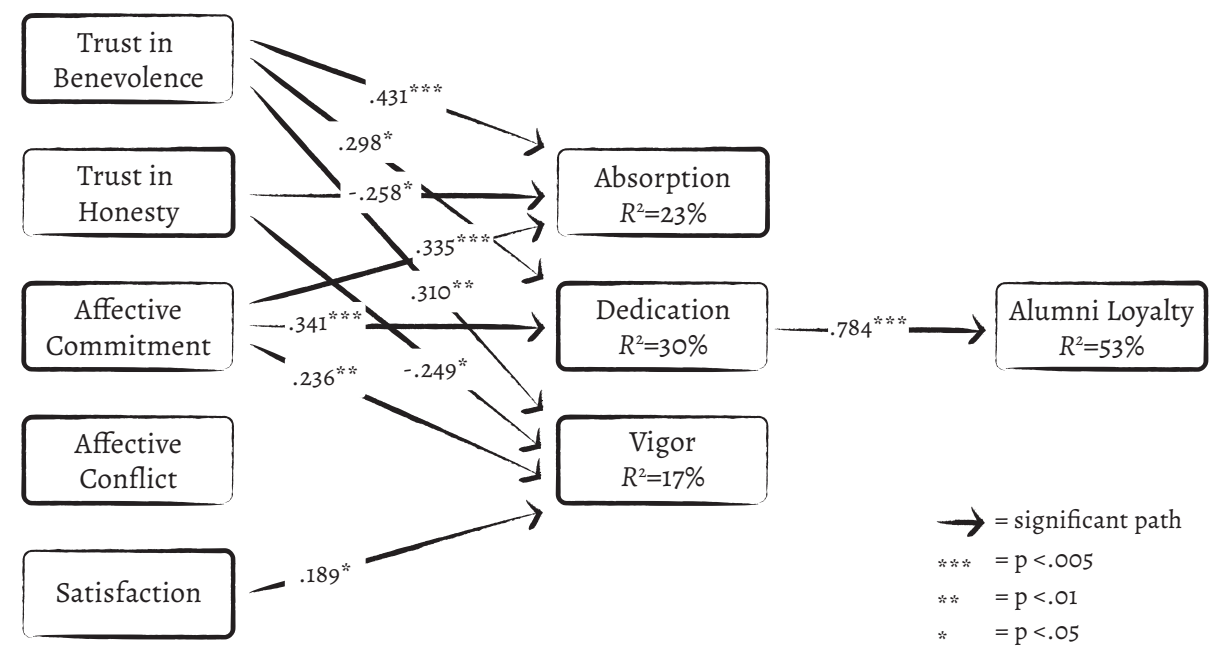

\section{Effect Sizes}

Effect sizes $f^{2}$ ranged from small (> .02) to medium (.10) to large (.35; Cohen, 1988). Small effect sizes were found for the paths between relationship quality's trust in benevolence and student engagement absorption (.09), dedication (.04), and vigor (.04); for trust in honesty and absorption (.03), and vigor (.03); for affective commitment and vigor (.05), and satisfaction and vigor (.03). Medium effect sizes were found for the paths between affective commitment and absorption (.11) and dedication (.12). A large effect size was found for the path between student engagement's dedication and loyalty (.60). 


\section{Mediator Analysis}

For the mediator analysis, further assessment of the structural model was conducted following Hair et al.'s procedure (Hair et al., 2017). First, we examined the specific indirect effects, that is, the paths between the relationship quality dimensions (independent variables) and student engagement dimensions (mediating variables; $\mathrm{Hi}$ a-e), and the paths between the student engagement dimensions (mediating variables) and alumni loyalty (dependent variable; $\mathrm{H} 2 \mathrm{a}-\mathrm{c}$ ). Statistically significant positive paths were found for the paths between the relationship quality dimensions of trust in benevolence and affective commitment, and the path between dedication and alumni loyalty.

Second, we examined the total indirect effects, that is, the paths between relationship quality dimensions and alumni loyalty ( $\mathrm{H}_{3} \mathrm{a}-\mathrm{e}$ ). Significant positive paths were found from trust in benevolence and affective commitment to alumni loyalty.

In conclusion, based on the paths between the variables that were used within the hypothesized model and those that were found statistically significant, dedication partially mediates the relation between trust in benevolence and alumni loyalty. Also, dedication partially mediates the relation between affective commitment and alumni loyalty.

\section{Discussion}

The present study investigated the associations of alumni perceptions of the quality of their former relationship with their former educational faculty/staff, their (previous) student engagement, and their current alumni loyalty. This study aimed to explore whether relationship quality dimensions (in)directly predict student engagement and (in turn) non-monetary alumni loyalty. Previous research has examined some of the reasons why alumni do or do not feel involved with the institution from which they have graduated. Former educational experiences and personal benefits (Thoits \& Hewitt, 2001), and in line with ideas from social exchange theory (Thibaut \& Kelley, 1959), the quality of students' former relationships with their educational faculty and staff (Koenig-Lewis et al., 2016) are indicative of future alumni loyalty. The findings of this study add that to establish alumni loyalty, one should also focus on relationship quality dimensions, such as students' affective commitment and trust in benevolence, although effect sizes range from small to large. These relationship quality dimensions can be seen as important predictors of student engagement and student/alumni loyalty. 
Most of the hypotheses within this study were supported. In the hypothesized and tested model, trust in benevolence had a statistically significant association with absorption, dedication, and vigor. In previous research (Snijders, Wijnia, Rikers, \& Loyens, 2020), where the sample consisted of enrolled students, trust in benevolence did not have a statistically significant association with student engagement. Perhaps alumni's perception of their former trust in faculty and staff's helpfulness changes over time. In retrospect, alumni might feel different towards faculty and staff's benevolence, compared when they were enrolled. A direct association was also found between trust in benevolence and alumni loyalty, albeit with a small effect size, which is in line with a study by Schlesinger et al. (2017) that also captured trust as an antecedent of loyalty in a higher education context.

For trust in honesty, a negative association with absorption and vigor was found. However, given the expectations within this study, that these relations are inverse is puzzling, since one would expect that students, as well as alumni, appreciate educational faculty/staff's honesty. Within the sample used for this study, though, the results imply that perceptions of their former trust in honesty did not positively contribute to the way alumni regarded their previous student engagement. Therefore, replicating this study can be of interest to determine whether this was coincidental.

Furthermore, no statistically significant positive associations were found between the relationship quality dimension of trust in honesty and dedication or alumni loyalty. It could be that former students' recollection of trust in their former educational faculty/ staff's honesty does not necessarily evoke positive feelings by alumni toward their university. Hence, educational faculty/staff can be honest in their responses to students; however, honesty does not always involve favorable educational replies, and therefore, could be not always stimulating for students' studying experience in general. For instance, an honest though disappointing response (e.g., feedback from a lecturer on a student's assignment) can be demotivating, which affects students' engagement negatively.

A statistically significant positive association was found between affective commitment and all student engagement dimensions. Affective commitment acted as a predictor for the student engagement dimension of dedication. In turn, dedication had a statistically significant positive association with loyalty, therefore suggesting that affective commitment might positively influence loyalty through dedication during students' enrollment and after graduation. These findings are in line with ideas from service/ relationship management research, in which commitment is discussed as a precursor for loyalty (Dick \& Basu, 1994). Commitment could be needed for loyalty, feelings, intentions, and perhaps behavior to eventually evolve. 
For relationship quality satisfaction, a statistically significant positive association (total effect, direct only) was found with alumni loyalty. This finding is in line with previous research by Rojas-Méndez et al. (2009) among enrolled students, with results showing positive associations between student loyalty and trust, satisfaction, and commitment (Rojas-Méndez et al., 2009). In our study, satisfaction did not have a statistically significant positive association with absorption and dedication, only with vigor. Although alumni perceptions of their overall satisfaction with the quality of their relationship with their former educational faculty/staff are important, these perceptions presumably do not affect their recollection of their educational experience in terms of their previous dedication to study, nor the way they were absorbed in their studies. Hence, remembering how and that they enjoyed studying or got excited about what they learned did not depend on how satisfied students were with the relationship they had with their (former) educational faculty/staff.

Affective conflict did not have a statistically significant positive association with any of the three student engagement dimensions, nor with alumni loyalty. A possible explanation could be that the degree of irritation and frustration concerning the quality of the relationship with educational faculty/staff is more related to the actual moment when this occurs (i.e., educational service encounter). In retrospect, those moments, if any did occur, were not of significance when recollecting students' engagement and current alumni loyalty.

As expected, a statistically significant positive association was found between student engagement dedication and alumni loyalty. Previous research (Snijders, Wijnia, Rikers, \& Loyens, 2020) explained this association by presuming that there might be a strong connection between students' commitment to their educational faculty/staff, and their dedication to their studies. Based on commitment-trust theory (R. M. Morgan \& Hunt, 1994), commitment acts through dedication as a precursor for loyalty. In contrast, student engagement's dimensions of absorption and vigor did not have a statistically significant positive association with alumni loyalty. Apparently, for alumni, it was not necessary to have been engaged with one's studies to share loyalty intentions afterward and show loyal behavior towards their former university and educational faculty/staff. This might be because, in retrospect, alumni regarded their previous relationship quality with educational faculty/staff positively, for instance, in terms of their trust in the educational faculty/staff's benevolence. Alumni perceptions of their relationship quality had a stronger positive (and statistically significant) association with their current loyalty than it had with their perceptions of their former academic engagement. 


\section{Limitations}

Although the hypotheses of this study were mainly supported, the findings are limited. First, the sample predominantly consisted of female alumni from a social work program; therefore, a direction for further research is to include alumni from other kinds of educational programs (e.g., economic and/or technical departments), and also a mixture of male and female alumni. Second, the nature of the data is cross-sectional and only concerns perceptions, with no behavioral measures included in the model; therefore, true causality could not be demonstrated.

Further research applying a longitudinal design could overcome this issue. Future studies that consider a qualitative approach could provide a broader view on (the importance of) relationship quality in relation to alumni loyalty, for example, data collected during alumni events that focus on social ties and other recollections of former educational experiences that are critical to student and alumni feelings.

Within our sample, we used alumni who were willing to respond. Therefore, it could be informative also to investigate alumni who did not respond, because they might have a different view of the relationship quality and engagement they experienced and different feelings about their loyalty. Last, we only focused on former students' perceptions, and for data triangulation, it would be worthwhile to include measures from various informants such as teachers' perceptions or other sources.

\section{Conclusion}

In conclusion, results from this study indicated that recollected relationship quality dimensions are important predictors of recollected student engagement and current (nonmonetary) alumni loyalty. More specifically, the findings show that the relationship quality dimensions of trust in benevolence and affective commitment are positively associated with the student engagement aspects of absorption, dedication, and vigor. Relationship quality satisfaction is also positively associated with dedication. Student engagement in the form of dedication is positively associated with alumni loyalty.

This study contributes to the existing literature on alumni loyalty in higher education. To date, alumni research has predominantly focused on research on monetary support, that is, alumni giving behavior. The present findings shed new light on the drivers that can initiate long-lasting relationships with former students in terms of non-monetary alumni loyalty. Therefore, this study provides necessary and useful insights into the importance of building relationships between higher education institutions as represented by faculty/staff, and 
their students and alumni. The former relationship quality experienced by students is important for establishing positive alumni loyalty intentions and feelings, particularly for European universities where loyalty is based on student and alumni non-monetary contributions. The findings of this study could, therefore, be relevant for educational practitioners who want to build and establish relationships among former students and educational faculty and staff. For example, higher education institutions should be focusing on the helpfulness of educational faculty/staff, such as by providing guidance and support regarding students' progress in their studies and choices of internships. Other ways are by stimulating and rewarding students' affective commitment, for instance, by recommending them for a place on a student advisory board, asking them to participate during open days, and encouraging participation in extracurricular activities. To induce students' satisfaction with the educational faculty/staff's overall performance, and to express educational faculty/ staff's understanding and empathy for students, it is necessary to start by understanding individual students' needs. Building relationships between students (i.e., future alumni) and higher education institutions can, in the short and long run, be fruitful for all parties: students, alumni, regional businesses, (local) government, and higher education institutions. 


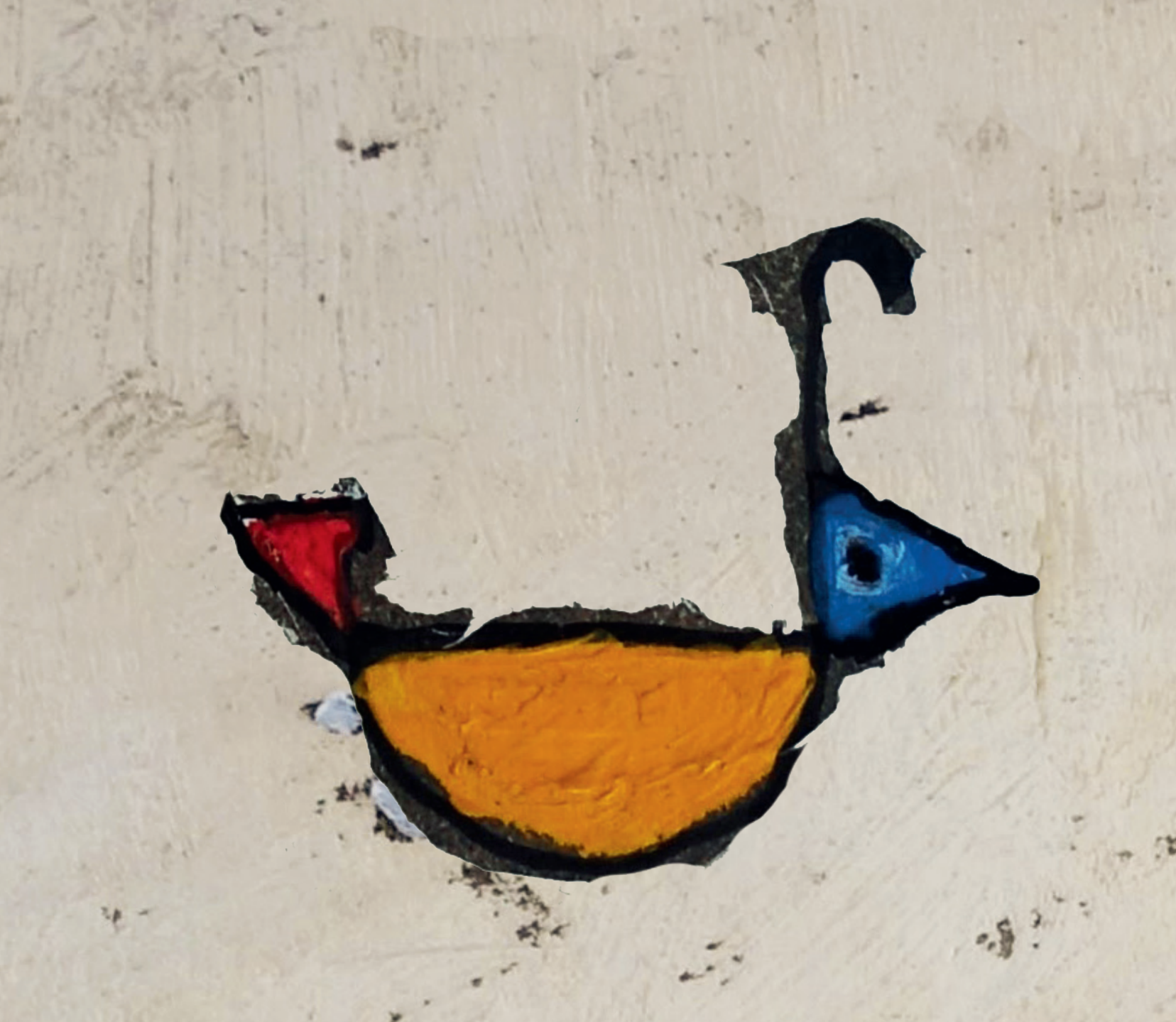




\section{Chapter $6^{2}$ \\ Relationship quality and the Interplay with Student Engagement, and Loyalty}
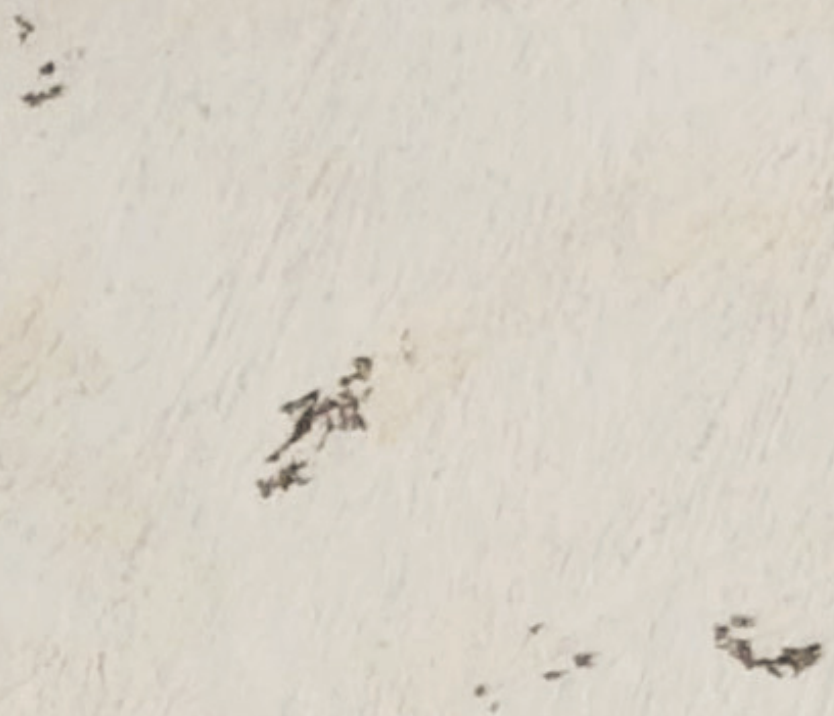

This chapter has been submitted for publication as:

Snijders, I., Wijnia, L., Kuiper, R. M., Rikers, R. M. J. P., \& Loyens, S. M. M. (2020). The interplay between relationship quality, student engagement, and student loyalty: A cross-lagged panel analysis [Manuscript submitted for publication]. University College Roosevelt, Utrecht University

Acknowledgement of author contributions: IS, LW, RR, and SL designed the study, IS recruited participants and collected the data, IS, RK, and LW analyzed the data, IS drafted the manuscript, all authors contributed to critical revisions of the paper, LW, RR and SL supervised the study. 


\section{Abstract}

To date, studies that have investigated the bonds between students and their institution have emphasized the importance of student-staff relationships. The measurement of the quality of those relationships (i.e., relationship quality) appears to be useful for investigating the relational ties students have with their higher education institutions. A growing interest has arisen in further investigating relationship quality in higher education, as it might predict students' involvement (e.g., student engagement and student loyalty). So far, most studies have used a cross-sectional design. Therefore, causality could not be determined. The aim of this study was twofold. First, we investigated the ordering of the relationship quality dimensions of trust (in benevolence and honesty) and affect (satisfaction, affective commitment, and affective conflict). Second, we examined the ordering of the paths between relationship quality, student engagement, and student loyalty. Our objectives were to gain a deeper understanding of the relationship quality construct in higher education and its future outcomes. Participants $(N=1649)$ were students from three Dutch higher education institutions who were studied in a program for technology economics, or social sciences.

Longitudinal data from two time-points were used to evaluate two types of cross-lagged panel models. The first analysis could not assume measurement invariance for affective conflict over time. Therefore, we tested an alternative model without affective conflict using the latent variables of trust and affect, the student engagement dimensions and student loyalty. In a second model, we investigated the manifest variables of relationship quality, student engagement, and student loyalty. The hypotheses were examined by evaluating simultaneous comparisons between estimates. Results indicated that in the first model, the relation between relationship quality at Time 1 with student engagement and loyalty at Time 2 is stronger than the reverse ordering. In the second model, results indicated that cross-lagged relations beween trust in benevolence and trust in honesty at Time 1, and affective commitment, affective conflict, and satisfaction at Time 2 are more likely than the reverse ordering. Furthermore, cross-lagged relations from relationship quality at Time 1 to student engagement and student loyalty at Time 2 also supported our hypothesis. This study contributes to the existing higher education literature indicating that students' trust in the quality of their relationship with faculty/staff is essential for the development of students' affective commitment and satisfaction and to avoid conflict over time. Second, relationship quality factors positively influence students' engagement in their studies and their loyalty towards the institution. A relational approach to establishing (long-lasting) bonds with students appears to be fruitful as a means for educational psychologists and practitioners' guidance and strategies. Recommendations are made for future research to further examine relationship quality in higher education in Europe and beyond. 


\section{Introduction}

Recent studies in the field of education demonstrated that improving and maintaining positive interpersonal relationships between students and teachers is essential (e.g., García-Moya et al., 2019; Pianta et al., 2012; Pöysä et al., 2019; Schlesinger et al., 2017; Xerri et al., 2018). Those relationships positively stimulate students' academic and social development, including students' engagement in their studies and student loyalty intentions (Bonet \& Walters, 2016; Taylor \& Parsons, 2011; Schaufeli et al., 2002; Umbach \& Wawrzynski, 2005). In turn, student loyalty intentions may result in positive student loyalty behavior toward their university. An example of loyalty behavior is positive wordof-mouth, which is a critical factor for higher education institutions' continuity and growth (Farrow \& Yuan, 2011; Hennig-Thurau et al., 2001; Rojas-Méndez et al., 2009; Snijders et al., 2019, Snijders, Wijnia, Rikers, \& Loyens, 2020; Sung \& Yang, 2009). Thus far, how students' relationships with the faculty and staff of their institution (i.e., relationship quality) develop over time, and how relationship quality subsequently affects student outcomes (i.e., student engagement and loyalty; e.g., Cho \& Auger, 2013; GarcíaMoya et al., 2019) has remained unclear.

In general, relationship quality can be defined as the overall strength of a relationship (Roberts et al., 2003). Within the relationship quality construct, two aspects can be distinguished: trust and affect. In line with previous research, we believe trust plays a central role in the relationship quality construct (Crosby et al., 1990; Hennig-Thurau et al., 2001; Jiang et al., 2016; R. M. Morgan \& Hunt, 1994). Without trust, there cannot be a relationship. Hence, trust can be seen as the foundation of a relationship's strength that, in time, results into the affective relationship quality aspects of satisfaction and (strong) commitment and reduction in conflict (Castaldo, 2007; i.e., in this study, "affect"). One must also consider the environment and the relational depth (or intensity) and duration to understand the relationship quality construct dynamics. The work by Van Maele et al. (2014), for instance, described the role of trust in school life and its importance to learning and teaching. To our knowledge, how students' trust in their relationship with faculty and staff develops in higher education has been underexplored.

Empirical research has emphasized the importance of students' relationships. It indicated that higher education institutions benefit from engaged and loyal students (Bowden, 2011), such as through active participation in extracurricular activities or loyalty intentions and behavior during or after enrollment. Other studies have also indicated that students' perceptions of the quality of their relationship with the educational institution are positively associated with student engagement and student/alumni loyalty (e.g., Snijders et al., 2019, Snijders, Wijnia, Rikers, \& Loyens, 2020). The relationship quality 
outcomes are of interest for educational psychologists and higher education institutions. However, previous studies in that field are mainly cross-sectional in nature (e.g., Miller et al., 2019; Schlesinger et al., 2017; Snijders, Wijnia, Rikers, \& Loyens, 2020). Thus, to indicate cause-and-effect, the directionality of the causal relations cannot be determined. The role of trust in a higher education context has also, to our knowledge, rarely been examined. This study addressed these gaps.

\section{Relationship Quality}

Previous educational psychology research primarily focused on student-teacher relationships (e.g., Košir \& Tement, 2014; Roorda et al., 2014; Zee et al., 2013). However, Snijders and colleagues (2018) demonstrated that relationship quality could be seen as a multidimensional construct, capturing students' perceptions of the quality of their relationship with their educational faculty and staff. This study builds on relationship quality research by Snijders et al. (2019), Snijders, Wijnia, Rikers and Loyens (2020) and Snijders, Wijnia, Dekker, Rikers and Loyens (2020) where they used the relationship quality construct in higher education. Relationship quality consisted of five dimensions based on students' perceptions of their educational faculty and staff. These dimensions include trust in honesty and trust in benevolence (in this study, "trust"), and affective commitment, satisfaction, and affective conflict (in this study, "affect").

\section{Trust}

Trust has been described in various ways, such as confidence one has in a relationship, and the belief a trusted person or actor is reliable or has integrity (e.g., Bryk \& Schneider, 2002; Tschannen-Moran, 2014). Students' trust in educational faculty and staff can be subdivided into trust in honesty and trust in benevolence (Roberts et al., 2003; Snijders et al., 2018).

Trust in honesty refers to the confidence students have in a university's credibility as expressed by its educational faculty and staff. Or in other words, it refers to students' trust in educational faculty/staff's integrity and trustworthiness (i.e., reliability), the staff and faculty's sincerity, and whether they will perform their role effectively and reliably.

Trust in benevolence in higher education includes the extent to which students believe faculty/staff are concerned about students' welfare, have intentions and motives beneficial to them and avoid acting in a way that will result in adverse outcomes for students (Roberts et al., 2003; Snijders et al., 2018, 2019, Snijders, Wijnia, Rikers, \& Loyens, 2020). Students' trust in educational faculty and staff's benevolence is based on students' perceptions of how faculty and staff respond to students' questions, such as timely responses to email requests, and give feedback on assignments and grades (Snijders, Wijnia, Dekker, Rikers, \& Loyens, 2020). 
For educational practitioners, it is important to think of how they respond to students. For instance, when students confide their problems, it is essential to for them to feel that they can count on their educational faculty and staff. Based on commitment-trust theory (R. M. Morgan \& Hunt, 1994), the factor of trust may lead to positive 'affect,' which is the affective relationship quality dimensions of commitment and satisfaction (Mohr \& Speckman, 1994).

\section{Affect}

Affect can be further divided into affective commitment, satisfaction, and affective conflict. Affective commitment compels students' feelings of belonging or connection to their educational faculty and staff or their institution. In other words, it is the feeling of having a connection or being emotionally attached and genuinely enjoying the relationship students experience with their educational faculty/staff. In general, commitment indicates a relationship's health and is, therefore, part of the relationship quality construct (Roberts et al., 2003). In higher education, where there are multiple and sequential interactions between students and their educational faculty/staff, affective commitment might develop over time (Castaldo, 20007).

In general, satisfaction is the "summary measure that provides an evaluation of the quality of all past interactions" (Roberts et al., 2003, p. 174). Within this study, we refer to satisfaction where we mean relationship satisfaction: students' perceptions of their degree of satisfaction with the quality of their relationship with their educational faculty/staff. In other words, we tried to capture the cumulative satisfaction students perceived regarding their relationship with their educational faculty/staff, represented by students' cognitive and affective evaluation based on their personal experiences across their education.

Affective conflict is determined by students' evaluations of their relationships with faculty/staff based on their perceived conflicts, such as irritation, frustration, or anger. It can be considered as the tension students experience due to the incompatibility of actual and desired responses from their educational faculty and staff (Snijders, Wijnia, Rikers \& Loyens, 2020). For instance, students who experience conflict in their relationships (with teachers) attain-in contrast to students who have close, positive, and supportive relationships-lower levels of achievement (Rimm-Kaufman \& Sandilos, 2010). Therefore, conflict reduction might also be necessary for the higher education context and the relations between students and their higher education institution.

Based on prior research on teacher-student relationships and the association between relationship quality and school outcomes (e.g., Culver, 2015), we assume that relationship quality positively affects student engagement and loyalty (e.g., Bonet \& Walters, 2016; 
Bowden, 2011; Hennig-Thurau et al., 2001; Taylor \& Parsons, 2011; Schaufeli et al., 2002; Snijders, Wijnia, Rikers, \& Loyens, 2020; Umbach \& Wawrzynski, 2005).

\section{Student Engagement}

Recent studies conducted in elementary or secondary school (e.g., Engels et al., 2016; Lee, 2012; Hennig Manzuoli et al., 2019; Nicholson \& Putwain, 2019) considered student engagement to be a multidimensional construct consisting of emotional, cognitive, and behavioral dimensions (Fredricks et al., 2004). However, in higher education, Schaufeli and Bakker (2003) provided an alternative interpretation and application of student engagement (Schaufeli et al., 2002). They defined engagement in terms of "a positive, fulfilling, work-related state of mind that is characterized by vigor, dedication and absorption" (Schaufeli \& Bakker, 2003, p. 4). "Vigor is characterized by high levels of energy and mental resilience while working, the willingness to invest effort in one's work, and persistence even in the face of difficulties" (Schaufeli \& Bakker, 2003, p. 4). Dedication refers to "being strongly involved in one's work and experiencing a sense of significance, enthusiasm, inspiration, pride, and challenge" (Schaufeli \& Bakker, 2003, p. 4/5). Absorption is "characterized by being fully concentrated and happily engrossed in one's work, whereby time passes quickly, and one has difficulties detaching oneself from work" (Schaufeli \& Bakker, 2003, p. 5).

\section{Student Loyalty}

Student loyalty refers to the extent to which students feel connected to the institution and how this is expressed in their attitudes and behaviors (Helgesen \& Nesset, 2007; Hennig-Thurau et al., 2001). In higher education, attitude may refer to students' (positive) feelings related to their faculty/staff and university. Student loyalty behavior is expressed in, for example, (positive) recommendations from students about their educational faculty/staff and university, active participation in extracurricular activities or loyalty intentions, and behavior during or after their period of enrollment. Higher education institutions benefit from loyal and successful students (Helgesen \& Nesset, 2007). Therefore, in the international literature on student behavior, student loyalty is increasingly considered a critical measure of those institutions (Rojas-Méndez et al., 2009).

\section{Present Study}

In the present study, we applied a cross-lagged panel analysis to longitudinal data from two time points. The data were based on students' questionnaire responses on relationship quality (Roberts et al., 2003; Snijders et al., 2018), student engagement (Schaufeli \& 
Bakker, 2003), and student loyalty (Hennig-Thurau et al., 2001). The purpose was twofold: 1) to examine the ordering of the relations between the relationship quality factors of trust at Time 1 and affect at Time 2, and 2) to explore the strength of the relations between relationship quality, student engagement, and loyalty (see Figures 6.1 and 6.2). This study has practical implications for educational psychologists and practitioners who want to understand the relational ties between students and their institution.

Figure 6.1

Cross-Lagged Panel Model

Time 1

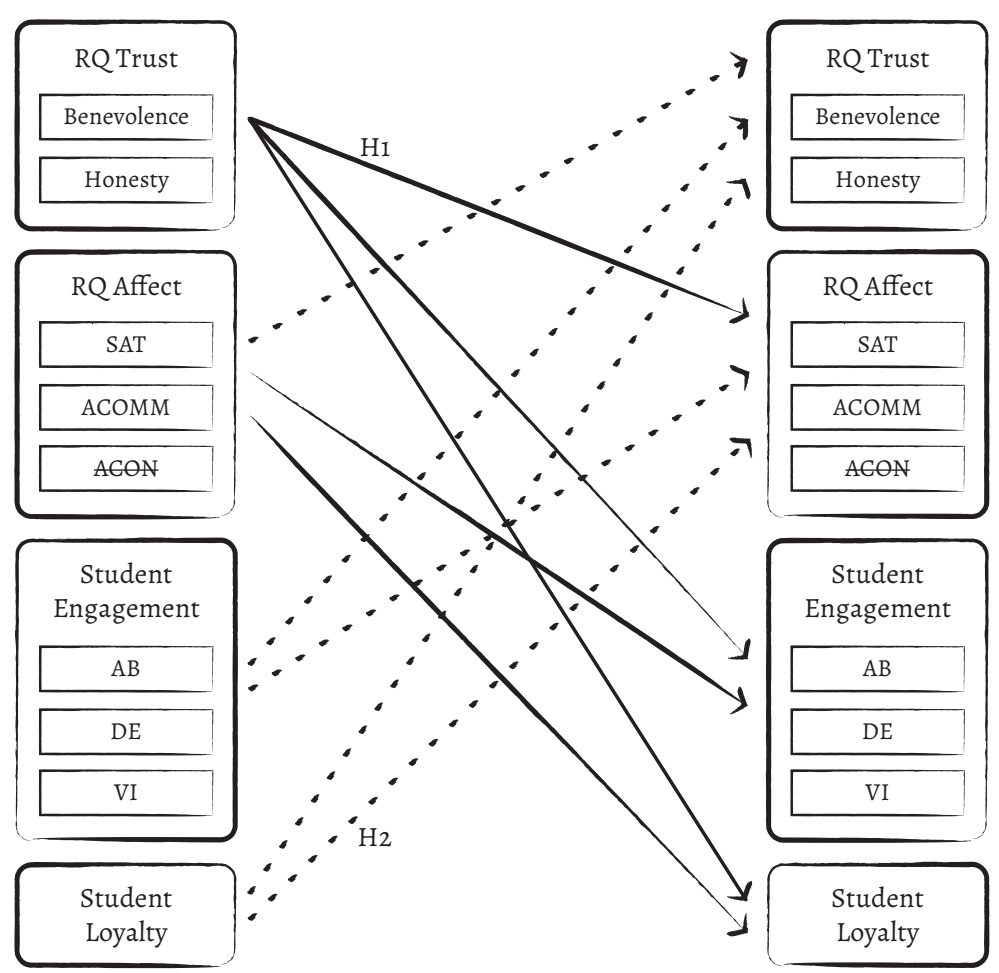

Note. The model reflects the relations between the relationship quality factors of trust $(\mathrm{T} 1)$ and affect ( $\mathrm{T} 2$ : Hypothesis 1) and the relations between trust and affect ( $(\mathrm{T} 1)$ and student engagement and student loyalty ( $\mathrm{T} 2$; Hypothesis 2). Solid lines represent stronger cross-lagged paths than the dashed line paths. The model is a simplification of the total model analyzed; all possible relations between $\mathrm{T} 1$ and $\mathrm{T} 2$ were examined, including correlations and residuals; however, for reasons of clarity, they were not all shown in the model. $R Q=$ Relationship Quality, SAT = Satisfaction, $A C O M M=$ Affective Commitment, $A C O N=$ Affective Conflict; $A B=$ Absorption, $D E=$ Dedication, $V I=$ Vigor. ACON was initially used in the first analysis and excluded from the consecutive analyses due to measurement invariance issues. 
Chapter 6 - Relationship Quality and the Interplay with Student Engagement, and Loyalty

Figure 6.2

Crossed-Lagged Panel Model

Time 1

Time 2

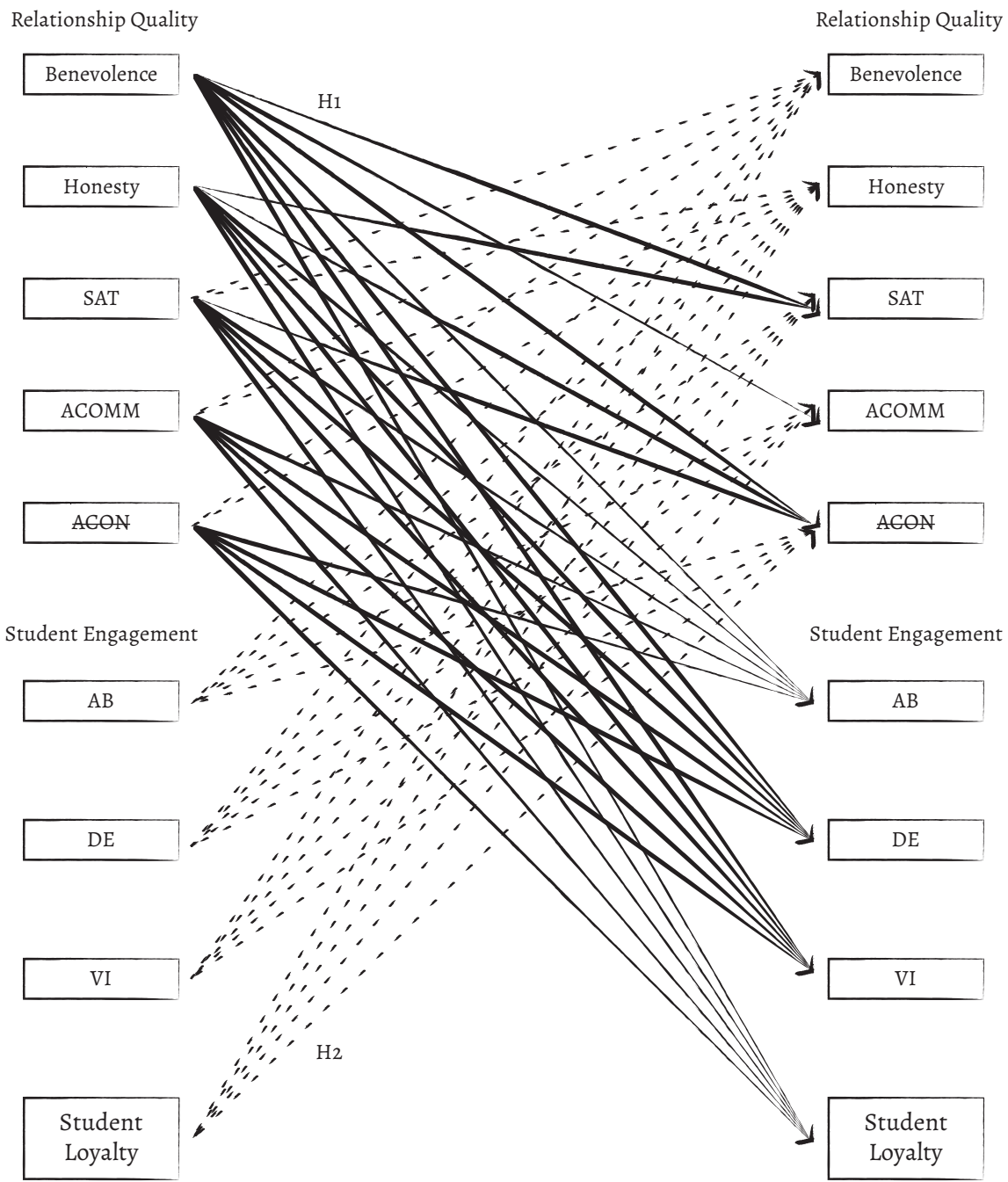

Note. The model reflects the relations between relationship quality trust/affect dimensions ( $\mathrm{T} 1$ ) and relationship quality affect/trust dimensions ( $\mathrm{T}_{2}$ ), and the relations between relationship quality dimensions ( $\mathrm{T} 1$ ) and student engagement (SE) dimensions and student loyalty (SL) (T2) (Hypothesis 2). Solid lines represent stronger cross-lagged paths than the dashed line paths. The model is a simplification of the total model analyzed; all possible relations between $\mathrm{T} 1$ and $\mathrm{T} 2$ were examined, including correlations and residuals; however, for reasons of clarity, they were not all shown in the model. SAT = Satisfaction, ACOMM = Affective Commitment, ACON = Affective Conflict; $A B=A b s o r p t i o n$, $\mathrm{DE}=$ Dedication, $\mathrm{VI}=$ Vigor. $\mathrm{ACON}$ was initially used in the first analysis and excluded from the consecutive analyses due to measurement invariance issues. 
The first research question that guided this study was: Does trust provide the basis for the relationship quality construct in higher education, that is, does trust influence affect over time? The second was: Does relationship quality at the start of the year predict student engagement and loyalty in the second semester?

Based on prior research (Hennig-Thurau et al., 2001; Snijders et al., 2019, Snijders, Wijnia, Dekker, Rikers, \& Loyens, 2020) and (interpersonal) trust literature (e.g., Castaldo, 2007; Lewicki et al., 2006), we assumed that over time, students' trust would result in (higher) satisfaction and affective commitment and less affective conflict (see Figure 6.1). Furthermore, we assumed that relationship quality aspects might positively influence students' engagement to study and their loyalty intentions when students perceive high-quality relationships with their educational faculty and staff. In sum, this study's purpose was first to examine the strength and directionality of the relations between the five relationship quality dimensions. Second, how the relationship quality dimensions are associated with student engagement and student loyalty over time was further investigated (see Figure 6.2).

In conformity with multiverse analysis (Steegen et al., 2016), we evaluated two types of cross-lagged panel models (CLPM): 1) on a higher level (i.e., latent relationship quality factors and a latent factor for engagement; see Figure 6.1), and 2) on a fine-grained level (i.e., the manifest constructs, see Figure 6.2). The following hypotheses were tested in these models:

H1: The relationship quality dimensions of trust in benevolence and honesty (Trust) at Time 1 have stronger relations with the relationship quality dimensions of affective commitment, satisfaction, and affective conflict (Affect) at Time 2 than the reciprocal lagged relations (i.e., the relations between Affect at Time 1 and Trust at Time 2).

H2: Relationship quality (i.e., trust in benevolence, trust in honesty, affective commitment, satisfaction, and affective conflict) at Time 1 has a stronger relation with student engagement and student loyalty at Time 2 than the reciprocal lagged relations (i.e., the relations between student engagement and student loyalty at Time 1 and relationship quality dimensions at Time 2). 


\section{Method}

\section{Participants and Procedure}

Participants were higher education students who were enrolled in a variety of programs in the field of economics, social work, and technology (T1: $N=1031, M_{\text {age }}=22.73$ years, $S D=6.39 ; \mathrm{T} 2: N=876, M_{\text {age }}=22.42$ years, $S D=5.59$ ). The total sample consisted of 1649 students' responses collected at three universities of applied sciences located in the southwest part of the Netherlands (Institution $1=1203$; Institution $2=291$; Institution $3=155$ ). In two consecutive years, the same survey was sent out to enrolled students twice per academic year, during the first (in the fall) and second (in the spring) semesters. Descriptive statistics regarding participants' gender and study year are included in Appendix F (see Supplemental materials, Table S6.1).

Completing the online survey took approximately fifteen minutes. Students were given a two-month period to respond. A reminder was sent after a two- to four-week period. From the total sample $(N=1649)$, 271 students filled out the questionnaire four times (both times in each academic year). When students participated in both academic years, we only included the data from one academic year, based on the number of measures filled out. For example, if only one measurement was filled out in year 1, but two in year 2 , the responses for year 2 were selected.

At each administration, participants were told that there were no (in)correct answers to the items, as long as the answers reflected their personal opinions. Participants were asked for informed consent, and only participants who gave their permission to use their responses for research were included in this study and were treated anonymously. The institutions provided ethical approval for the organization of the study.

\section{Measures}

A survey instrument using existing scales was distributed to measure relationship quality, student engagement, and student loyalty. All survey items are included in Appendix F (for construct definitions, items, and Cronbach's alpha coefficients see Table S6.2, Appendix F, Supplemental materials).

\section{Relationship Quality}

An existing relationship quality scale was used to measure relationship quality (Snijders et al., 2018, adapted from Roberts et al., 2003). Five relationship quality dimensions were used to measure the relationship quality construct in higher education by using a 15-item questionnaire. Students had to indicate on a 7-point Likert scale how much they agreed with the provided statements, ranging from 1 (strongly disagree) to 7 (strongly agree). 
In the current study, the Cronbach alpha coefficients reported for trust in benevolence $(.88, .85)$, trust in honesty $(.83, .80)$, satisfaction $(.94, .93)$, affective commitment $(.87$, $.83)$, and affective conflict $(.90, .89)$ showed good internal consistencies at Times 1 and 2 , respectively.

\section{Student Engagement}

Student engagement was measured with nine items from the Utrecht Work Engagement Scale-Student version (UWES-S-short version; Schaufeli \& Bakker, 2003). Items were rated on a 7-point Likert scale, ranging from 1 (almost never/a few times a year or less) to 7 (always/every day). Student engagement was divided into the subdimensions of absorption, dedication, and vigor. In the current study, cronbach's alphas also showed good internal consistencies (absorption .79, .79; dedication .85, .82, and vigor .80, .82) at Times 1 and 2, respectively.

\section{Student Loyalty}

Student loyalty was measured by an existing scale using five items from Hennig-Thurau et al. (2001). On a 7-point Likert scale, items had to be rated from I (strongly disagree) to 7 (strongly agree). In the current study, Cronbach's alphas showed good reliability: .86 at Time 1 and .87 at Time 2 .

\section{Additional Questions}

An open-ended question was included to allow students to express their thoughts about the questionnaire. Students were also asked some general questions related to their age, gender, ethnicity, study year, and educational program/major.

\section{Analyses}

First, we tested whether the missing data in our sample were missing completely at random using Little's MCAR test (see Little, 1988). Based on this test, $\chi^{2}(10)=10.326$, $p=.412$, we concluded that the missing values pattern did not depend on the data values; that is, the complete-cases data were a random subset. Therefore, we used complete-cases data.

Second, the data were investigated by evaluating two cross-lagged panel models (CLPM). Since we had only two time points, using a random intercept cross-lagged panel model analysis was impossible (Hamaker et al., 2015). In Model 1, we considered relationship quality as a higher-order construct consisting of two latent factors. Furthermore, a latent factor for engagement was included, for which the sum scores of vigor, dedication, and absorption were used as indicators. Finally, student loyalty was incorporated as a manifest variable. Both hypotheses were tested in this model. To evaluate Hypothesis 1 , we examined the strength of the relations between the relationship quality dimensions. We investigated 
the the ordering of the paths between trust at Time 1 and the "resulting" affective relationship quality dimensions of commitment, conflict, and satisfaction at Time 2 . The primary latent factor is trust, for which trust in honesty and trust in benevolence are used as indicators. The second latent factor is affect, which consists of the relationship quality dimensions of satisfaction, affective commitment, and (lack of) affective conflict. To test Hypothesis 2, we investigated whether the paths from trust and affect (Time 1) to engagement and loyalty (Time 2) were stronger than from engagement and loyalty (Time 1) to trust and affect (Time 2).

Model 2 included the five manifest constructs of relationship quality, the three student engagement manifest constructs, and student loyalty. To evaluate Hypothesis 1, we tested whether the combined paths from trust in honesty and benevolence (Time 1) to affective commitment, affective conflict, and satisfaction (Time 2) were stronger than the combined paths from the affective constructs (Time 1) to trust in honesty and benevolence (Time 2). To examine Hypothesis 2, we examined whether the sequence in which the combined paths from the relationship quality constructs (Time 1) go to engagement and loyalty (Time 2) was more likely than the other way around, in which engagement and loyalty (Time 1) lead to the relationship quality constructs (Time 2).

This study's analysis was conducted using the lavaan package for structural equation modeling in $\mathrm{R}$ ( $\mathrm{R}$ Core Team, 2012), in line with previous research in the field of educational psychology that examined cross-lagged relations (e.g., Burns et al., 2020; Košir \& Tement, 2014; Morinaj \& Hascher, 2019; Nicholson \& Putwain, 2019; Sánchez-Álvarez et al., 2019). The R code for the CLPM analyses, including the two types of evaluation of the hypotheses using the GORICA function, and supplemental materials, can be downloaded from https://github.com/ rebeccakuiper/GORICA_in_CLPM

The specifically hypothesized orderings of cross-lagged parameters cannot be tested with straightforwardly hypothesis testing. However, they can easily be evaluated with (orderconstrained) model selection. We used GORICA weights (Altinisik et al., 2018; Kuiper, 2020; Kuiper et al., 2011), an Akaike Information Criterion (AIC; Akaike, 1978) type of criterion, which can evaluate order-restricted, theory-based hypotheses as in the current study. We evaluated each of our hypotheses against its complement, representing all possible orderings (i.e., all other possible hypotheses; Vanbrabant et al., 2020). The resulting GORICA weights quantify the support for the hypotheses and their complements (cf. Akaike, 1978; Burnham \& Anderson, 2002; Wagenmakers \& Farrell, 2004). To calculate these GORICA weights, we used the goric function (Vanbrabant \& Kuiper, 2020) of the restriktor R package (Vanbrabant \& Rosseel, 2020). 


\section{Results}

\section{Descriptive Statistics}

In Table 6.1, sample size, means, and standard deviations of the constructs at Time 1 and Time 2 are shown.

\section{CLPM with Latent Factors for Trust and Affect}

Before we evaluated the hypotheses, we first checked for measurement invariance to examine whether the same constructs were measured over both time points (i.e., that the constructs have the same meaning across measurement occasions, see Putnick \& Bornstein, 2016). To that end, a model without constraints was compared with a model where the factor loadings were constrained (i.e., weak measurement invariance) using the $\chi^{2}$ difference test (see Table 6.2). First, we evaluated both hypotheses in a model where the latent relationship quality constructs for trust and affect were included (i.e., Model 1a). Because the $\chi^{2}$ difference test was statistically significant, we could not assume weak measurement invariance, although it has been argued that the criteria for testing measurement invariance may be too strict (Muthén \& Asparaouhov, 2013). Based on the comparisons of standardized factor loadings at Time 1 and Time 2, affective conflict measures differed over time (see also Appendix F, Supplemental materials).

Table 6.1

Sample Size (n), Means, and Standard Deviations (SD) of Constructs

\begin{tabular}{|c|c|c|c|c|c|c|}
\hline & \multicolumn{3}{|c|}{$\begin{array}{c}\text { Time I } \\
N^{\mathrm{a}}=1031\end{array}$} & \multicolumn{3}{|c|}{$\begin{array}{l}\text { Time 2 } \\
N=876\end{array}$} \\
\hline & $n$ & Mean ${ }^{\mathrm{b}}$ & $S D$ & $n$ & Mean & $S D$ \\
\hline \multicolumn{7}{|c|}{ Relationship Quality dimensions } \\
\hline Trust in Benevolence & 1024 & 15.62 & 3.76 & 864 & 14.97 & 3.76 \\
\hline Trust in Honesty & 1024 & 15.79 & 3.24 & 864 & 15.09 & 3.27 \\
\hline Satisfaction & 1024 & 14.70 & 3.85 & 864 & 14.33 & 3.92 \\
\hline Affective Commitment & 1024 & 14.96 & 4.07 & 864 & 14.41 & 3.94 \\
\hline Affective Conflict & 998 & 14.37 & 4.34 & 864 & 15.06 & 4.14 \\
\hline \multicolumn{7}{|c|}{ Student Engagement dimensions } \\
\hline Absorption & 998 & 12.96 & 3.78 & 798 & 12.41 & 3.81 \\
\hline Dedication & 998 & 16.00 & 3.57 & 798 & 15.51 & 3.47 \\
\hline Vigor & 998 & 12.86 & 3.62 & 798 & 12.32 & 3.59 \\
\hline Student Loyalty & 998 & 26.01 & 6.41 & 798 & 25.36 & 6.63 \\
\hline
\end{tabular}

Note. ${ }^{\text {a }}$ The number of students who started the survey; however, sometimes, students did not fill out the questionnaire completely. Therefore, the total numbers might not add up. ${ }^{\mathrm{b}}$ The mean is based on the sum scores of items (Relationship quality dimensions: 3-21; Student engagement dimensions: 3-21; Student loyalty 5-35). 
Table 6.2

Measurement Invariance

\begin{tabular}{llll}
\hline Model 1a (with affective conflict) & $\chi^{2}$ & $d f$ & $p \Delta \chi^{2}$ \\
\hline Unconstrained model & 885.53 & 114 & - \\
Weak factorial invariance (i.e., factor loadings constrained) & 865.45 & 109 & .001 \\
\hline Model 1b (without affective conflict) & & & \\
\hline Unconstrained model & 715.87 & 78 & - \\
Weak factorial invariance (i.e., factor loadings constrained) & 721.02 & 82 & .272 \\
Strong factorial invariance (i.e., factor loadings and intercepts constrained) & 725.49 & 84 & .107 \\
\hline
\end{tabular}

Therefore, we tested a new model in which affective conflict was excluded (i.e., Model ib). When affective conflict was removed from the analyses, we could assume strong measurement invariance since the $\chi^{2}$ difference test was not statistically significant (see Table 6.2), indicating that the same constructs were measured over time.

In Model $\mathrm{Ib}$, both hypotheses were evaluated. Results indicated that order-restricted Hypothesis 1 had 1.7 times more support than its complement. This means that there is support for the hypothesis that the relation between trust at Time 1 and affect at Time 2 is stronger than the reverse ordering. Furthermore, order-restricted Hypothesis 2 had 1.4 times more support than its complement. In other words, there is some support that the relation between relationship quality at Time 1 with student engagement and loyalty at Time 2 is stronger than the reverse ordering.

\section{CLPM with Manifest Variables}

Subsequently, we tested a model in which we examined all five dimensions of relationship quality and the three dimensions of engagement and student loyalty separately. All variables were included as manifest variables. Because our previous analyses indicated that we could not assume measurement (i.e., factorial) invariance for affective conflict over time, we estimated a model with affective conflict (i.e., Model 2a) and without affective conflict (i.e., Model 2b). Results for Model za revealed that, as hypothesized, the results showed that order-restricted Hypothesis 1 had 4.1 times more support than its complement. This result indicates that cross-lagged relations from trust in benevolence and trust in honesty at Time 1 to affective commitment, affective conflict, and satisfaction at Time 2 are more likely than the reverse ordering. Furthermore, cross-lagged relations from relationship quality at Time 1 to student engagement and student loyalty at Time 2 also supported our hypotheses. The results showed that order-restricted Hypothesis 2 had 148.3 times more support than its complement. 
Evaluation of the model without affective conflict (Model $2 b$ ), albeit the results were less strong, still confirmed the hypotheses, that is, order-restricted Hypothesis 1 had 2.6 times more support than its complement; order-restricted Hypothesis 2 had 14.0 times more support than its complement.

\section{Discussion}

Within the present study, we were interested in the theoretical underpinnings for the strength (directionality) of the relations between the relationship quality factors of trust and affect and of the associations between relationship quality, student engagement, and loyalty. This study used a relational approach by applying a newly developed relationship quality scale for higher education The focus was on students' perceptions of the quality of their relationships with all contact persons from their educational institution (e.g., teachers, professors, mentors, exam committee, librarians, and other faculty/staff members). Students' perceptions were examined to illuminate the associations of relationship quality dimensions in higher education over time, and with its outcomes (i.e., engagement with studies and loyalty intentions).

\section{Relationship Quality Over Time}

The relationship quality factors of trust and affect were tested at a higher level (i.e., latent factors for trust and affect) and a more fine-grained level (i.e., all relationship quality constructs separately). Both types of analyses confirmed that trust seems to be a precursor for affect; trust in benevolence and honesty at Time 1 have a stronger relation with affective commitment, satisfaction, and affective conflict at Time 2 than the reverse ordering. Our study's findings indicate that educational practitioners should focus on the way students perceive trust in faculty/staff. The current research adds value to the body of knowledge on interpersonal relationships in education.

A psychological approach to trust development (Lewicki et al., 2006) mentioned the existence of a trust-distrust continuum. Our study's findings indicate that educational practitioners should focus on the way students perceive trust in faculty/staff and their higher education institution and that they should take regard of the relational phase students are in (i.e., relationship intensity, see Castaldo, 2007).

When evaluating a second model leaving out affective conflict, the findings indicated that the path from trust to affect (i.e., satisfaction and affective commitment) is stronger than the reverse. Within this study, students responded differently over time to how they interpreted affective conflict, as evidenced by the test of factorial invariance, perhaps 
due to the multiple encounters within a student's experience. First-year students may understand the meaning of conflict differently from the conflict they later experience within that year (e.g., from unclear feedback on assignments or slow responsiveness to questions versus from negative binding study advice). Similarly, seniors also might interpret the meaning of conflict differently at the beginning of the year than near the end of the year, (e.g., from adequate guidance versus from feedback on graduation research). For students, the consequences of affective conflict seem to be bigger near the end of the year (e.g., difficulties surrounding internships, graduation research, negative binding study advice). Hence, our findings indicate that the meaning of affective conflict may change over time.

\section{Relationship Quality, Student Engagement, and Loyalty}

The second hypothesis focused on the strength of relations between relationship quality, student engagement, and student loyalty. Our results confirmed $\mathrm{H} 2$, which implied that relationship quality at Time 1 had a stronger association with student engagement and student loyalty at Time 2 than the reverse ordering. This study's findings contribute to the theoretical implications of student relationships in higher education (e.g., Hagenaur \& Volet, 2014), which covering a broad array of positive student outcomes such as motivational outcomes (Gehlbach et al., 2012). The present study's findings add to that body of knowledge, indicating that relationship quality is essential for student engagement and loyalty. Hence, building positive relationships with students through relationship quality might positively influence students' involvement. Following Castaldo's (2007) ideas of phases of relationship building, this study implies that relationship quality might eventually lead to loyalty during the relationship between students and faculty/staff. These findings are in line with previous studies (e.g., Hennig-Thurau et al., 2001). Student loyalty is essential for higher education institutions in several ways, for instance, positive word-of-mouth such as students' recommendations to others (Farrow \& Yuan, 2011).

\section{Limitations and Future Directions}

Although this study adds value to the existing literature in higher education, several limitations need to be mentioned. First, the data were based on self-reported student responses. Although surveys are an acceptable way to collect data on students' perceptions and attitudes, including responses from other actors, teachers or mentors might help get a more objective view (e.g., Demetriou et al., 2015). Therefore, it would be interesting to replicate the study and also include teachers' perceptions and compare them with students' perceptions (see, for example, Koomen \& Jellesma, 2015, who investigated both students' and teachers' perspectives in an elementary school setting). 
Second, the sample used was based on students from three Dutch higher education institutions. Students were relatively evenly distributed concerning age, gender, and different educational programs of study. However, we recommend investigating students from several institutions from other countries so that the intercultural interpretations of the constructs under study can be further examined (e.g., the relevance of intercultural competency through social exchange theory in a higher education setting; Pillay \& James, 2015).

Next, the relationship quality construct was measured with the same items per relationship quality dimension per measurement point; however, weak measurement invariance could not be assumed for affective conflict. This means that students evaluated the affective conflict items in a different way over time. A possible explanation might be that students in the second semester have had more positive or negative experiences and can better interpret what conflict means for them (i.e., irritations, frustration, and anger). Possibly, the more negative emotions (i.e., high levels of anxiety) students perceive in the relationships they have with their educational faculty and staff, the less students trust in faculty and staffs' integrity, reliability, and helpfulness (see also control-value theory; Artino \& Pekrun, 2014). Future work may focus on how conflict develops over time, for example, what defining moments students indicate as conflicts and why they are critical incidents in students' academic lives (Snijders, Wijnia, Dekker, Rikers, \& Loyens, 2020). Conflict within a student-teacher relationship might be due to the perception of reciprocal discontentment, disapproval, and unpredictability (Marengo et al., 2018).

Finally, collecting data from multiple time points over a closer interval could be used to apply a random-intercept cross-lagged panel analysis (Hamaker et al., 2015; e.g., Košir \& Tement, 2014). Please also note that the relationships that were found only apply to the time intervals used in this study. When using a shorter time interval, the associations between variables would probably have been stronger, which is interesting to examine in future research. Furthermore, when investigating the development of loyalty, it would also be important to look over time periods such as from year to year and from student to alumn.

\section{Conclusion}

This study was a first attempt to explore the ordering of the relationship quality dimensions of trust (i.e., trust in honesty and trust in benevolence) and affect (i.e., affective commitment, satisfaction and, affective conflict). Second, we investigated the ordering between relationship quality, student engagement, and student loyalty. To that end, we used data from two time points. 
Chapter 6 - Relationship Quality and the Interplay with Student Engagement, and Loyalty

This research adds to the existing body of knowledge that students' trust in the quality of their relationships with faculty/staff in higher education is essential for the development of commitment and satisfaction, and avoidance of conflict. Second, relationship quality factors positively influence students' engagement with their studies and their loyalty. Therefore, we recommend that higher education institutions apply a relational approach that considers students' relationship quality evaluations in more depth. We examined the hypotheses by evaluating simultaneous comparisons between estimates. The findings supported our hypotheses; however, further research is needed to theoretically capture the role of relationship quality in higher education more firmly. Moreover, we recommend investigating further the consequences for students' involvement and reciprocal effects using short-term longitudinal data. 


\section{6}




\section{करत्र}

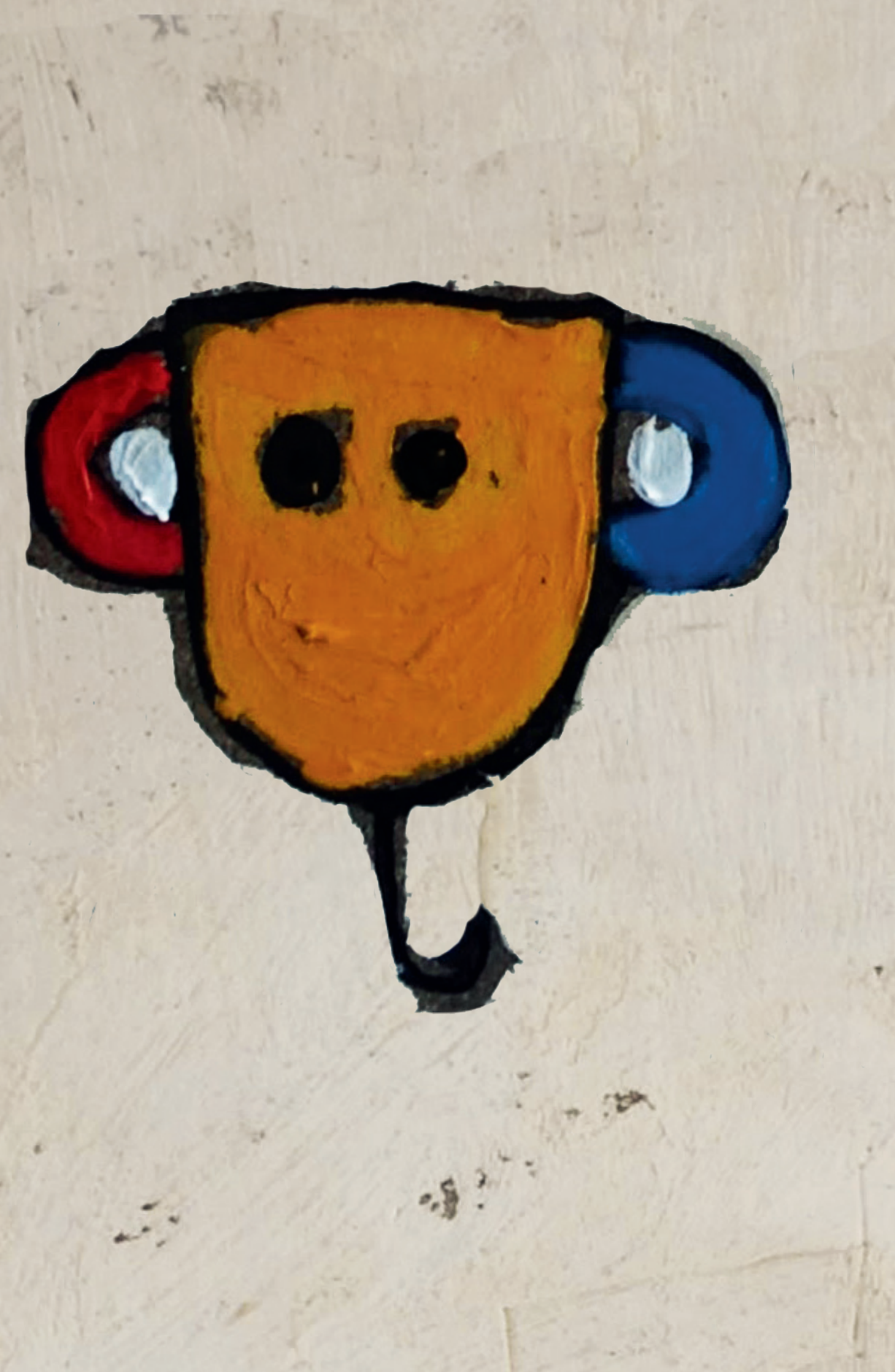

s) 

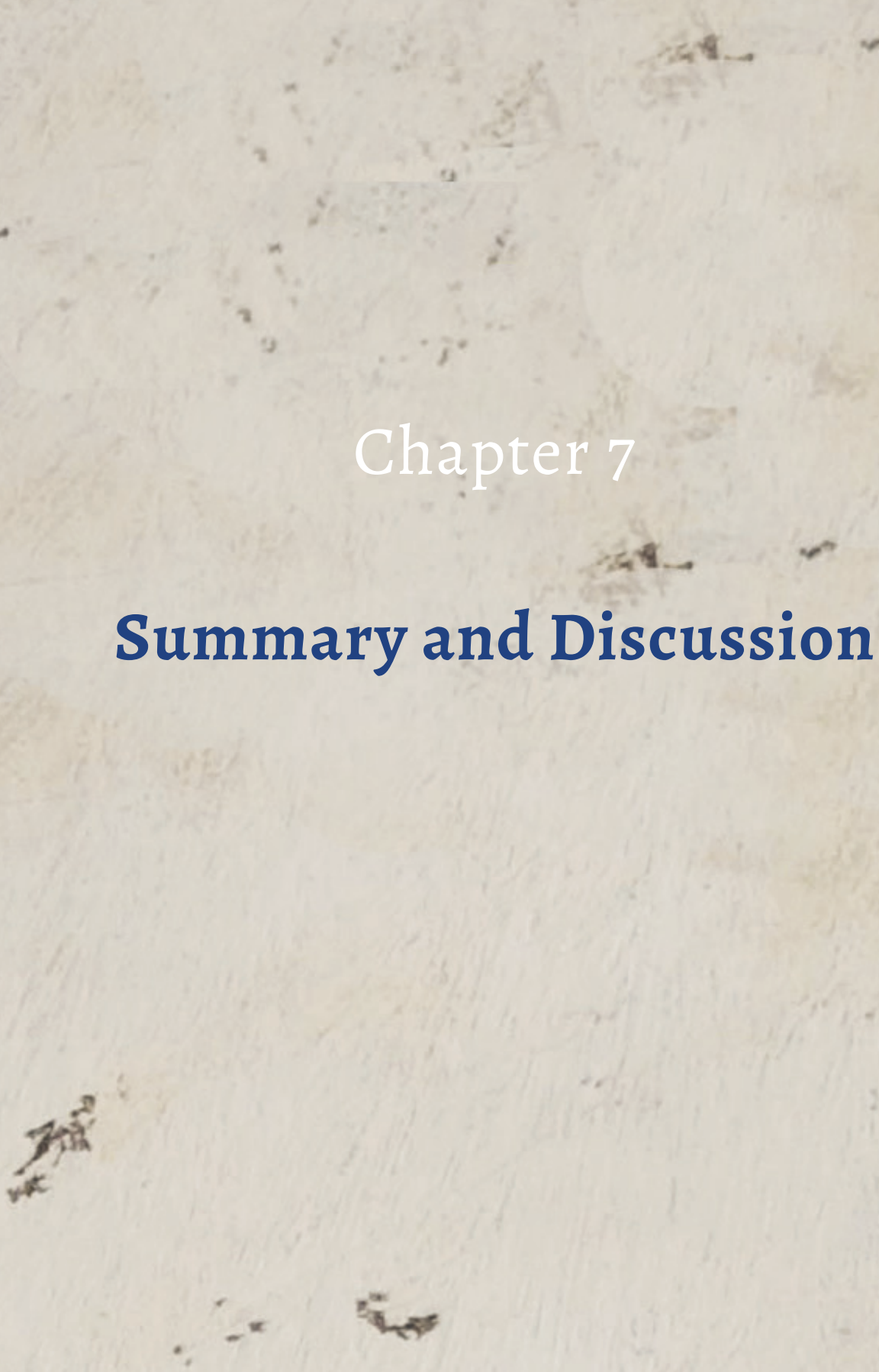
The changes that have taken place in higher education in the last decade, such as outputbased funding, global competition, and the marketization of higher education, call for a re-focus on the establishment of bonds between students and their educational institution. Previous studies have emphasized that teacher-student relationships should be a focal point in the educational process (e.g., Wubbels \& Brekelmans, 2005). Still, research in educational psychology is mostly limited to student-teacher relationships. Students have multiple and ongoing interactions with many different people from their university, contributing to their educational experience. Besides their teachers, students also have contact with other faculty or staff working at their university, for instance, the study counselors or advisors for their program of study, student psychologists, members of an exam board, janitors, librarians, and receptionists.

Furthermore, educational researchers investigating student relationships have mainly focused on primary or secondary education (e.g., Roorda et al., 2011, 2017). Although their research findings are important for gaining insight into educational processes, the instruments used in these studies are not always applicable in all educational settings. More specifically, higher education differs from other educational contexts regarding students' involvement and participation (Leenknecht et al., 2020). In primary and secondary education, the student-teacher relationship exists between a child and an adult; in higher education, the relationships are formed between adults (Hagenauer \& Volet, 2014). The attention paid to student-faculty relationships in primary and secondary education (e.g., Roorda et al., 2011, 2017) did not answer the question of how to establish and maintain positive relationships between students and their educational faculty/staff in higher education.

Building and maintaining (long-lasting) relationships with stakeholders are the cornerstones of relationship management. Underlining previous research on the use of relationship and services management in higher education (Ng \& Forbes, 2009), these ideas are now more often applied in the higher education context (e.g., T. Gibbs \& Kharouf, 2020; Yousaf et al., 2020). In these studies, education is treated as a service. Drawing from social exchange theory (e.g., Homans, 1961), educational service in higher education is based on the exchange between students and their educational institution. When a service consists of high-involvement interactions (Bloemer \& De Ruyter, 1999) as educational service in higher education does, it is important to focus on how higher education students, as the primary stakeholders (Bunce et al., 2017), perceive the educational service. The outcomes of the educational learning process depend on how students perceive the educational exchange. The gap model by Parasuraman et al. (1991) is often used to investigate possible quality gaps between stakeholders' expectations and perceptions, and the gap with organizations in services research (Zeithaml et al., 2009). The first steps in the "gap analysis" is to ask the main stakeholders for their quality expectations and perceptions. Therefore, the customers/ 
recipients of the service, in this case, students, play a central role. These ideas formed the starting point for our research.

In this thesis, we examined how students perceive the quality of their relationships with their educational faculty/staff, that is, relationship quality. As indicated by Osobajo and Moore (2017), definitions of relationship quality vary, which is mainly caused by the specific context under study. Osobajo and Moore provided a general description of relationship quality: "how healthy a relationship is based on the evaluation or assessment of the parties within that relationship" (Osobajo \& Moore, 2017, p. 4). The relationship quality instrument used in this thesis was a new approach in the educational literature measuring the quality of relationships between students and their educational faculty and staff. The construct was taken to consist of five relationship quality dimensions based on relationship management research (Roberts et al., 2003). We adapted the instrument to fit the context of higher education. It included trust in benevolence, which refers to the extent to which students believe faculty/staff are concerned about their welfare, have intentions and motives beneficial to them, and avoid acting in a way that will result in negative outcomes for students. We also included trust in honesty, which represents the trust students have in a university's credibility as represented by faculty/ staff, and affective commitment, which refers to students' willingness to belong or be connected to their university (i.e., their faculty/staff). Satisfaction was also included, referring to cumulative student satisfaction with the overall quality of the studentfaculty relationships, representing students' cognitive and affective evaluations based on their personal experiences across all educational service encounters. Finally, we included affective conflict, which can be seen as a negative indicator of relationship quality (Roberts et al., 2003). The affective conflict that students perceive, evident in such reactions as irritation, frustration, and anger, will lower the levels of perceived relationship quality.

To create an in-depth understanding of how students perceived the overall quality of their relationships with their university, we asked students to respond to questions in which we referred to the quality of relationships with all educational faculty/staff, thus including all members of the educational faculty and staff. If positive, these relationships could be beneficial for higher education institutions in terms of students' involvement, both during and after graduation.

\section{Overview of the Main Findings}

In Study 1, described in Chapter 2, our research question was: What is relationship quality in higher education, and how can we measure it? The focus was on the measurement of 
relationship quality in higher education using students' survey responses. A deductive approach was taken, using a relationship quality instrument based on services and relationship management research (Roberts et al., 2003). The aim was to contribute to improved understanding of the concept of relationship quality in higher education. The relationship quality instrument focused on students' perceptions of their overall relationships with educational faculty/staff. With this focus, we first explored the applicability of a relationship quality scale in higher education, using quantitative along with qualitative data. The relationship quality scale was used to determine whether the same underlying relationship quality components also held in the higher education context.

Five relationship quality dimensions were examined from a student's point of view regarding the quality of their relationship with their educational faculty and staff: students' trust in honesty and benevolence, their overall satisfaction, their affective commitment, and affective conflict. An online survey was sent out to the enrolled students from one Dutch university of applied sciences. In addition, a small-scale focus group discussion was used to investigate the concept and dimensions of relationship quality further. A good fit for the five-dimensional model of relationship quality in higher education was confirmed. Moreover, along with the relationship quality scale, the focus group discussion with students provided practical examples of how students perceived relationship quality.

Study 2, described in Chapter 3, presented qualitative research to get a deeper understanding of higher education students' dimensions of relationship quality. The study was based on 513 real-life descriptions of students' perceptions. The aim was to examine relationship quality in higher education and provide insights for educational faculty/ staff who want to develop and focus their policy based on students' relationship quality. Social exchange theory (SET) was used as an overarching framework (Blau, 1964; Emerson, 1976). SET helps to clarify how social interactions result in relationships and why these relationships are (dis)continued. The framework can be applied in various environments between two parties (e.g., romantic/friendly relationships between partners, professional relationships between a recipient and a provider, or between an employee and employer). Related ideas from the services and relationship management field, combined with educational literature, were used for development of measurement instruments and analyses. The critical incident technique (CIT) is a frequently used approach in services management research to examine recipients' perceptions of service more deeply. In Study 2, we used CIT to gather qualitative data consisting of positive and negative experiences based on students' online responses. Template analysis was applied to students' selfreported relational experiences with their educational faculty and staff. The five a priori 
relationship quality dimensions used for the template corresponded with those in the first study: students' trust in honesty and benevolence, overall satisfaction, affective commitment, and affective conflict (as a negative indicator of relationship quality).

Although all students from the institution under study similar to our first study, were invited to take the online survey, mainly first-year students responded. More negative $(n=395)$ than positive $(n=294)$ incidents were described by students, supporting recent research (e.g., Clem et al., 2020). We expected students' negative incidents would be reported as affective conflict. However, in this study students mainly referred to lack of trust in honesty and benevolence. For example, one student response addressed that there was "no common approach" among teachers/lecturers in guidance and to facilitate students. In general, having to wait for a response was perceived negatively. Interestingly, students in their last years before graduation indicated "prompt feedback" and "to be able to rely on honest and benevolent (re)actions" as important.

In Study 3 (Chapter 4), we used cross-sectional data to predict relationship quality and relationship quality outcomes among enrolled students from a Dutch university of applied sciences, and in Study 4 (Chapter 5) among alumni from the same institution. The methodological choices for the analysis were based on services and relationship management research. Specifically, partial least squares-structural equation modeling (PLS-SEM) analysis was used for predicting and exploring the constructs under study (Studies $3 \& 4$, Chapters 4 and 5).

In Study 3 (Chapter 4), our research question was: What influence does relationship quality have on student engagement, and (in turn), on student loyalty? We investigated students' perceptions of the quality of their relationships with their educational faculty/ staff and its associations with student engagement and student loyalty among enrolled students. The aim was to gain insights into whether relationship quality affected student engagement and loyalty. The hypothesized model investigating the associations between relationship quality, student engagement, and student loyalty explained $31 \%$ of the variance in the student engagement dimension of absorption, $45 \%$ in the student engagement dimension of dedication, $37 \%$ in the student engagement dimension of vigor, and $55 \%$ in student loyalty.

Similarly, in Study 4 (Chapter 5), we dealt with a similar research question, however, now focusing on alumni: What influence do alumni's perceptions of their relationship quality have on their former engagement, and (in turn) on their current loyalty. The aim was to explore whether relationship quality dimensions (in)directly predict student engagement and (in turn) non-monetary alumni loyalty. 
For enrolled students (Study 3, Chapter 4), statistically significant associations were found between trust in honesty and dedication, between affective conflict and absorption and vigor, and between affective commitment and all three student engagement dimensions. In contrast, for alumni (Study 4, Chapter 5), statistically significant associations were found between trust in honesty and absorption and vigor, between trust in benevolence and all three student engagement dimensions, between affective commitment and all three student engagement dimensions, and between satisfaction and vigor. In both models, a statistically significant association was found for affective commitment and loyalty. The variance in the model within our study explained respectively $53 \%$ and $55 \%$ in student/alumni loyalty, which also resembles recent studies' findings on higher education student loyalty (e.g., Doña Toledo \& Martínez, 2020).

Study 4 indicated that alumni perceptions of former relationship quality had a stronger positive (and statistically significant) association with their current loyalty than it had with their perceptions of their former student engagement. Former trust in benevolence and affective commitment as relationship quality dimensions were positively associated with former student engagement. Contrary to our hypotheses, trust in honesty had a negative association with absorption and vigor. No statistically significant associations were found between the relationship quality dimension of trust in honesty and dedication or alumni loyalty.

To overcome the limitations of correlational research (e.g., the cross-sectional designs of Studies 3 and 4), Study 5, described in Chapter 6, used longitudinal data from two time points. Based on the literature on interpersonal relationships and services and relationship management research, the relationship quality construct of trust was examined. In combination with educational literature, services and relationship management research served as the basis for investigating the development of relationship quality dimensions and their influence on the sequence of relationship quality outcomes, which are student engagement and student loyalty (Study 5, Chapter 6). The research questions were: 1) How do relationship quality dimensions develop over time? and 2) Does relationship quality predict student engagement and loyalty? We focused on the directionality of relations between relationship quality dimensions and relations between relationship quality, student engagement, and loyalty, based on students' responses from two time points.

Study 5 (Chapter 6) was a first attempt to explore the ordering between relationship quality dimensions, and, between relationship quality, student engagement, and student loyalty. In line with the trust literature (e.g., Castaldo, 2007), confirmation was found that trust as a relationship quality dimension has a stronger relation with the affective relationship quality dimensions of commitment, satisfaction, and conflict than the 
reverse ordering. Second, our hypothesis was confirmed that relationship quality had a stronger relation with student engagement and student loyalty than the reverse ordering.

\section{General Discussion}

The main research questions set out in the Introduction were: What are students' perceptions of relationship quality in higher education, and how does relationship quality influence students' involvement in time? Within the studies presented in this thesis, we empirically examined relationship quality as a multidimensional construct. The instrument was based on an existing scale previously applied to consumer services by Roberts et al. (2003). Students, as primary recipients of the educational service, in conformity with services management research, were asked for their perceptions. To examine relationship quality, we used quantitative and qualitative data collection methods and analyses (Studies 1 and 2, described in Chapters 2 and 3). Second, relationship quality outcomes were investigated in terms of student engagement and student/alumni loyalty (Studies 3, 4, and 5, described in Chapters 4, 5, and 6).

The studies presented (see Figure 7.1) were based on SET as an overarching framework. Related services and relationship management ideas were used in combination with ideas from the educational literature.

\section{Relationship Quality}

The framework for the formation of bonds in higher education (see Figure 1.1) was used as a starting point of this thesis. The thesis' studies are in line with other recent studies (Dollinger \& Lodge, 2020; Matthews et al., 2018) that have focused on fostering high quality student-faculty/staff relationships. The instrument that we developed to study relationship quality in higher education adds value to the conceptualization of relationship quality in higher education. To our knowledge, the studies presented in this thesis are the first to investigate relationship quality as a multidimensional construct and explore the prediction of relationship quality outcomes in higher education (i.e., student engagement and student loyalty). In this way, we contributed to the limited research that has so far been conducted on relationship quality in higher education (e.g., HennigThurau et al., 2001). In general, with our research findings, we also added value to the existing (educational and psychological) literature on interpersonal relationships and relationship management in higher education. 


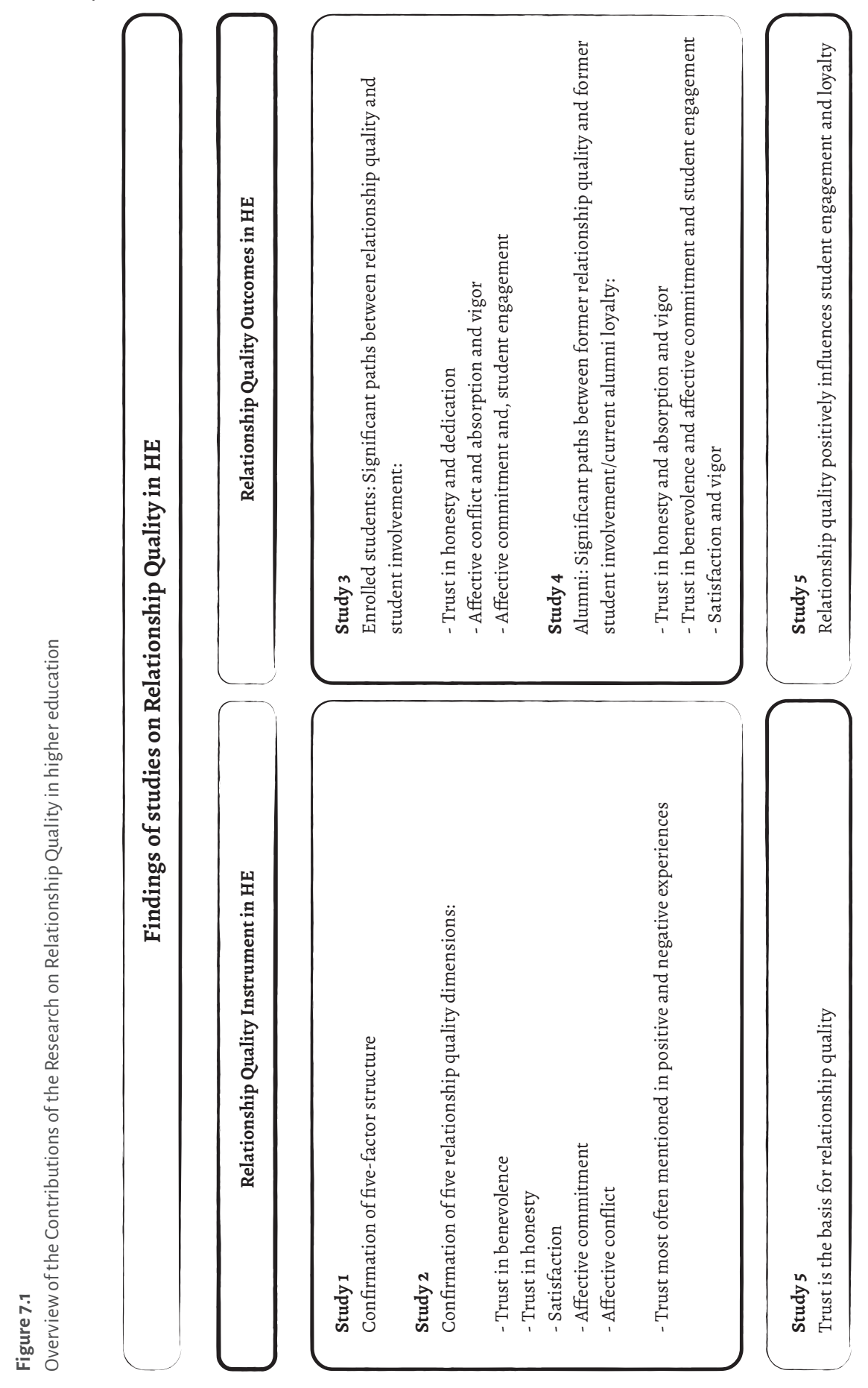


In Studies 1, 3, and 5 (Chapters 2, 4, and 6), the relationship quality instrument we used consisted of five dimensions: trust in benevolence, trust in honesty, satisfaction, affective commitment, and affective conflict. The results confirmed that relationship quality measurement can be done using the higher education relationship quality scale (HERQ scale). However, the findings of Studies 2 and 5 also showed that the five dimensions could be clustered into two main parts: trust and affect. Within educational practice, however, the relationship quality construct seems rather complicated. It depends on the relational phase a student might be in (i.e., first to fourth year, based on the frequency of experiences). Moreover, the analysis of students' positive and negative relationship quality perceptions in Study 2 (Chapter 3) indicated that the distinctions between the dimensions are not always clear. Perhaps some other relational aspects (e.g., fairness, equity, responsiveness) 'albeit linked to the relationship quality dimensions' might also play a role. Both quantitative and qualitative approaches, however, provided insights into the operationalization of relationship quality in higher education.

In Study 1, we examined the five-factor structure of relationship quality, which was confirmed. Study 2 implied that less explicit expressions of affective commitment were mentioned. Therefore, based on the number of descriptions of trust in this study, and on other research (e.g., Schlesinger et al., 2017), we hypothesized that students' trust in honesty and benevolence form the basis for relationship quality in higher education. In Study 5, we redefined the dimensions as trust (i.e., trust in honesty and trust in benevolence) and affect (affective commitment, satisfaction, and affective conflict). The dimensions of trust form the relationship quality construct's core; trust in honesty and trust in benevolence predict the affective relationship quality dimensions of commitment, conflict, and satisfaction. All studies imply that the relationship quality instrument is applicable in a higher education setting. Therefore, the HERQ scale has practical value for educational practitioners to use in a survey, in addition to course evaluations and national surveys such as the Dutch national student survey, Nationale Studenten Enquete (NSE; Studiekeuze123, 2020).

In all of the studies presented in this thesis, the relationship quality dimensions of trust in honesty and trust in benevolence were highly correlated. However, considering the relationship quality construct as multidimensional, this finding is not surprising. Moreover, some studies have not distinguished between trust in honesty and trust in benevolence (e.g., Hennig-Thurau et al., 2001). In Study 5 (Chapter 6), we investigated relationship quality using trust and affect. However, the results indicated that relationship quality measurement on a more multidimensional level gave more support for predicting engagement and loyalty. Yet, we question whether students could clearly differentiate between trust in educational faculty and staff's honesty and their benevolence. 
Based on the different statistically significant associations between the constructs under study that were seen in the models with enrolled students and alumni (Chapters 4 and 5), it seems that affective conflict might change over time. This idea was confirmed in the longitudinal sample (Study 4, described in Chapter 6). Weak measurement invariance for affective conflict was found, indicating that students might interpret affective conflict items differently during their academic years. This finding is not surprising when considering the challenges students face during their academic years; students might, in due time, develop a different attitude towards the kind of affective conflict they perceive during their studies. Students might come to feel different about irritations and frustrations that occur with their educational faculty and staff in their first and second years. For instance, students' affective conflict might be due to a lack of learning when the feedback on assignments is unclear. In the second part of their studies, students focus on developing a professional attitude and graduation. Responsiveness to grades and feedback in the final year of study is essential in order to graduate on time (see Study 2, Chapter 3). Within an academic year, students also might develop a different understanding of the affective conflict they perceive. For instance, students' irritations and frustrations at the beginning of their year of study might be related to unclear communication or the feeling of being mistreated. This might be different from how students perceive conflict at the end of the year of study when faced with, for example, dropping-out (e.g., a negative study advice) or graduation issues such as advice on studies and final examination.

\section{Effects of Relationship Quality on Students' Involvement}

\section{Student Engagement}

In services management literature, it is believed that, in general, quality leads to (consumer) engagement and, in turn, to loyalty intentions and behavior (see Zeithaml et al., 1996). Similarly, in previous educational studies, student-faculty interactions and student-teacher relationships were positively associated with students' involvement, such as their engagement. However, in this thesis, we examined relationship quality in a broader perspective, asking students about their perception of the quality of their relationships with all educational faculty and staff. Establishing a parallel with the related literature on engagement, we also measured student engagement multidimensionally (see Brodie et al., 2010 for a services management perspective; Veiga et al., 2014 for an educational, psychological perspective).

The cross-sectional data in Studies 3 and 4, described in Chapters 4 and 5, were based on responses from enrolled students and alumni. Both studies confirmed that relationship quality is positively associated with students' engagement in their studies. However, not all relationship quality dimensions had a statistically significant association with student engagement. In both models, a statistically significant positive association was 
found for relationship quality and the student engagement dimension of dedication, and, dedication and student/alumni loyalty, explaining $53 \%$ and $55 \%$ of the variance in student/ alumni loyalty, respectively.

The longitudinal data findings with two time points also revealed that relationship quality predicts student engagement (Study 5 , described in Chapter 6). Both study designs (cross-sectional and longitudinal) demonstrated the relevance of relationship quality in higher education. Study 5 confirmed that the relation between relationship quality and student engagement is stronger than the reverse temporal ordering.

In the studies in this thesis, we positioned student engagement as an outcome and as a mediating variable in the relationship between relationship quality and student loyalty. However, the findings from these studies do not convincingly imply that student engagement is a mediating variable in the relationship between relationship quality and student loyalty. This finding is in line with the systematic review by Quin (2017), where he questioned the position of student engagement.

Only the student engagement dimension of dedication was strongly related to student/ alumni loyalty (see Studies 3 and 4, Chapters 4 and 5). These results are in line with the findings by Farr-Wharton and colleagues (2018). They showed that engagement fully mediates the relations between the relation between students and lecturers and intention to leave (i.e., in our studies, the opposite of intentions to stay/continue). However, they only used six items from the UWES-S (Schaufeli et al., 2002), and hence a valid comparison cannot be made.

\section{Student Loyalty}

With Study 4, we took a first step exploring alumni loyalty emphasizing the non-monetary aspect of alumni contributions. Although there is considerable research on student and alumni loyalty (Iskhakova et al., 2017), these studies have mainly been conducted in the US and have considered alumni financial giving, which is less common in Europe. The variance explained in student loyalty in Study 4 (Chapter 5) resembles recent findings on student loyalty in higher education (e.g., Doña Toledo \& Martínez, 2020). In particular, relationship quality and affective commitment seem to affect student/alumni loyalty (Hennig-Thurau et al., 2001; Iskhakova et al., 2016). The findings of Study 4 (Chapter 5) confirm that to establish alumni loyalty, one should focus on affective commitment.

Study 5 confirmed that the relation between relationship quality and student loyalty is stronger than the reverse temporal ordering. Satisfaction is mainly mentioned as a precursor of student loyalty (Shahsavar \& Sudzina, 2017). Our study's findings add that 
satisfaction, in terms of students' relationship quality, might be caused by students' trust in honesty and benevolence (see Study 5).

In parallel with the literature on student retention and involvement (e.g., Astin, 1999; Tinto, 1975), with the studies presented in this thesis, we underline that it is essential for higher education institutions to sustain and to build a long-lasting relationship with students. The thesis's findings contribute to the existing literature on loyalty intentions in general, and student and alumni loyalty in higher education specifically, and have practical value. For instance, higher education institutions could initiate relationship management strategies based on the relationship quality dimensions using the HERQ scale. They should focus on different segments of their student/alumni population (e.g., enrolled students versus alumni, first-year experience versus students' experiences from higher years). In line with recent findings (Pedro et al., 2020a, 2020b), as we indicated in Study 4 (Chapter 5), it would be interesting for higher education institutions to examine whether alumni still want to be involved with their alma mater; if so, in what way.

\section{Implications}

Our contribution lies in our theoretical underpinnings concerning students' interpersonal relationships (Study 1, described in Chapter 2). Previous research focused mainly on the relationship between teachers and students (e.g., Hagenauer \& Volet, 2014; Pianta et al., 2012). Within this study, all university personnel with whom students are in contact were considered. The results confirmed that students appreciate their relationships with their teachers/lecturers, which was supported in recent and previous research investigating teacher-student relationships (e.g., Clem et al., 2020; Garcia-Moya et al., 2020; Roorda et al., 2011, 2017). However, students also indicated that their relationships with other staff members matter, for instance, with mentors or career coaches. In conclusion, using an instrument such as the relationship quality scale for higher education (HERQ scale) provides insight into students' perceptions of the quality of the relationship they have with their university, confirming prior assumptions that adopting a relationship management approach in higher education is fruitful (e.g., Bowden, 2011; Helgesen, 2008; Hennig-Thurau et al., 2001).

The findings in both Studies 3 and 4 indicate that relationship quality is a predictor of student engagement and loyalty. The studies were built on SET ideas and previous research in services and relationship management, combined with educational literature (e.g., Koenig-Lewis et al., 2016; Snijders et al., 2018, Snijders, Wijnia, Rikers, Rikers, \& Loyens, 2020; Thibaut \& Kelley, 1959; Thoits \& Hewitt, 2001). The relevance for educational practitioners is that to maintain long-lasting relationships with former students, they should focus on establishing relational ties with students during their studies. 
Study 4 also indicated that relationship quality dimensions are important predictors of student engagement and non-monetary alumni loyalty. So far, previous research has mainly focused on monetary alumni support. To shed new light, we focused on the nonmonetary aspect of alumni giving. The findings in Study 4 underlined those in a recent study by Pedro et al. (2020b), who indicated that most European universities still struggle with achieving a decent alumni culture. Therefore, with these findings, we add to the existing literature on alumni loyalty.

For practice, Study 3's findings emphasize that educational practitioners and policymakers may benefit from examining students' perceptions and monitoring them regularly. Moreover, in Study 4, our conclusion is that to establish alumni loyalty, one should also focus on relationship quality dimensions, such as students' affective commitment and trust in benevolence.

The practical implication of Study 5 was that educational practitioners and policymakers could make use of the fact that students' trust in the quality of the relationship they have with their educational faculty and staff can be established through satisfaction, commitment and avoidance of unnecessary conflict.

For quality assurance, higher education institutions use instruments such as a national student survey (e.g., NSE; Studiekeuze123, 2020). However, the findings of the studies in this thesis reveal a better understanding of the relationships that shape the educational process, indicating more specifically what perceptions determine the quality of their relationship with their institution. This was done by explicitly asking students how they perceive the quality of their relationships with their educational faculty and staff using multiple items. All studies combined suggest that it is important to consider students' relations with all staff and faculty instead of focusing only on teacher-student relationships. The proposed relationship quality constructs paved the way to a better understanding that all staff and faculty should be included. Therefore, this thesis's findings are of importance for policymakers and teaching staff/educational practitioners in multiple ways.

At the individual level in higher education, professors', teachers', or mentors' understanding of how students perceive the quality of their relationship might positively influence their attitude towards students and the guidance they offer. Therefore, their advice and guidance are essential in the way students' perceive relationship quality. At the group level, alignment within the teaching team is necessary to define how they (teachers, professors, and mentors) want to guide students during the education service process to graduation and beyond. However, for further discussion, we question: To what extent do 
teachers want to be benevolent? Does the faculty team agree upon the way they are and want to be sensitive to students' needs? How can students approach teachers and faculty/ staff? Is it by email or WhatsApp, online, or any time in their office? Do all faculty and staff respond within the same timeframe, for instance, when a student asks a question and the policy is to respond within two days? How do faculty and staff communicate so that students feel they are being treated fairly? Do faculty and staff have guidelines concerning how and when to respond? Therefore, faculty and staff need to define their (communications) strategies for their guidance in order to establish and maintain relationships with their students. Faculty and staff must keep in mind that students with different cultural backgrounds might respond differently. Previous research has indicated that the culture within an institution concerning students' cultural background will influence "the degree to which students feel comfortable in the learning environment" (Guo \& Jamal, 2007, p. 29), which still holds today. A recent study by Schachner et al. (2019) found that a sense of belonging mediates the relationship between students' cultural diversity and student outcomes.

\section{Limitations}

The studies presented in this thesis were subject to certain limitations. First, regarding the constructs used, student loyalty items measured behavioral intentions of student and alumni loyalty (e.g., recommendations, positive word-of-mouth, participation). Although students' intentions are believed to result in behavioral, educational outcomes such as after graduation (Pedro et al., 2020a, 2020b), intentions do not automatically result in actual behavior (see Theory of Planned Behavior, Ajzen, 1991; Armitage \& Christian, 2003).

Second, alumni loyalty was measured by asking alumni how they wanted to be connected to their former institution (Study 4) by monetary and non-monetary contributions (e.g., the feedback alumni give, providing internships, and employment for graduates). Despite the importance of positive alumni relationships, one must understand why alumni contribute in either a monetary or a non-monetary way. If universities keep track of alumni contributions (e.g., who financially contributes, who is giving guest lectures, etc.), then research with multiple time points is possible to investigate intentions and actual alumni behavior.

Third, within our studies, we approached enrolled and former students to participate; students who dropped out were not included in the research. However, the last forms an interesting group to further investigate because of their views on relationship quality.

Last, the research designs in the studies presented were based on self-report surveys. However, to develop a broader understanding, data triangulation, such as analysis 
of student evaluation data, could be useful to provide a more comprehensive view. Furthermore, students' responses were voluntary, and their willingness to respond to the survey multiple times resulted in a smaller number of responses in the longitudinal study. Although we stress the importance of students' willingness to participate in a survey freely, students' commitment to taking the survey is necessary to collect sufficient longitudinal data. Therefore, for further research, we recommend engaging students in such a project in advance and pointing out the significance of their role as respondents.

\section{Directions for Future Research}

Based on the findings and implications of this thesis, we suggest several directions for future research. First, as we described in the introduction of this thesis, according to the gap model by Parasuraman et al. (1991), service recipients' perceptions should be examined to evaluate the quality of the service. In higher education, students are the primary recipients of the educational service. In this thesis's studies, we only considered one side of the relationship (i.e., students' perceptions). In service contexts in general (e.g., Cronin \& Taylor, 1994; Zeithaml et al., 1996), and in higher education specifically, students are not inclined to distinguish between expectations beforehand and post-perceptions (Dollinger \& Lodge, 2020; Nadiri et al., 2009; Sultan \& Wong, 2010). Hence, a performance-based approach was applied in the studies presented. Therefore, in this thesis, we explicitly focused on the students' point of view, asking students for their perceptions only (Studies 1-5). However, other parties are also involved in the relationship with students, and their responses should, therefore, be examined. In line with interpersonal relationship research, it is important to collect information from both parties within the relationship to assess the stability of that relationship (Duck, 1990). Thus, the next step also includes investigating the perceptions of other stakeholders in the service delivery process, for instance, teachers, professors, or mentors. Although we asked former students about their relationship with their alma mater, additional research may provide information about what expectations alumni might have in return for their contributions.

Second, within this thesis we explored students' perceptions of quality of the relationships they have or had with educational faculty and staff. To that end, the HERQ scale was used as a measurement instrument. Although all studies' findings confirmed the applicability of the HERQ scale in the context of higher education, the research was limited to student responses from Dutch samples at three universities of applied sciences in the southwest part of the Netherlands. Further research should be conducted to compare different contexts, such as comparing similar institutions within and outside of the Netherlands and Europe, including institutions that have a well-established alumni policy. Therefore, replication is needed for further generalization of results. 
Next, in the samples used in this thesis, students were relatively evenly distributed among age, gender, and different educational programs. However, in line with SET, cultural norms and values may differ in higher education relationships (Pillay \& James, 2015) and influence their outcomes, for example, alumni loyalty (Iskhakova et al., 2020). Therefore, cross-cultural research on relationship quality would help by examining cultural differences in how relationship quality in higher education is perceived by (former) students from other cultures (García-Moya et al., 2020). As indicated, there may be a difference between countries in how alumni contributions and their involvement might be expressed (e.g., the United States versus Europe). To generalize the findings from these studies, we recommend investigating students from several institutions from other countries so that the cultural interpretations of the constructs under study can be compared and further examined.

In addition, numerous studies have investigated student loyalty in higher education (e.g., Brown \& Mazzarol, 2009; Carvalho \& de Oliveira Mota, 2010; Doña Toledo \& Martínez, 2020; Hennig-Thurau et al., 2001; Helgesen \& Nesset, 2007; Iskhakova et al., 2016; Iskhakova et al., 2017; Newman \& Petrosko, 2011; Perin et al., 2012; Rojas-Mendez et al., 2009; Thomas, 2011). However, in higher education research, the variables used to examine or predict student/alumni loyalty are multiple, for example, trust, satisfaction, commitment, service quality, and university image. A sound conceptual model, including all relevant variables, is needed to align how student/alumni loyalty in higher education can be investigated. When such a model is used when collecting data at several higher education institutions in different countries, cross-cultural differences can be further examined. Educational practitioners might learn from these insights on establishing fruitful and long-lasting relationships with all kinds of students.

Study 5 (Chapter 6) implied that trust forms the basis of the relationship quality construct in higher education, predicting the future affective relationship quality dimensions of commitment, conflict, and satisfaction. In a replication study, these findings could be further investigated. For instance by asking students for their cooperation in a longitudinal project whereby their responses are warranted by participating in giving response. In addition, an in-depth study on affective conflict (as a negative relationship quality dimension parallel to trust) might provide insight into how students' perceptions of conflict change over time.

Last, COVID-19 caused adjustments in the education process. Blended and hybrid learning currently dominate in students' education. Therefore, a comparison between pre- and post-COVID-19 onset differences in students' relationship quality would be interesting to examine. 


\section{Conclusion}

The focus of this thesis was on the formation of bonds between students and their higher education institution. It aimed to investigate the influence the quality of those relationships can have on students' involvement. Distinct from previous research in the educational literature, the studies presented in this thesis take a novel approach using social exchange theory (SET) as an overarching framework to examine social interactions and relationships in higher education. Used in parallel with SET, theoretical underpinnings from the services and relationship management literature, combined with educational literature, formed the basis for the studies and the exploration of the relations between relationship quality, student engagement, and student/alumni loyalty.

The studies in this thesis were a first attempt to examine students' perceptions of the quality of their relationships with their educational faculty and staff, that is, relationship quality. The research resulted in a practical instrument found applicable in higher education for capturing students' perceptions of the quality of the relationships they have (or had) with educational faculty and staff: the HERQ scale. Quality assurance in higher education is an important way for policymakers to serve and successfully build relationships with students and other stakeholders, such as work field relations. Management support is needed, such as in strategic and process decisions on measuring and monitoring students' experiences. By applying the HERQ scale used in our studies, the measurement of relationship quality in higher education can be improved to better understand the relational aspects of students' educational service experience. Moreover, it would likely become much easier to react adequately to the indications of students' positive and negative perceptions if the scale is used to monitor students' evaluations regularly .

The underlying studies confirm that to build and maintain a positive relationship with students, investigating relationship quality is necessary in order to understand students' relational needs. When relationship quality is perceived positively by students, they will become more engaged in their studies, and in turn, will become (more) loyal. Although differences in the prediction of relationship dimensions among enrolled and former students were found, overall, relationship quality acts as a predictor of future student engagement and loyalty.

Applying a relationship approach could thus be beneficial for higher education institutions. To improve the formation of bonds with students, higher education policymakers and educational practitioners should strategically focus on relational aspects of their students' educational service experience. As proposed, alumni should be actively 
Chapter 7 - Summary and discussion

involved in establishing an alumni culture where long-term relationships exist, in order to sustain those relationships (Pedro et al., 2020a, 2020b; Schlesinger et al., 2017). In such a way, students, alumni, and higher education institutions could benefit from the educational experience they all create together. 
25. - 5

is हैखक्र

$+4$

$+\infty$

4

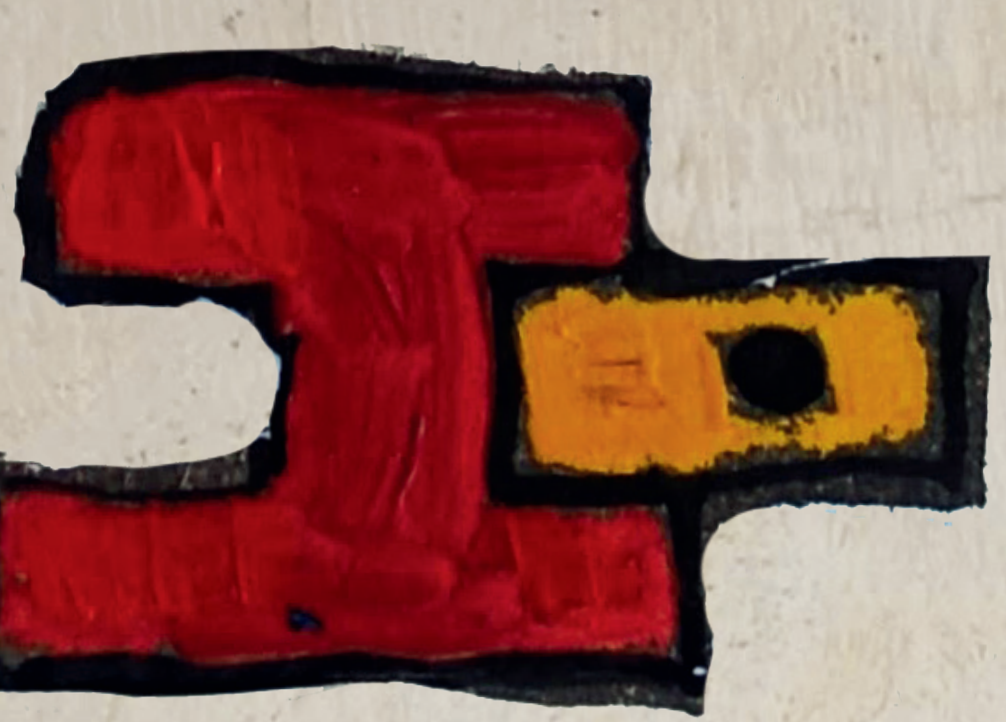

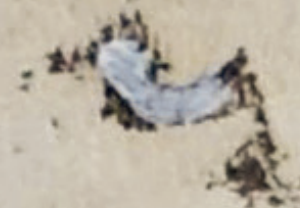

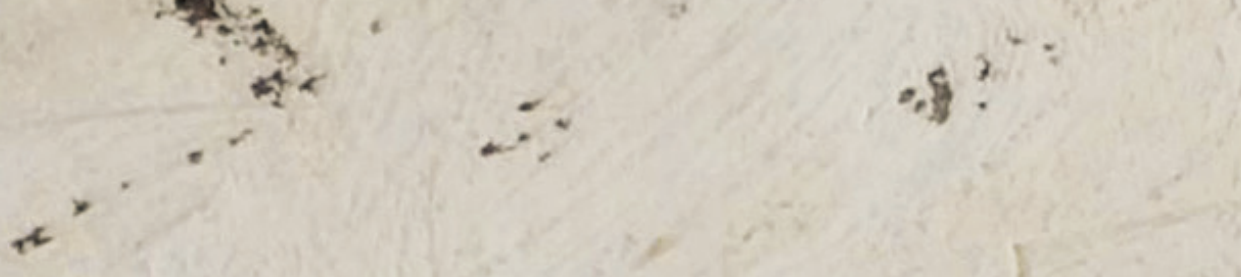




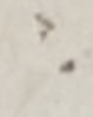

\section{Chapter 8 \\ Samenvatting en Discussie}
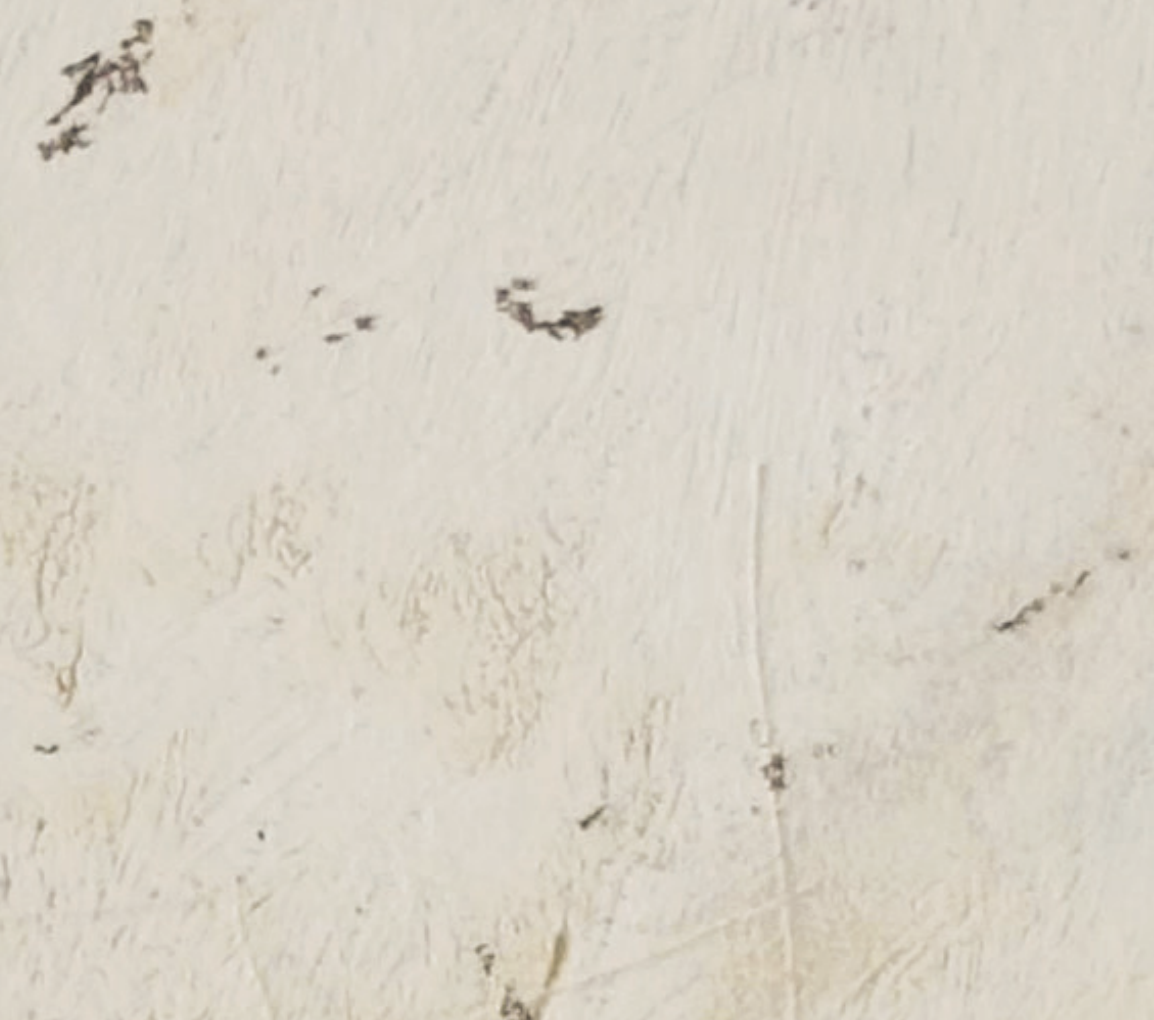
De veranderingen die de afgelopen tien jaar in het hoger onderwijs hebben plaatsgevonden, zoals de op hoeveelheid afgegeven diploma's gebaseerde financiering, de wereldwijde concurrentie onder universiteiten en de vercommercialisering van het hoger onderwijs, vragen om een heroriëntatie op het tot stand brengen van de relaties tussen studenten en hun onderwijsinstelling. Eerdere studies benadrukken dat de relatie tussen docenten en studenten een centraal punt in het onderwijsproces moet zijn (zie bijvoorbeeld Wubbels \& Brekelmans, 2005). Onderzoek in de onderwijspsychologie beperkt zich vooral tot leerling-leerkrachtrelaties. Studenten in het hoger onderwijs hebben echter verschillende en zich herhalende interacties met verscheidene personeelsleden van hun universiteit of hogeschool. Naast de docenten hebben studenten ook contact met bijvoorbeeld studieadviseurs of -begeleiders, studentenpsychologen, leden van een examencommissie, conciërges, bibliothecarissen, ICT-helpdeks en receptionisten. Deze interacties tezamen dragen bij aan de beleving van het onderwijs dat studenten genieten.

Onderwijsonderzoekers die de relaties met studenten onderzochten zijn vooral gericht op het basis- of voortgezet onderwijs (zie bijvoorbeeld Roorda et al., 2011, 2017). Hoewel deze onderzoeksresultaten belangrijk zijn om inzicht te verkrijgen in onderwijsprocessen, zijn de instrumenten die deze studies gebruiken niet altijd in alle onderwijssituaties toepasbaar. Het hoger onderwijs verschilt vooral van andere onderwijscontexten waar het gaat om betrokkenheid en participatie van studenten (Leenknecht et al., 2020). In het basis- en voortgezet onderwijs is de relatie die tussen een kind en een volwassene; in het hoger onderwijs gaat het om de relaties tussen volwassenen (Hagenauer \& Volet, 2014). Het onderzoek van student-docentrelaties in het basis-en voortgezet onderwijs (zie bijvoorbeeld Roorda et al., 2011, 2017) geeft echter geen antwoord op de vraag hoe een positieve relatie tussen studenten en hun onderwijsfaculteit/personeel in het hoger onderwijs tot stand gebracht en onderhouden wordt.

Het opbouwen en onderhouden van (duurzame) relaties met belanghebbenden (stakeholders of actoren) zijn de fundamenten van service (diensten)- en relatiemanagement. Resultaten uit eerder onderzoek waarbij services- en relatiemanagement in het hoger onderwijs is onderzocht ( $\mathrm{Ng} \&$ Forbes, 2009) onderstrepen dat deze ideeën van toepassing zijn en dat deze inmiddels steeds vaker worden onderzocht in de context van het hoger onderwijs (zie bijvoorbeeld Gibbs \& Kharouf, 2020; Yousaf et al., 2020). Deze studies behandelen het onderwijs als een dienst, gebaseerd op de socialeuitwisselingstheorie (social exchange theory; SET; zie Homans, 1961). De "onderwijsdienst" in het hoger onderwijs bestaat uit sociale interacties tussen studenten en hun onderwijsinstelling. Vooral wanneer er sprake is van een dienst met een hoge mate van betrokkenheid (Bloemer \& Ruyter, 1999), zoals in het hoger onderwijs, is het belangrijk 
om de aandacht te richten op de manier waarop studenten als primaire stakeholders (Bunce et al., 2017) de onderwijsdienst ervaren. De uitkomsten van het onderwijsproces zijn afhankelijk van de manier waarop studenten de onderwijsuitwisseling ervaren. Het kwaliteitsmodel van Parasuraman et al. (1991) wordt vaak gebruikt in dienstenonderzoek om mogelijke hiaten (gaps) tussen stakeholders en organisaties in dienstenonderzoek te onderzoeken. De eerste stap in de "gapanalyse" is het bevragen van de belangrijkste stakeholders naar hun perceptie. De klanten/ontvangers van de dienst, in dit geval studenten, spelen hierin een centrale rol. De ideeën gebaseerd op SET vormden het uitgangspunt voor ons onderzoek.

In dit proefschrift hebben we onderzocht hoe studenten de kwaliteit van de relaties met hun opleiding ervaren, oftewel wat is de relatiekwaliteit. Zoals Osobajo en Moore (2017) aangeven, variëren de definities van relatiekwaliteit, wat vooral wordt veroorzaakt door de specifieke context die wordt bestudeerd. Osobajo en Moore geven een algemene beschrijving van relatiekwaliteit waarin ze verwijzen naar de gezondheid van een relatie door te kijken naar de ervaring van de partijen in die relatie (zie Osobajo \& Moore, 2017). Het relatiekwaliteitsinstrument dat in dit proefschrift wordt toegepast is een nieuwe benadering in de onderwijsliteratuur om de kwaliteit van de relaties tussen studenten en hun onderwijsfaculteit en medewerkers te meten. Het instrument bestaat uit vijf relatiekwaliteitsdimensies gebaseerd op relatiemanagementonderzoek (Roberts et al., 2003). We hebben het instrument qua bewoording aangepast aan de context van het hoger onderwijs. De volgende dimensies zijn hierin opgenomen: vertrouwen in welwillendheid (trust in benevolence), wat verwijst naar de mate waarin studenten denken dat de faculteit/ personeelsleden zich bekommeren om hun welzijn, dat ze bedoelingen en motieven hebben die studenten ten goede komen en dat ze niet handelen op een manier die negatieve gevolgen voor hen heeft. We hebben ook vertrouwen in eerlijkheid (trust in honesty) opgenomen, wat het vertrouwen vertegenwoordigt dat studenten hebben in de geloofwaardigheid van een universiteit/hogeronderwijsinstelling die wordt vertegenwoordigd door de faculteit/het personeel. Affectieve betrokkenheid (affective commitment) verwijst naar het gevoel van studenten om bij hun universiteit (dat wil zeggen hun faculteit/ personeel) te willen horen of ermee verbonden willen zijn. Tevredenheid (satisfaction) werd ook opgenomen en bestaat uit de cumulatieve tevredenheid van de student met de algemene kwaliteit van de relatie met de opleiding. Tot slot is affectief conflict (affective conflict) opgenomen, dat kan worden gezien als de negatieve indicator voor de kwaliteit van de relatie, als tegenpool van vertrouwen (Roberts et al., 2003). Het affectief conflict dat studenten ervaren zal de mate van hun gepercipieerde relatiekwaliteit verlagen, door het gevoel van irritatie, frustratie en boosheid. 
Om een diepgaand inzicht te krijgen in hoe studenten de algehele kwaliteit van hun relatie met hun universiteit of hogeschool zien, hebben we de studenten gevraagd te reageren op vragen waarin we verwezen naar de kwaliteit van de relaties met alle leden van de onderwijsfaculteit en het personeel. Als deze relaties positief zijn, zijn ze gunstig voor hoger onderwijsinstellingen in termen van studentbetrokkenheid ${ }^{1}$, zowel tijdens als na het afstuderen.

\section{Overzicht van de Belangrijkste Bevindingen}

De studie in Hoofdstuk 2, ging in op de onderzoeksvraag: Wat is relatiekwaliteit in het hoger onderwijs en hoe kunnen we die meten? De focus lag op het meten van relatiekwaliteit aan de hand van een enquête. Een deductieve benadering werd gebruikt door het toepassen van een instrument voor relatiekwaliteit op basis van services- en relatiemanagementonderzoek (Roberts et al., 2003). Het doel was om bij te dragen aan een beter begrip van relatiekwaliteit in het hoger onderwijs. Het relatiekwaliteitsinstrument richtte zich op de perceptie van studenten van de algemene relaties met de onderwijsfaculteit of het personeel. Met deze focus hebben we eerst de toepasbaarheid van een relatiekwaliteitsschaal onderzocht aan de hand van kwantitatieve data, aangevuld met kwalitatieve gegevens. De relatiekwaliteitsschaal is gebruikt om te bepalen of dezelfde onderliggende relatiekwaliteitsdimensies ook gelden in de context van het hoger onderwijs.

De vijf eerdergenoemde relatiekwaliteitsdimensies onderzocht vanuit het oogpunt van de studenten met betrekking tot de kwaliteit van de relatie met de onderwijsfaculteit en haar medewerkers bestaan uit: het vertrouwen van de studenten in eerlijkheid en welwillend-heid (trust in honesty \& trust in benevolence), hun algemene tevredenheid ten aanzien van de kwaliteit van de relatie (satisfaction), hun affectief commitment met onderwijspersoneel (affective commitment), en hun affectief conflict (affective conflict). Een online-enquête werd verstuurd naar de ingeschreven studenten van één hogeschool. Daarnaast is een kleinschalige focusgroepdiscussie gehouden om de dimensies van relatiekwaliteit verder te onderzoeken. Er werd bevestigd dat er een goede fit is voor het vijfdimensionale model van relatiekwaliteit in het hoger onderwijs. Bovendien leverde de focusgroepdiscussie met studenten naast de kwantitatieve gegevens ook praktische voorbeelden op van hoe studenten relatiekwaliteit ervaren.

Student involvement bestaat uit "student engagement" en "student loyalty" en wordt gezien als betrokkenheid van studenten bij hun onderwijsinstelling als geheel. Onder "student engagement" wordt de betrokkenheid van studenten bij het studeren gezien. Zowel "involvement" als "engagement" zijn in het Nederlands vertaald als "studentbetrokkenheid". 
In Hoofdstuk 3, presenteert de tweede studie kwalitatief onderzoek met als doel om een dieper inzicht te krijgen in de relatiekwaliteitsdimensies van studenten in het hoger onderwijs. Het onderzoek was gebaseerd op 513 real-life beschrijvingen van studentpercepties. Het doel was om de relatiekwaliteit in het hoger onderwijs te onderzoeken en inzichten te verschaffen in de relationele ervaringen van studenten met hun opleiding. SET werd gebruikt als een overkoepelend kader (Blau, 1964; Emerson, 1976). Uitgangspunt van SET is om duidelijk te maken hoe sociale interacties tot relaties leiden en waarom deze relaties (des)continueren. Het raamwerk kan worden toegepast in verschillende omgevingen tussen twee partijen, bijvoorbeeld romantische of vriendschapsrelaties tussen partners, professionele relaties tussen een consument of klant en een bedrijf of organisatie of een werknemer en werkgever. Gerelateerde ideeën uit de dienstverlening (klantgericht denken) en relatiebeheer, in combinatie met de onderwijsliteratuur, zijn toegepast voor de meetinstrumenten en analyses in ons onderzoek. De kritische incidentmethode (Critical Incident Technique; CIT) is een veelgebruikte benadering in serviceonderzoek om de perceptie van de ontvanger van de dienst verder uit te diepen. In de tweede studie hebben we CIT gebruikt om kwalitatieve gegevens te verzamelen uit onlinereacties van studenten die bestaan uit positieve en negatieve ervaringen. Templateanalyse werd toegepast op de zelf-gerapporteerde relationele ervaringen van studenten met hun onderwijsfaculteit en medewerkers. De vijf a priori relatiekwaliteitsdimensies die we voor de template gebruikten waren dezelfde als die van de eerste studie: het vertrouwen in eerlijkheid en welwillendheid, de algemene tevredenheid, affectieve commitment van studenten en affectief conflict (als negatieve indicator voor de kwaliteit van de relatie).

Hoewel alle studenten werden uitgenodigd om de online-enquête in te vullen, hebben vooral eerstejaarsstudenten gereageerd. De studenten beschreven meer negatieve $(n=395)$ dan positieve $(n=294)$ incidenten. Dit gegeven komt overeen met recent onderzoek (zie bijvoorbeeld Clem et al., 2020). We hadden verwacht dat de negatieve incidenten van studenten affectief conflict zouden bevatten. In dit onderzoek werd echter vooral gewezen op een gebrek aan vertrouwen in eerlijkheid en welwillendheid. Eén van de kritiekpunten van de studenten luidde bijvoorbeeld: "docenten hebben geen gemeenschappelijke aanpak om studenten te begeleiden en te faciliteren”. In het algemeen werd het wachten op een reactie als negatief ervaren. Interessant is dat studenten in hun laatste jaren voor hun afstuderen juist "snelle feedback" en "het kunnen vertrouwen op eerlijke en welwillende (re)acties" als belangrijk en als positieve ervaring aangaven.

In de derde studie beschreven in Hoofdstuk 4, gebruikten we cross-sectionele gegevens om relatiekwaliteit onder ingeschreven studenten te voorspellen. In de daaropvolgende studie beschreven in Hoofdstuk 5 hebben we het onderzoek herhaald, maar nu onder alumni. De methodologische keuzes voor de analyse werden gemaakt in overeenstemming 
met services en relatiemanagementonderzoek, zoals de toepassing van partial least squares-structural equation modeling (PLS-SEM) voor de analyse in het voorspellen en verkennen van de onderzochte variabelen (Hoofdstukken 4 \& 5). Er werd uitgegaan van de vijf relatiekwaliteitsdimensies vertrouwen in eerlijkheid, vertrouwen in welwillendheid, tevredenheid, affectief commitment en affectief conflict. Studentbetrokkenheid (engagement) werd onderzocht aan de hand van drie dimensies: absorptie (absorption), toewijding (dedication) en vitaliteit (vigor).

In Hoofdstuk 4 was de onderzoeksvraag: Welke invloed heeft relatiekwaliteit op studentbetrokkenheid (engagement), en (op zijn beurt) op studentloyaliteit? We onderzochten de relatiekwaliteitspercepties van studenten met hun onderwijsfaculteit en haar personeel en de associaties met studentbetrokkenheid en loyaliteit onder ingeschreven studenten. Het doel was om inzicht te krijgen de voorspellende waarde van de door studenten positief ervaren relaties en hoe deze leiden tot positief geëngageerde en loyale studenten. Het model verklaarde $31 \%$ van de variantie in absorptie, $45 \%$ in toewijding, $37 \%$ in vitaliteit en $55 \%$ in studentloyaliteit.

In Hoofdstuk 5 hebben we een soortgelijke onderzoeksvraag behandeld, echter nu gericht op voormalig-studenten (alumni): Welke invloed heeft de perceptie van relatiekwaliteit bij oud-studenten op hun vroegere betrokkenheid bij hun studeren (engagement), en (op zijn beurt) op hun huidige loyaliteit? Het doel was om te onderzoeken of relatiekwaliteitsdimensies (in)direct studentbetrokkenheid en (op hun beurt) alumniloyaliteit voorspellen. Hierbij veronderstelden we dat relatiekwaliteit een positief verband zou hebben met studentbetrokkenheid en met studentloyaliteit, en, studentbetrokkenheid met studentloyaliteit. De hypothesen van deze studies werden gedeeltelijk ondersteund, maar de resultaten verschilden tussen het onderzoek onder huidige studenten en het onderzoek onder alumni.

Statistisch significante verschillen werden gevonden tussen de associaties van de relatiekwaliteitsdimensies en studentbetrokkenheidsdimensies (absorptie, toewijding en vitaliteit). Voor ingeschreven studenten werden statistisch significante associaties gevonden voor: vertrouwen in eerlijkheid en toewijding; affectief conflict en absorptie en vitaliteit; affectief commitment en alle drie de dimensies van studentbetrokkenheid (absorptie, toewijding en vitaliteit). Voor alumni daarentegen werden statistisch significante associaties gevonden voor: vertrouwen in eerlijkheid en toewijding en vitaliteit, vertrouwen in welwillendheid en affectief commitment voor alle drie de dimensies van studentenbetrokkenheid, en tevredenheid en vitaliteit. In beide modellen werd een statistisch significante associatie gevonden voor de relatiekwaliteitsdimensie van affectief commitment en loyaliteit. Voor studentloyaliteit werd $53 \%$ van de variantie 
verklaard. Voor alumniloyaliteit werd $55 \%$ van de variantie verklaard. De verklaarde varianties in loyaliteit komen overeen met recente bevindingen over loyaliteit in het hoger onderwijs (zie bijvoorbeeld Doña Toledo \& Martínez, 2020).

Studie 4 (Hoofdstuk 5) gaf aan dat de alumnipercepties van relatiekwaliteit een sterker positief (en statistisch significant) verband hadden met hun huidige loyaliteit dan met hun perceptie van hun vroegere studentbetrokkenheid. Vertrouwen in welwillendheid en affectief commitment als relatiekwaliteitsdimensies werden positief geassocieerd met studentbetrokkenheid. In tegenstelling tot onze hypotheses had het vertrouwen in eerlijkheid een negatieve associatie met de studentbetrokkenheidsdimensies absorptie en vitaliteit. Er werden geen statistisch significante positieve associaties gevonden tussen de relatiekwaliteitsdimensie van vertrouwen in eerlijkheid en toewijding (studentbetrokkenheiddimensie) of alumniloyaliteit.

Om de beperkingen van correlationeel onderzoek te overbruggen, zoals in de studies beschreven in Hoofdstukken 4 en 5, werd in Studie 4 (Hoofdstuk 6), gebruikgemaakt van longitudinale gegevens uit twee tijdsmomenten waarmee voorspellingen konden worden gedaan in de tijd. Op basis van de literatuur over interpersoonlijke relaties en onderzoek in services en relatiemanagement werd "vertrouwen" (trust) als aspect van relatiekwaliteit nader onderzocht. In combinatie met de onderwijsliteratuur en onderzoek van services en relatiemanagement werden de volgordelijkheid van de relatiekwaliteitsdimensies en de sterkte van de relatiekwaliteitsuitkomsten onderzocht, namelijk studentbetrokkenheid en studentloyaliteit (Studie 5, Hoofdstuk 6). De onderzoeksvragen waren: 1) Hoe ontwikkelen de relatiekwaliteitsdimensies zich in de loop van de tijd? en 2) Zorgt relatiekwaliteit voor een voorspelling van studentbetrokkenheid (engagement) en studentloyaliteit? We hebben ons gefocust op de richting van de relaties tussen relatiekwaliteitsdimensies en de relaties tussen relatiekwaliteit, studentbetrokkenheid (engagement) en loyaliteit op basis van een steekproef van studentresponses gebaseerd op twee tijdsmomenten.

Studie 5 (Hoofdstuk 6) was een eerste poging om de volgorde van de relaties tussen relatiekwaliteitsdimensies en de sterkte van relaties tussen relatiekwaliteit, studentbetrokkenheid en studentloyaliteit te onderzoeken. In lijn met de literatuur over vertrouwen (zie bijvoorbeeld Castaldo, 2007) werd bevestigd dat vertrouwen als relatiekwaliteitsdimensie een sterker verband heeft met de affectieve relatiekwaliteitsdimensies commitment, tevredenheid en conflict dan omgekeerd. Ten tweede werd onze hypothese bevestigd dat relatiekwaliteit een sterkere relatie heeft met studentbetrokkenheid en studentloyaliteit dan omgekeerd. 


\section{Algemene Discussie}

De belangrijkste onderzoeksvragen in de inleiding waren: Wat is het beeld dat studenten hebben van relatiekwaliteit in het hoger onderwijs en hoe beïnvloedt relatiekwaliteit studentbetrokkenheid en loyaliteit? Binnen de gepresenteerde studies van dit proefschrift hebben we empirisch onderzoek verricht naar relatiekwaliteit als een multidimensionaal construct. Het instrument is gebaseerd op een bestaande schaal die eerder door Roberts et al. (2003) werd toegepast op consumentendiensten. Studenten, als primaire ontvangers van de onderwijsdienst, werd gevraagd naar hun perceptie van de onderwijsdienst. Om dit te onderzoeken is gebruikgemaakt van kwantitatieve en kwalitatieve dataverzamelingsmethoden en -analyses (Studies $1 \& 2$, beschreven in de Hoofdstukken $2 \& 3$ ). Vervolgens werden de uitkomsten van relatiekwaliteit onderzocht in termen van studentbetrokkenheid (engagement) en studentloyaliteit (Studies 3, 4, \& 5, beschreven in de Hoofdstukken $4,5, \& 6)$.

De gepresenteerde studies (zie Figuur 8.1) waren gebaseerd op SET als overkoepelend kader. Daarnaast werd er gebruikgemaakt van aanverwante ideeën uit de service- en relatiemanagement literatuur in combinatie met onderwijsliteratuur.

\section{Relatiekwaliteit}

Dit proefschrift heeft als uitgangspunt het aangaan van langetermijn (duurzame) relaties in het hoger onderwijs. Onze studies sluiten aan bij andere, recente studies (zie bijvoorbeeld Dollinger \& Lodge, 2020; Matthews et al., 2018) die zich richten op het onderzoek naar het bevorderen van klantbetrokkenheid en klantgericht denken. Het instrument dat we hebben ontwikkeld om de relatiekwaliteit in het hoger onderwijs te bestuderen (HERQ-schaal) voegt waarde toe aan de operationalisering van het relatiekwaliteitsconcept in het hoger onderwijs. Voor zover wij weten zijn de studies die in dit proefschrift worden gepresenteerd de eerste die relatiekwaliteit als een multidimensionaal construct hebben bestudeerd en de voorspelling van de resultaten van relatiekwaliteit in het hoger onderwijs (d.w.z. studentbetrokkenheid en loyaliteit) hebben onderzocht. Hiermee dragen we bij aan het tot nu toe nog beperkte inzicht in relatiekwaliteit in het hoger onderwijs (zie bijvoorbeeld HennigThurau et al., 2001). We dragen met deze onderzoeksresultaten nieuwe ideeën aan in de bestaande (onderwijs en psychologie) literatuur over interpersoonlijke relaties en relatiebeheer in het hoger onderwijs. 


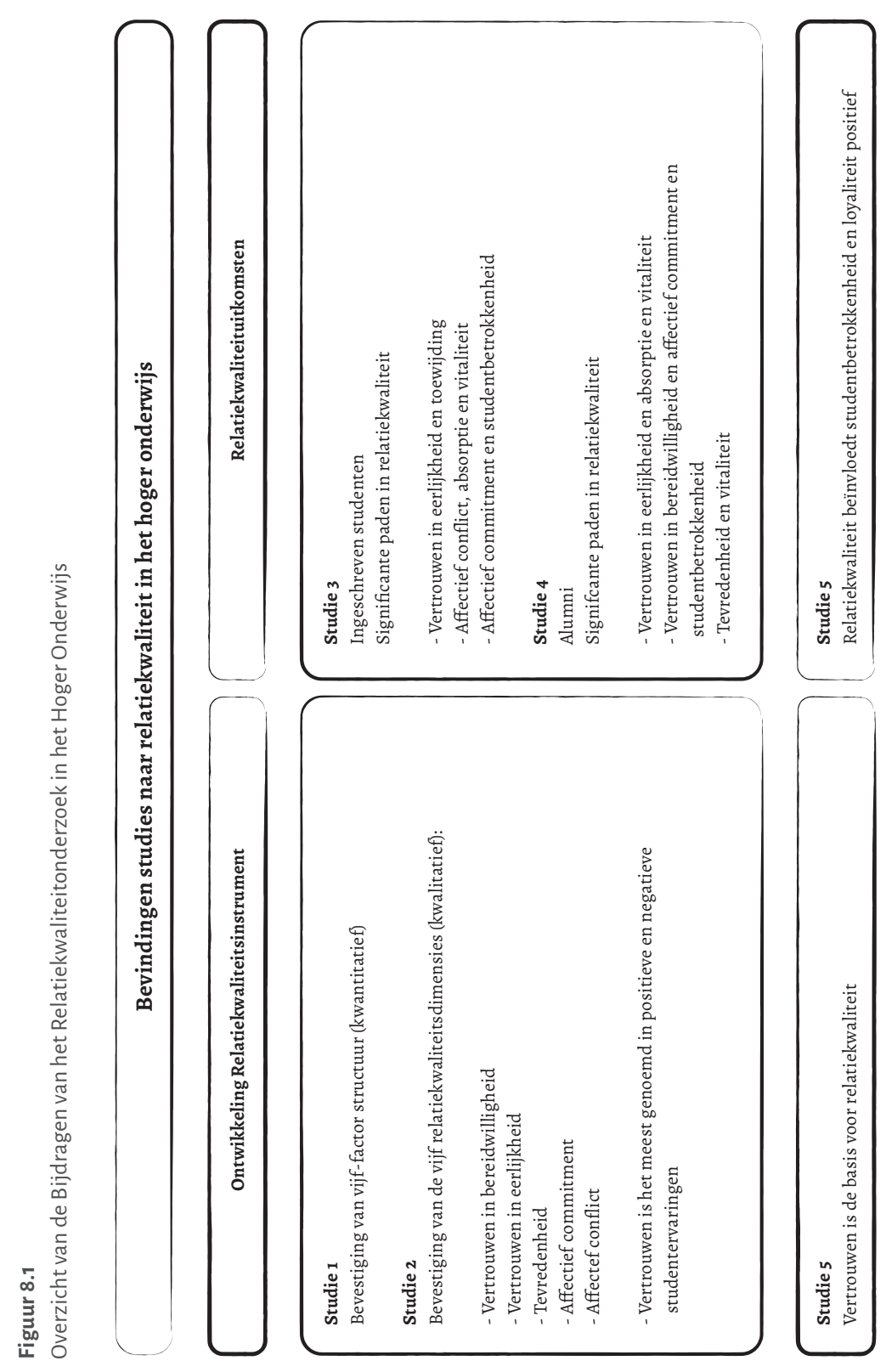


In dit proefschrift pasten we het relatiekwaliteitsinstrument toe bestaande uit vijf dimensies: vertrouwen in welwillendheid (trust in benevolence), vertrouwen in eerlijkheid (trust in honesty), affectief commitment (affective commitment), tevredenheid (satisfaction) en affectief conflict (affective conflict). De resultaten bevestigden dat het meten van relatiekwaliteit kan worden toegepast met behulp van de geïmplementeerde relatiekwaliteitsschaal (HERQ-schaal). De bevindingen beschreven in Hoofdstukken 3 en 6 toonden echter ook aan dat de vijf dimensies geclusterd kunnen worden in twee hoofdonderdelen: vertrouwen (trust) en affectie (affect). Binnen de onderwijspraktijk lijkt het voor studenten moeilijk om een onderscheid te maken tussen de relatiekwaliteitsdimensies. Tevens hangt het af van de relationele fase waarin een student zich bevindt (d.w.z., de frequentie van de ervaringen die studenten ondervinden tijdens hun studiejaren kan bepalend zijn voor de interpretatie van relatiekwaliteit; eerstejaars vs. hogerejaars studenten). Bovendien blijkt uit de analyse van de positieve en negatieve relatiekwaliteitspercepties van studenten in Hoofdstuk 3, dat het onderscheid tussen de vijf relatiekwaliteitsdimensies soms niet altijd duidelijk is. Misschien spelen ook enkele andere relationele aspecten (bijvoorbeeld billijkheid, gevoel van gelijkwaardigheid, interesse en responsiviteit) een rol, zij het in verband met de vijf relatiekwaliteitsdimensies. Zowel kwantitatieve als kwalitatieve benaderingen geven echter inzicht in de operationalisering van relatiekwaliteit in het hoger onderwijs.

Hoofdstuk 2 bevestigde de vijfdimensionale structuur van relatiekwaliteit. Hoofdstuk 3 daarentegen vermeldde slechts enkele expliciete uitingen van affectief commitment en affectief conflict als relatiekwaliteitsdimensies. Op basis van het aantal beschrijvingen voor vertrouwen in Hoofdstuk 3 en ander recent onderzoek (zie Schlesinger et al., 2017) hebben we de hypothese geformuleerd dat het vertrouwen van studenten in eerlijkheid en welwillendheid de basis vormt voor de relatiekwaliteit. In Hoofdstuk 6 hebben we de dimensies daarom samengevoegd tot twee componenten: 1) vertrouwen (d.w.z. vertrouwen in eerlijkheid en vertrouwen in welwillendheid) en 2) affectie (affectief commitment, tevredenheid en affectief conflict). De dimensies van vertrouwen vormen de kern van de relatiekwaliteitsconstructies; vertrouwen in eerlijkheid en vertrouwen in welwillendheid als voorspeller van de affectieve relatiekwaliteitsdimensies van commitment, conflict en tevredenheid. Beide studies impliceren dat het instrument voor relatiekwaliteit toepasbaar is in de context van het hoger onderwijs. Daarom heeft de HERQ-schaal praktische waarde voor de onderwijspraktijk bij het toepassen van het instrument bijvoorbeeld door middel van een enquête in aanvulling op cursusevaluaties en nationale enquêtes zoals de Nationale Studenten Enquête (NSE; Studiekeuze123, 2020). 
In alle studies waren de relatiekwaliteitsdimensies van vertrouwen in eerlijkheid en welwillendheid sterk gecorreleerd. Echter, gezien het relatiekwaliteitsconcept als een multidimensionaal concept, is deze bevinding niet verrassend. Bovendien maken sommige studies geen onderscheid tussen vertrouwen in eerlijkheid en vertrouwen in welwillendheid (zie bijvoorbeeld Hennig-Thurau et al., 2001). In Studie 5 (Hoofdstuk 6) hebben we de kwaliteit van de relatie onderzocht met behulp van twee componenten: vertrouwen (trust) en affectie (affect). De resultaten gaven echter aan dat de meting van de relatiekwaliteit op vijfdimensioneel niveau meer ondersteuning bood om studentbetrokkenheid (student engagement) en loyaliteit te voorspellen. Toch vragen we ons af of studenten een duidelijk verschil kunnen maken tussen vertrouwen in de eerlijkheid of vertrouwen in de welwillendheid van het onderwijspersoneel.

Op basis van de statistisch significante associaties tussen de onderzochte variabelen zijn er verschillen in onderzoeksresultaten tussen ingeschreven studenten en alumni (Hoofdstukken $4 \& 5$ ). Het lijkt erop dat affectief conflict in de loop van de tijd aan verandering onderhevig is. Dit idee werd bevestigd in het onderzoek met twee tijdsmomenten (Studie 5, beschreven in Hoofdstuk 6). Er werd in het eerste model een zwakke meetinvariantie (measurement invariance; d.w.z. indien groepen respondenten worden vergeleken bijvoorbeeld op basis van schaalscores, dan is dat slechts mogelijk indien de schaalitems op dezelfde wijze worden geïnterpreteerd) voor affectief conflict gevonden, wat erop wijst dat studenten affectief conflict in de loop van hun studie anders zouden kunnen gaan interpreteren.

Deze bevinding is niet verrassend als we kijken naar de uitdagingen waarmee studenten tijdens hun studiejaren worden geconfronteerd. Studenten zouden in de loop van hun studietijd een andere houding kunnen ontwikkelen ten opzichte van het soort conflict dat ze waarnemen tijdens hun studie. Studenten zouden zich in hun eerste en tweede jaar anders kunnen gaan voelen als het gaat om irritaties en frustraties die zich voordoen in de relatie met hun opleiding. Het affectief conflict van studenten kan bijvoorbeeld te wijten zijn aan een gebrek aan kennis wanneer zij feedback op opdrachten ontvangen die onduidelijk is. Wanneer studenten hogerejaars zijn richten zij zich verder op het ontwikkelen van een professionele houding en het afstuderen. Daarin is voor studenten de reactie van docenten op het geven van cijfers en feedback op opdrachten in het laatste studiejaar essentieel, en dat zij weten waar ze aan toe zijn om op tijd af te kunnen studeren (zie Studie 2, Hoofdstuk 3). Binnen een studiejaar kunnen studenten ook een ander begrip ontwikkelen van het affectieve conflict dat ze ervaren. Zo kunnen de irritaties en frustraties van studenten aan het begin van hun studiejaar bestaan uit onduidelijke communicatie of het gevoel dat ze onjuist behandeld worden. Dit kan anders zijn dan de manier waarop studenten het conflict aan het einde van het studiejaar ervaren 
als ze bijvoorbeeld te maken hebben met studieuitval (bijvoorbeeld door een negatief advies) of in het laatste jaar rondom studieadvies en hun afstuderen.

\section{Effecten van Relatiekwaliteit}

\section{Studentbetrokkenheid}

In de literatuur over services- en relatiemanagement wordt aangenomen dat kwaliteit in het algemeen leidt tot (consument)betrokkenheid (engagement) en daarmee tot loyaliteitsintenties en -gedrag (zie Zeithaml et al., 1996). Ook in eerdere onderwijsstudies worden de interacties tussen studenten en docenten en de relaties tussen studenten en docenten positief geassocieerd met de betrokkenheid van studenten bij hun afstuderen. In dit proefschrift hebben we echter de kwaliteit van de relatie in een breder perspectief bekeken, waarbij we de studenten vroegen naar hun perceptie van de kwaliteit van de relaties met alle betrokken medewerkers van de onderwijsfaculteit. Door een parallel te trekken met verwante literatuur over betrokkenheid (engagement), hebben we ook studentbetrokkenheid multidimensionaal gemeten (zie bijvoorbeeld Brodie et al., 2010 vanuit een dienstenmanagement perspectief; Veiga et al., 2014 vanuit een onderwijskundig, psychologisch perspectief).

De cross-sectionele gegevens in Hoofdstukken 4 en 5, zijn gebaseerd op de reactie van huidige en oud-studenten (alumni). Beide studies bevestigen dat relatiekwaliteit positief wordt geassocieerd met studentbetrokkenheid (engagement). Echter, niet alle dimensies van relatiekwaliteit hadden een statistisch significant verband met studentbetrokkenheid. In beide modellen werd een statistisch significante associatie gevonden voor relatiekwaliteit met de studentbetrokkenheidsdimensie toewijding, en toewijding en loyaliteit. Een hoge variantie in de loyaliteit van studenten en alumni werd verklaard door, respectievelijk 53 en 55 procent. Uit de longitudinale bevindingen met twee tijdsmomenten bleek ook dat relatiekwaliteit studentbetrokkenheid voorspelt (zie Hoofdstuk 6), waarbij werd bevestigd dat de relatie tussen relatiekwaliteit en studentbetrokkenheid (engagement) sterker is dan andersom. De studies tonen de relevantie van relatiekwaliteit in het hoger onderwijs daarvan aan.

In dit proefschrift hebben we studentbetrokkenheid (engagement) gepositioneerd als uitkomst en als mediator in de relatie tussen relatiekwaliteit en studentloyaliteit. De bevindingen van deze studies impliceren echter niet overtuigend dat studentbetrokkenheid een mediërende variabele is in de relatie tussen relatiekwaliteit en studentloyaliteit. Deze constatering is in lijn met bevindingen van de systematische literatuurstudie door Quin (2017), waarbij de positie van studentbetrokkenheid bediscussieerd wordt. 
In de studies van dit proefschrift, was alleen toewijding (dedication) als studentbetrokkenheidsdimensie sterk gerelateerd aan student en alumniloyaliteit (zie Hoofdstukken 4 \& 5). Hierbij zijn we uitgegaan van de UWES-S verkorte variant met 9 items. Deze resultaten komen overeen met de bevindingen van Farr-Wharton en collega's (2018). Zij toonden aan dat "toewijding" de relaties tussen studenten en docenten en de intentie om hun studie te beëindigen medieert (d.w.z., in onze studies, het tegenovergestelde van intenties om de studie te blijven/voort te zetten). Echter, ze gebruikten slechts zes items uit de UWES-S verkorte schaal waarmee studentbetrokkenheid (engagement) werd gemeten (Schaufeli et al., 2002). Daarom kan er geen volledig geldige vergelijking worden gemaakt met de bevindingen uit onze studies.

\section{Studentloyaliteit}

Hoewel er veel onderzoek is gedaan naar student/alumniloyaliteit (Iskhakova et al., 2017), worden deze studies voornamelijk uitgevoerd in de Verenigde Staten. Daarin wordt studentloyaliteit veelal beschouwd als de financiële bijdrage of donaties van alumni. Dit is echter minder gebruikelijk in Europa. Met de bevindingen van Studie 4 in Hoofdstuk 5 hebben we alumniloyalteit onderzocht waarbij de nadruk werd gelegd op het niet-financiële aspect. De verklaarde variantie die in Hoofdstuk 5 wordt uitgelegd in studentloyaliteit lijkt op recente bevindingen over studentloyaliteit in het hoger onderwijs (bijvoorbeeld Doña Toledo \& Martínez, 2020). Met name relatiekwaliteit en toewijding lijken invloed te hebben op de loyaliteit van studenten/alumni (Hennig-Thurau et al., 2001; Iskhakova et al., 2016). De bevindingen zoals in Hoofdstuk 5, bevestigen dat men zich moet richten op affectief commitment om alumniloyaliteit te bewerkstelligen.

Hoofdstuk 6 bevestigde dat de relatie tussen relatiekwaliteit en studentloyaliteit sterker is dan omgekeerd. Tevredenheid wordt vooral genoemd als voorspeller van studentloyaliteit (Shahsavar \& Sudzina, 2017). Onze bevindingen voegen hieraan toe dat tevredenheid, in termen van de relatiekwaliteit gepercipieerd door studenten, mogelijk wordt veroorzaakt door het vertrouwen van studenten in de eerlijkheid en welwillendheid dat zij hebben in docenten en medewerkers van hun opleiding.

Parallel aan de onderwijskundige literatuur over studentbetrokkenheid (zie bijvoorbeeld Astin, 1999; Tinto, 1975) is het voor hoger onderwijsinstellingen essentieel om een langdurige relatie met studenten te onderhouden en op te bouwen. Daarom dragen de bevindingen van dit proefschrift bij aan de bestaande literatuur en praktische waarde van het bevorderen van klantloyaliteit in het algemeen, en student/alumniloyaliteit in het bijzonder. Zo zouden onderwijsinstellingen bijvoorbeeld strategieën ten aanzien van hun studenten kunnen initiëren op basis van de relatiekwaliteitsdimensies (HERQschaal). Ze zouden zich daarbij moeten richten op verschillende segmenten van hun 
studentenpopulatie (bijvoorbeeld ingeschreven studenten versus alumni, ervaringen van eerstejaars studenten versus ervaringen van studenten uit hogere jaren). In lijn met recente bevindingen (Pedro et al., 2020a, 2020b), zoals we in Hoofdstuk 5 hebben aangegeven, zou het voor onderwijsinstellingen interessant zijn om te onderzoeken of alumni nog steeds betrokken willen zijn bij hun voormalig onderwijsinstituut, en zo ja, op welke manier.

\section{Implicaties}

De bijdrage van dit proefschrift ligt in de theoretische onderbouwing voor het aangaan van interpersoonlijke relaties met studenten zoals beschreven in Hoofdstuk 2. In eerder onderzoek lag de focus nog vooral op de relatie tussen docenten en studenten (zie bijvoorbeeld Hagenauer \& Volet, 2014; Pianta et al., 2012). Binnen dit proefschrift is gekeken naar de relatie van studenten met alle medewerkers van de opleiding waarmee zij in contact (kunnen) komen bij hun opleiding. De resultaten bevestigen dat studenten aangeven de relaties met hun docenten te waarderen, hetgeen wordt ondersteund in recent onderzoek naar de relaties tussen docenten en studenten (bijvoorbeeld Clem et al., 2020; Moya et al., 2020; Roorda et al., 2011, 2017). Studenten geven echter ook aan dat de relaties met andere medewerkers, bijvoorbeeld met mentoren of studieloopbaancoaches, van belang zijn. Tot slot geeft het gebruik van een instrument als de relatiekwaliteitsschaal in het hoger onderwijs (HERQ-schaal) inzicht in de perceptie van studenten van de relatiekwaliteit die zij ervaren met hun universiteit/hoger onderwijsinstelling. Deze bevindingen sluiten aan bij eerder onderzoek dat aangeeft dat de toepassing van een relatiemanagementbenadering in het hoger onderwijs vruchtbaar kan zijn (zie bijvoorbeeld Bowden, 2011; Helgesen, 2008; Hennig-Thurau et al., 2001).

Zowel in Hoofdstuk 4 als 5 geven de bevindingen van Studies 3 en 4 aan dat relatiekwaliteit een voorspeller is voor studentbetrokkenheid (engagement) en student/alumniloyaliteit. De studies bouwen voort op ideeën van SET en eerder onderzoek op het gebied van dienstverlening en relatiebeheer in combinatie met de onderwijsliteratuur (zie bijvoorbeeld Koenig-Lewis et al., 2016; Snijders et al., 2018, Snijders, Wijnia, Rikers, \& Loyens, 2020; Thibaut \& Kelley, 1959; Thoits \& Hewitt, 2001). De relevantie voor de onderwijspraktijk is dat, om langdurige relaties met (oud-)studenten te initiëren, zij zich moeten richten op het leggen van de relationele banden met studenten tijdens hun studie.

In Hoofdstuk 5 werd ook aangegeven dat de relatiekwaliteitsdimensies belangrijke voorspellers zijn voor niet-financiële alumniloyaliteit. Tot nu toe heeft eerder onderzoek zich vooral gericht op de loyaliteit van alumni in de vorm van financiële bijdragen. Om een nieuw licht te werpen, hebben we ons gericht op het niet-financiële aspect van bijdragen van alumni. De bevindingen zoals beschreven in Hoofdstuk 5, ondersteunen een recente 
studie van Pedro et al. (2020b), die aangeven dat de meeste Europese universiteiten nog steeds worstelen met een degelijk ingerichte alumnicultuur. Met deze bevindingen voegen we dan ook waarde toe aan de bestaande literatuur over alumniloyaliteit.

Voor de onderwijspraktijk benadrukken de bevindingen beschreven in Hoofdstuk 4, dat onderwijskundigen en beleidsmakers er baat bij kunnen hebben om de percepties van studenten te onderzoeken en regelmatig te monitoren. Bovendien is onze conclusie n.a.v. Hoofdstuk 5 dat om loyale alumni te bewerkstelligen, de opleiding en het instituut zich ook moet richten op de relatiekwaliteitsdimensies, zoals het affectieve commitment en het vertrouwen dat studenten hebben in de welwillendheid van (docenten en medewerkers van) hun (voormalige) opleiding.

De praktische implicatie is dat docententeams, onderwijskundigen en beleidsmakers gebruik kunnen maken van deze bevindingen. Met name de manier waarop het vertrouwen van studenten in de kwaliteit van de relatie die zij hebben met hun opleiding kan worden opgebouwd zoals door tevredenheid en betrokkenheid, en het vermijden van onnodige conflicten.

Voor kwaliteitsborging maken hoger onderwijsinstellingen onder meer gebruik van kwaliteitsmeetinstrumenten zoals de nationale studentenenquête (NSE; Studiekeuzer23, 2020). De bevindingen van de onderliggende studies laten echter een andere interpretatie zien van de relaties die het onderwijsproces vormgeven. Via de HERQ-schaal wordt specifieker aangegeven welke percepties studenten hebben ten aanzien van de kwaliteit van hun relatie met hun instituut. Dit gebeurt door studenten expliciet te vragen hoe zij de kwaliteit van hun relatie met de opleiding ervaren aan de hand van meerdere items. Alle studies van dit proefschrift tezamen, suggereren dat het belangrijk is om de relatie van studenten met alle contactpersonen van de opleiding in ogenschouw te nemen, in plaats van alleen te richten op de relatie tussen docent en student. De vijf relatiekwaliteitsdimensies geven hierbij een beter beeld. De bevindingen van dit proefschrift zijn daarom op meerdere manieren van belang voor beleidsmakers en onderwijspersoneel/onderwijsgevenden.

Op het individuele niveau van het hoger onderwijs kunnen professoren, leerkrachten of mentoren het begrip van de kwaliteit van de relatie met de studenten positief beïnvloeden. Hun advies en begeleiding is essentieel en hierin zouden de kwaliteitsdimensies van de relatie in overweging moeten worden genomen. Op groepsniveau is afstemming binnen het onderwijsteam noodzakelijk om te bepalen hoe zij (docenten, professoren en mentoren) studenten willen begeleiden in het onderwijsproces tot aan het afstuderen en daarna. Voor verdere discussie stellen 
we echter vragen. In hoeverre willen docenten welwillend zijn? Is het faculteitsteam het eens over de manier waarop het in wil spelen en voorzien in de behoeften van de studenten? Hoe kunnen studenten docenten en ander onderwijspersoneel benaderen, via e-mail of WhatsApp, online of op elk gewenst moment op kantoor? Reageren docenten en onderwijspersoneel binnen dezelfde tijd; bijvoorbeeld wanneer een student een vraag stelt en het beleid is om binnen twee dagen te reageren? Hoe communiceren de faculteit en het (onderwijs)personeel op zo'n manier dat studenten het gevoel hebben dat ze eerlijk worden behandeld? Hebben de faculteit en het (onderwijs) personeel richtlijnen over hoe en wanneer te reageren? Ons advies is dat de faculteit en het (onderwijs)personeel hun (communicatie)strategieën definiëren ten aanzien van de begeleiding om relaties met hun studenten op te bouwen en te onderhouden. Hierbij zullen de faculteit en het onderwijspersoneel rekening ermee moeten houden dat studenten met diverse culturele achtergronden verschillend kunnen reageren. Zo gaf eerder onderzoek aan dat de cultuur binnen een instelling met betrekking tot de culturele achtergrond van studenten van invloed kan zijn op het gevoel van studenten in hoeverre zij zich comfortabel voelen in de omgeving waarin het onderwijs wordt verzorgd (zie Guo \& Jamal, 2007). Een recente studie van Schachner et al. (2019) gaf aan dat een gevoel van saamhorigheid de relatie tussen de culturele diversiteit en de studentenresultaten bevordert.

\section{Limitaties}

De gepresenteerde studies van dit proefschrift waren aan bepaalde beperkingen onderhevig. Ten eerste, met betrekking tot de gebruikte constructen, maten de items van studentloyaliteit de gedragsintenties van de student- en alumniloyaliteit (bijvoorbeeld in de vorm van aanbevelingen doen, positieve mond-tot-mondreclame, deelname). Hoewel intenties van studenten worden verondersteld te resulteren in gedragsmatige, onderwijs/ leeruitkomsten (Pedro et al., 2020a, 2020b), resulteren intenties niet automatisch in daadwerkelijk gedrag (zie theorie van gepland gedrag, Ajzen, 1991; Armitage \& Christian, 2003).

Ten tweede werd de loyaliteit van alumni gemeten door te vragen hoe zij met hun voormalige instituut (Studie 4) verbonden zouden zijn door financiële en niet-financiële bijdragen (bijvoorbeeld de feedback die alumni geven, het aanbieden van stages en de tewerkstelling van afgestudeerden). Positieve alumnirelaties zijn van belang voor hoger onderwijsinstellingen. Echter om deze te begrijpen moet men weten waarom alumni ofwel op een financiële dan wel op een niet-financiële manier willen bijdragen. Als universiteiten en hoger onderwijsinstellingen een trackrecord hebben (bijvoorbeeld wie financieel bijdraagt, wie gastcolleges geeft), dan is onderzoek tussen verschillende tijdspunten mogelijk om intenties en feitelijk gedrag te onderzoeken. 
Ten derde, in dit onderzoek zijn ingeschreven studenten en alumni benaderd voor deelname aan de onderzoeken. Studenten die zijn uitgevallen zijn niet meegenomen in dit onderzoek. Omwille van hun standpunten ten aanzien van relatiekwaliteit vormen zij een interessante groep om nader te onderzoeken.

Ten slotte zijn de onderzoeksontwerpen in de gepresenteerde onderzoeken gebaseerd op zelfrapportage (van studenten). Om een breder idee te ontwikkelen, kan datatriangulatie nuttig zijn om een vollediger beeld te geven, zoals de analyse van de evaluatiegegevens van de studenten. Bovendien waren de antwoorden van de studenten vrijwillig, en hun bereidheid om meerdere malen op de enquête te reageren resulteerde in een kleiner aantal antwoorden in het longitudinale onderzoek. Hoewel we het belang benadrukken van de bereidheid van studenten om vrijwillig deel te nemen aan de enquêtes, is de inzet van studenten om de enquête in te vullen noodzakelijk om voldoende longitudinale gegevens te verzamelen. Voor verder onderzoek raden we daarom aan om studenten vooraf te betrekken bij een dergelijk project en te wijzen op het belang van hun rol als respondenten.

\section{Richtlijnen Voor Vervolgonderzoek}

Op basis van de bevindingen en implicaties van dit proefschrift suggereren we verschillende opties voor vervolgonderzoek. Ten eerste, zoals we in de inleiding van dit proefschrift hebben beschreven, moet volgens het kwaliteitsmodel van Parasuraman et al. (1991) eerst de perceptie van de afnemers (stakeholders) van de diensten worden onderzocht om de kwaliteit van de dienstverlening te evalueren. In het hoger onderwijs zijn studenten de primaire stakeholders van de onderwijsdienst. In de studies van dit proefschrift hebben we daarom slechts één kant van de relatie (namelijk de perceptie van de studenten) in ogenschouw genomen. In dienstverleningscontexten in het algemeen (Cronin \& Taylor, 1994; Zeithaml et al., 1996), en in het hoger onderwijs in het bijzonder, zijn studenten niet geneigd om onderscheid te maken tussen verwachtingen vooraf en post-percepties (Dollinger \& Lodge, 2020; Nadiri et al., 2009; Sultan \& Wong, 2010). Daarom is in de gepresenteerde studies een benadering toegepast die gebaseerd is op alleen de ervaringen met de geleverde dienst (performance-based). In dit proefschrift hebben we ons expliciet gericht op het standpunt van de studenten, waarbij we de studenten alleen vragen naar hun percepties (Studies 1-5). Er zijn echter ook andere partijen betrokken bij de relatie met de studenten, en hun antwoorden moeten daarom worden onderzocht. In lijn met de literatuur en onderzoek naar interpersoonlijke relaties is het belangrijk om informatie te verzamelen van verschillende partijen binnen de relatie om de stabiliteit van diens relatie te beoordelen (Duck, 1990). De volgende stap omvat daarom dus ook om de perceptie van andere belanghebbenden in het dienstverleningsproces, bijvoorbeeld leraren, professoren of mentoren mee te nemen in vervolgonderzoek. Verder, ondanks dat we oud-studenten 
hebben bevraagd over de relatiekwalteit met hun voormalig onderwijsinstituut zou vervolgonderzoek een beter beeld kunnen geven over de verwachtingen van alumni ten aanzien van wat zij terugverwachten voor hun bijdrage.

Ten tweede hebben we binnen dit proefschrift de kwaliteit van de perceptie van studenten van de relatie die ze hebben of hadden met de onderwijsfaculteit en het personeel onderzocht. Daartoe is de HERQ-schaal als meetinstrument gebruikt. Hoewel de bevindingen van alle studies de toepasbaarheid van de HERQ-schaal in het kader van het hoger onderwijs bevestigen, is het onderzoek beperkt gebleven tot de reacties van studenten uit Nederlandse steekproeven van drie hogescholen in Zuidwest-Nederland. Verder onderzoek moet worden gedaan om verschillende contexten te vergelijken, zoals het vergelijken van vergelijkbare instellingen binnen en buiten Nederland en Europa, en onder instituten waarbij een alumnibeleid al langere tijd is ingevuld. Daarom is replicatie nodig voor een verdere toepasbaarheid van de resultaten.

Vervolgens werden de studenten in de onderhavige onderzoeken relatief gelijkmatig verdeeld over leeftijd, geslacht en verschillende onderwijsprogramma's. Echter, gerelateerd aan SET, kunnen culturele normen en waarden verschillen (Pillay \& James, 2015) en de uitkomsten ervan beïnvloeden, zoals alumni loyaliteit (Iskhakova et al., 2020). Daarom zou intercultureel onderzoek naar relatiekwaliteit helpen bij het onderzoeken van culturele verschillen in de manier waarop relatiekwaliteit in het hoger onderwijs wordt ervaren door (oud-)studenten uit andere culturen (García-Moya et al., 2020). Zoals aangegeven kan er tussen landen een verschil bestaan in de wijze waarop de bijdragen van alumni en hun betrokkenheid tot uitdrukking komen (bijvoorbeeld de Verenigde Staten versus Europa). Om de bevindingen van het onderzoek te veralgemeniseren raden wij aan om studenten van verschillende instellingen uit andere landen te onderzoeken, zodat de culturele interpretaties van de onderzochte variabelen beter kunnen worden vergeleken.

Daarnaast hebben vandaag de dag tal van studies de loyaliteit van studenten in het hoger onderwijs onderzocht. Echter, in deze onderzoeken zijn er variabelen die worden gebruikt om de loyaliteit van studenten/alumni te onderzoeken of te voorspellen, zoals; vertrouwen, tevredenheid, betrokkenheid, kwaliteit van de dienstverlening en het imago van de universiteit. Een degelijk conceptueel model, met inbegrip van de relevantie van alle variabelen, is nodig om de loyaliteit van studenten/alumni in het hoger onderwijs op één lijn te brengen. Interculturele verschillen kunnen nader worden onderzocht indien een model bestaat uit gegevens van verschillende onderwijsinstellingen in verschillende landen. De onderwijspraktijk kan van deze inzichten leren om vruchtbare en langdurige relaties met studenten van allerlei culturen op te bouwen. 
De semi-longitudinale studie impliceerde dat vertrouwen de basis vormt van relatiekwaliteit in het hoger onderwijs en dat deze de affectieve relatiekwaliteitsdimensies van betrokkenheid, conflict en tevredenheid voorspelt. In een replicatiestudie zouden de bevindingen verder onderzocht kunnen worden; zoals in een onderzoek waarin verschillende studentcohorten gevraagd worden om hun betrokkenheid in een longitudinaal project. Daarnaast kan een diepgaand onderzoek naar affectief conflict (als een negatieve relationele kwaliteitsdimensie tegenovergesteld aan vertrouwen) inzicht geven in hoe studenten hun perceptie van conflicten verandert in de loop van de tijd.

Ten slotte zorgde COVID-19 voor aanpassingen in het onderwijsproces. Blended en hybride leren domineren momenteel het onderwijs van studenten. Daarom zou een vergelijking tussen pre- en post-COVID-19 verschillen in de relatiekwaliteit van studenten interessant zijn om te onderzoeken.

\section{Conclusie}

De focus van dit proefschrift ligt op de binding tussen studenten en hun onderwijsinstelling. Het doel was te onderzoeken welke invloed relatiekwaliteit heeft op studentbetrokkenheid (student involvement; bij het studieproces (engagement) en bij de loyaliteit aan de opleiding of het instituut). In tegenstelling tot de eerdere onderzoeken in de onderwijsliteratuur wordt in dit proefschrift de sociale uitwisselingstheorie als overkoepelend kader gebruikt om sociale interacties en relaties in het hoger onderwijs te onderzoeken. Parallel aan sociale uitwisselingstheorie vormden de theoretische onderbouwing van de service- en relatiemanagementliteratuur, in combinatie met de onderwijsliteratuur, de basis voor de gepresenteerde studies om de relaties tussen relatiekwaliteit, studentbetrokkenheid en student/alumniloyaliteit te onderzoeken.

De onderzoeken van dit proefschrift waren een eerste poging waarin onderzocht werd hoe studenten aankijken tegen de kwaliteit van de relatie met hun opleiding. Het onderzoek resulteerde in een praktisch toepasbaar instrument in het hoger onderwijs om de perceptie van studenten van de kwaliteit van de relatie die zij hebben (of hadden) met de onderwijsfaculteit en het personeel vast te leggen: de HERQ-schaal. Kwaliteitsborging in hoger onderwijs is een belangrijke manier voor beleidsmakers om relaties met studenten en andere belanghebbenden, zoals relaties in het werkveld, te dienen en succesvol op te bouwen. Ondersteuning van het management is nodig, bijvoorbeeld bij strategische en procesbeslissingen over het meten en monitoren van de ervaringen van studenten. Door de HERQ-schaal die in onze studies wordt gebruikt toe te passen, kan de meting van de relatiekwaliteit in het hoger onderwijs worden verbeterd om de relationele 
aspecten van de onderwijservaring van studenten beter te begrijpen. Bovendien is het op die manier veel gemakkelijker om adequaat te reageren op de indicaties van de positieve en negatieve percepties van studenten.

De studies bevestigen dat om een positieve relatie met studenten op te bouwen en te onderhouden, het onderzoeken van de kwaliteit van de relatie noodzakelijk is om daarmee de relationele behoeften van studenten te begrijpen. Wanneer relatiekwaliteit positief wordt ervaren door (oud-)studenten, zullen zij meer betrokken raken bij de studie en op hun beurt (meer) loyaal worden. Hoewel er verschillen zijn gevonden tussen de voorspelling van relatiekwaliteitsdimensies tussen huidige en oud-studenten, fungeert relatiekwaliteit over het algemeen als een voorspeller van toekomstige studentbetrokkenheid (bij het studieproces) en loyaliteit.

Het toepassen van een relatiebenadering kan dus gunstig zijn voor hoger onderwijsinstellingen. Om binding met studenten te verbeteren, moeten de beleidsmakers en de onderwijspraktijk zich strategisch richten op de relationele aspecten met hun studenten. Zoals voorgesteld, zouden alumni actief betrokken moeten zijn bij het creëren van een alumnicultuur die op langdurige relaties is gebaseerd (Pedro et al., 2020a, 2020b; Schlesinger et al., 2016). Op deze manier zouden studenten, alumni, werkveld en hoger onderwijsinstellingen profiteren van het onderwijs dat zij tezamen creëren. 
$\bullet$ 


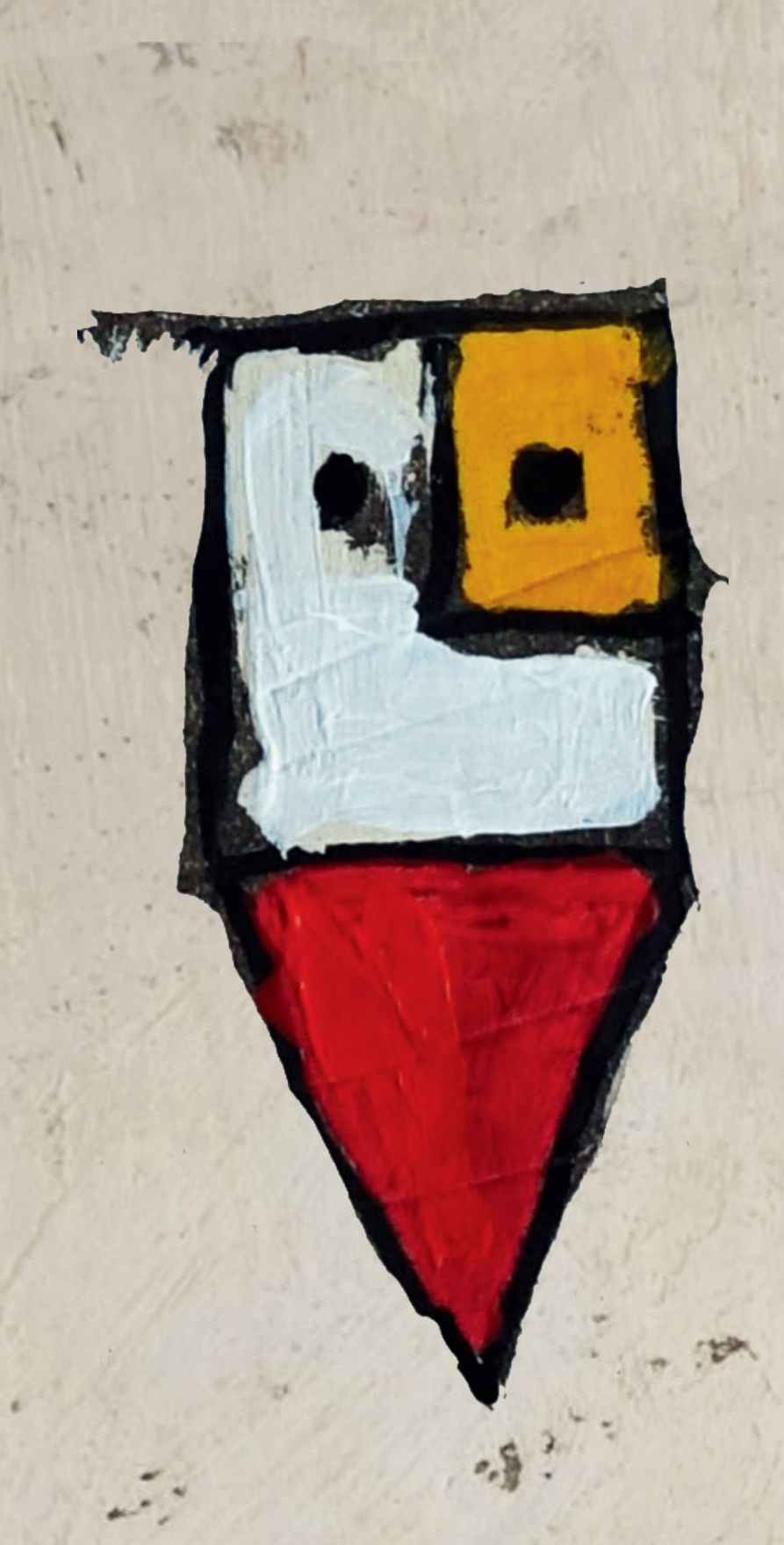




\section{7}

\section{References}

\section{项}
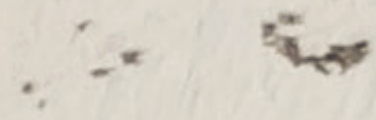
Ajzen, I. (1991). The theory of planned behavior. Organizational Behavior and Human Decision Processes, 50(2), $179-211$. https://doi.org/10.1016/0749-5978(91)90020-T

Akaike, H. (1978). On the likelihood of a time series model. Journal of the Royal Statistical Society. Series D, The Statistician, 27(3/4), 217-235. https://doi.org/10.2307/2988185

Alderman, R. V. (2008). Faculty and student out-of-classroom interaction: student perceptions of quality of interaction (Publication No. 3321628) [Doctoral dissertation, Texas A\&M University]. ProQuest Dissertations and Theses Global.

Ali, F., Zhou, Y., Hussain, K., Nair, P. K., \& Ragavan, N. A. (2016). Does higher education service quality effect student satisfaction, image and loyalty? Quality Assurance in Education, 24(1), 70-94. https://doi.org/10.1108/qae02-2014-0008

Allen, J. M., \& Smith, C. L. (2008). Faculty and student perspectives on advising: Implications for student dissatisfaction. Journal of College Student Development, 49(6), 609-624. https://doi.org/10.1353/csd.0.0042

Altinisik, Y., Nederhof, E., Hoijtink, H., Oldehinkel, A., \& Kuiper, R. M. (2018). Evaluation of inequality constrained hypotheses using a generalization of the AIC [Unpublished manuscript]. Utrecht University. https://www.iops.nl/ wp-content/uploads/2015/06/Thesis_Yasin_Altinisik.pdf

Alves, H., \& Raposo, M. (2007). Conceptual model of student satisfaction in higher education. Total Quality Management \& Business Excellence, 18(5), 571-588. https://doi.org/10.1080/14783360601074315

Anderson, J. C., \& Gerbing, D. W. (1988). Structural equation modeling in practice: A review and recommended two-step approach. Psychological Bulletin, 103(3), 411-423. https://doi.org/10.1037/0033-2909.103.3.411

Appleton, J. J., Christenson, S. L., Kim, D., \& Reschly, A. L. (2006). Measuring cognitive and psychological engagement: Validation of the student engagement instrument. Journal of School Psychology, 44(5), 427-445. https://doi.org/10.1016/j.jsp.2006.04.002

Arbuckle, J. (2013). IBM SPSS Amos 22 user's guide. Amos Development Corporation.

Arena, M., Arnaboldi, M., \& Azzone, G. (2010). Student perceptions and central administrative services: The case of higher education in Italy. Studies in Higher Education, 35(8), 941-959. https://doi.org/10.1080/03075070903420708

Armitage, C. J., \& Christian, J. (2003). From attitudes to behaviour: Basic and applied research on the theory of planned behaviour. Current Psychology, 22(3), 187-195. https://doi.org/10.1007/s12144-003-1015-5

Arnett, D. B., German, S. D., \& Hunt, S. D. (2003). The identity salience model of relationship marketing success: The case of nonprofit marketing. Journal of Marketing, 67(2), 89-105. https://doi.org/10.1509/jmkg.67.2.89.18614

Artino, A. R., Jr., \& Pekrun, R. (2014). Using control-value theory to understand achievement emotions in medical education. Academic Medicine, 89(12), 1696. https://doi.org/10.1097/acm.0000000000000536

Astin, A. W. (1999). Student involvement: A developmental theory for higher education. Journal of College Student Development, 40(5), 518-531.

Athanasopoulou, P. (2009). Relationship quality: A critical literature review and research agenda. European Journal of Marketing, 43(5/6), 583-610. https://doi.org/10.1108/03090560910946945

Atnip, B. (2015). Assessing the relationship between student and faculty perceptions of student engagement at Central Mountain College (Publication No. 3689327) [Doctoral dissertation, The University of Nebraska]. ProQuest Dissertations and Theses Global.

Bakker, A. B., Demerouti, E., \& Sanz-Vergel, A. I. (2014). Burnout and work engagement: The JD-R approach. Annual Review of Organizational Psychology and Organizational Behavior, 1(1), 389-411. https://doi.org/10.1146/ annurev-orgpsych-031413-091235

Bakker, A. B., Sanz Vergel, A. I., \& Kuntze, J. (2015). Student engagement and performance: A weekly diary study on the role of openness. Motivation and Emotion, 39, 49-62. https://doi.org/10.1007/s11031-014-9422-5 
Barnard, Z., \& Rensleigh, C. (2008). Investigating online community portals for enhanced alumni networking. The Electronic Library, 26(4), 433-445. https://doi.org/10.1108/02640470810893710

Berry, L. L. (2002). Relationship marketing of services perspectives from 1983 and 2000. Journal of Relationship Marketing, 1(1), 59-77. https://doi.org/10.1300/j366vo1no1_05

Betts, J. E., Appleton, J. J., Reschly, A. L., Christenson, S. L., \& Huebner, E. S. (2010). A study of the factorial invariance of the Student Engagement Instrument (SEI): Results from middle and high school students. School Psychology Quarterly, 25(2), 84-93. https://doi.org/10.1037/a0020259

Blau, P. (1964). Exchange \& power in social life. Wiley.

Bloemer, J., \& De Ruyter, K. (1999). Customer loyalty in high and low involvement service settings: the moderating impact of positive emotions. Journal of Marketing Management, 15(4), 315-330. https://doi. org/10.1362/026725799784870388

Bonet, G., \& Walters, B. R. (2016). High impact practices: Student engagement and retention. College Student Journal, 50(2), 224-235. https://www-ingentaconnect- https://academicworks.cuny.edu/cgi/viewcontent. cgi?article=1101\&context=kb_pubs

Bowden, J. L. H. (2009). The process of customer engagement: A conceptual framework. Journal of Marketing Theory and Practice, 17(1), 63-74. https://doi.org/10.2753/mtp1069-6679170105

Bowden, J. L. H. (2011). Engaging the student as a customer: A relationship marketing approach. Marketing Education Review, 21(3), 211-228. https://doi.org/10.2753/mer1052-8008210302

Bowden, J. L. H., Tickle, L., \& Naumann, K. (2019). The four pillars of tertiary student engagement and success: a holistic measurement approach. Studies in Higher Education, 1-18. https://doi.org/10.1080/03075079.2019.1672647

Bowden, J. L. H., \& Wood, L. (2011). Sex doesn't matter: the role of gender in the formation of student-university relationships. Journal of Marketing for Higher Education, 21(2), 133-156. https://doi.org/10.1080/08841241.2011.623731

Braun, J., \& Zolfagharian, M. (2016). Student participation in academic advising: Propensity, behavior, attribution and satisfaction. Research in Higher Education, 57(8), 968-989. https://doi.org/10.1007/s11162-016-9414-2

Brodie, R. J., Hollebeek, L. D., Jurić, B., \& Ilić, A. (2011). Customer engagement: Conceptual domain, fundamental propositions, and implications for research. Journal of Service Research, 14(3), 252-271. https://doi. org/10.1177/1094670511411703

Brown, C., Varley, P., \& Pal, J. (2009). University course selection and services marketing. Marketing Intelligence \& Planning, 27(3), 310-325. https://doi.org/10.1108/02634500910955227

Brown, R. M., \& Mazzarol, T. W. (2009). The importance of institutional image to student satisfaction and loyalty within higher education. Higher Education, 58, 81-95. https://doi.org/10.1007/s10734-008-9183-8

Bryk, A., \& Schneider, B. (2002). Trust in schools; A core resource for improvement. Russell Sage Foundation.

Bunce, L., Baird, A., \& Jones, S. E. (2017). The student-as-consumer approach in higher education and its effects on academic performance. Studies in Higher Education, 42(11), 1958-1978. https://doi.org/10.1080/03075079.2015.1 127908

Burnham, K. P., \& Anderson, D. R. (2002). Model selection and multimodel inference: A practical information-theoretic approach. Springer-Verlag.

Burns, R. A., Crisp, D. A., \& Burns, R. B. (2020). Re-examining the reciprocal effects model of self-concept, selfefficacy, and academic achievement in a comparison of the cross-lagged panel and random-intercept crosslagged panel frameworks. British Journal of Educational Psychology, 90(1), 77-91. https://doi.org/10.1111/bjep.12265

Butterfield, L. D., Borgen, W. A., Amundson, N. E., \& Maglio, A. T. (2005). Fifty years of the critical incident technique: 1954-2004 and beyond. Qualitative Research, 5(4), 475-497. https://doi.org/10.1177/1468794105056924

Buttle, F., \& Maklan, S. (2015). Customer relationship management: Concepts and technologies. Routledge. 
Byrne, B. (2013). Structural equation modeling with AMOS: Basic concepts, application, and programming (2nd ed.). Taylor \& Francis.

Carvalho, S. W., \& de Oliveira Mota, M. (2010). The role of trust in creating value and student loyalty in relational exchanges between higher education institutions and their students. Journal of Marketing for Higher Education, 20(1), 145-165. https://doi.org/10.1080/08841241003788201

Castaldo, S. (2007). Trust in market relationships. Edward Elgar Publishers.

Chirikov, I. (2016). How global competition is changing universities: Three theoretical perspectives. UC Berkeley: Center for Studies in Higher Education. https://escholarship.org/uc/item/50g3t797

Cho, M., \& Auger, G. A. (2013). Exploring determinants of relationship quality between students and their academic department. Journalism \& Mass Communication Educator, 68(3), 255-268. https://doi.org/10.1177/1077695813495048

Clem, A. L., Rudasill, K. M., Hirvonen, R., Aunola, K., \& Kiuru, N. (2020). The roles of teacher-student relationship quality and self-concept of ability in adolescents' achievement emotions: temperament as a moderator. European Journal of Psychology of Education. Advance online publication. https://doi.org/10.1007/s10212-020-00473-6

Coates, H. (2010). Development of the Australasian survey of student engagement (AUSSE). Higher Education, 60, 1-17. https://doi.org/10.1007/s10734-009-9281-2

Cohen, J. (1988). Statistical power analysis for the behavioral sciences (2nd ed.). Lawrence Erlbaum Associates.

Connell, J. P., \& Wellborn, J. G. (1991). Competence, autonomy, and relatedness: A motivational analysis of selfsystem processes. In R. Gunnar \& L. Sroufe (Eds.), Self processes and development: Minnesota symposium on child psychology (pp. 43-77). Chicago University Press.

Cook, K. S., \& Rice, E. (2003). Social exchange theory. In J. Delamater (Ed.), Handbook of social psychology (pp. 53-76). Springer.

Cook-Sather, A., \& Luz, A. (2015). Greater engagement in and responsibility for learning: What happens when students cross the threshold of student-faculty partnership. Higher Education Research \& Development, 34(6), 10971109. https://doi.org/10.1080/07294360.2014.911263

Cotten, S. R., \& Wilson, B. (2006). Student-faculty interactions: Dynamics and determinants. Higher Education, 51(4), 487-519. https://doi.org/10.1007/s10734-004-1705-4

Cronin, J. J., Jr., \& Taylor, S. A. (1994). SERVPERF versus SERVQUAL: reconciling performance-based and perceptions-minus-expectations measurement of service quality. Journal of Marketing, 58(1), 125-131. https://doi. org/10.2307/1252256

Cropanzano, R., Anthony, E. L., Daniels, S. R., \& Hall, A. V. (2017). Social exchange theory: A critical review with theoretical remedies. Academy of Management Annals, 11, 479-516. https://doi.org/10.5465/annals.2015.0099

Crosby, L. A., Evans, K. R., \& Cowles, D. (1990). Relationship quality in services selling: An interpersonal influence perspective. Journal of Marketing, 54(3), 68-81. https://doi.org/10.2307/1251817

Culver, J. (2015). Relationship quality and student engagement (Publication No. 3700604) [Doctoral dissertation, Wayne State University]. ProQuest Dissertations and Theses Global.

Dagger, T. S., Danaher, P. J., \& Gibbs, B. J. (2009). How often versus how long. Journal of Service Research, 11(4), 371388. https://doi.org/10.1177/1094670508331251

De Vries, W., Goud, A., \& Goud, B. (2012). Strategic service management. Noordhoff Uitgevers.

Deci, E. L., \& Ryan, R. M. (2008). Self-determination theory: A macrotheory of human motivation, development, and health. Canadian Psychology/Psychologie Canadienne, 49(3), 182-185. https://doi.org/10.1037/a0012801

Demetriou, C., Ozer, B. U., \& Essau, C. A. (2015). Self-report questionnaires. In R. I. Caution \& S. O. Lilienfeld (Eds.), The encyclopedia of clinical psychology (pp. 1-6). Wiley. https://onlinelibrary.wiley.com/doi/ abs/10.1002/9781118625392.wbecp507 
Di Battista, S., Pivetti, M., \& Berti, C. (2014). Engagement in the university context: exploring the role of a sense of justice and social identification. Social Psychology of Education, 17(3), 471-490. https://doi.org/10.1007/s11218-0149255-9

Dick, A. S., \& Basu, K. (1994). Customer loyalty: Toward an integrated conceptual framework. Journal of The Academy of Marketing Science, 22(2), 99-113. https://doi.org/10.1177/0092070394222001

Dobransky, N. D., \& Frymier, A. (2004). Developing teacher-student relationships through out of class communication. Communication Quarterly, 52(3), 211-223. https://doi.org/10.1080/01463370409370193

Dollinger, M., \& Lodge, J. (2020). Understanding value in the student experience through student-staff partnerships. Higher Education Research \& Development, 39(5), 940-952. https://doi.org/10.1080/07294360.2019.16 95751

Doña Toledo, L., \& Luque Martínez, T. (2020). How loyal can a graduate ever be? The influence of motivation and employment on student loyalty. Studies in Higher Education, 45(2), 353-374. https://doi.org/10.1080/03075079.201 8.1532987

Douglas, J., Davies, J., Sundbury, L., \& McLelland, R. (2008). Comparing critical incident technique and survey questionnaires as a means of collecting student feedback. In Proceedings of the 11th Toulon-Verona international conference on quality in services: Higher education, health care, local government, tourism, banking (pp. 59-69). Firenze University Press. https://digital.casalini.it/9788884538550

Douglas, J., McClelland, R., \& Davies, J. (2008). The development of a conceptual model of student satisfaction with their experience in higher education. Quality Assurance in Education, 16(1), 19-35. https://doi. org/10.1108/09684880810848396

Douglas, J. A., McClelland, R., Davies, J., \& Sundbury, L. (2009). Using critical incident technique (CIT) to capture the voice of the student. The TQM Journal, 21(4), 305-318. https://doi.org/10.1108/17542730910965038

Duck, S. (1990). Relationships as unfinished business: Out of the frying pan and into the 1990s. Journal of Social and Personal Relationships, 7(1), 5-28. https://doi.org/10.1177/0265407590071001

Ebert, K., Axelsson, L., \& Harbor, J. (2015). Opportunities and challenges for building alumni networks in Sweden: A case study of Stockholm University. Journal of Higher Education Policy and Management, 37(2), 252-262. https://doi. org/10.1080/1360080x.2015.1019117

Elken, M., Hovdhaugen, E., \& Stensaker, B. (2016). Global rankings in the Nordic region: Challenging the identity of research-intensive universities? Higher Education, 72(6), 781-795. https://doi.org/10.1007/s10734-015-9975-6

Emerson, R. M. (1976). Social exchange theory. Annual Review of Sociology, 2(1), 335-362. https://doi.org/10.1146/ annurev.so.02.080176.002003

Engels, M. C., Colpin, H., Van Leeuwen, K., Bijttebier, P., Van Den Noortgate, W., Claes, S., Goossens, L., \& Verschueren, K. (2016). Behavioral engagement, peer status, and teacher-student relationships in adolescence: A longitudinal study on reciprocal influences. Journal of Youth and Adolescence, 45(6), 1192-1207. https://doi. org/10.1007/s10964-016-0414-5

Epstein, J., Santo, R. M., \& Guillemin, F. (2015). A review of guidelines for cross-cultural adaptation of questionnaires could not bring out a consensus. Journal of Clinical Epidemiology, 68(4), 435-441. https://doi.org/10.1016/j. jclinepi.2014.11.021

Estermann, T., \& Claeys-Kulik, A-L. (2016). Performance-based funding of universities in Europe. International Higher Education, 85, 31-33. https://doi.org/10.6017/ihe.2016.85.9250

Farrow, H., \& Yuan, Y. C. (2011). Building stronger ties with alumni through Facebook to increase volunteerism and charitable giving. Journal of Computer-Mediated Communication, 16(3), 445-464. https://doi.org/10.1111/j.10836101.2011.01550.x

Farr-Wharton, B., Charles, M. B., Keast, R., Woolcott, G., \& Chamberlain D. (2018). Why lecturers still matter: The impact of lecturer-student exchange on student engagement and intention to leave university prematurely. Higher Education, 75(1), 167-185. https://doi.org/10.1007/s10734-017-0190-5 
Foa, E. B., \& Foa, U. G. (1980). Resource theory: Interpersonal behavior as exchange. In K. J. Gergen, M. S. Greenberg, \& R. H. Wills (Eds.), Social exchange (pp. 77-95). Springer. https://doi.org/10.1007/978-1-4613-3087-5_4

Fogg, P. (2008). How colleges use alumni to recruit students. The Chronicle of Higher Education, 54(34). https://www. chronicle.com/article/How-Colleges-Use-Alumni-to/22270

Fornell, C., \& Larcker, D. F. (1981). Structural equation models with unobservable variables and measurement error: Algebra and statistics. Journal of Marketing Research, 18(3), 382-388. https://doi.org/10.2307/3150980

Frambach, J. M., Driessen, E. W., Beh, P., \& Van der Vleuten, C. P. M. (2014). Quiet or questioning? Students' discussion behaviors in student-centered education across cultures. Studies in Higher Education, 39(6), 1001-1021. https://doi.org/10.1080/03075079.2012.754865

Fraser, B. J., \& Walberg, H. J. (2005). Research on teacher-student relationships and learning environments: Context, retrospect and prospect. International Journal of Educational Research, 43(1-2), 103-109. https://doi. org/10.1016/j.ijer.2006.03.001

Fredricks, J. A., Blumenfeld, P. C., \& Paris, A. H. (2004). School engagement: Potential of the concept, state of the evidence. Review of Educational Research, 74(1), 59-109. https://doi.org/10.3102/00346543074001059

Fredricks, J. A., Filsecker, M., \& Lawson, M. A. (2016). Student engagement, context, and adjustment: Addressing definitional, measurement, and methodological issues. Learning and Instruction, 43, 1-4. https://doi.org/10.1016/j. learninstruc.2016.02.002

Fredricks, J. A., \& McColskey, W. (2012). The measurement of student engagement: A comparative analysis of various methods and student self-report instruments. In S. L. Christenson, A. L. Reschly, \& C. Wylie (Eds.), Handbook of research on student engagement (pp. 763-782). Springer. https://doi.org/10.1007/978-1-4614-2018-7_37

Fuentes, M. V., Ruiz Alvarado, A., Berdan, J., \& DeAngelo, L. (2014). Mentorship matters: Does early faculty contact lead to quality faculty interaction? Research in Higher Education, 55(3), 288-307. https://doi.org/10.1007/s11162-0139307-6

García-Moya, I., Brooks, F., \& Moreno, C. (2020). Humanizing and conducive to learning: An adolescent students' perspective on the central attributes of positive relationships with teachers. European Journal of Psychology of Education, 35(1), 1-20. https://doi.org/10.1007/s10212-019-00413-z

García-Moya, I., Bunn, F., Jiménez-Iglesias, A., Paniagua, C., \& Brooks, F. M. (2018). The conceptualisation of school and teacher connectedness in adolescent research: A scoping review of literature. Educational Review, 71(4), 423-444. https://doi.org/10.1080/00131911.2018.1424117

García-Moya, I., Moreno, C., \& Brooks, F. M. (2019). The 'balancing acts' of building positive relationships with students: Secondary school teachers' perspectives in England and Spain. Teaching and Teacher Education, 86, Article 102883. https://doi.org/10.1016/j.tate.2019.102883

Gehlbach, H., Brinkworth, M. E., \& Harris, A. D. (2012). Changes in teacher-student relationships. British Journal of Educational Psychology, 82(4), 690-704. https://doi.org/10.1111/j.2044-8279.2011.02058.x

Ghosh, A. K.., Whipple, T. W., \& Bryan, G. A. (2001). Student trust and its antecedents in higher education. The Journal of Higher Education, 72(3), 322. https://doi.org/10.2307/2649334

Gibbs, A. (1997). Focus groups. Social Research Update, 19(8). http://sru.soc.surrey.ac.uk/SRU19.html

Gibbs, T., \& Kharouf, H. (2020). The value of co-operation: An examination of the work relationships of university professional services staff and consequences for service quality. Studies in Higher Education. Advance online publication. https://doi.org/10.1080/03075079.2020.1725878

Grönroos, C. (1990). Service management \& marketing: Managing the moments of truth in service competition. Jossey-Bass.

Grönroos, C. (1994). Quo vadis, marketing? Toward a relationship marketing paradigm. Journal of Marketing Management, 10(5), 347-360. https://doi.org/10.1080/0267257x.1994.9964283 
Grönroos, C. (2016). Service management and marketing (4th ed.). Wiley.

Guilbault, M. (2016). Students as customers in higher education: Reframing the debate. Journal of Marketing for Higher Education, 26(2), 132-142. https://doi.org/10.1080/08841241.2016.1245234

Gummesson, E. (1994). Broadening and specifying relationship marketing. Asia-Australia Marketing Journal, 2(1), 3143. https://doi.org/10.1016/s1320-1646(94)70276-8

Gummesson, E., \& Grönroos, C. (2012). The emergence of the new service marketing: Nordic School perspectives. Journal of Service Management, 23(4), 479-497. https://doi.org/10.1108/09564231211260387

Guo, S., \& Jamal, Z. (2007). Nurturing cultural diversity in higher education: a critical review of selected models. Canadian Journal of Higher Education, 37(3), 27-49. https://journals.sfu.ca/cjhe/index.php/cjhe/article/ view/529/575

Guzman, L. (2015). Consistent alumni volunteers: The influence of social experiences in sustaining alumni volunteerism [Doctoral dissertation, University of Michigan]. Deep Blue. http://hdl.handle.net/2027.42/116669

Hagedorn, L. S. (2015). A national initiative of teaching, researching, and dreaming: Community college faculty research in "Achieving the Dream" colleges. New Directions for Community Colleges, 2015(171), 49-62. https://doi. org/10.1002/cc.20154

Hagenauer, G., Hascher, T., \& Volet, S. E. (2015). Teacher emotions in the classroom: Associations with students' engagement, classroom discipline and the interpersonal teacher-student relationship. European Journal of Psychology of Education, 30(4), 385-403. https://doi.org/10.1007/s10212-015-0250-0

Hagenauer, G., \& Volet, S. E. (2014). Teacher-student relationship at university: An important yet under-researched field. Oxford Review of Education, 40(3), 370-388. https://doi.org/10.1080/03054985.2014.921613

Hair, J. F., Hult, G. M., Ringle, C. M., \& Sarstedt, M. (2014). A primer on partial least squares structural equation modeling (PLS-SEM). SAGE.

Hair, J. F.., Hult, G. M., Ringle, C. M., \& Sarstedt, M. (2017). A primer on partial least squares structural equation modeling (PLS-SEM) (2nd ed.). SAGE.

Hallowell, R. (1996). The relationships of customer satisfaction, customer loyalty, and profitability: An empirical study. International Journal of Service Industry Management, 7(4), 27-42. https://doi.org/10.1108/09564239610129931

Hamaker, E. L., Kuiper, R. M., \& Grasman, R. P. P. P. (2015). A critique of the cross-lagged panel model. Psychological Methods, 20(1), 102-116. https://doi.org/10.1037/a0038889

Hatch, D. K., \& Garcia, C. E. (2017). Academic advising and the persistence intentions of community college students in their first weeks in college. The Review of Higher Education, 40(3), 353-390. https://doi.org/10.1353/rhe.2017.0012

Helgesen, $\emptyset$. (2008). Marketing for higher education: A relationship marketing approach. Journal of Marketing for Higher Education, 18(1), 50-78. https://doi.org/10.1080/08841240802100188

Helgesen, $\varnothing$., \& Nesset, E. (2007). What accounts for students' loyalty? Some field study evidence. International Journal of Educational Management, 21(2), 126-143. https://doi.org/10.1108/09513540710729926

Hemsley-Brown, J., \& Oplatka, I. (2010). Market orientation in universities. International Journal of Educational Management, 24(3), 204-220. https://doi.org/10.1108/09513541011031565

Hennig Manzuoli, C., Pineda-Báez, C., \& Vargas Sánchez, A. D. (2019). School engagement for avoiding dropout in middle school education. International Education Studies, 12(5), 35-48. https://doi.org/10.5539/ies.v12n5p35

Hennig-Thurau, T., \& Klee, A. (1997). The impact of customer satisfaction and relationship quality on customer retention: A critical reassessment and model development. Psychology and Marketing, 14(8), 737-764.

Hennig-Thurau, T., Langer, M. F., \& Hansen, U. (2001). Modeling and managing student loyalty. Journal of Service Research, 3(4), 331-344. https://doi.org/10.1177/109467050134006 
Hodge, B., Wright, B., \& Bennett, P. (2018). The role of grit in determining engagement and academic outcomes for university students. Research in Higher Education, 59(4), 448-460. https://doi.org/10.1007/s11162-017-9474-y

Homans, G. (1961). Social behavior: Its elementary forms. Harcourt, Brace \& World.

Hu, L., \& Bentler, P. M. (1999). Cutoff criteria for fit indexes in covariance structure analysis: Conventional criteria versus new alternatives. Structural Equation Modeling: A Multidisciplinary Journal, 6(1), 1-55. https://doi. org/10.1080/10705519909540118

Hu, Y.-L., Hung, C.-H., \& Ching, G. S. (2015). Student-faculty interaction: Mediating between student engagement factors and educational outcome gains. International Journal of Research Studies in Education, 4(1), 43-53. https://doi. org/10.5861/ijrse.2014.800

Hughes, H. (2008). Critical incident technique. In S. Lipu, A. Lloyd, \& K. Williamson (Eds.) Exploring methods in information literacy research. Topics in Australasian Library and Information Studies (pp. 49-66). Centre for Information Studies, Charles Sturt University.

HZ University of Applied Sciences. (2020). About us. https://hz.nl/en/about-hz/about-us

Iskhakova, L., Hilbert, A., \& Hoffmann, S. (2016). An integrative model of alumni loyalty-an empirical validation among graduates from German and Russian universities. Journal of Nonprofit \& Public Sector Marketing, 28(2), 129163. https://doi.org/10.1080/10495142.2015.1006490

Iskhakova, L., Hilbert, A., \& Joehnk, P. (2020). Cross-cultural research in alumni loyalty: An empirical study among master students from German and Russian universities. Journal of Nonprofit \& Public Sector Marketing. Advance online publication. http://doi.org/ 10.1080/10495142.2020.1760995

Iskhakova, L., Hoffmann, S., \& Hilbert, A. (2017). Alumni loyalty: Systematic literature review. Journal of Nonprofit $\&$ Public Sector Marketing, 29(3), 274-316. https://doi.org/10.1080/10495142.2017.1326352

Jadnanansing, T. (2015, October 29). HBO en MBO verwaarlozen alumni [Higher and senior secondary vocational education neglect alumni]. ScienceGuide. https://www.scienceguide.nl/2015/10/hbo-en-mbo-verwaarlozenalumni/

Jang, H., Reeve, J., \& Deci, E. L. (2010). Engaging students in learning activities: It is not autonomy support or structure but autonomy support and structure. Journal of Educational Psychology, 102(3), 588-600. https://doi. $\operatorname{org} / 10.1037 / a 0019682$

Jarvis, W., Halvorson, W., Sadeque, S., \& Johnston, S. (2014). A large class engagement (LCE) model based on service-dominant logic (SDL) and flipped classrooms. Education Research and Perspectives, 41(1), 1-42. https:// researchrepository.murdoch.edu.au/id/eprint/54358/1/flipped\%2oclassrooms.pdf

Jiang, Z., Shiu, E., Henneberg, S., \& Naude, P. (2016). Relationship quality in business to business relationshipsreviewing the current literatures and proposing a new measurement model. Psychology \& Marketing, 33(4), 297313. https://doi.org/10.1002/mar.20876

Jones, D. P. (2016). Outcomes-based funding: Taking stock(ED599359). ERIC. https://files.eric.ed.gov/fulltext/ED599359.pdf

Kahu, E. R. (2013). Framing student engagement in higher education. Studies in Higher Education, 38(5), 758-773. https://doi.org/10.1080/03075079.2011.598505

Kidd, J. M. (2008). Exploring the components of career well-being and the emotions associated with significant career experiences. Journal of Career Development, 35(2), 166-186. https://doi.org/10.1177/0894845308325647

Kim, M., \& Schallert, D. L. (2011). Building caring relationships between a teacher and students in a teacher preparation program word-by-word, moment-by-moment. Teaching and Teacher Education, 27(7), 1059-1067. https://doi.org/10.1016/j.tate.2011.05.002

Kim, Y. K., \& Lundberg, C. A. (2016). A structural model of the relationship between student-faculty interaction and cognitive skills development among college students. Research in Higher Education, 57(3), 288-309. https://doi. $\operatorname{org} / 10.1007 /$ s11162-015-9387-6 
Kim, Y. K., \& Sax, L. J. (2009). Student-faculty interaction in research universities: Differences by student gender, race, social class, and first-generation status. Research in Higher Education, 50(5), 437-459. https://doi.org/10.1007/ s11162-009-9127-x

Kim, Y. K., \& Sax, L. J. (2017). The impact of college students' interactions with faculty: A review of general and conditional effects. In M. Paulsen (Ed.), Higher education: Handbook of theory and research (pp. 85-139). Springer.

King, N. (2012). Doing template analysis. In G. Symon \& C. Cassell (Eds.), Qualitative organizational research: Core methods and current challenges (pp. 426-450). SAGE. https://doi.org/10.4135/9781526435620.n24

King, N., \& Brooks, J. (2016). Template analysis for business and management students. SAGE.

Klem, A. M., \& Connell, J. P. (2004). Relationships matter: Linking teacher support to student engagement and achievement. Journal of School Health, 74(7), 262-273. https://doi.org/10.1111/j.1746-1561.2004.tbo8283.x

Koenig-Lewis, N., Asaad, Y., Palmer, A., \& Petersone, E. (2016). The effects of passage of time on alumni recall of 'student experience'. Higher Education Quarterly, 70(1), 59-80. https://doi.org/10.1111/hequ.12063

Komarraju, M., Musulkin, S., \& Bhattacharya, G. (2010). Role of student-faculty interactions in developing college students' academic self-concept, motivation, and achievement. Journal of College Student Development, 51(3), 332342. https://doi.org/10.1353/csd.0.0137

Koomen, H. M. Y., \& Jellesma, F. C. (2015). Can closeness, conflict, and dependency be used to characterize students' perceptions of the affective relationship with their teacher? Testing a new child measure in middle childhood. British Journal of Educational Psychology, 85(4), 479-497. https://doi.org/10.1111/bjep.12094

Košir, K., \& Tement, S. (2014). Teacher-student relationship and academic achievement: a cross-lagged longitudinal study on three different age groups. European Journal of Psychology of Education, 29(3), 409-428. https://doi. org/10.1007/s10212-013-0205-2

Krueger, R. A., \& Casey, M. A. (2000). Focus groups. SAGE.

Kuh, G. D. (2001). Assessing what really matters to student learning inside the national survey of student engagement. Change: The Magazine of Higher Learning, 33(3), 10-17. https://doi.org/10.1080/00091380109601795

Kuh, G. D. (2009). What student affairs professionals need to know about student engagement. Journal of College Student Development, 50(6), 683-706. https://doi.org/10.1353/csd.0.0099.

Kuh, G. D., \& Hu, S. (2001). The effects of student-faculty interaction in the 1990s. The Review of Higher Education, 24(3), 309-332. https://doi.org/10.1353/rhe.2001.0005

Kuiper, R. M. (2020). AIC-type theory-based model selection for structural equation models. Structural Equation Modeling: A Multidisciplinary Journal (Teachers' Corner). Advance online publication. https://doi.org/10.1080/107 05511.2020 .1836967

Kuiper, R. M., Hoijtink, H., \& Silvapulle, M. J. (2011). An Akaike-type information criterion for model selection under inequality constraints. Biometrika, 98(2), 495-501. https://doi.org/10.1093/biomet/asroo2

Kumar, N., Scheer, L. K., \& Steenkamp, J. E. M. (1995). The effects of perceived interdependence on dealer attitudes. Journal of Marketing Research, 32(3), 348-356. https://doi.org/10.1177/002224379503200309

Lages, C., Lages, C. R., \& Lages, L. F. (2005). The RELQUAL scale: A measure of relationship quality in export market ventures. Journal of Business Research, 58(8), 1040-1048. https://doi.org/10.1016/j.jbusres.2004.03.001

Lambert, A. D., \& Miller, A. L. (2014). Lower response rates on alumni surveys might not mean lower response representativeness. Educational Research Quarterly, 37(3), 40-53. https://files.eric.ed.gov/fulltext/EJ1061974.pdf

Ledden, L., Kalafatis, S. P., \& Samouel, P. (2007). The relationship between personal values and perceived value of education. Journal of Business Research, 60(9), 965-974. https://doi.org/10.1016/j.jbusres.2007.01.021

Lee, J. (2012). The effects of the teacher-student relationship and academic press on student engagement and academic performance. International Journal of Educational Research, 53, 330-340. https://doi.org/10.1016/j. ijer.2012.04.006 
Leenknecht, M. J. M., Snijders, I., Wijnia, L., Rikers, M. J. M. P., \& Loyens, S. M. M. (2020). Building relationships in higher education to support students' motivation. Teaching in Higher Education. Advance online publication. https://doi.org/10.1080/13562517.2020.1839748

Lewicki, R. J., Tomlinson, E. C., \& Gillespie, N. (2006). Models of interpersonal trust development: Theoretical approaches, empirical evidence, and future directions. Journal of Management, 32(6), 991-1022. https://doi. org/10.1177/0149206306294405

Li, M., \& Frieze, I. H., (2016). Developing civic engagement in university education: Predicting current and future engagement in community services. Social Psychology of Education, 19(4), 775-792. https://doi.org/10.1007/s11218016-9356-8

Little, R. J. A. (1988). A test of missing completely at random for multivariate data with missing values. Journal of the American Statistical Association, 83(404), 1198-1202. https://doi.org/10.1080/01621459.1988.10478722

Lovelock, C., \& Wirtz, J. (2016). Services marketing. World Scientific.

Lusch, R. F., \& Vargo, S. L. (2014). Service-dominant logic: Premises, perspectives, possibilities. University Printing House.

Marengo, D., Jungert, T., Lotti, N.O., Settanni, M., Thornberg, R., \& Longobardi, C., (2018) Conflictual studentteacher relationship, emotional and behavioral problems, prosocial behavior, and their associations with bullies, victims, and bullies/ victims, Educational Psychology, 38(9), 1201-1217. https://doi.org/10.1080/01443410.2018.1481 199

Macintosh, G. (2007). Customer orientation, relationship quality, and relational benefits to the firm. Journal of Services Marketing, 21(3), 150-159. https://doi.org/10.1108/08876040710746516

Marsh, H. W., Hau, K.-T., Roche, L., Craven, R., Balla, J., \& McInerney, V. (1993). Problems in the application of structural equation modeling: Comment on Randhawa, Beamer, and Lundberg (1993). Journal of Educational Psychology, 86(3), 457-462. https://doi.org/10.1037/0022-0663.86.3.457

Martin, M. M., Chesebro, J. L., \& Mottet, T. P. (1997). Students' perceptions of instructors' socio-communicative style and the influence on instructor credibility and situational motivation. Communication Research Reports, 14(4), 431-440. https://doi.org/10.1080/08824099709388686

Mason, B. A., Hajovsky, D. B., McCune, L. A., \& Turek, J. J. (2017). Conflict, closeness, and academic skills: A longitudinal examination of the teacher-student relationship. School Psychology Review, 46(2), 177-189. https://doi. org/10.17105/SPR-2017-0020.V46-2

Matthews, K. E., Dwyer, A., Hine, L., \& Turner, J. (2018). Conceptions of students as partners. Higher Education, 76(6), 957-971. https://doi.org/10.1007/s10734-018-0257-y

Maulana, R., Opdenakker, M., Stroet, K., \& Bosker, R. (2013). Changes in teachers' involvement versus rejection and links with academic motivation during the first year of secondary education: A multilevel growth curve analysis. Journal of Youth and Adolescence, 42(9), 1348-1371. https://doi.org/10.1007/s10964-013-9921-9

McAlexander, J. H., Koenig, H. F., \& Schouten, J. W. (2006). Building relationships of brand community in higher education: A strategic framework for university advancement. International Journal of Educational Advancement, 6(2), 107-118. https://doi.org/10.1057/palgrave.ijea.2150015

McManus, J., \& Mosca, J. (2015). Strategies to build trust and improve employee engagement. International Journal of Management \& Information Systems, 19(1), 37-42. https://doi.org/10.19030/ijmis.v19i1.9056

Meeuwisse, M., Severiens, S. E., \& Born, M. P. (2010). Learning environment, interaction, sense of belonging and study success in ethnically diverse student groups. Research in Higher Education, 51(6), 528-545. https://doi. org/10.1007/s11162-010-9168-1

Meyers, S. A. (2003). Strategies to prevent and reduce conflict in college classrooms. College Teaching, 51(3), 94-98. https://doi.org/10.1080/87567550309596419 
Meyers, S. A., Bender, J., Hill, E. K., \& Thomas, S. Y. (2006). How do faculty experience and respond to classroom conflict? International Journal of Teaching and Learning in Higher Education, 18(3), 180-187. https://files.eric.ed.gov/ fulltext/EJ1068075.pdf

Miller, A. L., Williams, L. M., \& Silberstein, S. M. (2019). Found my place: The importance of faculty relationships for seniors' sense of belonging. Higher Education Research \& Development, 38(3), 594-608. https://doi.org/10.1080/ 07294360.2018 .1551333

Mohr, J., \& Spekman, R. (1994). Characteristics of partnership success: Partnership attributes, communication behavior, and conflict resolution techniques. Strategic Management Journal, 15(2), 135-152. https://doi.org/10.1002/ smj.4250150205

Molesworth, M., Scullion, R., \& Nixon, E. (2011). The marketisation of higher education. Routledge.

Molm, L. D., Collett, J. L., \& Schaefer, D. R. (2006). Conflict and fairness in social exchange. Social Forces, 84(4), 23312352. https://doi.org/10.1353/sof.2006.0100

Moore, S., \& Kuol, N. (2007). Retrospective insights on teaching: Exploring teaching excellence through the eyes of the alumni. Journal of Further and Higher Education, 31(2), 133-143. https://doi.org/10.1080/03098770701267598

Morgan, D. L. (1997). The focus group guidebook. SAGE.

Morgan, D. L., \& Krueger, R. A. (1993). When to use focus groups and why. In D. L. Morgan (Ed.), Successful focus groups: Advancing the state of the art (pp. 3-19). SAGE.

Morgan, R. M., \& Hunt, S. D. (1994). The commitment-trust theory of relationship marketing. Journal of Marketing, 58(3), 20-38. https://doi.org/10.2307/1252308

Morinaj, J., \& Hascher, T. (2019). School alienation and student well-being: A cross-lagged longitudinal analysis. European Journal of Psychology of Education, 34(2), 273-294. https://doi.org/10.1007/s10212-018-0381-1

Murdvee, M. (2009). Social exchange. http://tut.ee/public/m/mart-murdvee/EconPsy/5/6._EconPsy_-_Social_ exchange.pdf

Muthén, B., \& Asparouhov, T. (2013). New methods for the study of measurement invariance with many groups. Mplus Technical Report. https://www.statmodel.com.

Myers, S. A. (2004). The relationship between perceived instructor credibility and college student in-class and outof-class communication. Communication Reports, 17(2), 129-137. https://doi.org/10.1080/08934210409389382

Nadiri, H., Kandampully, J., \& Hussain, K. (2009). Students' perceptions of service quality in higher education. Total Quality Management \& Business Excellence, 20(5), 523-535. https://doi.org/10.1080/14783360902863713

Nesset, E., \& Helgesen, $\varnothing$. (2009). Modeling and managing student loyalty: A study of a Norwegian university college. Scandinavian Journal of Educational Research, 53(4), 327-345. https://doi.org/10.1080/00313830903043117

Newman, M. D., \& Petrosko, J. M. (2011). Predictors of alumni association membership. Research in Higher Education, 52(7), 738-759. https://doi.org/10.1007/s11162-011-9213-8

Ng, I. C. L., \& Forbes, J. (2009). Education as service: The understanding of university experience through the service logic. Journal of Marketing for Higher Education, 19(1), 38-64. https://doi.org/10.1080/08841240902904703

Nicholson, L. J., \& Putwain, D. W. (2019). A cross-lagged panel analysis of fear appeal appraisal and student engagement. British Journal of Educational Psychology, 90(3), 830-847. https://doi.org/10.1111/bjep.12334

Nunnally, J. C. (1967). Psychometric theory. McGraw-Hill.

O'Keeffe, P. (2013). A sense of belonging: Improving student retention. College Student Journal, 47(4), 605-613. https:// www.ingentaconnect.org/content/prin/csj/2013/00000047/00000004/art00005

Oldfield, B. M., \& Baron, S. (2000). Student perceptions of service quality in a UK university business and management faculty. Quality Assurance in Education, 8(2), 85-95. https://doi.org/10.1108/09684880010325600 
Onwuegbuzie, A. J., Burke Johnson, R., \& Collins, K. M. (2009). Call for mixed analysis: A philosophical framework for combining qualitative and quantitative approaches. International Journal of Multiple Research Approaches, 3(2), 114-139. https://doi.org/10.5172/mra.3.2.114

Osobajo, O. A., \& Moore, D. (2017). Methodological choices in relationship quality (RQ) research 1987 to 2015: A systematic literature review. Journal of Relationship Marketing, 16(1), 40-81. https://doi.org/10.1080/15332667.2016. 1242395

Palmatier, R. W. (2008). Interfirm relational drivers of customer value. Journal of Marketing, 72(4), 76-89. https://doi. org/10.1509/jmkg.72.4.76

Palmatier, R. W., Dant, R. P., Grewal, D., \& Evans, K. R. (2006). Factors influencing the effectiveness of relationship marketing: A meta-analysis. Journal of Marketing, 70(4), 136-153. https://doi.org/10.1509\%2Fjmkg.70.4.136

Parasuraman, A. P., Berry, L. L., \& Zeithaml, V. A. (1991). Refinement and reassessment of the SERVQUAL scale. Journal of Retailing, 67(4), 420-450.

Pascarella, E. T. (1980). Student-faculty informal contact and college outcomes. Review of Educational Research, 50(4), 545-595. https://doi.org/10.2307/1170295

Pascarella, E. T., \& Terenzini, P. T. (1977). Patterns of student-faculty informal interaction beyond the classroom and voluntary freshman attrition. The Journal of Higher Education, 48(5), 540-552. https://doi.org/10.2307/1981596

Pascarella, E. T., \& Terenzini, P. T. (1991). How college affects students: Findings and insights from twenty years of research. Jossey-Bass.

Pascarella, E. T., \& Terenzini, P. T. (2005). How college affects students. Jossey-Bass.

Pascarella, E. T., Terenzini, P. T., \& Hibel, J. (1978). Student-faculty interactional settings and their relationship to predicted academic performance. The Journal of Higher Education, 49(5), 450-463. https://doi.org/10.2307/1980509

Pedro, I. M., da Costa Mendes, J., \& Nobre Pereira, L. (2020a). Identifying patterns of alumni commitment in key strategic relationship programmes. International Review on Public and Nonprofit Marketing, 17, 445-468. https://doi. org/10.1007/s12208-020-00256-1

Pedro, I. M., da Costa Mendes, J., \& Nobre Pereira, L. (2020b). Understanding alumni-alma mater commitment relationships upstream and downstream. Journal of Marketing for Higher Education. Advance online publication. https://doi.org/10.1080/08841241.2020.1768200

Perin, M. G., Sampaio, C. H., Simões, C., \& de Pólvora, R. (2012). Modeling antecedents of student loyalty in higher education. Journal of Marketing for Higher Education, 22(1), 101-116. https://doi.org/10.1080/08841241.2012.705797

Pianta, R. C., Hamre, B. K., \& Allen, J. P. (2012). Teacher-student relationships and engagement: Conceptualizing, measuring, and improving the capacity of classroom interactions. In S. Christenson, A. Reschly, \& C. Wylie (Eds.), Handbook of research on student engagement (pp. 365-386). Springer.

Pillay, S., \& James, R. (2015). Examining intercultural competency through social exchange theory. International Journal of Teaching and Learning in Higher Education, 27(3), 320-329. https://files.eric.ed.gov/fulltext/EJ1093704.pdf

Plewa, C., Galán-Muros, V., \& Davey, T. (2015). Engaging business in curriculum design and delivery: A higher education institution perspective. Higher Education, 70(1), 35-53. https://doi.org/10.1007/s10734-014-9822-1

Pöysä, S., Vasalampi, K., Muotka, J., Lerkkanen, M., Poikkeus, A., \& Nurmi, J. (2019). Teacher-student interaction and lower secondary school students' situational engagement. British Journal of Educational Psychology, 89(2), 374392. https://doi.org/10.1111/bjep.12244

Putnick, D. L., \& Bornstein, M. H. (2016). Measurement invariance conventions and reporting: The state of the art and future directions for psychological research. Developmental Review, 41, 71-90. https://doi.org/10.1016/j. dr.2016.06.004 
Quin, D. (2017). Longitudinal and contextual associations between teacher-student relationships and student engagement: A systematic review. Review of Educational Research, 87(2), 345-387. https://doi. org/10.3102\%2F0034654316669434

R Core Team. (2012). R: The R project for statistical computing. http://www.R-project.org/

Rauyruen, P., \& Miller, K. E. (2007). Relationship quality as a predictor of B2B customer loyalty. Journal of Business Research, 60(1), 21-31. https://doi.org/10.1016/j.jbusres.2005.11.006

Rimm-Kaufman, S., \& Sandilos, L. (2010). Improving students' relationships with teachers to provide essential supports for learning: Positive relationships can also help a student develop socially. American Psychological Association. https:// www.apa.org/education/k12/relationships

Ringle, C. M., Wende, S., \& Becker, J. M. (2015). SmartPLS3. Smartpls.com. https://www.smartpls.com/.

Roberts, K., Varki, S., \& Brodie, R. (2003). Measuring the quality of relationships in consumer services: An empirical study. European Journal of Marketing, 37(1/2), 169-196. https://doi.org/10.1108/03090560310454037

Robinson, N. M., \& Celuch, K. G. (2016). Strategic and bonding effects of enhancing the student feedback process. Journal of Marketing for Higher Education, 26(1), 20-40. https://doi.org/10.1080/08841241.2016.1146386

Roffey, S. (2012). Developing positive relationships in schools. In S. Roffey (Ed.) Positive relationships: Evidence based practice across the world (pp. 145-162). Springer. https://doi.org/10.1007/978-94-007-2147-0_9

Rojas-Méndez, J. I., Vasquez-Parraga, A. Z., Kara, A., \& Cerda-Urrutia, A. (2009). Determinants of student loyalty in higher education: A tested relationship approach in Latin America. Latin American Business Review, 10(1), 21-39. https://doi.org/10.1080/10978520903022089

Roorda, D. L., Jak, S., Zee, M., Oort, F. J., \& Koomen, H. M. (2017). Affective teacher-student relationships and students' engagement and achievement: A meta-analytic update and test of the mediating role of engagement. School Psychology Review, 46(3), 239-261. http://doi.org/10.17105/SPR-2017-0035.V46-3

Roorda, D. L., Koomen, H. M. Y., Spilt, J. L., \& Oort, F. J. (2011). The influence of affective teacher-student relationships on students' school engagement and achievement. Review of Educational Research, 81(4), 493-529. https://doi.org/10.3102/0034654311421793

Roorda, D. L., Verschueren, K., Vancraeyveldt, C., Van Craeyevelt, S., \& Colpin, H. (2014). Teacher-child relationships and behavioral adjustment: Transactional links for preschool boys at risk. Journal of School Psychology, 52(5), 495510. https://doi.org/10.1016/j.jsp.2014.06.004

Rousseau, D. M., Sitkin, S. B., Burt, R. S., \& Camerer, C. (1998). Not so different after all: A cross-discipline view of trust. Academy of Management Review, 23(3), 393-404. https://doi.org/10.5465/amr.1998.926617

Sánchez-Álvarez, N., Extremera, N., \& Fernández-Berrocal, P. (2019). The influence of trait meta-mood on subjective well-being in high school students: A random intercept cross-lagged panel analysis. Educational Psychology, 39(3), 332-352. https://doi.org/10.1080/01443410.2018.1543854

Schachner, M. K., Schwarzenthal, M., van de Vijver, F. J. R., \& Noack, P. (2019). How all students can belong and achieve: Effects of the cultural diversity climate amongst students of immigrant and nonimmigrant background in Germany. Journal of Educational Psychology, 111(4), 703-716. https://doi.org/10.1037/eduo000303

Schaufeli, W. B., \& Bakker, A. B. (2003). UWES Utrecht Work Engagement Scale: Preliminary manual. Occupational Health Psychology Unit, Utrecht University. https://www.wilmarschaufeli.nl/publications/Schaufeli/Test $\% 20$ Manuals/Test_manual_UWES_English.pdf.

Schaufeli, W. B., Bakker, A. B., \& Salanova, M. (2006). The measurement of work engagement with a short questionnaire. Educational and Psychological Measurement, 66(4), 701-716. https://doi.org/10.1177/0013164405282471

Schaufeli, W. B., Martínez, I. M., Marques Pinto, A., Salanova, M., \& Bakker, A. B. (2002). Burnout and engagement in university students. Journal of Cross-Cultural Psychology, 33(5), 464-481. https://doi. org/10.1177/0022022102033005003 
Schertzer, C. B., \& Schertzer, S. M. B. (2004). Student satisfaction and retention: A conceptual model. Journal of Marketing for Higher Education, 14(1), 79-91. https://doi.org/10.1300/j050v14no1_05

Schlesinger, W., Cervera, A., \& Pérez-Cabañero, C. (2017). Sticking with your university: The importance of satisfaction, trust, image, and shared values. Studies in Higher Education, 42(12), 2178-2194. https://doi.org/10.108 o/03075079.2015.1136613

Shahsavar, T., \& Sudzina, F. (2017). Student satisfaction and loyalty in Denmark: Application of EPSI methodology. PLOS ONE, 12(12), Article e0189576. https://doi.org/10.1371/journal.pone.0189576

Sklar, D. P., \& McMahon, G. T. (2019). Trust between teachers and learners. JAMA, 321(22), 2157-2158. https://doi. org/10.1001/jama.2018.22130

Snijders, I., Rikers, R. M. J. P., Wijnia, L., \& Loyens, S. M. M. (2018). Relationship quality time: The validation of a relationship quality scale in higher education. Higher Education Research \& Development, 37(2), 404-417. https://doi. org/10.1080/07294360.2017.1355892

Snijders, I., Wijnia, L., Dekker, J. J., Rikers, R. M. J. P., \& Loyens, S. M. M. (2020). What's in a student-faculty relationship? A template analysis on students' positive and negative critical incidents with their educational faculty and staff [Manuscript submitted for publication]. University College Roosevelt, Utrecht University.

Snijders, I., Wijnia, L., Rikers, R. M. J. P., \& Loyens, S. M. M. (2019). Alumni loyalty drivers in higher education. Social Psychology of Education, 22(3), 607-627. https://doi.org/10.1007/s11218-019-09488-4

Snijders, I., Wijnia, L., Rikers, R. M. J. P., \& Loyens, S. M. M. (2020). Building bridges in higher education: Studentfaculty relationship quality, student engagement, and student loyalty. International Journal of Educational Research, 100, 101538. https://doi.org/10.1016/j.ijer.2020.101538

Steegen, S., Tuerlinckx, F., Gelman, A., \& Vanpaemel, W. (2016). Increasing transparency through a multiverse analysis. Perspectives on Psychological Science, 11(5), 702-712. https://doi.org/10.1177/1745691616658637

Steiger, J. H. (1990). Structural model evaluation and modification: An interval estimation approach. Multivariate Behavioral Research, 25(2), 173-180. https://doi.org/10.1207/s15327906mbR ${ }^{2} 502 \_4$

Stevic, C. R., \& Ward, R. M. (2008). Initiating personal growth: The role of recognition and life satisfaction on the development of college students. Social Indicators Research, 89(3), 523-534. https://doi.org/10.1007/s11205-0089247-2

Strauss, L. C., \& Volkwein, J. F. (2004). Predictors of student commitment at two-year and four-year institutions. The Journal of Higher Education, 75(2), 203-227. https://doi.org/10.1353/jhe.2004.0007

Studiekeuze123. (2020). Nationale Studenten Enquete. https://www.studiekeuze123.nl/nse

Suhre, C. J. M., Jansen, E. P. W. A., \& Torenbeek, M. (2013). Determinants of timely completion: The impact of bachelor's degree programme characteristics and student motivation on study progress. Higher Education Research \& Development, 32(3), 479-492. https://doi.org/10.1080/07294360.2012.684374

Sultan, P., \& Wong, H. (2010). Performance-based service quality model: an empirical study on Japanese universities. Quality Assurance in Education, 18(2), 126-143. https://doi.org/10.1108/09684881011035349

Sung, M., \& Yang, S. (2009). Student-university relationships and reputation: A study of the links between key factors fostering students' supportive behavioral intentions towards their university. Higher Education, 57(6), 787811. https://doi.org/10.1007/s10734-008-9176-7

Tantleff-Dunn, S., Dunn, M. E., \& Gokee, J. L. (2002). Understanding faculty-student conflict: Student perceptions of precipitating events and faculty responses. Teaching of Psychology, 29(3), 197-202. https://doi.org/10.1207/ S15328023TOP2903_03

Taylor, L., \& Parsons, J. (2011). Improving student engagement. Current Issues in Education, 14(1). https://www. learntechlib.org/p/53580/ 
Temmerman, N. (2018, April 13). The importance of listening to university stakeholders. University World News. https:// www.universityworldnews.com/post.php?story=20180410151237739

Tett, L., Cree, V. E., \& Christie, H. (2017). From further to higher education: Transition as an on-going process. Higher Education, 73(3), 389-406. https://doi.org/10.1007/s10734-016-0101-1

Thibaut, J. W., \& Kelley, H. H. (1959). The social psychology of groups. Wiley.

Thoits, P. A., \& Hewitt, L. N. (2001). Volunteer work and well-being. Journal of Health and Social Behavior, 42(2), 115131. https://doi.org/10.2307/3090173

Thomas, S. (2011). What drives student loyalty in universities: An empirical model from India. International Business Research, 4(2), 183-192. https://doi.org/10.5539/ibr.v4n2p183

Tinto, V. (1975). Dropout from higher education: A theoretical synthesis of recent research. Review of Educational Research, 45(1), 89-125. https://doi.org/10.3102/00346543045001089

Tinto, V. (1997). Classrooms as communities: Exploring the educational character of student persistence. The Journal of Higher Education, 68(6), 599-623. https://doi.org/10.2307/2959965

Tomlinson, M. (2017). Student perceptions of themselves as 'consumers' of higher education. British Journal of Sociology of Education, 38(4), 450-467. https://doi.org/10.1080/01425692.2015.1113856

Tompkins, K. A., Brecht, K., Tucker, B., Neander, L., \& Swift, J. K. (2016). Who matters most? The contribution of faculty, student-peers, and outside support in predicting graduate student satisfaction. Training and Education in Professional Psychology, 10(2), 102-108. https://doi.org/10.1037/tepoo00115

Trolian, T. L, Jach, E. A., Hanson, J. M., \& Pascarella, E. T. (2016). Influencing academic motivation: The effects of student-faculty interaction. Journal of College Student Development, 57(7), 810-826. https://doi.org/10.1353/ csd.2016.0080

Tschannen-Moran, M. (2014). Trust matters: Leadership for successful schools (2nd ed.). Wiley.

Tschannen-Moran, M., \& Gareis, C. R. (2015). Principals, trust, and cultivating vibrant schools. Societies, 5(2), 256276. https://doi.org/10.3390/soc5020256

Umbach, P. D., \& Wawrzynski, M. R. (2005). Faculty do matter: The role of college faculty in student learning and engagement. Research in Higher Education, 46(2), 153-184. https://doi.org/10.1007/s11162-004-1598-1

Usman, U., \& Mokhtar, S. S. M. (2016). Analysis of service quality, university image and student satisfaction on student loyalty in higher education in Nigeria. International Business Management, 10(12), 2490-2502. https://doi. org/10.36478/ibm.2016.2490.2502

Vanbrabant, L., \& Kuiper, R. M. (2020). The restriktor project. Restriktor.org. https://restriktor.org

Vanbrabant, L., \& Rosseel, Y. (2020). Restriktor: Restricted statistical estimation and inference for linear models. R package version $0.2-15$. http://restriktor.org

Vanbrabant, L., Van Loey, N., \& Kuiper, R. M. (2020). Evaluating a theory-based hypothesis against its complement using an AIC-type information criterion with an application to facial burn injury. Psychological Methods, 25(2), 129-142. https://doi.org/10.1037/metoooo238

Van Doorn, J., Lemon, K. N., Mittal, V., Nass, S., Pick, D., Pirner, P., \& Verhoef, P. C. (2010). Customer engagement behavior: Theoretical foundations and research directions. Journal of Service Research, 13(3), 253-266. https://doi. org/10.1177/1094670510375599

Vander Schee, B. A. (2008a). Review of "Minority student retention: The best of the Journal of College Student Retention: Research, theory \& practice" [Review of the book Minority student retention: The best of the Journal of College Student Retention: Research, theory \& practice, by A. Seidman (Ed.)]. Journal of Student Affairs Research and Practice, 45(2). https://doi.org/10.2202/1949-6605.1954 
Vander Schee, B. A. (2008b). The utilization of retention strategies at church-related colleges: A longitudinal study. Journal of College Student Retention: Research, Theory \& Practice, 10(2), 207-222. https://doi.org/10.2190/cs.10.2.f

Vander Schee, B. A. (2010). Students as consumers: Programming for brand loyalty. Services Marketing Quarterly, 32(1), 32-43. https://doi.org/10.1080/15332969.2011.534331

Van Maele, D., Forsyth, P. B., \& Van Houtte, M. (2014). Trust and school life. Springer.

Veiga, F., Reeve, J., Wentzel, K., \& Robu, V. (2014). Assessing students' engagement: A review of instruments with psychometric qualities. In F. Veiga (Ed.), Envolvimento dos Alunos na Escola: Perspetivas Internacionais da Psicologia e Educação [Students' engagement in school: International perspectives of psychology and education] (pp. 38-57). Instituto de Educação da Universidade de Lisboa. http://hdl.handle.net/10451/18036

Veldman, I., van Tartwijk, J. W. F., Brekelmans, M., \& Wubbels, T. (2013). Job satisfaction and teacher-student relationships across the teaching career: Four case studies. Teaching and Teacher Education, 32, 55-65. https://doi. org/10.1016/j.tate.2013.01.005

Verhoef, P. C., Reinartz, W. J., \& Krafft, M. (2010). Customer engagement as a new perspective in customer management. Journal of Service Research, 13(3), 247-252. https://doi.org/10.1177/1094670510375461

Wagenmakers, E., \& Farrell, S. (2004). AIC model selection using Akaike weights. Psychonomic Bulletin \& Review, 11(1), 192-196. https://doi.org/10.3758/bfo3206482

Weerts, D. J., \& Ronca, J. M. (2008). Characteristics of alumni donors who volunteer at their alma mater. Research in Higher Education, 49(3), 274-292. https://doi.org/10.1007/s11162-007-9077-0

Weerts, D. J., Cabrera, A. F., \& Sanford, T. (2010). Beyond giving: Political advocacy and volunteer behaviors of public university alumni. Research in Higher Education , 51(4), 346-365. https://doi.org/10.1007/s11162-009-9158-3

Weiner, B. (1972). Attribution theory, achievement motivation, and the educational process. Review of Educational Research, 42(2), 203-215. https://doi.org/10.3102/00346543042002203

Wentzel, K. (Host). (2018-present). How student-teacher relationships impact student engagement and learning. Critical Window from the Alliance for Excellent Education [Audio podcast]. https://allued.org/when-students-trusttheir-teachers/

Wilkins, C. H. (2018). Effective engagement requires trust and being trustworthy. Medical Care, 56, S6-S8. https:// doi.org/10.1097/mlr.0000000000000953

Wolff, B., Knodel, J., \& Sittitrai, W. (1993). Focus groups and surveys as complementary research methods. In D. L. Morgan (Ed.), Successful focus groups (pp. 118-136). SAGE.

Wong, T. K. Y., Parent, A., \& Konishi, C. (2019). Feeling connected: The roles of student-teacher relationships and sense of school belonging on future orientation. International Journal of Educational Research, 94, 150-157. https:// doi.org/10.1016/j.ijer.2019.01.008

Woo, K., \& Ennew, C. T. (2004). Business-to-business relationship quality. European Journal of Marketing, 38(9/10), 1252-1271. https://doi.org/10.1108/03090560410548960

Woodall, T., Hiller, A., \& Resnick, S. (2014). Making sense of higher education: Students as consumers and the value of the university experience. Studies in Higher Education, 39(1), 48-67. https://doi.org/10.1080/03075079.2011.648 373

Wubbels, T., \& Brekelmans, M. (2005). Two decades of research on teacher-student relationships in class. International Journal of Educational Research, 43(1-2), 6-24. https://doi.org/10.1016/j.ijer.2006.03.003

Xerri, M. J., Radford, K., \& Shacklock, K. (2018). Student engagement in academic activities: a social support perspective. Higher Education, 75(4), 589-605. https://doi.org/10.1007/s10734-017-0162-9

Yousaf, A., Mishra, A., \& Bashir, M. (2020). Brand trust, institutional commitment, and their impact on student loyalty: Evidence for higher education in India. Studies in Higher Education, 45(4), 878-891. https://doi.org/10.108 o/03075079.2018.1558441 
Zee, M., Koomen, H. M. Y., \& Van der Veen, I. (2013). Student-teacher relationship quality and academic adjustment in upper elementary school: The role of student personality. Journal of School Psychology, 51(4), 517-533. https://doi. org/10.1016/j.jsp.2013.05.003

Zeithaml, V. A. (1981). How consumer evaluation processes differ between goods and services. In J. Donnely \& W. George (Eds.), Marketing of services (pp. 186-190). American Marketing Association.

Zeithaml, V. A., Berry, L. L., \& Parasuraman, A. (1996). The behavioral consequences of service quality. Journal of Marketing, 60(2), 31-46. https://doi.org/10.2307/1251929

Zeithaml, V. A., Bitner, M. J., Gremler, D. D., \& Lovelock, C. (2009). Services marketing. McGraw-Hill / Irwin.

Zepke, N. (2015). What future for student engagement in neo-liberal times? Higher Education, 69(4), 693-704. https:// doi.org/10.1007/s10734-014-9797-y

Zepke, N., Leach, L., \& Butler, P. (2014). Student engagement: Students' and teachers' perceptions. Higher Education Research \& Development, 33(2), 386-398. https://doi.org/10.1080/07294360.2013.832160

Zhu, L., \& Anagondahalli, D. (2017). Effects of academic entitlement on conflict management: Implications of a consumer culture for the student-teacher relationship. Communication Reports, 30(1), 14-25. https://doi.org/10.1 $080 / 08934215.2016 .1225223$ 
75

11 कारश

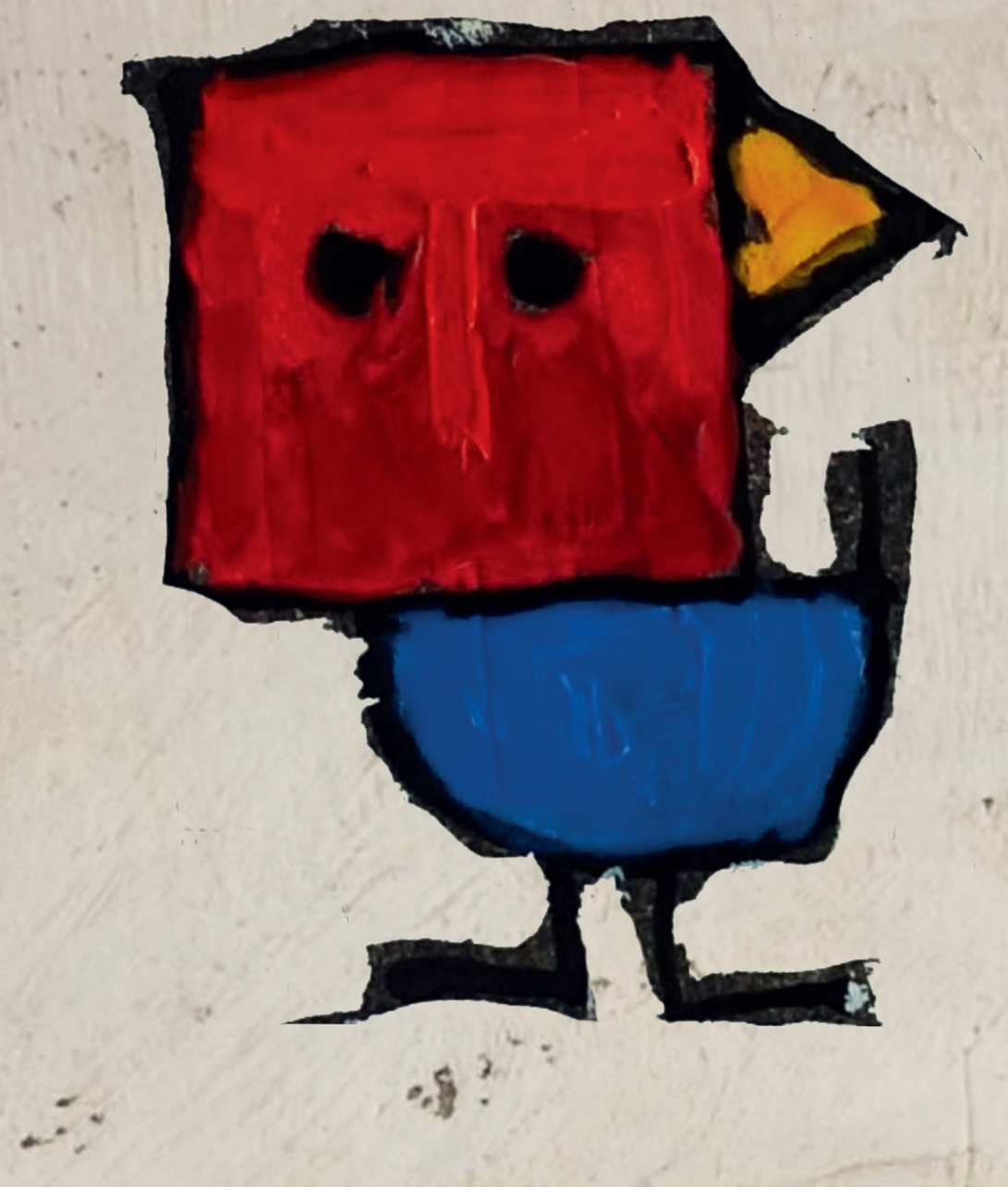

13
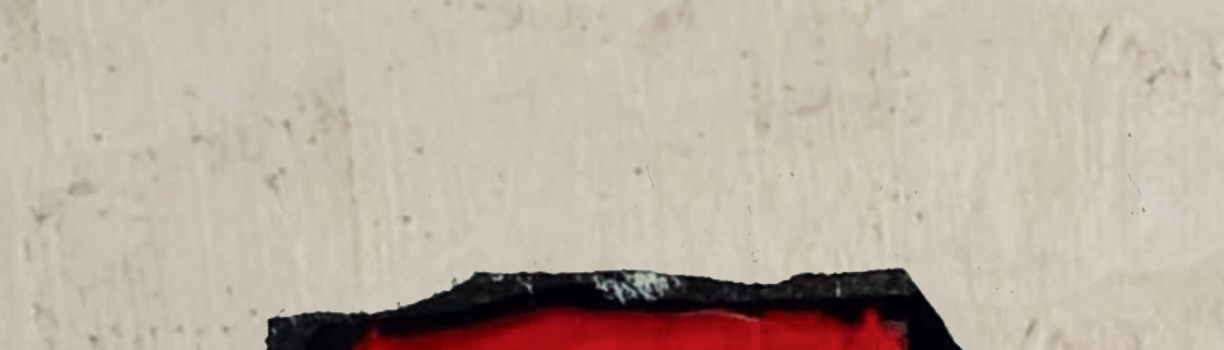


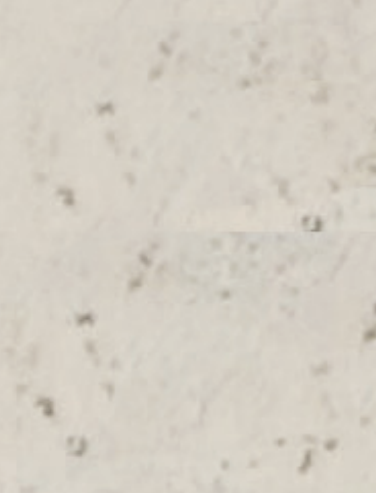

\section{Appendices}

Appendix A

Focus group questions (Chapter 2)

Appendix B

Coding using final template (Chapter 3)

Appendix C

Relationship quality related experiences (Chapter 3)

Appendix D

(In) direct effects after bootstrapping procedure (Chapter 4)

Appendix E

Sample Characteristics (Chapter 5)

Appendix F

Supplemental materials (Chapter 6) 


\section{Appendix A}

\section{Focus Group Questions (Chapter 2)}

\section{Overview 2.1}

Focus Croup Questions

1. Please give an example of your experience with the quality of the relationship you have with your faculty/staff.

2. If you were asked to describe aspects of relationship quality, in your opinion, what following aspects do you recognize?

a) Trust in the university people's honesty (teaching and supporting front office staff) such as sincerity, integrity, or reliability.

b) Trust in the university people's benevolence such as willingness to help, concern, and accountability.

c) The degree to which you are satisfied with the relationship you have with the people from your university. For example, how happy, content, or satisfied you are with their performance.

d) The extent to which you feel committed to the people from your university. For instance, the way you feel affectively attached or associated.

e) The degree of affective conflict you experience in the relationship you have with the university people. For example, the degree to which you are angry, irritated, or frustrated about your relationship with those people.

3. How important is the relationship you experience with the people from your university, in general, in relation to your study achievements and/or to life itself? Please explain why.

4. Would you like to add or further explain something you have heard or (have not) said about the topics we discussed. 

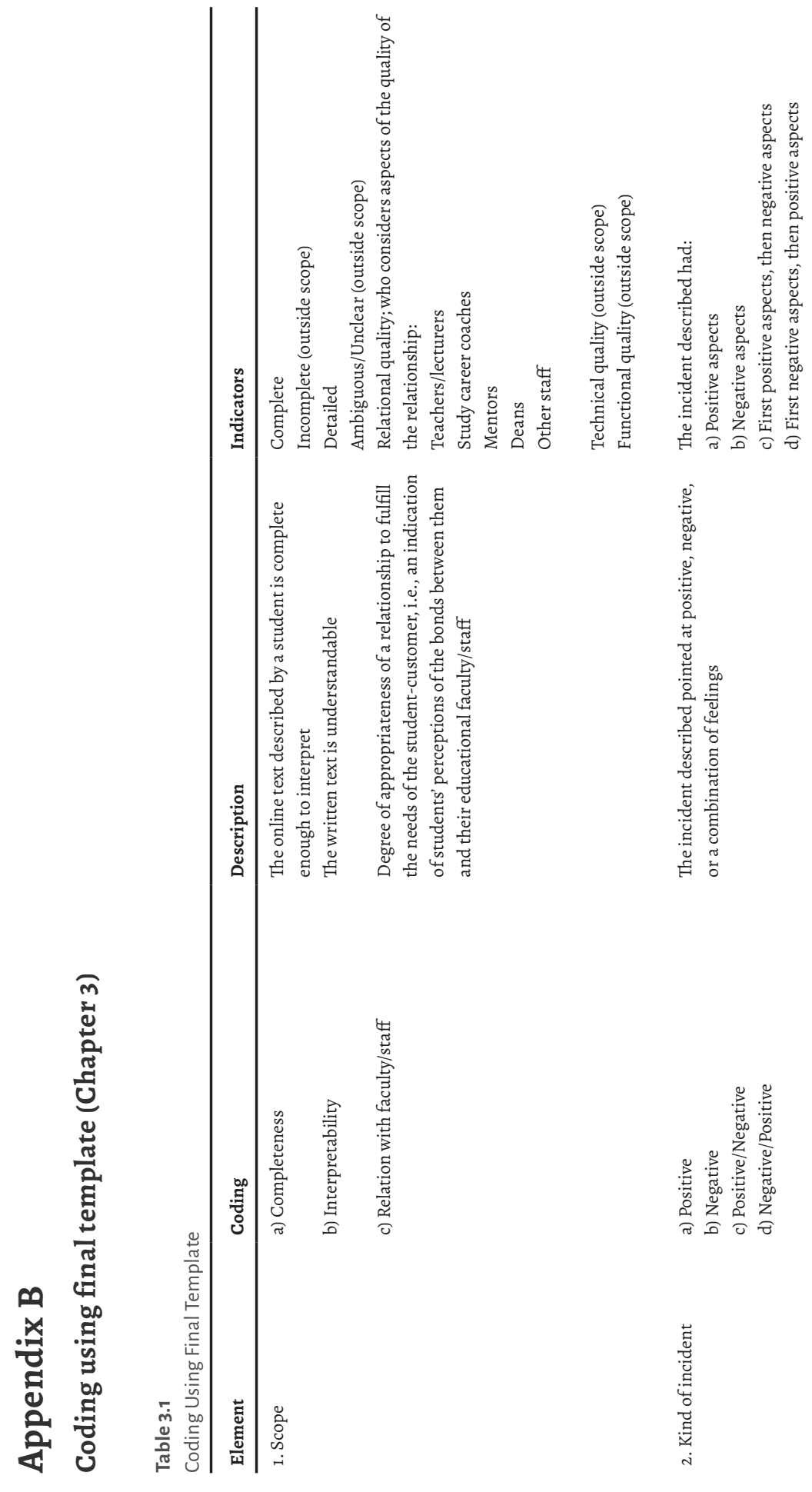

A
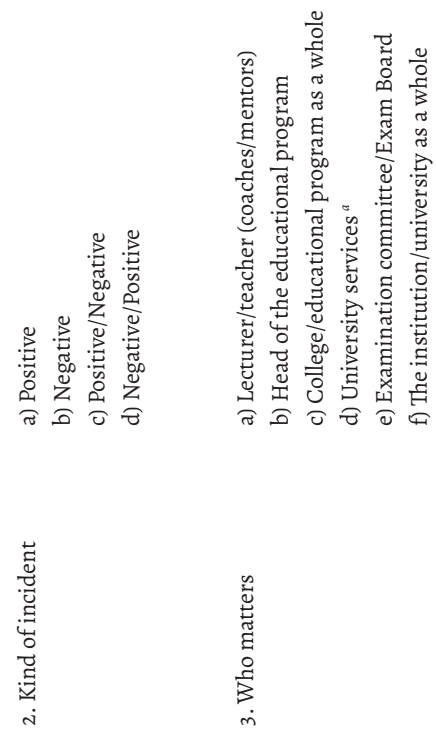
Appendices - B

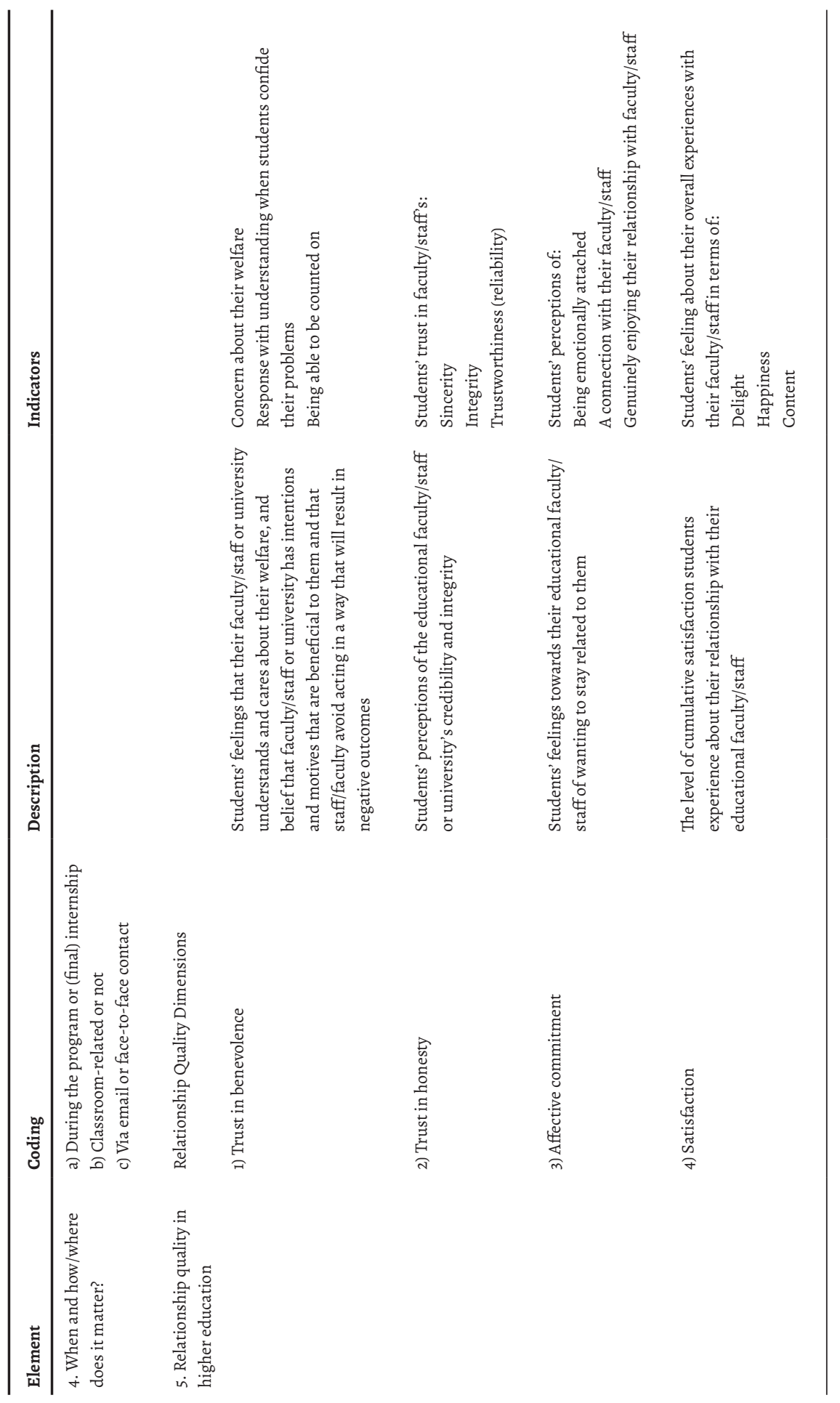




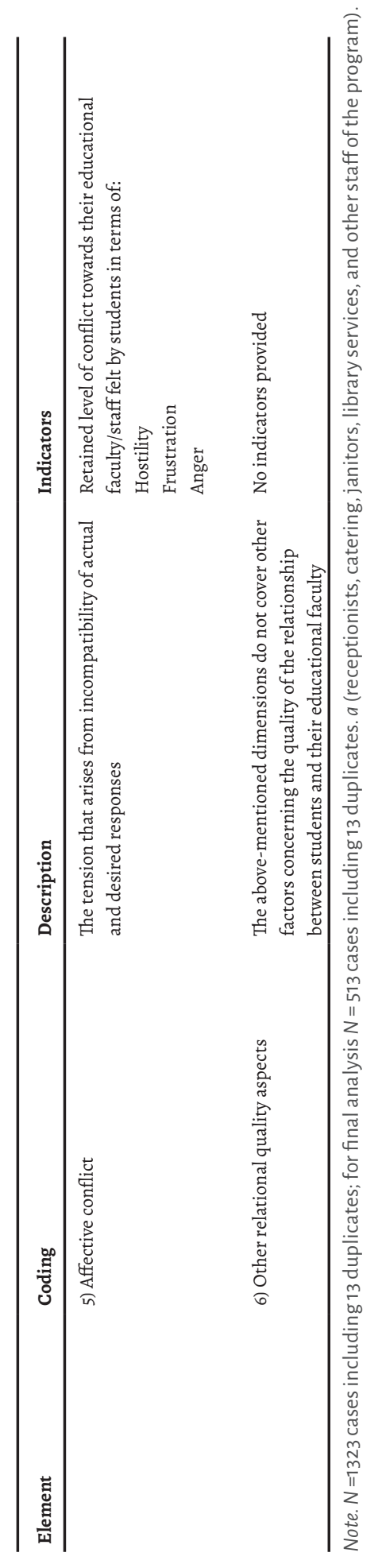




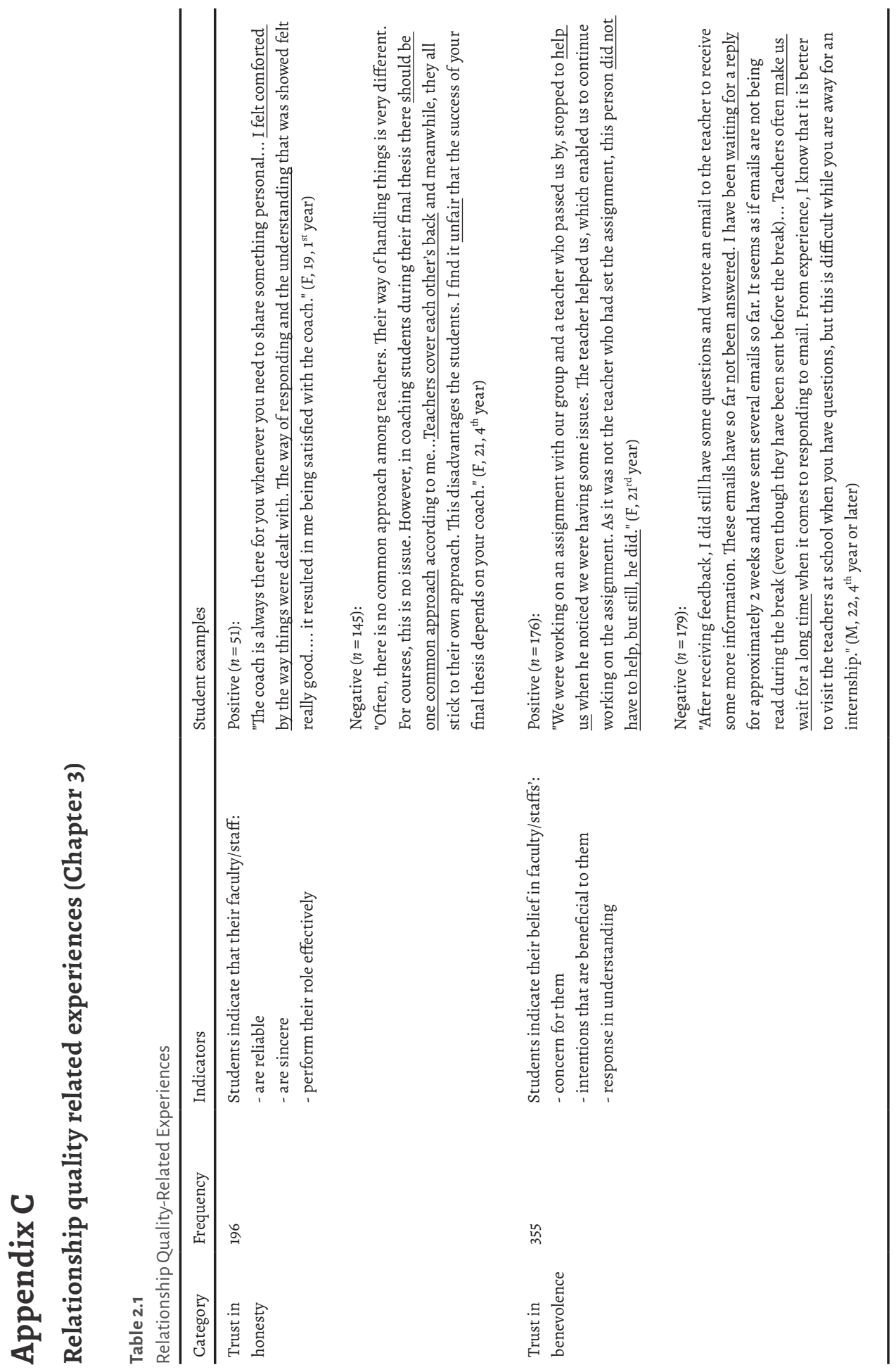




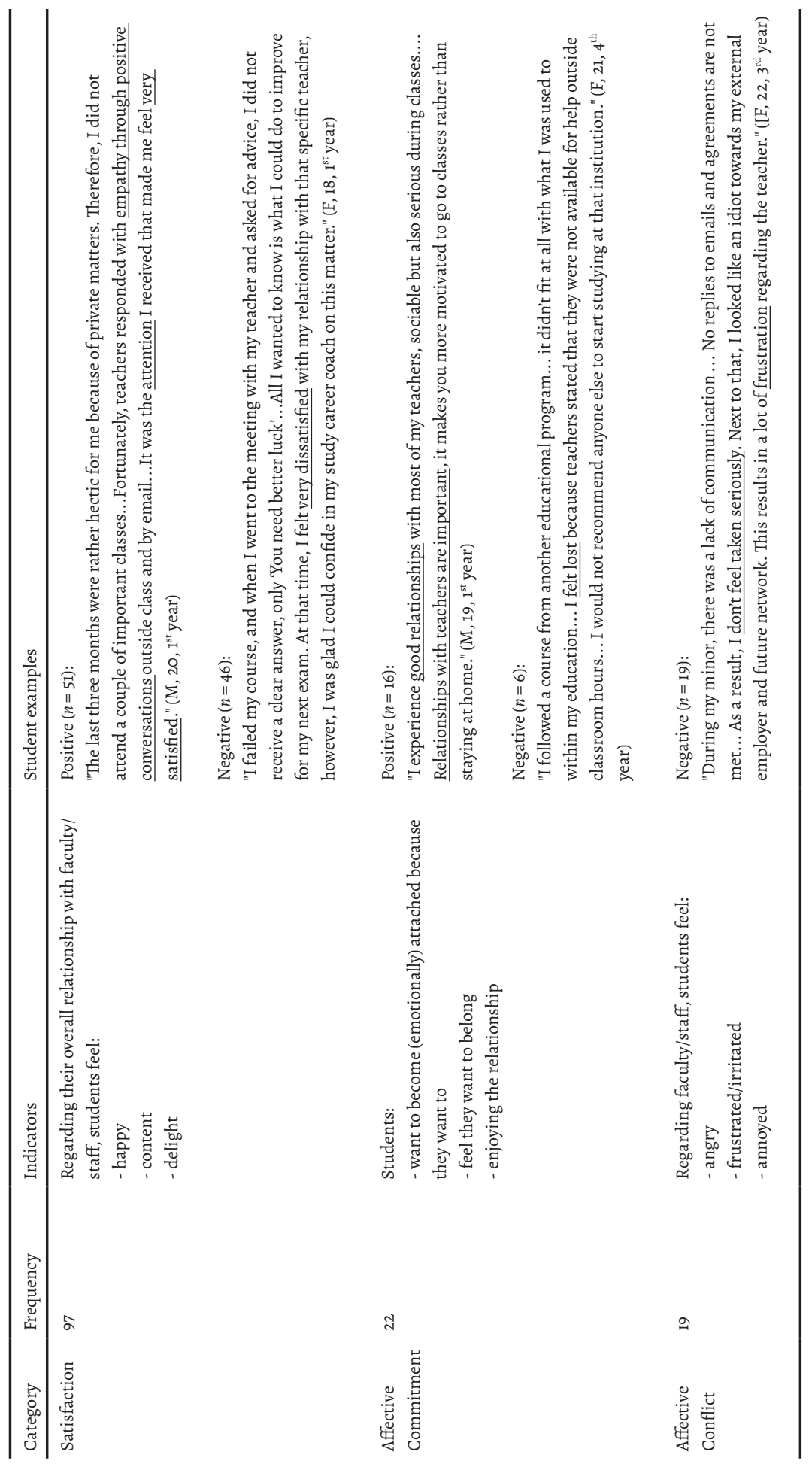


Appendices - C, D

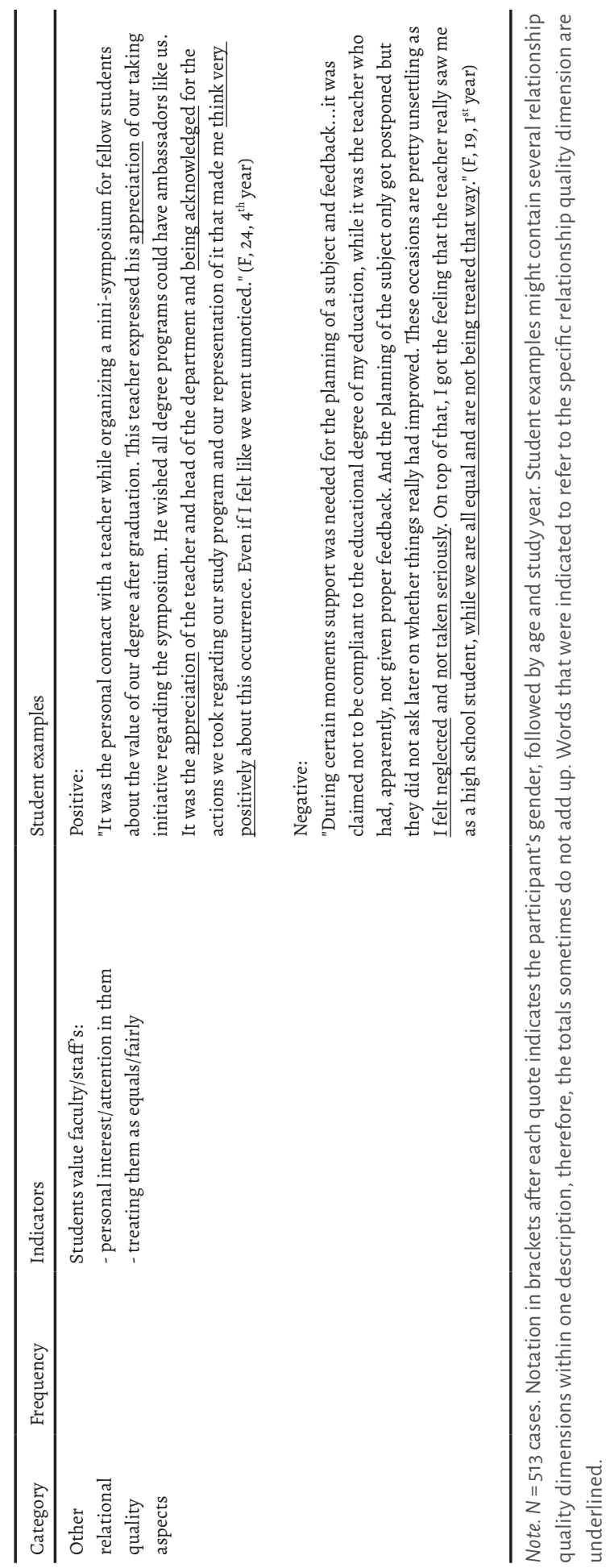




\section{Appendix D}

\section{(In) direct effects after bootstrapping procedure (Chapter 4)}

Table 4.1

(In) Direct Effects After Bootstrapping Procedure

\begin{tabular}{|c|c|c|c|}
\hline Relation & Sample Mean $(M)^{a}$ & $\begin{array}{l}t \text { Statistics } \\
\text { (O/STDEV) }\end{array}$ & $p$ Values \\
\hline Hia:RQT_B $>$ SE_AB & .100 & 1.364 & .173 \\
\hline H1a:RQT_B ->SE_DE & -.019 & .255 & .799 \\
\hline H1a:RQT_B $\rightarrow$ SE_VI & -.015 & .212 & .832 \\
\hline Hib: RQT_H $\rightarrow$ SE_AB & -.036 & .538 & .591 \\
\hline Hib: RQT_H $\rightarrow$ SE_DE & .150 & 2.132 & .033 \\
\hline Hıb:RQT_H $->$ SE_VI & -.042 & .637 & .524 \\
\hline H1c: RQ_ACOMM $>$ SE_AB & .475 & 8.621 & .000 \\
\hline H1c: RQ_ACOMM -> SE_DE & .480 & 9.247 & .000 \\
\hline Hic: RQ_ACOMM $\rightarrow$ SE_VI & .465 & 9.631 & .000 \\
\hline Hid: RQ_ACON $->$ SE_AB & -.102 & 2.076 & .036 \\
\hline Hid: RQ_ACON $->$ SE_DE & -.080 & 1.883 & .060 \\
\hline Hid: RQ_ACON ->SE_VI & -.258 & 5.524 & .000 \\
\hline Hie: RQ_SAT ->SE_AB & -.019 & .298 & .765 \\
\hline Hie: RQ_SAT -> SE_DE & .092 & 1.527 & .127 \\
\hline Hie: RQ_SAT ->SE_VI & .051 & .822 & .411 \\
\hline $\mathrm{H} 2$ a: SE_AB $\rightarrow$ SL & -.107 & 1.936 & .053 \\
\hline $\mathrm{H} 2 \mathrm{~b}: \mathrm{SE} \_\mathrm{DE}->\mathrm{SL}$ & .683 & 13.728 & .000 \\
\hline H2 c: SE_VI-> SL & .192 & 3.294 & .001 \\
\hline H3 a: RQT_B -> SL & .016 & .273 & .785 \\
\hline H3 b: RQT_H -> SL & .224 & 3.985 & .000 \\
\hline H3 c: RQ_ACOMM -> SL & .328 & 9.052 & .000 \\
\hline H3 d: RQ_ACON $>$ SL & -.130 & 3.518 & .000 \\
\hline H3 e: RQ_SAT -> SL & .221 & 4.069 & .000 \\
\hline H4 a: RQT_B $->$ SE_AB $->$ SL & -.011 & 1.057 & .290 \\
\hline H4 a: RQT_B $->$ SE_DE $->$ SL & -.013 & .255 & .799 \\
\hline H4 a:RQT_B $\rightarrow$ SE_VI $\rightarrow$ SL & -.003 & .205 & .838 \\
\hline H4 b: RQT_H $->$ SE_AB $\rightarrow$ SL & .004 & .447 & .655 \\
\hline H4 b: RQT_H $>$ SE_DE $->$ SL & .102 & 2.087 & .037 \\
\hline H4 b: RQT_H $\rightarrow$ SE_VI $>$ SL & -.008 & .604 & .546 \\
\hline
\end{tabular}


Appendices - D, E

\begin{tabular}{lccc}
\hline Relation & Sample Mean (M) & $\begin{array}{c}\text { a } \\
(\text { Statistics }\end{array}$ & $p$ Values \\
\hline H4 c: RQ_ACOMM -> SE_AB -> SL & -.051 & 1.841 & .066 \\
H4 c: RQ_ACOMM -> SE_DE -> SL & .328 & 7.324 & .000 \\
H4 c: RQ_ACOMM -> SE_VI -> SL & .089 & 3.003 & .003 \\
H4 d: RQ_ACON -> SE_AB -> SL & .011 & 1.334 & .182 \\
H4 d: RQ_ACON -> SE_DE -> SL & -.54 & 1.870 & .062 \\
H4 d: RQ_ACON -> SE_VI -> SL & -.050 & 2.813 & .005 \\
H4 e: RQ_SAT -> SE_AB -> SL & .002 & .257 & .797 \\
H4 e: RQ_SAT -> SE_DE -> SL & .063 & 1.504 & .133 \\
H4 e: RQ_SAT -> SE_VI -> SL & .010 & .769 & .442 \\
\hline
\end{tabular}

Note.RQ_ACOMM=RelationshipQualityAffectiveCommitment; RQ ACON=RelationshipQualityAffectiveConflict; RQ_SAT=RelationshipQualitySatisfaction; RQT_B=RelationshipQualityTrustin Benevolence; RQT_H=Relationship Quality Trust in Honesty; SE_AB = Student Engagement Absorption; SE_DE = Student Engagement Dedication; SE_VI = Student Engagement Vigor, and SL = Student Loyalty. a. Sample mean values represent the bootstrap estimates on average. 


\section{Appendix E}

\section{Sample Characteristics (Chapter 5)}

\section{Table S5.1}

Sample Characteristics $(N=152)$

\begin{tabular}{|c|c|}
\hline Characteristics & Sample frequency \\
\hline \multicolumn{2}{|l|}{ Graduation Year } \\
\hline 2016 & 13 \\
\hline 2015 & 16 \\
\hline 2014 & 26 \\
\hline 2013 & 29 \\
\hline 2012 & 29 \\
\hline 2011 & 6 \\
\hline 2010 & 6 \\
\hline 2009 & 3 \\
\hline before 2009 & 24 \\
\hline \multicolumn{2}{|l|}{ Paid job } \\
\hline Yes & 140 \\
\hline No & 12 \\
\hline \multicolumn{2}{|c|}{ Job satisfaction in relation to studies } \\
\hline Very bad & 8 \\
\hline Bad & 12 \\
\hline Neutral & 32 \\
\hline Good & 68 \\
\hline Very good & 32 \\
\hline \multicolumn{2}{|c|}{ Alumni membership } \\
\hline Yes & 55 \\
\hline No & 97 \\
\hline \multicolumn{2}{|c|}{ Willingness to financially support } \\
\hline Yes & 1 \\
\hline No & 151 \\
\hline
\end{tabular}


Appendices - F

\section{Appendix F}

\section{Supplemental Materials (Chapter 6)}

Table S6.1

Gender and Year of Study

\begin{tabular}{lcc}
\hline & Time 1 & Time 2 \\
& $N^{a}=1032$ & $N=879$ \\
\hline Gender & 69\% (females) & $65 \%$ (females) \\
Year 1 & & \\
Year 2 & 306 & 234 \\
Year 3 & 202 & 164 \\
Year 4 & 221 & 170 \\
Year 5+ & 228 & 263 \\
\hline
\end{tabular}

Note. ${ }^{\text {a }}$ Number of students who started the survey 
Table S6.2

Survey Scales and Cronbach's $\alpha$

\begin{tabular}{|c|c|c|c|}
\hline \multirow[t]{2}{*}{ Scales } & \multirow[t]{2}{*}{ Response ranges and Items } & \multicolumn{2}{|c|}{ Cronbach's a } \\
\hline & & Time 1 & Time 2 \\
\hline & & $N^{a}=1032$ & $N=879$ \\
\hline Relationship Quality ${ }^{1}$ & I (strongly disagree) to 7 (strongly agree) & & \\
\hline \multicolumn{4}{|l|}{ Trust } \\
\hline Trust in Benevolence & $\begin{array}{l}\text { My faculty/staff is concerned about my welfare } \\
\text { When I confide my problems to my faculty/staff, I know they will } \\
\text { respond with understanding } \\
\text { I can count on my faculty/staff considering how their actions } \\
\text { affect me }\end{array}$ & .88 & .85 \\
\hline Trust in Honesty & $\begin{array}{l}\text { My faculty/staff is honest about my problems } \\
\text { My faculty/staff has high integrity } \\
\text { My faculty/staff is trustworthy }\end{array}$ & .83 & .80 \\
\hline \multicolumn{4}{|l|}{ Affect } \\
\hline Affective commitment & $\begin{array}{l}\text { I feel emotionally attached to my faculty/staff } \\
\text { I continue to interact with my faculty/staff because I like being } \\
\text { associated with them } \\
\text { I continue to interact with my faculty/staff because I genuinely } \\
\text { enjoy my relationship with them }\end{array}$ & .87 & .83 \\
\hline Affective conflict & $\begin{array}{l}\text { I am angry with my faculty/staff } \\
\text { I am frustrated with my faculty/staff } \\
\text { I am annoyed with my faculty/staff }\end{array}$ & .90 & .89 \\
\hline Satisfaction & $\begin{array}{l}\text { I am delighted with the performance of my faculty/staff } \\
\text { I am happy with my faculty/staff's performance } \\
\text { I am content with my faculty/staff's performance }\end{array}$ & .95 & .93 \\
\hline Student Engagement ${ }^{2}$ & I (almost never/a few times a year or less) to 7 (always/every day) & & \\
\hline Absorption & $\begin{array}{l}\text { Times flies when I am studying } \\
\text { When I am studying, I forget everything else around me } \\
\text { I am immersed when I'm studying }\end{array}$ & .79 & .79 \\
\hline Dedication & $\begin{array}{l}\text { I find the studying that I do full of meaning and purpose } \\
\text { My studying inspires me } \\
\text { I am proud of the studying that I do }\end{array}$ & .85 & .82 \\
\hline Vigor & $\begin{array}{l}\text { At univeristy, I feel bursting with energy } \\
\text { At university, I feel strong and vigorous } \\
\text { When I get up in the morning, I feel like going to school }\end{array}$ & .80 & .82 \\
\hline
\end{tabular}


Appendices - F

\begin{tabular}{|c|c|c|c|}
\hline \multirow[t]{2}{*}{ Scales } & \multirow[t]{2}{*}{ Response ranges and Items } & \multicolumn{2}{|c|}{ Cronbach's a } \\
\hline & & Time 1 & Time 2 \\
\hline & & $N^{a}=1032$ & $N=879$ \\
\hline \multirow[t]{2}{*}{ Student Loyalty ${ }^{3}$} & 1 (strongly disagree) to 7 (strongly agree) & .86 & .87 \\
\hline & $\begin{array}{l}\text { I'd recommend my course of studies to someone else } \\
\text { I'd recommend my university to someone else } \\
\text { I'm very interested in keeping in touch with "my faculty" } \\
\text { If I were faced with the same choice again, I'd still choose the } \\
\text { same course of studies } \\
\text { If I were faced with the same choice again, I'd still choose the } \\
\text { same university }\end{array}$ & & \\
\hline
\end{tabular}

${ }^{1}$ Adapted from Roberts et al. (2003), applied in higher education by Snijders et al. (2018; 2019; Snijders, Wijnia, Rikers, \& Loyens, 2020).

${ }^{2}$ Adapted from UWES-S, short version by Schaufeli and Bakker (2003).

${ }^{3}$ Adapted from Hennig-Thurau et al. (2001).

Table S6.3

Fit Indices for Model $1 \mathrm{~b}$

\begin{tabular}{|c|c|c|c|c|c|c|c|c|}
\hline Model & & $\chi^{2}$ & $d f$ & $p$ & RMSEA & SRMR & CFI & TLI \\
\hline \multicolumn{9}{|c|}{ Model ib } \\
\hline & Configural Invariance & 715.87 & 78 & $<.001$ & \multirow{5}{*}{.07} & \multirow{5}{*}{.05} & \multirow{5}{*}{.94} & \multirow{5}{*}{.92} \\
\hline & Weak factorial invariance & 721.02 & 82 & & & & & \\
\hline & Strong factorial invariance & 725.49 & 84 & & & & & \\
\hline & $\begin{array}{l}\text { Chi-square difference test } \\
\text { configural vs. weak }\end{array}$ & 5.15 & 4 & .272 & & & & \\
\hline & $\begin{array}{l}\text { Chi-square difference test weak } \\
\text { vs. strong }\end{array}$ & 4.47 & 2 & .107 & & & & \\
\hline
\end{tabular}

Note. RMSEA = root mean square error of approximation; SRMR = standardized root mean square residual; $\mathrm{CFI}=$ comparative fit index; TLI = Tucker-Lewis index 


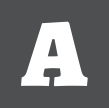




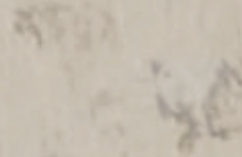

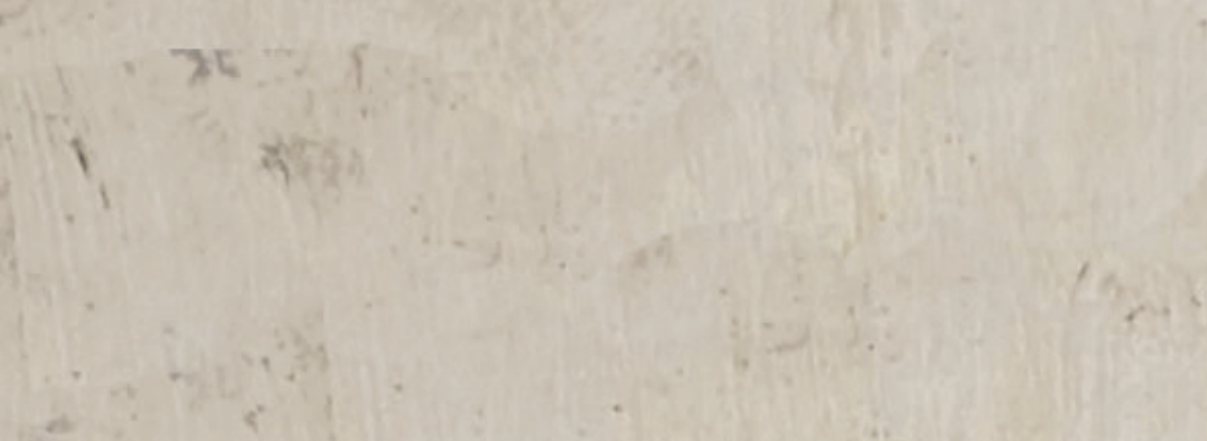

\section{Fe?}

is)

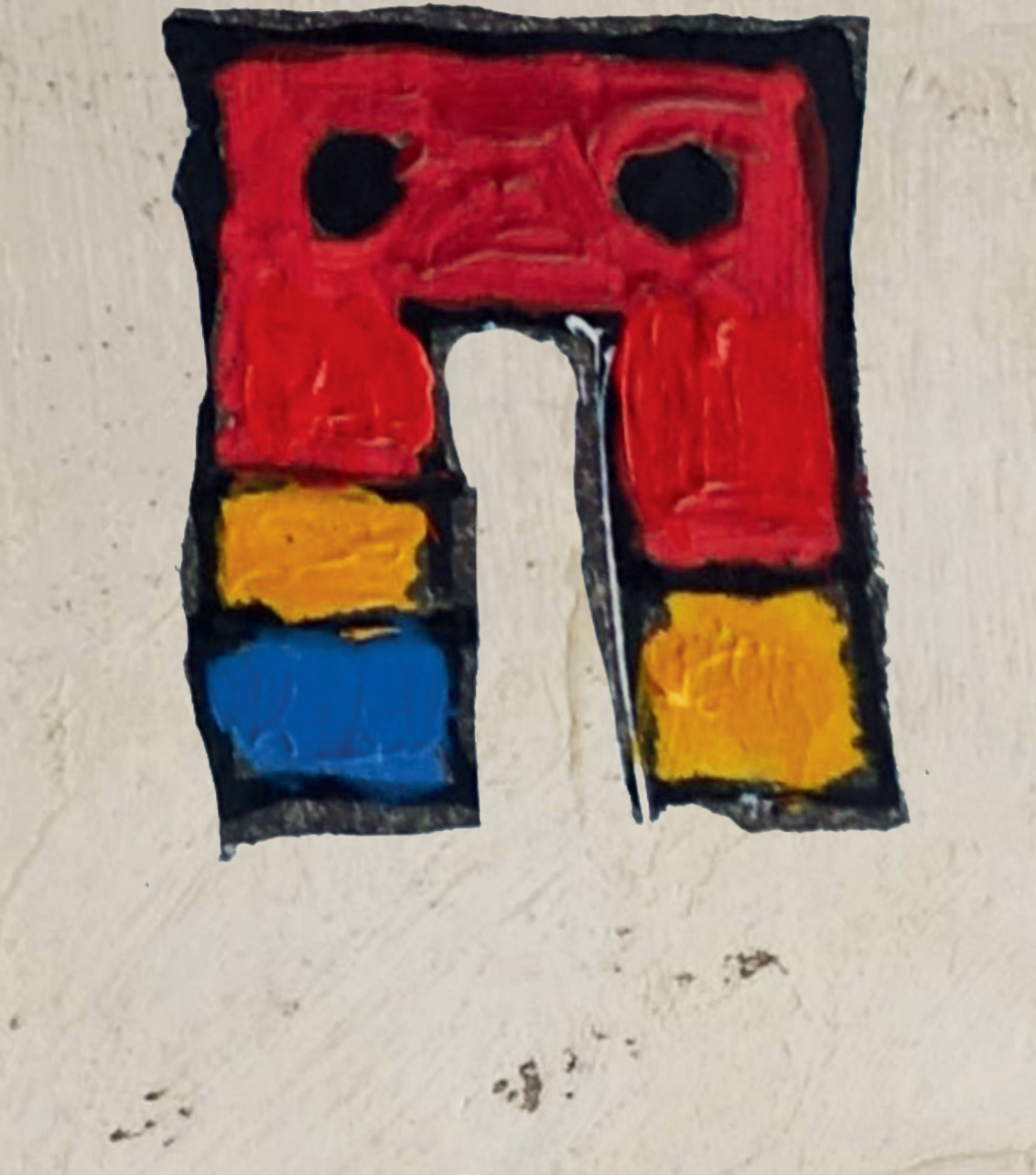




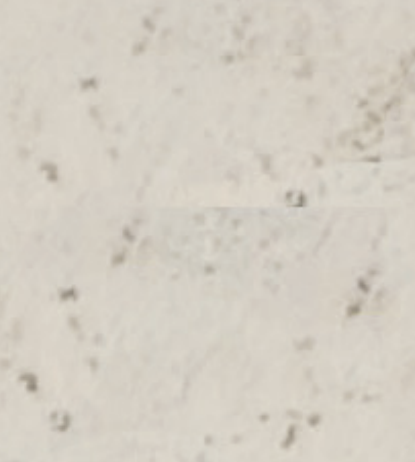

About the Author
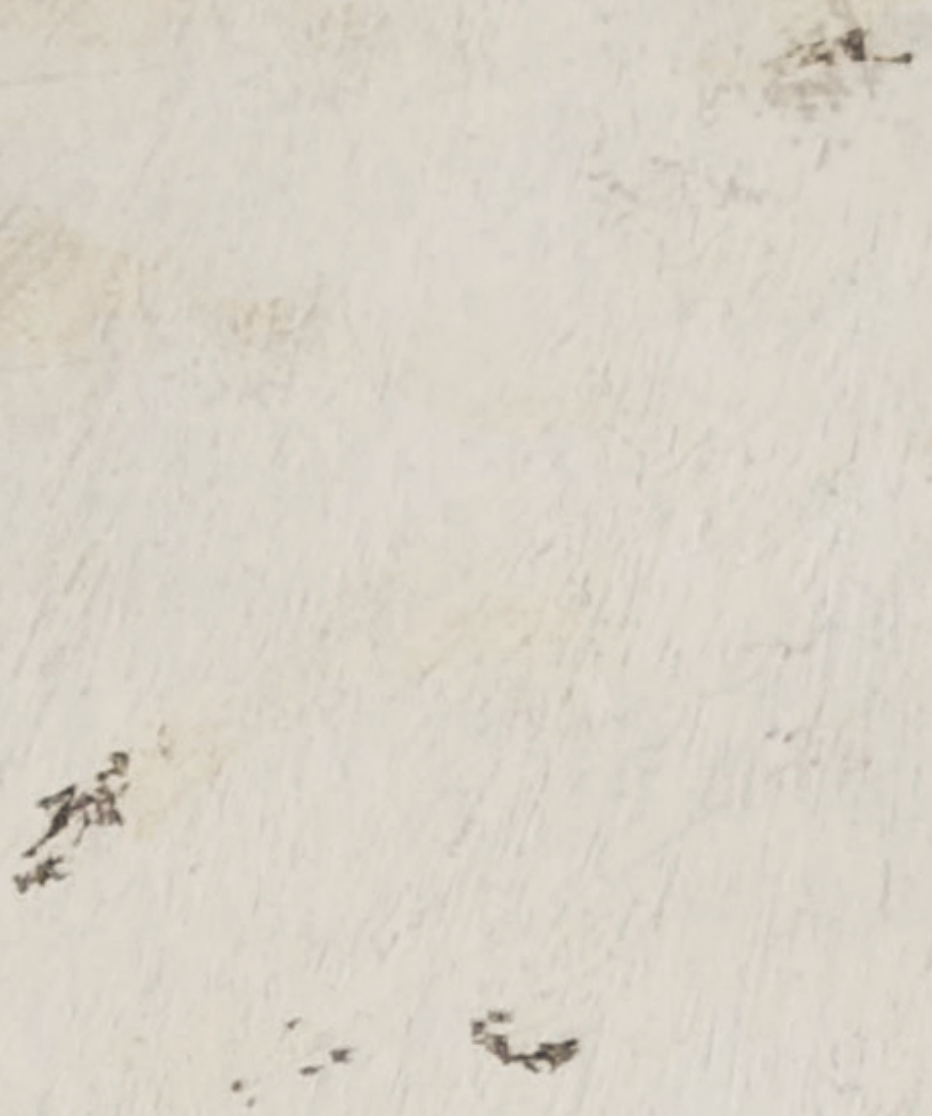


\section{Curriculum Vitae}

Ingrid Snijders was born on June 19, 1976, in Middelburg, the Netherlands. She completed her secondary education (HAVO) in 1993 at Stedelijke Scholen Gemeenschap Middelburg in Middelburg. In 1997, she graduated from the bachelor's program in commercial economics at $\mathrm{HZ}$ University of Applied Sciences (HZ) in Vlissingen. After her graduation, she had several jobs and subsequently, started working as a team leader of the administration office at HZ. She continued her work as a quality assurance specialist, and simultaneously participated in the GOLEWE ("Goesting in leren en werken") project, where she was (co-) author and presenter of several papers on student guidance and dropout. From 2006 to 2014, she held the position of coordinator of study career coaching at the economic department of HZ. In addition to her work, she studied Management Sciences at Open University, where she received her master's degree in September 2011. During that time, she tutored graduation research projects, and she was also one of the principal lecturers for courses in research methods for economic and communications students in their final year of study. Subsequently, in 2015, she started as a Ph.D. candidate at the Roosevelt Center for Excellence in Education (UCR / Utrecht University) in Middelburg. Her research was granted an award by the Netherlands Organization for Scientific Research (NWO). Ingrid has attended and presented several papers at (international) educational and management/marketing conferences, and published several papers in international journals. The outcomes of her Ph.D. project are reported in this thesis. Her focus and motivation for future work is to continue her research. 


\section{Publications}

Leenknecht, M. J. M., Snijders, I., Wijnia, L., Rikers, M. J. M. P., \& Loyens, S. M. M. (2020). Building relationships in higher education to support students' motivation. Teaching in Higher Education. Advance online publication. https://doi.org/10.1080/13562517.2020.183 9748

Snijders, I., Wijnia, L., Rikers, R. M. J. P., \& Loyens, S. M. M. (2020). Building bridges in higher education: Student-faculty relationship quality, student engagement, and student loyalty. International Journal of Educational Research, 100, 101538. https://doi.org/10.1016/j. ijer.2020.101538

Snijders, I., Wijnia, L., Rikers, R. M. J. P., \& Loyens, S. M. M. (2019). Alumni loyalty drivers in higher education. Social Psychology of Education, 22(3), 607-627. http://doi.org 10.1007/ s11218-019-09488-4

Snijders, I., Rikers, R. M. J. P., Wijnia, L., \& Loyens, S. M. M. (2018). Relationship quality time: The validation of a relationship quality scale in higher education. Higher Education Research \& Development, 37(2), 404-417. http://doi.org/ 10.1080/07294360.2017.1355892

\section{Presentations \& Symposium contributions}

Snijders, I., Dekker, J. J., Wijnia, L., Rikers, R. M. J. P., \& Loyens, S. M. M. (2020, Apr 17- 21). What students tell us: Relationship quality experiences in higher education [Roundtable session]. Annual meeting of the American Educational Research Association (AERA), San Francisco, CA, United States. (Conference canceled due to COVID-19)

Snijders, I., \& Leenknecht, M. J. M. (2019, May 21-24). 'Hey teachers! Don't leave your students alone': A new perspective on relationship quality and students' motivation to learn [Paper presentation]. Self Determination Theory Conference (SDT), Egmond aan Zee, The Netherlands.

Snijders, I., Rikers, R. M. J. P., Wijnia, L., \& Loyens, S. M. M. (2018, April, 13-17). Are we still connected? Alumni loyalty drivers in higher education [Roundtable discussion]. Annual meeting of the American Educational Research Association (AERA), New York, NY, United States.

Reijnierse, H., \& Snijders, I. (2018, April 13-17). What young people need: 21st-Century skills obtained by cultural participation [Roundtable discussion]. Annual meeting of the American Educational Research Association (AERA), New York City, NY, United States. 
Snijders, I. (2018, July 9-13). Relationship quality in higher education. Invited speaker at the Biennial International Seminar on the Teaching of Psychological Science (BISTOPS), Paris, France.

Snijders, I., Rikers, R. M. J. P., \& Loyens, S. M. M. (2017, August 29-September 2). Studentfaculty relationships in higher education [Paper presentation]. 17th Biennial European Association for Research on Learning and Instruction (EARLI), Tampere, Finland.

Snijders, I., Rikers, R. M. J. P., \& Loyens, S. M. M. (2017, August 27-28). Alumni loyalty behavior in higher education [Roundtable session]. 21th JUnior REsearchers (JURE) of EARLI Conference, Tampere, Finland.

Snijders, I., Rikers, R. M. J. P., Wijnia, L., \& Loyens, S. M. M. (2017, April 27-May 1). The influence of relationship quality on student engagement and loyalty [Paper presentation]. Annual meeting of the American Educational Research Association (AERA), San Antonio, TX, United States.

Snijders, I., Rikers, R. M. J. P., \& Loyens, S. M. M. (2015, June 30-July 3). Student loyalty in higher education: The impact of service quality, student satisfaction, and motivation to learn [Paper presentation]. 3rd International Conference on Contemporary Marketing Issues (ICCMI), London, United Kingdom.

Dekker, J. J., \& Snijders, I. (2014, June 18-20). Developing a short retail service quality scale for PLS analysis [Paper presentation]. 2nd International Conference on Contemporary Marketing Issues (ICCMI), Athens, Greece.

Snijders, I. (2018, June 13-15) Loyale Alumni, wens van elke opleiding! Een verkenning van voorspellende factoren van alumniloyaliteit [Paper presentation]. Onderwijs Research Dagen (ORD), Nijmegen, The Netherlands.

Snijders, I. (2017, December 14). Relatiekwaliteit student-opleiding, basis voor leersucces [Minisymposium B(l)oeiende samenwerking ter gelegenheid van het afscheid van Jan Zwemer]. HZ University of Applied Sciences, Vlissingen, The Netherlands.

Snijders, I. (2017, November 10). Duurzame relaties in het onderwijs [Symposium]. Vereniging Hogescholen, St. Michielsgestel, The Netherlands.

Snijders, I. (2016, March 17). De theorie achter Service Blueprinting. Van klantreis naar service design en blueprint [Symposium]. Platform voor Klantgericht Ondernemen, Leusden, The Netherlands. 
Snijders, I. (2015, November 18). Duurzame relaties in het Hoger Onderwijs [Symposium], Uitreiking NWO Promotiebeurs voor Leraren by Ministerie van OC\&W, The Hague, The Netherlands.

Snijders, I., Bartholomeus, M., Denoo, E., Goossens, B., \& Lommertzen, M., (2001, May 20) Studiekeuzebegeleiding [Symposium]. Slotconferentie Goesting in leren en werken (GOLEWE) Antwerp, Belgium.

\section{Grants \& awards}

\section{Best paper award}

Dekker, J. J., \& Snijders, I. (2014, June 13-15). Developing a short retail service quality scale for PLS analysis [Paper presentation]. 2nd International Conference on Contemporary Marketing Issues (ICCMI), Athens, Greece.

\section{Grant NWO/Dutch Organisation for Scientific Research}

NWO Promotiebeurs voor Leraren, Grantnumber 023.006.035, https://www.nwo.nl/onderzoek-en-resultaten/programmas/promotiebeurs+voor+leraren/ toekenningen $+2015-1$

(€ 32.800 per year for four to five years maximum) 


\title{
"The only thing constant in the world is change That's why today I take life as it comes"
}

\author{
India Arie
}

Van basisschoolleerling met een, overigens niet opgevolgd, Cito-advies voor de mavo, een heao-diploma op eenentwintigjarige leeftijd tot aan een succesvol afgeronde masteropleiding managementwetenschappen bij de Open Universiteit naast een fulltimebaan en de daardoor ontstane passie voor het doen van onderzoek en stimulans voor mijn promotiereis, is een lang verhaal. Langer dan de woorden die ik hier kwijt kan.

Het was een hele klus. Allereerst de aanvraag voor de NWO Promotiebeurs voor Leraren, waarbij in eerste instantie prof. dr. Hans van Trijp en dr. Harm Biemans van Wageningen University hebben geholpen en later mijn huidige promotoren van het Roosevelt Center for Excellence, Universiteit Utrecht. Binnen mijn baan bij HZ University of Applied Sciences was het aanpoten om het promotieonderzoek uit te zetten, de data te verzamelen, artikelen te schrijven, te publiceren, ze naast de andere werkzaamheden uit te voeren en vervolgens ook nog een mens te zijn in je eigen familiaire omgeving. Om recht te doen aan de onderzoeken, successen, ups \& downs en de samenwerking met en medeleven van promotoren en collega-promovendi, collega's, studenten, familie, vrienden en bekenden, die tijdens dit promotietraject deze bijzondere beleving deelden en daarmee hebben bijgedragen aan de uitkomsten die gebundeld zijn in dit proefschrift, wil ik stilstaan bij en dank betuigen aan een aantal mensen.

Dank aan de studenten van HZ University of Applied Sciences, Fontys, HAN, en HS Zuyd. Zonder hun reactie op onder meer de vragenlijsten die ik ze voorlegde (meerdere keren!) en de medewerking van collega's van deze hogescholen zou ik geen onderzoek heb kunnen uitvoeren.

Sofie, om uw Vlaamse oorsprong in acht te nemen, $U, u$ bent een eerste bijzondere begeleider geweest in dit promotietraject. We hebben gelachen en gehuild en wat voor mij heel fijn was, is dat ik altijd, als er echt hoge maar ook 'lage' nood was, een appje kon sturen of belletje kon doen, zelfs's avonds, in het weekend of tijdens vakanties. Dank daarvoor.

"Iedereen kan schilderen met Ravensburger, maar een promotieonderzoek is toch wel wat anders". Remy, tweede bijzondere begeleider, bovenstaande is slechts één van de vele 'foute' voorbeelden die je weleens in het heetst van de discussies erin gooide en die me keer op keer tot vreselijk lachen heeft gebracht, juist als het niet ging zoals ik wilde of tegenslag 
had. Dit waren de ware opkikkers! Lisette, derde bijzondere begeleider, dank je wel voor de privé-statistieklessen en niet te vergeten de 'indoctrinatie' van APA. Het was een genoegen om met je samen te werken en ik hoop dat we dat zeker nog lang kunnen voortzetten, waar je ook werkzaam bent. Waar dat ook moge zijn; ze hebben goud in handen met jou als onderzoeker.

Jaap en Martijn, mijn collega-promovendi. Tussen de verhuisdozen startten we in De Burg in Middelburg. Al gauw verliet ik de kamer, waar wij in eerste instantie met ons drieën zaten samen met de zwammen aan de muur. Het ging niet ten koste van de samenwerking, integendeel. Dat was goed merkbaar bij de JURE- en EARLI-conferentie in 2017. Ingegeven door indrukken uit het Finse landschap hebben we discussies gevoerd op verschillende niveaus, denk aan de functie van de wc-slang, draaiende plateaus uitkijktoren en bespreking van het Italiaanse nagerecht van het restaurantje in Tampere en specifiek voor Martijn, het SDT-dansje in Egmond aan Zee. Van de RCEE-partij voegden later Kelly en Patrick zich erbij, die ook voor een gezellige noot in De Burg zorgden. Jullie hadden vooral altijd ruimte voor een evaluatiemoment, van het bespreken van een nieuwe eettent in Middelburg, tot een reflectie op het onderzoek en alles daartussenin.

Rebecca Kuiper, dank voor je medewerking in de statistische analyses van de CLPA-studie. Het was voor mij in het begin echt Chinees, maar je bereidheid altijd even snel tussendoor te mailen op wat vragen en de uitgebreide bespreking die we hadden in Utrecht heeft me enorm geholpen. Toch blijft Chinees wel lastig overigens.

Dear Emily Fox, you are a true PhD lifesaver. Thank you so much for the many edited suggestions you made and keen (and sometimes funny) remarks!

Verder wil ik natuurlijk de leden van de promotiecommissie bedanken voor de tijd, aandacht en professionele beoordeling van mijn proefschrift en hun gewaardeerde oppositie: dr. Harm Biemans, prof. dr. Wim Geijselaars, prof. dr. Bert van den Brink, prof. dr. Jan van Tartwijk en prof. dr. Marijk van der Wende en prof. dr. Michael Burke.

Ik realiseer me dat ik een bevoorrecht mens ben doordat ik omringd ben door heel veel lieve collega's van HZ University of Applied Sciences. In het bijzonder wil ik bedanken in willekeurige volgorde: Bert Schollema voor zijn reacties op en oprechte mening over de verschillende versies van het proefschrift, Peter van Dijk voor het ingaan op een spontane vraag om te reageren op de Nederlandse discussie van dit proefschrift en Bregje Weeda, thanks voor de Engelse vertalingen van studentenquotes. Paul Vader dank ik voor zijn zeer kritische blik en opbouwende feedback op de discussie en dankwoord. Het lijkt me meer dan noodzakelijk om dit na te spreken samen met Ronald, hond Jimmy, onder het genot 
van een Coteaux Bourguignon. In het bijzonder bedank ik Hans Dekker, collega "arrogant frog", voor zijn zeer eigen wijze in het onderzoek van de kwalitatieve studie. Dank voor de stimulans die je hebt gegeven, onder meer door ons best paper award bij ICCMI (Athene, 2014) en de vele gesprekken over het doen van onderzoek zoals onderweg naar de PLS-SEM-training in Hamburg, maar ook de wording van een onderzoeker met een eigen mening.

Eveneens dank ik mijn HZ-collega's voor de positieve en ondersteunde berichten en gesprekken zoals van mijn collega's van de HZ-Toetscommissie, team Commerciële Economie, Pabo/Lectoraat Onderwijsexcellentie, voormalig IBL-collega's, oud-collega vertrouwenspersoon Jan Zwemer, en bemoedigende woorden en posters zoals "almost perfect is just as good", waarvoor dank Mies Wiskerke.

Dank aan alle collega's van de HZ die ik hier niet met naam heb genoemd, maar die op een of andere manier hebben bijgedragen aan dit proefschrift.

Ook buiten de $\mathrm{HZ}$ heb ik inmiddels veel contacten opgedaan via de internationale congressen van AERA in Washington, San Antonio en New York tot BISTOPS in Parijs, waar ik mijn onderzoek heb gepresenteerd en wat resulteerde in nieuw onderzoek met collega's in Frankrijk, Engeland en Amerika. Thank you very much Doug Bernstein and Doris Vasconcellos for your trust and friendship, and, introduction in this fabulous international world of research.

Heel hartelijk bedank ik in het bijzonder Wim Hofman voor het speciaal voor dit proefschrift ontworpen kunstwerk dat gebruikt is voor de voorkant. Wim, je hebt dit onderzoek voortreffelijk gevangen met afbeeldingen die ingaan op "dat wat de ziel is van de universiteit, of behoort te zijn" (aldus prof. dr. Wim Kremer, Universiteit Utrecht, die niet aanwezig kon zijn als opponent).

Via facebook, feestjes in de pre-COVID-19-periode en familiebezoek ben ik een ramp geweest in reacties of beter: het uitblijven daarvan. Lieve vrienden, relaties en bekenden, now you know of niet; ik kon niet anders omwille van de vorming van dit boekje dat er nu ligt. Gelukkig weet ik dat er mensen zijn zoals oud-buurtjes van de Branderijmolengang en goede vrienden met wie ik schaars contact heb gehouden, die geduld hebben en wel weten dat het etentje of die borrel er weer van komt. En ja, dan ga ik de keuken in voor een Griekse stiffado, Indiase schotel of Mediterraan probeersel.

Om mij af te leiden hebben de bijpraatborrels en feestjes met verkleedpartij zoals die van Halloween en viering van mijn 40 ste verjaardag met de meidenclub enorm geholpen. 
Bedankt Susanne, Judith, Ilse en Karin! Laten we vooral een mondkapjesfeest inplannen om elkaar snel weer te treffen om bij te praten.

In stalpraat, dank je wel Syl, voor het aanhoren van mijn promotie-"shit". Onze paarden hebben er niet om geleden; op hun manier leefden ze mee.

Mijn moeder typeert mij en mijn karakter aan de hand van het oude speelgoed dat ze op zolder heeft gesorteerd na het overlijden van mijn vader. Het zijn uit elkaar gehaalde barbies en poppen, wier haar en gezicht verfraaid zijn met viltstift en een nieuw kapsel, veelal onherstelbaar geknipt in een slechte coupe. Auto's, houten blokken en onderdelen van trofeeën van playbackoptredens die ik tijdens de lagere school als hobby erop nahield. "Het is overduidelijk dat Ingrid als kind al bezig was met het onderzoeken en analyseren van hoe dingen in elkaar zitten," aldus mama. Hoe terug te gaan naar het origineel was toen nog wel een probleem. Veel van de spullen waren gewoon kapot. Lieve mam, dank je wel voor je trouwe en vaste geloof in mij.

Irene, lieve en fantastische zus, je bent altijd zo positief over mijn werk, zelfs als ik een idee over een conceptueel model op een whiteboard aan je liet zien dat vol met pijlen en onduidelijke aantekeningen zat, bleef je betrokken. Dank voor je oprechte steun. Kris en Tess, ik heb jullie als paranimfen gevraagd. Nu blijkt in deze periode een fysieke bijeenkomst onduidelijk of niet mogelijk. Niettemin, jullie zijn erbij fysiek, online of in gedachten!

Hans, je bent de meest makkelijke en moeilijkste man om mee samen te wonen. Je hebt me altijd gestimuleerd in verdere ontwikkeling. Dat heb je ook waargemaakt in je altijd aanwezige steun tijdens mijn promotietraject. Ik zegde op het laatste moment feestjes af, kon toch niet meegaan omdat ik "nog even wat moest doen voor mijn onderzoek", en was vervolgens 's avonds laat nog steeds bezig toen je me thuis aantrof. Hoe vaak heb ik je gevraagd om 'even' naar mijn stuk te kijken en vooral kritisch te zijn in je feedback? Volgens jou is en was het altijd goed. En dat was niet goed genoeg voor mij, het kon altijd beter. Dat perfectionistisch trekje was zelfs tot vervelends aan toe, tijdens vakanties, weekenden, of middenin de nacht, omdat ik dan nog even moest kijken of ik alles wel goed gesubmit had. Lieverd, wat heb je een ijzeren geduld met me gehad en me enorm gesteund. Maar ja, dat hoort bij artikel 26 van onze Italiaanse huwelijksakte bij het uitspreken van "Si, lo voglio".

Ten slotte wil ik iemand noemen die er niet meer is, maar die ik ondanks het noodgedwongen afscheid van hem in 2016 toch als stimulans heb ervaren om dit project succesvol af te ronden. In mijn vaders woorden: "Je bent een topper!". Hij was en is er altijd, en is trots op mij. Dank je wel papa. 